\title{
GRABGAM Analysis of Ultra-Low-Level HPGe Gamma Spectra
}

by

W. G. Winn

Westinghouse Savannah River Company

Savannah River Site

Aiken, South Carolina 29808

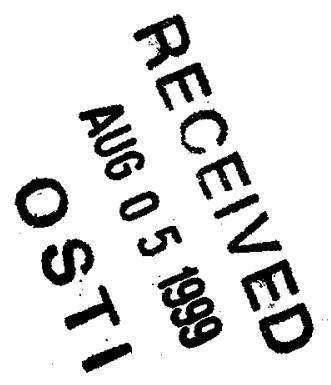

DOE Contract No. DE-AC09-96SR18500

This paper was prepared in connection with work done under the above contract number with the U.S. Department of Energy. By acceptance of this paper, the publisher and/or recipient acknowledges the U.S. Government's right to retain a nonexclusive, royalty-free license in and to any copyright covering this paper, along with the right to reproduce and to authorize others to reproduce all or part of the copyrighted paper. 


\section{DISCLAIMER}

This report was prepared as an account of work sponsored by an agency of the United States Government. Neither the United States Government nor any agency thereof, nor any of their employees, makes any warranty, express or implied, or assumes any legal liability or responsibility for the accuracy, completeness, or usefulness of any information, apparatus, product, or process disclosed, or represents that its use would not infringe privately owned rights. Reference herein to any specific commercial product, process, or service by trade name, trademark, manufacturer, or otherwise does not necessarily constitute or imply its endorsement, recommendation, or favoring by the United States Government or any agency thereof. The views and opinions of authors expressed herein do not necessarily state or reflect those of the United States Government or any agency thereof.

This report has been reproduced directly from the best available copy.

Available to DOE and DOE contractors from the Office of Scientific and Technical Information, P. O. Box 62, Oak Ridge, TN 37831; prices available from (423) 576-8401.

Available to the public from the National Technical Information Service, U. S. Department of Commerce, 5285 Port Royal Road, Springfield, VA 22161. 


\section{DISCLAIMER}

Portions of this document may be illegible in electronic image products. Images are produced from the best available original document. 


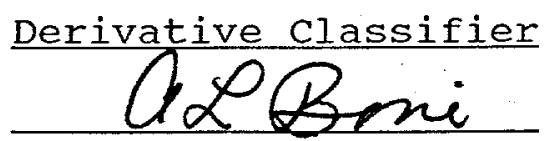

GRABGAM Analysis of Ultra-Low-Level HPGe Gamma Spectra

W.G. Winn

July 6,1999

\section{DISTRIBUTION :}

C.R. Wolfe, 773-A

P.T. Deason, 773-A

A.L. Boni, 773-A

J.E. Halverson, 735-A

W.A. Emel, 735-A

W.W. Bowman, 735-A

J.R. Cadieux, 735-A

D.W. Hayes, 735-A

R.C. Hochel, 773-41A

K.J. Hofstetter, 735-A

F.S. Moore, 773-A

S.R. Salaymeh, 773-41A

R.A. Sigg, 773-41A

T.L. Sidener, 735-A

W.I. Lewis, III, 730-A

S.L. Tibrea, 773-A

S.L. Collins, 305-1A

L.A. Refalo, 305-A

H.T. Sessions, Jr, 305-A

R. Lorenz, 735-16A

A. Gibbs, 724-21E

O.G. Lien, 704-28S

R.S. Thomason, 707-F

T.G. Hinton, 737-G

TIS File copies (4) 
GRABGAM Analysis of Ultra-Low-Level

HPGe Gamma Spectra

W.G. Winn

TABLE OF CONTENTS

I. INTRODUCTION $\ldots \ldots \ldots \ldots \ldots \ldots \ldots$

II. OVERVIEW OF PROGRAMS AND FILES ...... 2

III. GRABGAM ALGORITHMS ........... 4

A. Peak Search .............. 4

B. Singlet Analysis .......... 5

C. Multiplet Analysis ......... 9

D. MDA Analysis ............. 11

E. Library Matching Method .... 12

IV. USER OPERATION OF GRABGAM ........ 13

A. GRABGAM Inputs .......... 13

B. GRABGAM Execution ......... 14

C. GRABGAM User output ....... 15

D. Supp. Analyses Programs .... 16

E. Auxiliary Programs ........ 18

V. DISCUSSION/CONCLUSIONS .......... 20

A. Philosophy of LL HPGe Anal .. 20

B. Algorithm Features/Limits ...221

C. Performance History ....... 23

D. Conclusions ............. 24

ACKNOWLEDGEMENTS ............. 25

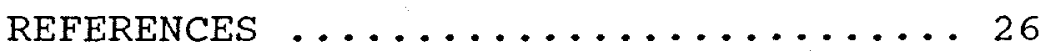

TABLES (1)

FIGURES (13)

APPENDIX A: RECENT MULTIPLET REFINEMENTS

APPENDIX B: GRABGAM CODE LISTINGS 
GRABGAM Analysis of Ultra-Low-Level

HPGe Gamma spectra

W.G. Winn

\section{INTRODUCTION}

The GRABGAM code has been used successfully for ultra-low level HPGe gamma spectrometry analysis since its development in 1985 at Savannah River Technology Center (SRTC). Although numerous gamma analysis codes existed at that time, reviews of institutional ${ }^{1}$ and commercial codes ${ }^{2}$ indicated that none addressed all features that were desired by SRTC. Furthermore, it was recognized that development of an in-house code would better facilitate future evolution of the code to address SRTC needs based on experience with low-level spectra. GRABGAM derives its name from Gamma Ray Analysis BASIC Generated At MCA/PC.

Initially the code was developed for the five HPGe detectors of the SRTC Ultra-Low-Level counting Facility (ULLCF). 3-4 Typical samples were counted overnight, but their spectra included very few peaks; thus, the initial version of the code addressed singlet peaks only. A major concern during initial development was to incorporate earlier HPGe efficiency calibration data that included three vial sizes as a function of height, an air filter geometry, and a well geometry. No commercial code was found to address a suitable interpolation for generating efficiencies as a function of vial height. Such a feature allows counting of all of a limited size sample rather than reducing or diluting it to match a fixed geometry, so that the sample counting efficiency is optimized for low-level counting.

The above initial version of the code was adequate until the ULLCF needed to analyze local fallout from the Chernobyl accident in the spring of 1986.6-7 Unlike the earlier samples, those from Chernobyl yielded numerous spectral peaks so that multiplet analyses were required. GRABGAM was upgraded to include a multiplet analysis, whereby three different size filters were introduced. The smallest filter finds peaks within a multiplet, while largest retains the ability to distinguish low-level singlets. from the background. This version of the code was also applied to the HPGe detectors of the SRTC Underground Counting Facility, which began sample analysis at this time. ${ }^{8-9}$ More recent improvements in the multiplet analysis have refined the background model for the multiplet region and improved the method for partitioning the peak areas. 
Further refinements also provided the user with different options for analyzing the minimum detectable activity (MDA), including a determination leve ${ }^{9-10}$ and the traditional $95 \%$ detection level recommended by currie. ${ }^{10}$ The former is a precision level below which peak detection is assumed questionable. The latter corresponds to an activity level that would be detected with 95\% probability, as based on a threshold level that permits only $5 \%$ probability of false positives from background.

Throughout the evolution of GRABGAM, attention has been given to ease of use and helpful diagnostics. The code is operable from an IBM PC, and it provides a logical sequence of input frames for the user. The peak analysis printout provides typical peak data as well as isotope activity, measured and expected peak full width at half maximum (FWHM), and any non-sample peak backgrounds. A supplementary program allows the user to select weighted averages of isotope activities based on those of the individual peaks. Other support programs were also developed, and these address detector efficiency calibrations, backgrounds, isotope libraries, and diagnostics.

When GRABGAM was developed, other existing gamma analysis codes $^{1-2}$ relied on Gaussian or modified Gaussian peak fitting algorithms. A recent review of the literature revealed that many subsequent developments ${ }^{11-21}$ also use this approach. Because such fittings require adequate counting statistics for deducing peak parameters, their ability to address low-level peak analyses is limited. By contrast, GRABGAM deduces the integral peak probability function to analyze properties of the peak. Others have also developed non-Gaussian approaches for analyzing low-level spectral peaks. $22-24$

\section{OVERVIEW OF PROGRAMS AND FILES}

This section provides an overview of the programs and files used to set up, execute, and append the GRABGAM analysis. Table 1 correlates these programs and files, which are summarized below. More detailed information is given in section IV, which discusses the user operation of GRABGAM.

Setup operations are typically performed before analyzing samples on a routine basis. A group of auxiliary programs may be used to create the necessary files for a GRABGAM spectral analysis, as noted below:

ISOLIBAS - creates isotope library file ISOLIBRY.LIB which includes user-assigned isotopes, their gamma energies with decay intensities, half-lives, and a MDA analysis flag. 
DETLIBAS - creates vial efficiency parameters library DETLIBRY.LIB for up to three vial sizes and five detectors, providing efficiency as a function of vial fill height.

MERGBACK - creates a backgnd. BKG file that includes the peak count rates of gammas detected in the background of a detector, where backgnd is a user-assigned file label.

MERGCALB - creates a detreff.DCF efficiency file for a specific detector geometry, based on user input data. The program also inputs the DETLIBRY.LIB efficiency parameters to allow reference comparisons as appropriate.

Routine execution of the GRABGAM spectral analysis uses the files of the setup programs as given in Table 1, where it is noted that chained programs GRABDKR1 and GRABDKR2 are run. Specifically, these programs operate as follows:

GRABDKR1 - accepts keyboard inputs for spectral analysis and receives file data from DETLIBRY.LIB, backgnd.BKG, detreff.DCF, and counted gamma spectrum.CHN. It also conducts the peak search.

GRABDKR2 - continues with peak and multiplet analyses, including peak background corrections from backgnd.BKG, isotope correlations with ISOLIBRY.LIB, and flagged MDA analyses. It produces the peak printout table and also generates files DATACALB.DAT, DATASPEC.DAT, DATAISOS.DAT, DATAPEAK.DAT, and DATAMISC.DAT to allow operations with the supplementary analyses programs.

Appendage calculations for the GRABGAM spectral analysis may be performed with the supplementary programs. Each of these programs input the data. DAT files created by GRABDKR2. (The names of the data. DAT files are representative of the type of data contained). These programs are described as follows:

GRABISOS - groups and orders all peaks with regard to isotopic identification, allowing the user to select a weighted average of each isotopic activity for a more comprehensive analysis.

GRABBACK - produces peak background file backgnd.BKG based on the preceding GRABGAM spectral analysis for a detector background, as appropriate. It also has option to average with results from earlier peak background file results. 
GRABCALB - produces detector efficiency file detreff. DCF based on preceding GRABGAM spectral analysis of calibration standard, as appropriate. It also provides for summing corrections using the spectrum peaks and continuum.

GRABDIAG - produces a diagnostic table to study presence of artifact peaks including compton edges, backscatter, and escape peaks.

GRABPLOT - provides interactive peak analysis on monitor screen for user selected peaks.

PEAKPART - refines the multiplet analysis to better address overlapping peak areas.

\section{GRABGAM ALGORITHMS}

The primary data reduction algorithms are (1) the peak search, (2) singlet analysis, (3) multiplet analysis, (4) MDA analysis, and (5) library matching method. The algorithm discussion refers to two different FWHMs, denoted as FWHM and FWHM ${ }^{*}$. A FWHM is deduced from the spectral peak analysis, while a FWHM $^{*}$ is a user-input energydependent value.

\section{III.A. Peak Search}

The constructions for the peak search algorithms are summarized in Figure 1. Shown are three peak filters that are mathematically similar to second derivatives used in other search algorithms ${ }^{1-2}$ and initially developed by Mariscotti ${ }^{25}$ for Gaussian peaks. Here the figure denotes that each filter "traps" or "ropes" an area $A_{f}$ for peak spectral counts, viz.

$$
A_{f}=g-b 1-b 2 \pm(g+b 1+b 2)^{1 / 2}
$$

where $g$ is the number of counts in the $2 \mathrm{n}$ middle channels spanned by the filter, and b1 and b2 are the counts in adjacent $n$ channels sampled by the filter. The error is recognized as the 1- $\sigma$ counting error. Each channel grouping is customarily denoted as a region of interest (ROI). In effect, as each filter moves across the spectrum, it calculates successive test peak areas $A_{f}$ based on its ROIs. For each filter the adjacent background n-channel ROIs (with b1 and b2 counts) are each displaced $n$ channels from the middle gross peak $2 n$-channel ROI ( $g$ counts) to help accentuate the peak/noise ratio. 
In GRABGAM a peak is found when the test $A_{f}$ exceeds its corresponding 1- $\sigma$ counting error by a factor of 3 . A peak location channel then approximates the centroid as the local maximum $A_{f}$ from subsequent tests during passage of the filter over the peak. If two peaks are separated by $<0.47$ FWHM $^{*}$ they are combined as a single peak that is broadened by $<21 \%$. The peak location channels are stored monotonically in an array for later detailed peak analysis.

The three filters simultaneously trap their respective areas $A_{f}$ relative to the same spectral region as shown in Figure 1 . The smallest filter (2-pt rope) is first tested for the $A_{f} \geq 3 \sigma$ criteria for peak presence; if satisfied, this smallest filter subsequently finds the peak location to allow better resolution definition should the peak be within a multiplet. Should the smallest filter not indicate a peak, the middle (4-pt rope) is tested, and should it fail, the largest (8-pt rope) is tested. These progressively larger filters are more sensitive for trapping a detectable $A_{f}$ but provide less resolution for discriminating peaks within multiplets. As the candidate peaks are found during execution, they are displayed in a table on the monitor screen, as illustrated in Figure 2 .

\section{III.B. Singlet Analysis}

The singlet analysis is activated when adjacent peaks are separated by at least $3.5 \mathrm{FWHM}^{*}$, so that adequate background ROIs exist on both sides of such peaks. The singlet analysis primarily seeks to use an integral peak analysis to accommodate low-level peaks more readily than the customary differential approach with peak fitting. In cases where the integral approach fails, other analysis options are applied as appropriate.

The peak-adjacent background ROIs are found first. Both background ROIs have an identical width of $\mathrm{m}$ channels corresponding to the FWHM ${ }^{*}$ associated with the peak location channel determined by the peak search algorithm; however, the code limits the minimum background ROI to three channels. The ROI backgrounds B1 and B2 are initially placed adjacent to the peak location channel as shown in Figure 3. Then first the B1 ROI and then the B2 ROI move down their respective sides of the peak while being tested for leveling out in appropriate background regions. As these ROIs move toward their destinations, their adequacy is tested against the criteria:

$$
\begin{aligned}
& \mathrm{B} 1 \mathrm{p}-\mathrm{B} 1 / \mathrm{m}<2\left(\mathrm{~B} 1 \mathrm{p}+\mathrm{B} 1 / \mathrm{m}^{2}\right)^{1 / 2} \\
& \mathrm{~B} 2 \mathrm{p}-\mathrm{B} 2 / \mathrm{m}<2\left(\mathrm{~B} 2 \mathrm{p}+\mathrm{B} 2 / \mathrm{m}^{2}\right)^{1 / 2}
\end{aligned}
$$

where B1p or B2p denotes the counts in the channel just adjacent to the BI ROI or B2 ROI, on the peak side. 
The peak gross region is determined from its adjacent background regions. As indicated by Equation 2, the extreme end channels $\mathrm{H} 1$ and $\mathrm{H} 2$ of the peak gross region must have counts that are less than $2-\sigma$ above the adjacent background regions. If by chance the resulting gross region is less than 2 FWHM, the average 3-point maximum channel Hmax of the gross peak is determined, and the gross region is defined by

$$
\begin{aligned}
& \dot{\mathrm{H} 1}=\mathrm{Hmax}-\mathrm{FWHM}^{*}-1 \\
& \mathrm{H} 2=\mathrm{Hmax}+\mathrm{FWHM}^{*}
\end{aligned}
$$

Should the gross region be an uneven number of channels, it is forced to be even by adding a channel to the low side of the gross region, effectively lowering $\mathrm{H} 1$ by 1 . Then the $\mathrm{B} 1$ and $\mathrm{B} 2$ region are made adjacent to the final gross peak region. In every singlet peak analysis, the size of each background region is modified on its peak-remote side so that it has half the number of channels as the gross region. Using the ROI counts for gross counts $G$ and adjacent backgrounds $\mathrm{B} 1$ and $\mathrm{B} 2$, the peak acceptance must satisfy

$$
\mathrm{G}-\mathrm{B} 1-\mathrm{B} 2 \geq 3(\mathrm{G}+\mathrm{B} 1+\mathrm{B} 2)^{1 / 2}
$$

Having accepted a peak and its ROIs, the code proceeds with the integral calculations. The area calculation is trivial and given by

$$
A=G-B I-B 2 \pm(G+B 1+B 2)^{1 / 2}
$$

The centroid, FWHM, and tail are determined by performing the peak integral, subject to the following assumption. Typically HPGe spectral peaks exhibit a flat background (BI) on the lower-energy side of the peak that is noticeably higher than a similar one (B2) on the high-energy side of the peak. The additional background on the lower-energy side of the peak is due to the escape of gammainduced electrons from the sensitive detector volume and forward Compton scattering within the sample, which are assumed to have distributions as shown in Figure 4. The theoretical distribution (perfect resolution) shows the peak as a spike and the escape electrons plus forward compton as a step function. The detected distribution illustrates the resolution effect. The figure denotes the parallels of the two distributions. In effect, if we view the peak with centroid $\mathrm{Eg}$ as a differential probability function $f(E-E g)$, the step background will be related to its integral 
probability $F(E-E g)$, and we may write the differential gross gamma response $g(E)$ in the peak region as

$$
g(E)=A f(E-E g)+b(1-F(E-E g))+c+v(E)
$$

where $A$ is the peak area, $b$ is the step background per keV, and $C+V(E)=z(E)$ is the background per keV upon which the peak distribution is superposed. For later convenience, $\mathrm{z}(\mathrm{E})$ is divided into its constant $C$ and energy-dependent $v(E)$ components. The uppercase $(A, F)$. Correspond to integral values, and the lowercase $(g, f, b, c$, and $v)$ correspond to differential values. Integrating the above expression over a single channel j yields

$$
g_{j}=A\left(F_{j+1 / 2}-F_{j-1 / 2}\right)+b_{c}-b_{c}\left(F_{j+1 / 2}+F_{j-1 / 2}\right) / 2+c_{c}+v_{j}
$$

where $g_{j}$ denotes the counts in channel $j, F_{j+1 / 2}$ is the integral of $f(E-E g)$ up to channel $j$ upper limit of $j+1 / 2, b_{c}$ and $c_{c}$ are the constant background components per channel, and $v_{j}$ is $v(E)$ in channel units. The expression $\left(F_{j+1 / 2}+F_{j-1 / 2}\right) / 2$ is taken as the average $F(E-E g)$ over channel $j$. The above equation may be rearranged as a recursion relation to solve $F_{j+1 / 2}$ as

$$
F_{j+1 / 2}=\left[g_{j}-v_{j}+\left(A+b_{c} / 2\right) F_{j-1 / 2}-\left(b_{c}+c_{c}\right)\right] /\left[A-b_{c} / 2\right]
$$

which has an initial value $F_{i-1 / 2}=0$ associated with the lowest channel $i$ of the gross peak region. Actually GRABGAM uses a different but equivalent formalism for $F_{j+1 / 2}$, as developed by summing Equation 7 from $j=i$ to $k$, viz

$$
\sum_{j=i}^{k}\left(g_{j}-v_{j}\right)=A\left(F_{k+1 / 2}-F_{i-1 / 2}\right)+(k-i+1)\left(b_{c}+c_{c}\right)-b_{c} \sum_{j=i}^{k}\left(F_{j+1 / 2}+F_{j-1 / 2}\right) / 2
$$

We note that the sum in the last term may be written as

$$
\sum_{j=i}^{k}\left(F_{j+1 / 2}+F_{j-1 / 2}\right) / 2=\left(F_{k+1 / 2}+F_{i-1 / 2}\right) / 2+\sum_{j=i}^{k-1} F_{j+1 / 2}
$$

where it is noted that $F_{j-1 / 2}$ for $j=p+1$ equals $F_{j+1 / 2}$ for $j=p$. 
Recalling that $F_{i-1 / 2}=0$ and substituting Equation 10 into Equation 9 and rearranging yields

$$
F_{k+1 / 2}=\left[\sum_{j=i}^{k}\left(g_{j}-v_{j}\right)+b_{c} \sum_{j=i}^{k-1} F_{j+1 / 2}-(k-i+1)\left(b_{c}+c_{c}\right)\right] /\left[A-b_{c} / 2\right]
$$

With $F(E-E g)$ solved per $F_{k+1 / 2}$, the following definitions result from the inverse function $\mathrm{E}(\mathrm{F})$ for energy:

$$
\begin{aligned}
& \text { Cent } \equiv \mathrm{E}(0.50) \\
& \text { SigA } \equiv \mathrm{E}(0.16) \\
& \text { SigB } \equiv \mathrm{E}(0.84) \\
& \mathrm{FWHM} \equiv(2.355 / 2)(\mathrm{Sig} A-\mathrm{SigB}) \\
& \text { TaiI } \equiv(\text { Cent-SigA)/(SigB-Cent) }
\end{aligned}
$$

Effectively, this analysis provides operational definitions of the centroid, FWHM, and tail with analogy to a Gaussian peak. The FWHM definition is consistent with other methods for calculating Gaussian peak FWHMs, which show better than $10 \%$ agreement. 26

The current GRABGAM singlet analysis assumes $v_{j}=0$ for Equation 11 , and thus singlet peaks on non-constant $z$ (E) backgrounds are not directly addressed. However, for a singlet such backgrounds have essentially no impact on the peak area calculation and only a minor impact on the peak centroid. On the other hand, multiplet peaks can be significantly impacted, and a more realistic $v_{j}$ is modeled for this case, as discussed in the next section along with a detailed development in Appendix A.

There are cases where the F-integral analysis is not used, and these are flagged by negative values of the tail, as denoted in Figure 4. For these cases the centroid is set as the middle channel of the gross region $(\mathrm{H} 1+\mathrm{H} 2) / 2$ and the FWHM is the gross width $(\mathrm{H} 2-\mathrm{H} 1+1)$, where again $\mathrm{H} 1$ and $\mathrm{H} 2$ are the end channels of the gross region. The negative tail and the abnormally large FWHM alert the user that the analysis may require further scrutiny. 


\section{III.C. Multiplet Analysis}

A multiplet analysis is used for consecutive peaks that have their locations separated by less than 3.5 FWHM $^{*}$. The FWHM ${ }^{*}$ is assumed constant over the multiplet region and calculated based on the middle channel between the first and last peak of the multiplet.

Initially background regions $\mathrm{B} 1$ and $\mathrm{B} 2$ above and below the multiplet are found similarly to that of a singlet peak, except that the B1 region "ropes" down to a region on the low-energy side of the first multiplet peak and the B2 region "ropes" down to a region on the high-energy side of the last multiplet peak. The B1 and B2 regions are required to be displaced at least a FWHM ${ }^{*}$ from their adjacent multiplet peaks. To give better representation against fluctuations, any points in the final "constant" B1 or B2 regions that exceed their respective averages by $3 \sigma$ are removed from the average background per channel calculations.

The minima between adjacent peaks of the multiplet are found next, as illustrated in Figure 5. Three options are examined for calculating these minima. First, the gross minimum is sought, whereby it is assumed that effects from the underlying continuum background are negligible. If the resulting minimum is not displaced at least one channel from both adjacent peak locations, a relative minimum is sought as the maximum difference between channel counts and the line connecting the adjacent peak maxima. Again, if this minimum is not displaced from both adjacent peak locations by at least one channel, then the minimum is taken as the inverse center of gravity of the adjacent peak maxima. This minimum is forced to be displaced at least one channel from its adjacent peaks. The latter two minima analyses provide better capability for defining a boundary between closely spaced multiplet peaks that display shoulders as opposed to true minima, as illustrated in Figure 6.

The total area $A_{M}$ of the multiplet is then calculated using the gross counts $G$ between the adjacent background regions, in analogy to the method used for singlet peaks, or

$$
\begin{gathered}
A_{M}=G-\left(N_{M} / 2 N_{1}\right) B 1-\left(N_{M} / 2 N_{2}\right) B 2 \pm \sigma\left(A_{M}\right) \\
\sigma\left(A_{M}\right)=\left[G+\left(N_{M} / 2 N_{1}\right)^{2} B 1+\left(N_{M} / 2 N_{2}\right)^{2} B 2\right]^{1 / 2}
\end{gathered}
$$

where $N_{M}, N_{1}$, and $N_{2}$ are the number of channels in the multiplet and background regions.

The integral $\mathrm{F}$-function is generated in the same manner as that for the singlet analysis, as the sum of individual peak integrals within the multiplet yields the F-function for the 
multiplet. This is seen by noting how the individual peaks in the multiplet contribute as individual components of Equation 6 . In particular,

$$
g(E)=\Sigma A_{m} f\left(E-E_{m}\right)+\sum b_{m}\left(1-F\left(E-E_{m}\right)\right)+c+v(E)
$$

where the summation is over the multiplet peaks, each denoted by subscript $m$. Because the ratio of the step background $b_{m}$ and peak area $A_{m}$ should be essentially the same for each peak in the multiplet, we may substitute $b_{m}=\beta A_{m}$ in Equation 14 yielding

$$
g(E)=\Sigma A_{m} f\left(E-E_{m}\right)+\beta \sum A_{m}\left(1-F\left(E-E_{m}\right)\right)+C+v(E)
$$

which may also be expressed as

$$
g(E)=\sum A_{m} \frac{\sum A_{m} f\left(E-E_{m}\right)}{\sum A_{m}}+\beta \sum A_{m} \frac{\sum A_{m}\left(I-F\left(E-E_{m}\right)\right)}{\sum A_{m}}+C+V(E)
$$

where it is recognized that $f_{M}(E) \equiv \Sigma A_{m} f\left(E-E_{m}\right) / \sum A_{m}$ is a differential probability function composed of peak-weighted probability functions of the multiplet, corresponding to integral probability $F_{M}(E) \equiv \Sigma A_{m} F\left(E-E_{m}\right) / \Sigma A_{m}$. Noting that $A_{M}=\Sigma A_{m}$ is the total of peak areas of the multiplet and also noting that $b_{M}=\beta$ $\Sigma A_{m}=\Sigma b_{m}$ is the total of the step background components of the peaks, we may write

$$
g(E)=A_{M} f_{M}(E)+b_{M}\left(1-F_{M}(E)\right)+c+v(E)
$$

which is identical in form to Equation 6 for a singlet peak. Thus, the peak multiplet integral $F_{M}(E)$ may be determined using the same algorithms developed for the singlet peak analysis of $F(E-E g)$ developed in section III.B.

For the most recent multiplet analysis, $z(E)=c+v(E)$ is modeled as a cubic polynomial in $E$, so that the background under the multiplet is smoothly matched to its adjacent background regions. The model also incorporates the step background, improves the peak centroid estimates, and refines the total multiplet area $A_{M}$ to be consistent with its modeled background. The details for the modeling are discussed in Appendix A. Unlike the singlet analysis, the individual peak areas $A_{m}$ can be strongly impacted by the underlying background. At the same time, prior GRABGAM analyses did 
not reveal frequent impacts from such variable backgrounds as the statistical counting errors tended to dominate.

As the $F$-function is generated, the fraction $F_{m / M}$ for each multiplet peak is determined by denoting the portion of $F$ between successive minima, whereby the end channels $\mathrm{H} 1$ and $\mathrm{H} 2$ of the gross multiplet region are also treated as minima. The area $A_{m}$ of an individual multiplet peak is then given by

$$
A_{m}=F_{m / M} A_{M} \pm\left(F_{m / M}\right)^{1 / 2} \sigma\left(A_{M}\right)
$$

The counting error for $A_{m}$ is approximated assuming that the $F_{m / M}$ fraction exactly represents the peak area. Although useful as a guide to the counting statistics, the true error will be larger due to the analysis error. In particular, the analysis assumes that multiplet minima bound representative areas for individual peaks, and this is obviously an approximation due to peak overlap errors. These errors may be reduced by executing PEAKPART for the peaks of a multiplet, as described in Appendix A. For multiplets with very low statistics, the method encounters difficulties, and warning flags are issued to alert the user, as indicated the Figure 5.

\section{III.D. MDA Analyses}

MDA analysis is performed for two types of peaks. In one case a statistically significant peak has been detected in the spectrum, but it has a background file peak that cancels the spectral peak. In the other case, the MDA flag of a gamma energy in the isotope library causes an analysis although no corresponding spectral peak was found. Specifically, the peak channel for the gamma energy is determined, and gross peak and background channels are assigned based on the input FWHM", whereby the results output are a centroid at channel $(\mathrm{H} 1+\mathrm{H} 2) / 2$, a "false" FWHM equal to the gross width of $(\mathrm{H} 2-\mathrm{H} 1+1)$, and a "false" tail assigned as -1 to flag the MDA analysis.

Both cases are calculated similarly. Each calculates a peak area $A$ and an error $\sigma(A)$, which essentially derives from an expression,

$$
A \pm \sigma(A)=[(A+B)-B] \pm(A+2 B)^{1 / 2}
$$

where $B$ is the effective background above which true signal A must be detected. Accordingly, from $A$ and $\sigma(A)$ the value of the background can be determined as

$$
B=\left(\sigma(A)^{2}-A\right) / 2 \text {. }
$$


Two types of MDAs are utilized in GRABGAM. One MDA is a determination level, ${ }^{10}$ which GRABGAM has modified so that results are presented as $^{9}$

$$
\begin{aligned}
& A \pm \sigma(A) \text { for } A \geq 3 \sigma(A) \\
& <3 \sigma(A) \text { for } A<3 \sigma(A)
\end{aligned}
$$

The MDA format of the peak printout is "<3 $\sigma(\mathrm{A})=3 \sigma / \mathrm{A} / \sigma(\mathrm{A})$ " where the bold entries are the calculated numbers; this format preserves the information for converting to $A \pm \sigma(A)$ if desired. The other MDA result uses the currie definition of detection limit ${ }^{10}$, which is given as

$$
<2.71+4.65 \mathrm{~B}^{1 / 2}
$$

which by itself is insufficient for conversion to $A \pm \sigma(A)$. In this case the peak printout is "<2.71 $+4.65 \mathrm{~B}^{1 / 2} \mathrm{MDA}=\mathrm{C}+\mathrm{b} "$. Overall, the calculation of both MDAs provides the user more options for interpretation.

\section{III.E. Library Matching Method}

The peak data are merged with matching library data as the code executes. Each peak that is found is analyzed in monotonically increasing order with energy. After each peak centroid and energy is determined, the monotonically ordered energies of the isotope library are stepped up to the region of the centroid energy to seek a match. If a match is found, the isotope data associated with the energy is transferred as part of the peak data for later calculations. If no match is found, the peak is labeled as "no-lib" and a set of default parameters (100\% branching, zero decay time, etc) is assigned. This essentially one-dimensional matching approach speeds the search relative to a two-dimensional lookup technique.

For library-flagged MDAs that do not correspond to the found peaks, the code calculates these cases and simultaneously merges them within the above sequence in order of gamma energy. In this process the energies/MDA flags of the entire isotope library are stepped monotonically between the peak energies found earlier so that the new MDA analyses can be placed in the correct energy order within the peak list. 


\section{USER OPERATION OF GRABGAM}

This section describes the user operations for GRABGAM, while Appendix B provides code listings. Discussed below are inputs, code execution, basic output, supplementary analyses, and auxiliary programs. The GRABGAM sequence diagram of Figure 7 assists the discussion, as well as the earlier Table 1 overview.

\section{IV.A. GRABGAM Inputs}

The inputs are both manual via keyboard and automatic from files. For the present we will assume that the input files are available; their creation will be discussed along with the supplementary analyses of section IV.D and auxiliary programs of section IV.E.

Upon execution of a batch code, an isotope library file ISOLIBRY.LIB and a detector library file DETLIBRY.LIB will be automatically input. ISOLIBRY.LIB provides a monotonic userselected list of gamma-ray energies, along with their isotope symbols, halflives, intensities, and flags for MDA analyses. DETLIBRY. LIB provides sets of detector calibration curve parameters for three vial sizes as function of fill height. However, the user is not limited to these choices and can for example select a calibration file detreff. DCF developed for a specific geometry. For each detector a corresponding peak background file backgnd. BKG will also normally have been prepared prior to running the code although one may select a "no background subtraction" option if desired.

Following the above preliminaries, two informational frames (\#1 and \#2) are presented. Then the user is prompted to begin the input from the keyboard. The first analysis input frame (\#3) queries whether background subtraction is to be used and the type of countrate units (e.g. cph for low-level samples, cps for calibration standards). At the bottom of each frame an option is given to edit the input per re-entering. Subsequent frames (\#4 and \#5) query information in the following order:

\footnotetext{
- Two points for energy vs channel calibration

- Two points for FWHM vs energy calibration

o. Detector for analysis

- Detector efficiency for sample geometry
}

The energy $(E)$ vs channel $(C)$ calibration is linear $(E=a C+b)$, but the FWHM vs energy calibration assumes the Fano effect, ${ }^{27}$ which is related to the square root $\left(\mathrm{FWHM}^{*}=[\mathrm{CE}+\mathrm{d}]^{1 / 2}\right)$. The detector may be selected from the list or designated as "other" if not listed. 
Listed detectors have queries for some or all of the following calibration geometry options - vials (up to three sizes) vs sample height, well, air filter. Selection for efficiency $=1$ or parameter inputs for log-polynomial and/or log-hyperbola efficiencies are manual options for both listed and other detectors. Normally the "other" detector choice will use a calibration file detreff.DCF prepared for a specific geometry. A corresponding backgnd. BKG file is also queried for input, if the background subtract option has been selected. The user has the option of displaying an energy vs efficiency table on the screen before proceeding.

The final input frame (\#6) queries the user for the spectral file to be analyzed and other aspects of the analysis. The spectral file is assumed to have the format of an EG\&G ORTEC ADCAM file denoted as spectrum. CHN. Other analysis queries are the title, sample age, activity units (e.g. $\mathrm{Bq} / \mathrm{kg}$ ), numerator factor (e.g. conversion to $\mathrm{Bq}$ ), denominator factor (e.g. number of $\mathrm{kg}$ ), start/end channels for analysis, and the $\pm \mathrm{keV}$ range for isotope identification. For this final screen, individual inputs may be changed by menu operations at the bottom of the frame. Following completion of any such changes, the code begins to execute.

\section{IV.B. GRABGAM Execution}

GRABGAM execution initially prints out a summary of the input parameters. Then the screen displays a listing of the peaks as they are found by the filters. These peaks are further analyzed and then printed out in the basic analysis table. Finally, the user is queried if supplementary analyses are desired; if so, appropriate files are created before the program terminates.

First, the input parameters are printed out as in the example given in Figure 8. This printout has proved useful as a $Q A$ check for the analyses. At the top of the printout is the user-input title for the analysis, which is followed by three main sections. These sections are Sample counting Information, Sample Analysis Information, and Detector status Information. A detailed discussion of this printout is given in section IV.C.

Next, the screen displays the peaks as they are found by the filters, as shown in Figure 2. A screenprint hardcopy of this may also be obtained if desired. The table gives the channel number, energy, peak area trapped by filter, $1-\sigma$ percent error of this area, and the filter size or "rope". The rope filter sizes are designated "2-pt", "4-pt", and "8-pt" as defined in Figure 1. The number of forced MDA cases is also displayed immediately after this table.

After this a hardcopy summary of the multiplet parameters is printed to allow later refinement with PEAKPART as appropriate. For each multiplet peak, the table includes its maximum, bounding 
minima, area, energy, and isotope identification. The minima codes $(1,2,3)$ denote whether a minimum was determined as (1) a gross minimum, (2) relative minimum, or (3) inverse center of gravity between adjacent peaks. Further details are given in Appendix $A$.

Then, the basic peak analysis table is printed after the peaks have undergone further analysis and have been appended with background corrections and MDA cases. An example of the peak analysis table is shown in Figure 9, where the peak channel, energy, FWHM, tail, counts, peak rate, peak background rate, isotope identification, activity, and 1- $\sigma$ errors are given. A more detailed description of the table is given in section IV.C. Note that the basic peak analysis table is actually entitled "Detailed Sample Analysis" because final sample isotopic activities are also included.

Finally, the user is queried whether supplementary analyses are desired. These analyses can use the spectral data for developing background files, calibration files, or simply for examining the analysis in more detail. operation of the supplementary analysis programs is discussed in section IV.D. After the supplementary analysis query is answered, the GRABGAM execution is completed.

\section{IV.C. GRABGAM User output}

After execution of GRABGAM, the user will have hardcopy tables of the input parameters and the peak analysis, as already introduced. The present section discusses these tables in more detail as a guide to their utilization.

The printout of the input parameters is examined in reference to the example in Figure 8. The Sample counting Information at the top of the printout gives the sample spectral file and its associated ADCAM information, including MCA components (MCB/segment), start count (time/date), and count times (Iive/real). The Sample Analysis Information at the middle of the printout provides the channels analyzed (start/end), a peak search parameter (now defaulted), the $\pm \mathrm{keV}$ limits for isotope identification, and the activity units along with associated numerator and denominator factors. The Detector status Information at the bottom of the printout denotes the detector along with its background and efficiency calibration files, as well as the analysis configuration geometry and the calibration equations used for energy (EN), FWHM", and efficiency (EFF). A quick review of this printout assures that the input data are appropriate for the intended analysis.

The Detailed Sample Analysis printout table is illustrated in

Figure 9. (Just before this, a multiplet parameter table is printed, as discussed in section IV.B and Appendix A). It has both 
a heading and a footing for each column, which correlate with the top and bottom column entry of each peak data set. For example, the "top" peak energy corresponds to the centroid calculated by the code, while the "bottom" energy corresponds to the library value of the associated isotope. Similarly, for peak widths, the top value is the spectral analysis FWHM and the bottom is the guide FWHM $^{*}$ input by the user. Such information provides the user with a $Q A$ check on the adequacy of the calibrations used, as well as providing guidelines for recalculation with other calibration choices when necessary. For multiplet peaks, the top FWHM becomes the number of peaks in the multiplet and the tail denotes the number of the peak within the multiplet. other infrequent peak flags have been summarized in Figures 4 and 5 .

The Detailed Sample Analysis often indicates "less-than" values in the Activity column. For this situation, the top number corresponds to the GRABGAM determination limit ${ }^{9}$ and the bottom number corresponds to the customary 95\%-confidence minimal detection limit (MDA) developed by currie. ${ }^{10}$ Adjacent to the

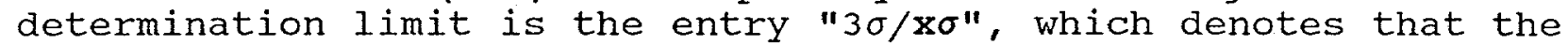
code requires that a positive peak area had to exceed its determination limit of $3 \sigma$ but the actual peak only had a smaller area of $x \sigma$. This allows the user to transform the determination limit to a measured activity with an error. Such a transformation is not possible with the single number provided by the conventional MDA, which is denoted in the table by the notation "MDA $=c+b$ ". overall, the $3 \sigma$ determination limit is comparable to the conventional MDA.

\section{IV.D. Supplementary Analysis Programs}

Six supplementary analyses programs may be run following GRABGAM execution, provided that the query for such analyses (except for the PEAKPART analysis) was affirmed to create appropriate data files. The supplementary programs are listed in Table 1.

GRABISOS is generally executed on a routine basis following GRABGAM sample analysis. Upon execution, GRABISOS bubble sorts all the peaks of the Detailed Sample Analysis table in the following ascending alphanumeric order: isotope mass number (A), isotope symbol $(Z-A)$, and peak energy (Eg). This being done, the screen displays the first isotope (lowest $A, Z$ ) and its Iist of peak energy activities. From the list of peak activities, the user may flag those useful for a weighted average of the isotope activity. Then the analysis and result are recorded by the printer, as illustrated in Figure 10. The sequence is then repeated for the second isotope (lowest remaining $A, Z$ ) and subsequent isotopes until all have been addressed. The final peak grouping is for an artificial isotope that includes all peaks that were not identified with an isotope, such as x-rays, annihilation peak, escape peaks, and peaks that had 
no counterpart in the isotope library. These peaks, ordered monotonically in energy, are assigned activities assuming 100\% branching intensity and zero decay time, as this helps facilitate manual identifications of the residual peaks.

GRABBACK produces a peak background file from the background spectrum of a detector. GRABBACK can use a single spectral file for developing a background file backgnd. BKG or merge it with data of an earlier background file to improve statistics. Upon execution GRABBACK leads the user to these options. The merged file is an even weighted average of the new peak backgrounds with the peaks of the existing background file, so that the values are more representative of recent peak backgrounds. Two other options for making background files also exist. One option uses a text editor file creation, whereby line inputs for energy, countrate, and error are entered in monotonic order with energy using peak data from an appropriate background spectrum analysis. The other option uses the MERGBACK code, which is discussed in section IV.E.

GRABCALB produces an efficiency calibration file for a specific detector and geometry. (Calibrations with vial height interpolations are performed externally and parameters are input to the DETLIBRY.LIB file using the DETLIBAS code described in section IV.E). Upon execution, GRABCALB retrieves data saved by the GRABGAM analysis of the calibration standard, and then queries information for the decay time from the standard calibration date, which is entered from the keyboard. The code then sequentially displays the peaks in the spectrum, giving their isotope identification, energy, and countrate, whereby the user can select those to be used in the calibration along with their gamma rates at the certified standard date. After completing these selections, a screen table is presented for acceptance or editing. Then, a loglog efficiency vs energy plot of the raw data appears on the screen with a query for correcting coincidence summing. For summing corrections, a representative detector thickness is entered along with summing gammas and their coincident fractions. The log-log efficiency plot of the refined data points is then redrawn for acceptance.

GRABCALB curve fitting proceeds following the corresponding data entry and refinement. With the data points displayed on the screen, the user moves three cursors that are sufficient for "artistically" constructing a log-log hyperbola to fit the data points. A comparison of the fit is given for each point, and then the comparison is improved by auto-renormalization that makes the average of the deviations zero. One may then opt to improve the fit further by applying a least-squares fitting to the hyperbola. A final option is to improve the fit by analyzing the perturbations from the hyperbola with a cubic least-squares fit. After the fitting options have been exhausted, the calibration parameter file detreff.DCF is created. Another option for making the detreff. DCF file is to use the MERGCALB code discussed in section IV.E. 
GRABDIAG is a diagnostic program that explores whether a detected peak may be an artifice such as a compton scatter or an escape peak. Upon running the code, each gamma peak of energy $E(\mathrm{keV})$ from the preceding GRABGAM execution has the following calculations tabulated:

- Compton Edge $=E /(1+511 / 2 \mathrm{E})$

o Compton Backscatter $=E /(1+2 \mathrm{E} / 511)$

- Single Escape Peak Parent $=E+511$

- Double Escape Peak Parent $=E+1022$

Usage of GRABDIAG has revealed no Compton artifices, affirming that the GRABGAM filters are favorable for finding peaks alone. Escape peaks of concern for SRTC low-level gamma spectrometry have been identified and placed in the isotope library to assist the user. Thus, GRABDIAG is not generally needed for routine analysis. Yet it remains a tool for helping diagnose the spectra of unusual samples.

GRABPLOT is used to plot peak regions to allow appraisal and possible reanalysis. This tool was primarily used in the early development of GRABGAM, but still remains available for peak studies. The peak to be plotted is selected by number from the preceding GRABGAM spectral analysis. The plot is displayed on the screen with colored regions to identify the RoIs used in the analysis. The ROIs may be varied by the user for an alternative analysis as appropriate.

PEAKPART refines the multiplet peak areas to better account for peak overlap. For a given multiplet the user inputs the GRABGAM peak centroids, areas, and their bounding minima. Then, the code calculates the Gaussian peak fractions that contribute to these minima-bounded areas. In turn these peak fractions act as coefficients of the refined areas, which are solved within a set of $M$ linear equations, where $M$ is the number of peaks in the multiplet. Further details are given in Appendix A.

\section{IV.E. Auxiliary Programs}

Four auxiliary programs also create files for GRABGAM. These stand-alone programs do not require prior execution of GRABGAM. The programs are given in Table 1, and each program is explained in the following discussion.

ISOLIBAS contains the isotope library information that the user selects as appropriate. This BASICA program is configured so that lines from 20,000 to 23,000 contain a DATA line for each isotopic gamma ray. The gamma energies are monotonically sequenced 
by using DATA lines corresponding to the energies. For example the data for the $834.8 \mathrm{keV}$ gamma of $\mathrm{Mn}-54$ is entered in Iine 20835 as:

$$
20835 \text { DATA "Mn-54", 312.7, 834.8, 99.98, } 0
$$

where 312.7 is the half-life in days, 834.8 is the gamma energy in $\mathrm{keV}$, and 99.98 is its intensity per decay in percent. Finally, the 0 indicates that an MDA analysis is not forced. BY contrast, if the 0 were replaced by a 1 , an MDA would be forced when the peak is not detected. Upon execution of ISOLIBAS, the information of all such DATA lines is written to the file ISOLIBRY.LIB.

DETLIBAS contains the detector library information for up to five detectors for three different vial sizes as a function of fill height. The fitted efficiency function is the product of a hyperbola and a third order polynomial in $h$ and $\ln _{5}(E)$, where $h$ is the vial fill height and $E$ is the gamma energy. ${ }^{5}$ The parameters for these efficiency functions are determined by a special leastsquares program and then entered into DATA lines within the DETLIBAS program. Upon execution of DETLIBAS, the information of these data lines is written to the file DETLIBRY.LIB.

MERGBACK is a stand-alone analog of GRABBACK, which was discussed earlier in section IV.D. MERGBACK requires the user to have tabulated the peak background rates for keyboard entry. overall, GRABBACK effectively streamlines the text editor approach for making the backgnd. BKG file by providing better ease for input and editing.

MERGCALB is the stand-alone analog of GRABCALB, which was discussed earlier is section IV.D. Unlike GRABCALB, MERGCALB requires the user to have tabulated the appropriate energyefficiency pairs for manual entry. Also any summing corrections will need to have been already applied since the spectral information for this is not provided by MERGCALB. With the data entered and ready for analysis, the subsequent execution of MERGCALB is identical to GRABCALB, yielding the file detreff.DCF, which includes parameters of the fitted efficiency curve. 


\section{V.A. Philosophy of Low-Level HPGe Spectral Analysis}

Spectral analyses of low-level gamma peaks are always subject to statistical limitations with regard to peak fitting. Accordingly GRABGAM pursues an integral approach to peak analysis as opposed to a differential fitting. Theoretically, the GRABGAM integral function $F$ is automatically corrected for its background, regardless of the actual peak shape. This is also true for the Ffunction of a multiplet. Overall, the F-function defines a consistent centroid (as median), FWHM (integral limits), and tail (integral asymmetry) for each singlet peak, with no requirement on the detector performance for producing ideal peaks. of course, even the integral approach has its statistical limitations, but even if the F-analysis fails to give acceptable results, a basic ROI analysis is flagged to yield an estimate so that the peak can be considered.

Singlets are anticipated to be predominant in low-level gamma spectrometry. Due to concerns for statistical and resolution limitations, the GRABGAM peak search routine does not distinguish peaks that are separated by less than $0.47 \mathrm{FWHM}^{*}$; however, the Fanalysis for the FWHM and tail measured for the resulting singlet peak alerts the user that the observed peak may be a composite of peaks. Concern for the statistics similarly restricts the multiplet analysis, as a given peak within a multiplet may also be a composite. Overall, GRABGAM experience in counting low-level samples has not been hampered by such hidden composite peaks, as the probability of such occurrences is generally low. Furthermore, typical unresolved composite peaks often may be identified from other gammas within the spectra, as is the case for a composite of the $185.7 \mathrm{keV}$ gamma of ${ }^{235} \mathrm{U}$ and the $186.2 \mathrm{keV}$ gamma of ${ }^{226} \mathrm{Ra}$ since ${ }^{235} \mathrm{U}$ frequently exhibits other gammas in the spectrum.

GRABGAM calculates both a determination limit and a detection limit. The GRABGAM determination imit $^{9}$ of $A \geq 3 \sigma$ is comparable to that of the currie detection limit ${ }^{10}$ (95\% probability detection), but both are always higher than the currie critical level ${ }^{10}$ (5\% false positive) for being detected above background. These three values can be derived as a function of background counts $B$ and are plotted in Figure 11. GRABGAM assures that its minimum detection has a $1-\sigma$ statistical error no worse than $33 \%$, while recorded detection at the currie critical level has errors in excess of $60 \%$. Instead of directly accepting peaks with such high errors, the GRABGAM philosophy is to flag MDA analyses for potentially useful

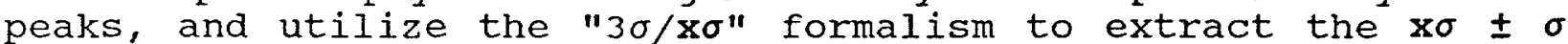
activity as appropriate. Consequently GRABGAM has a low false positive acceptance in general, while providing an inspection option for reconsidering the acceptance of flagged MDA peaks. 
Although the GRABGAM determination level and the currie detection limit are comparable in magnitude, their associated MDAs have different interpretations. The currie MDA is the level for which $95 \%$ of the time an actual peak at this level would exceed the Currie critical level for $5 \%$ false positives. As such, the currie MDA is based on a priori reasoning. The GRABGAM MDA indicates that the detected peak was less than this amount, and thus uses a posteriori reasoning. Overall, the Currie MDA may be stated as the "minimum detectable amount" and the GRABGAM MDA be stated as the "minimum detected amount". An attractive feature of the GRABGAM MDA is that the detected values always exceed the MDA, whereas the Currie MDA can contradict this situation. One may prefer to use a determination limit no with $n<3$ to provide more sensitivity at the expense of more false positives, and GRABGAM effectively provides this option within its " $3 \sigma / x \sigma$ " formalism for flagged MDA peaks. Other approaches to detection limits have also been offered, such as the use of direct Poisson statistics ${ }^{28}$ and individual peak channel evaluations for peak areas. ${ }^{21}$

\section{V.B. Algorithm Features and Limitations}

The peak search algorithm uses filters that trap the area above displaced adjacent background regions, as illustrated earlier in Figure 1. As GRABGAM was originally developed for $2000 \mathrm{keV}$ spectra spanning 4000 channels, a filter with a $4.0 \mathrm{keV}$ ( 8 channel) gross region was selected to contain essentially all of the area of a $1332 \mathrm{keV}$ gamma peak with FWHM of $2.0 \mathrm{keV}$, which is fairly representative of HPGe performance. Adjacent background regions of $2.0 \mathrm{keV}$ (4 channels) displaced from the peak region by $2.0 \mathrm{keV}$ ( 4 channels) then assured a good signal-to-background selection, even for a significantly larger FWHM. Upon developing the multiplet analysis, similar smaller filters with gross regions of $1.0 \mathrm{keV}$ (2 channels) and $2.0 \mathrm{keV}$ ( 4 channels) were added to help resolve peaks. These filters also have the potential to accentuate the signal to background. However, the $1.0 \mathrm{keV}$ filter could miss evidence of a peak (or shoulder) indicated by two high count channels relative to the two directly (as opposed to displaced) adjacent channels. On the other hand, two high channels provides little peak definition to assure its existence as opposed to a fluctuation, and thus their missed detection by GRABGAM is not considered a serious loss. Filter fluctuations occasionally identify two peaks that are displaced by less than $0.47 \mathrm{FWHM}^{*}$, which would not render two peaks for even identical gaussian peaks separated by this amount. In these cases the two peaks are combined as a single peak. Overall, the GRABGAM filters find peaks that can be comparable or broader than those of the user input FWHM ${ }^{*}$ for the analysis. The subsequent detailed peak analysis provides information concerning whether the peak is a true singlet or a broader composite of peaks. 
The singlet peak algorithms do not depend on fitting parameters for a particular model, which is customary for differential peak fitting. ${ }^{1-2}$ Instead, the adjacent background RoIs are selected by searching for the flat regions on either side of the peak, as illustrated in Figure 3. Thus, even if the peak is a pure Gaussian, smeared by amplifier drift, or degraded by a tail, the calculated peak area corresponds to the full-energy gamma response within the gross peak region. Additionally, the integral F-analysis provides adequate values for median, FWHM, and tail. A peak found by the search algorithm will be rejected if the peak analysis indicates $A<3 \sigma$. This possibility exists since the signal-to-noise enhancement of the filters may cause peak identification for statistical fluctuations. However, experience has shown that the combination of search and singlet algorithms effectively eliminate these false positive cases. Also, GRABGAM does not detect other spectral artifices such as compton edges or backscatter.

In the F-analysis for both singlets and multiplets, it had been assumed until recently that constant adjacent background regions existed. This is generally true in low-level gamma spectrometry, as such background regions are normally determined within statistical requirements. On the contrary, a significantly variable background does have an impact on an F-analysis which assumes $v(E)=0$, as illustrated in Figure 12. In this example, the $F$-analysis is in error because the average background on the lowerenergy side of the peak is higher than nearby points of the peak region and the average background on the higher-energy side is lower. Thus, for the singlet $F$ developed in section III.B, the $F$ values will be negative on the low-energy side of the peak and also modified on the high-energy side. Yet, the singlet peak area is essentially unaffected and the centroid, FWHM, and tail experience only minor inconsequential impacts. For multiplets the effects can be more detrimental, and Appendix A describes the recently upgraded $F$ algorithm that addresses such variable backgrounds; however, even the earlier analysis flagged the user when the $F$ algorithm was not appropriate. Overall, numerous GRABGAM analyses over 14 years have encountered minimal impact from variable backgrounds.

The multiplet algorithms produce an analysis like the example in Figure 5. The F-function approach uses an individual background subtraction for each gross channel count within the multiplet. The total area $A_{M}$ of all peaks in the multiplet is generally determined with accuracy comparable to that of a singlet peak. However, a calculational error exists for partitioning $A_{M}$ among the individual peaks of the multiplet, as the area $A_{m}$ of an individual peak is the area between its adjacent minima. The analysis assumes that the peak areas that extend beyond the minimum between the two peaks are equal; however, the accuracy of this approximation deteriorates for smaller peak spacing and larger differences in peak magnitude. As described in Appendix $A$, the supplementary program PEAKPART may be applied to correct such errors. 
Further improvement on the current multiplet analysis will require more detailed information on the peak shapes. Ideally, peak shapes could be extracted using the larger peaks of the sample spectrum, so that the intrinsic generality of the GRABGAM analysis for a spectrum is preserved; however, the prospect of a sufficient set of peaks is not likely for low-level samples. Thus, spectral shapes from calibration standards and/or modelling will be required for each detector as well as geometry in some cases, so that the intrinsic generality of the analysis would be compromised. $A$ standard addition method in which identical spiked and unspiked samples are counted would essentially retain intrinsic generality and provide the peak shapes; however, quality spiking of samples with gamma standards can be expensive and labor intensive.

Multiplets with low-level counting statistics can cause additional concerns, and if $F$ is not well-behaved, warning flags are printed with the output. This approach follows the overall GRABGAM philosophy of presenting the user with the option of reevaluating marginal cases rather than automatically removing them from consideration. In practice, with these guidelines and those mentioned above, the GRABGAM multiplet analysis has generally provided a useful tool for appraising closely spaced peaks.

\section{V.C. Performance History}

The GRABGAM code has successfully supported low-level HPGe gamma spectrometry at SRS for over 14 years, involving analyses of over 10,000 samples. Various projects supported during this period include studies of Chernobyl fallout, ${ }^{6-7}$ appraisal of LDEF satellite samples for NASA, ${ }^{29}$ monitoring radioactive levels in the Savannah River, ${ }^{30-31}$ evaluation of sediment levels in SRS cooling ponds, $31-34$ environmental analyses of high volume air samples near SRS, ${ }^{35}$ and studies of the Arctic ocean. ${ }^{36}$ In addition to these, numerous customer service samples have been conducted for SRS and offsite patrons.

GRABGAM analyses have been applied to both laboratory and inthe-field detectors. Laboratory applications include $13 \mathrm{HPGe}$ detectors with efficiency range of $10-160 \%$, which have been used in the Ultra-Low-Level Counting Facility ${ }^{3-4}$ and the Underground counting Facility. ${ }^{8-9}$ The two HPGe detectors on the SRS TRAC mobile laboratory ${ }^{37}$ also used GRABGAM for a number of years. One early TRAC applications was the collection and analysis of air samples following the chernobyl accident, where the TRAC vehicle analyzed regional samples during transits within Georgia and south Carolina. ${ }^{7}$ Although microphonics associated with the vehicle motion degraded the quality of the spectral peaks, the general nature of the peak analysis with the F-function properly analyzed these peaks, giving good agreement for similar samples analyzed at the ULLCF laboratory. ${ }^{6}$ similar performance is exhibited in the quality 
chart of Figure 13, which illustrates how the peak areas remained constant for a detector that gradually degraded in resolution over the years. In-the-field spectra obtained with a HPGe sonde 38 and an HPGe underwater detector ${ }^{31-34}$ have also been successfully analyzed with GRABGAM.

The output hardcopies of GRABGAM have provided useful guidance and documentation of the sample analyses. The initial input summary sheet lists information on all user inputs as a quality check. The peak listing prints both the peak energy determined by the analysis and the energy matched by the isotope library, guiding the user on any need for reanalysis with a refined energy calibration. Also the analysis-determined FWHM and the user-input FWHM ${ }^{*}$ are printed, allowing a quality check on detector performance and advising the user on whether the input FWHM $^{*}$ is adequate in selecting ROIdependent analyses such as flagged MDAs. Examination of FWHM and tail provide either singlet quality information or flags concerning MDAs, ROI analyses, and multiplet features.

The GRABGAM printouts have also provided consistency checks for the adequacy of detector backgrounds and efficiencies. The spectral peak counts and statistical errors are printed adjacent to those from background spectra, for direct consistency checks. Subsequent GRABISOS calculations frequently provide the user with consistency checks on the stability of the detector efficiency curve by comparing the different peak activities deduced for an individual isotope. For example, soil samples often contain radium daughters $\mathrm{B}-214$ and $\mathrm{Pb}-214$ that are in equilibrium, whereby several nicely spaced gammas are detected over a range of $200-1800 \mathrm{keV}$. Agreement for the isotope activities for these peaks shows that the efficiency curve is consistent in a relative sense. This information, coupled with monthly check source tests, affirms the absolute efficiency calibration as well. In summary, the above routine information from GRABGAM analyses provides the user with excellent guidelines for affirming the quality of the results.

\section{V.D. Conclusions}

GRABGAM has performed well in its role for analyzing low-level environmental samples by HPGe analysis. Overall, the analysis has attempted to provide user options for evaluating the presence of marginal but potentially real peaks, while automatically processing peaks with $1-\sigma$ detection statistics that are better than 33\%. Evaluation of marginal peaks is possible by conversion of the GRABGAM-formatted MDA data and/or by direct inspection of the spectrum. However, the best option is to continue counting for a time based on the statistics of the marginal peak. None of these options would be available if GRABGAM discarded the marginal peaks. 
The general nature of the GRABGAM peak search and analysis does not depend on specific peak shape parameters. Accordingly, other types of spectroscopy are expected to be amenable to the GRABGAM algorithms. Indeed, a NaI version GRABNAI was developed for an underwater NaI detector in the Savannah River to monitor effluent activities from SRS and the Plant Vogtle power reactors. 30 While not an advanced NaI peak stripping code, GRABNAI has provided useful gamma peak analyses for time profiles of the effluent discharges, which have correlated well with recorded discharges at the source. Another spinoff is GRABTRIT, which was developed to analyze SRS low-level tritium samples counted within gas proportional counters. ${ }^{3-4}$ In this case a spectrum results for the detector signals following their pulse-shape discrimination, which separates cosmic-ray background components from a narrow tritium peak. A code GRABALFA for surface barrier alpha spectrometry has also been written, as features of alpha tailing due to sample thickness should be handled well by the singlet algorithm. However, an algorithm for handling alpha multiplets still needs to be developed. Finally, the peak search algorithm was utilized in a gas chromatography spectral analysis code at SRS.

Improvements in GRABGAM have continued to be sought. Although the multiplet algorithm has provided adequate information for SRS applications in the past, an improved algorithm could provide a more complete deconvolution of the peaks. Due to recent improvements for addressing variable backgrounds, the F-function now provides a better estimate for the background profile beneath the multiplet peaks. The resulting peak areas are refined additionally with the partitioning code PEAKPART. For further refinements, peak shape information will be required, but this can only be marginally applied due to statistical limitations for lowlevel spectra.

\section{ACKNOWLEDGEMENTS}

The author gratefully acknowledges those who assisted with GRABGAM development and checkout. Ray Sigg, Martti Kantelo, and Gordon Lien provided input for the initial development, including computer coding techniques, low-level spectroscopy goals, and hardware configuration. Also acting as users, they have been followed by Worth Dalton, C.D. Ouzts, Tim Wilson, and Jim Cadieux, all of whom have provided useful feedback for enhancing GRABGAM over the years. 
REFERENCES

1. K. Delbertin and R.G. Helmer, Gamma- and X-Ray Spectrometry with Semiconductor Detectors, North-Holland / Elsevier Science Publishing Co., New York (1988).

2. C.G. Sanderson, Environmental International 14, 379 (1988).

3. W.W. Bowman, M.B. Hughes, Methods of Low-Level counting and Spectrometry (IAEA Proceedings Series, Berlin, April 6-7, 1981), 353 (1981).

4. R.C. Hochel, D.W. Hayes, Nuclear Instruments and Methods $130,183(1975)$.

5. W.G. Winn, Nuclear Technology, 103, 162 (1993).

6. W.G. Winn and M.V. Kantelo, Trans. Am. Nuc. Soc. 60, 75 (1989).

7. R.A. Sigg, Trans. Am. Nuc. Soc. 60, 73 (1989).

8. W.G. Winn, W.W. Bowman, A.L. Boni, The Science of the Total Environment 69, 107 (1988).

9. W.G. Winn, Trans. Am. Nuc. Soc. 54, 34 (1987).

10. L.A. Currie, Analytical Chemistry 40,586 (1968).

11. H.Mancher, Nuclear Instruments and Methods A258, 246 (1987).

12. A.E. Proctor, EG\&G Idaho Report, 311pp (1987).

13. W.K. Hensley, E.A. Lepel, M.E. Yuly, K.H. Abel, Journal of Radioanalytical and Nuclear Chemistry 124, 481 (1988).

14. R.B. Welch, F. Gyger, D.T. Jost, H.R. Von Gunton, U. Krahenbuhl, Nuclear Instruments and Methods A269, 615 (1988).

15. E.W. Killian and J.K. Hartwell, IEEE Transactions in Nuclear Science 36,615 (1989).

16. J.S. Yadav, J. Bruckner, J.R. Arnold, Nuclear Instruments and Methods A277, 591 (1989).

17. V. Hnatowicz, Computer Physics Communications Netherlands $60,111(1990)$.

18. T.J. Kennett, W.V. Prestwich, Nuclear Instruments and Methods A297, 315 (1990). 
REFERENCES (continued)

19. L.C. Longoria, A.H. Naboulsi, P.W. Gray, T.D. MacMahon, Nuclear Instruments and Methods A299, 308 (1990).

20. L.A. Hammond, P.W. Gray, A.H. Naboulsi, T.D. MacMahon, Nuclear Instruments and Methods A334, 543 (1993).

21. T.P. Luedeke, G.E. Tripard, Nuclear Instruments and Methods A372, 283 (1996).

22. C.V. Hampton, B. Lian, Wm.C. McHarris, Nuclear Instruments and Methods A353, 280 (1994).

23. L. Meray, Nuclear Instruments and Methods A353, 272 (1994).

24. N.D. Gagunashvili, Nuclear Instruments and Methods A343, 606 (1994).

25. M.A. Mariscotti, Nuclear Instruments and Methods 50, 309 (1967).

26. N. Markevich, I. Gertner, Nuclear Instruments and Methods A283, 72 (1989).

27. V. Fano, Phys. Rev. 70, 44 (1946).

28. G. Bernasconi, E.D. Greaves, L. Sajo-Bohus, Nuclear Instruments and Methods A307, 491 (1991).

29. W.G. Winn, NASA Conference Publication 3134 (Kissimee, FL), Part 1, 287 (1991).

30. W.G. Winn, S. Sundaram, ANS Topical Meeting Proceedings ISBN : 0-89448-188-6 (Charleston, SC), 101 (1993).

31. W.G. Winn, Journal of Radioanalytical and Nuclear Chemistry 194, no 2 , 334 (1995).

32. W.G. Winn, Trans. Am. Nuc. Soc. 66, 32 (1992).

33. W.G. Winn, D.L. Dunn, P.J. Bresnahan, Trans. Am. Nuc. Soc. 75, 54 (1996).

34 D.L. Dunn, W.G. Winn, P.J. Bresnahan, Trans. Am. Nuc. SoC. 75,52 (1996).

35. W.G. Winn, J.R. Cadieux, Trans. Am. Nuc. Soc., 486 (1997).

36. E.R. Landa, E. Reimnitz, D.M. Beals, J.M. Pochowski, W.G. Winn, I. Rigor, Arctic, 27 (1998). 
REFERENCES (continued)

37. R.A. Sigg, ANS Topical Meeting Proceedings, CONF-860932 (Bethesda, MD), 131 (1986).

38. W.G. Winn, K.J. Hofstetter, K.W. MacMurdo, Trans. Am. Nuc. SOC. 73, 83 (1995). 
Table 1: Overview of Programs and Files

\begin{tabular}{|c|c|c|c|}
\hline OPERATIONS & PROGRAMS & \multicolumn{2}{|c|}{ FILES } \\
\hline setup & Auxiliary & creation & Usage \\
\hline Isotope Iibrary & ISOLIBAS & ISOLIBRY.LIB & \\
\hline Vial efficiencies & DETLIBAS & DETLIBRY . LIB & \\
\hline Peak backgrounds & MERGBACK & backgnd. BKG & \\
\hline other efficiency & MERGCALB & detreff. DCF & DETLIBRY . LIB \\
\hline Execution & GRABGAM & creation & Usage \\
\hline $\begin{array}{l}\text { Analysis setup } \\
\text { Peak search }\end{array}$ & GRABDKR 1 & & $\begin{array}{r}\text { DETLIBRY.LIB } \\
\text { backgnd. BKG } \\
\text { detreff.DCF } \\
\text { spectrum. CHN }\end{array}$ \\
\hline $\begin{array}{l}\text { Peak analysis } \\
\text { Multiplet analysis } \\
\text { Background correct } \\
\text { MDA analysis } \\
\text { Peak results table }\end{array}$ & GRABDKR2 & $\begin{array}{l}\text { DATACALB.DAT } \\
\text { DATASPEC.DAT } \\
\text { DATAISOS.DAT } \\
\text { DATAPEAK.DAT } \\
\text { DATAMISC.DAT }\end{array}$ & $\begin{array}{l}\text { ISOLIBRY. IIB } \\
\text { backgnd. BKG }\end{array}$ \\
\hline Appendage & supplementary & Creation & Usage \\
\hline Wtd Isotopics & GRABISOS & & $\begin{array}{l}\text { All GRABname } \\
\text { Programs }\end{array}$ \\
\hline Peak backgrounds & GRABBACK & backgnd. BKG & DATACÁLB.DAT \\
\hline other efficiency & GRABCALB & detreff.DCF & $\begin{array}{l}\text { DATASPEC.DAT } \\
\text { DATAISOS.DAT }\end{array}$ \\
\hline Artifact peaks & GRABDIAG & & $\begin{array}{l}\text { DATAPEAK. DAT } \\
\text { DATAMISC.DAT }\end{array}$ \\
\hline Peak plot analysis & GRABPLOT & & i \\
\hline Multiplet peaks & PEAKPART & $<$ printout $>$ & $<$ printout $>$ \\
\hline
\end{tabular}



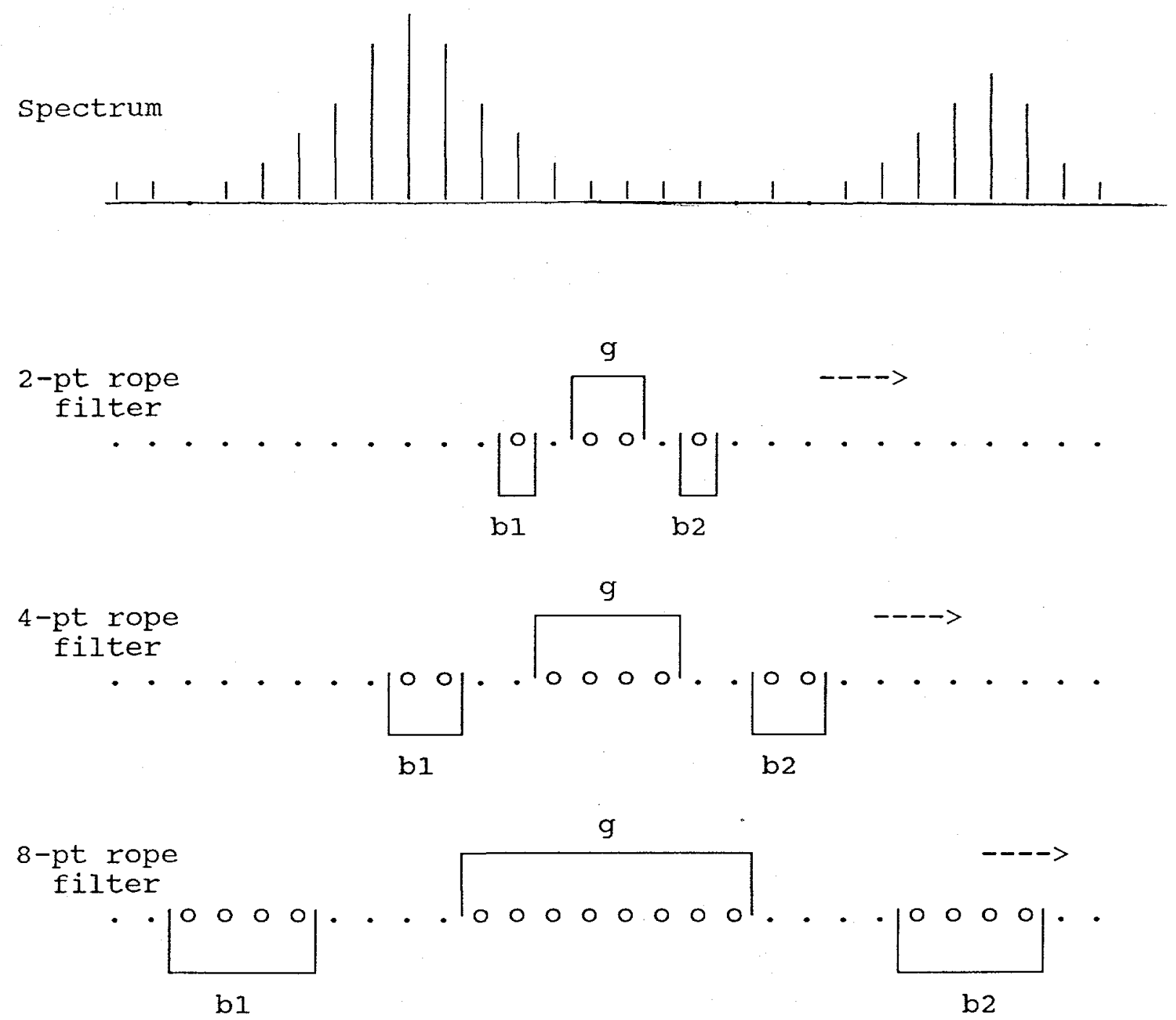

Fig. 1. Spectrum examined by three different size filters. Each filter sums spectral counts $g$ in the middle channels and counts bl and b2 in adjacent channels, as indicated. The counts $A_{f}$ trapped by filter is $g-b 1-b 2$ with counting $\sigma=(g+b 1+b 2)^{1 / 2}$. If $A_{f} \geq 3 \sigma$, a candidate peak is retained for further analysis. 


\begin{tabular}{|c|c|c|c|c|c|}
\hline peak & channel & $\mathrm{KeV}$ & Areā & $\%$-error & Fope \\
\hline 1 & 146 & 72.89731 & 176 & 12.44824 & $2-p t$ \\
\hline$\varepsilon$ & 151 & 75.37191 & 449 & 6.271772 & $2-p t$ \\
\hline 3 & 156 & 77.84651 & 88 & 21.50101 & $2-\rho t$ \\
\hline 4 & 171 & 85.2703 & 235 & 9.842581 & $2-\sigma t$ \\
\hline 5 & 176 & 87.74499 & 140 & 13.55262 & $e-p t$ \\
\hline 8 & 187 & 93.18901 & 91 & 17.13017 & $2-p t$ \\
\hline 7 & 264 & 131.2978 & 111 & 26.06392 & $B-p t$ \\
\hline 8 & 370 & 183.7593 & \$3 & 32.52577 & $\theta-p t$ \\
\hline 9 & 376 & 186.7288 & 60 & 27.98809 & $2-p t$ \\
\hline 10 & 481 & 238.6954 & 312 & 7.489309 & $e-p t$ \\
\hline 11. & 488 & 242.1598 & 94 & 19.08974 & $e-p t$ \\
\hline 12 & 596 & 295.6111 & 133 & 13.88435 & $e-p t$ \\
\hline 13 & 625 & 309.9638 & 53 & 32.29669 & $4-p t$ \\
\hline 14 & 683 & 338.6691 & 62 & 22.92366 & $e-p t$ \\
\hline 15 & 710 & 352.0319 & 287 & 7.593901 & $2-p t$ \\
\hline 16 & 735 & 364.4049 & 71 & 19.86864 & $2-p t$ \\
\hline 17 & 825 & 408.9476 & 79 & 26.15693 & $8-p t$ \\
\hline 18 & 935 & 463.3888 & 30 & 32.65986 & $2-p t$ \\
\hline 19 & 967 & 479.2262 & 62 & 30.85666 & $8-p t$ \\
\hline 20 & 1031 & 510.9011 & 139 & 16.79513 & $2-p t$ \\
\hline 21 & 1078 & 534.1623 & 34 & 32.21897 & $4-p t$ \\
\hline 22 & 1177 & 583.1593 & 76 & 16.00727 & $2-p t$ \\
\hline 23 & 1230 & 609.39 & 190 & 9.930507 & $2-p t$ \\
\hline 24 & 1249 & 618.7935 & 21 & 52.64597 & $2-q t$ \\
\hline 25 & 1336 & 661.9515 & 71 & 17.87124 & $2-p t$ \\
\hline 26 & 1363 & 675.2144 & 21 & 31.2259 & $2-p t$ \\
\hline 27 & 1469 & 727.6758 & 33 & 24.8041 & $2-p t$ \\
\hline 28 & 1551 & 768.2591 & 23 & 31.04969 & $2-p t$ \\
\hline 29 & 1721 & 852.3955 & 21 & 31.2259 & $2-p t$ \\
\hline 30 & 1811 & 896.9382 & 18 & 31.42697 & $2-p t$ \\
\hline 31 & 1840 & 911.2909 & 59 & 17.36771 & $2-p t$ \\
\hline $3 e$ & 1897 & 939.5013 & 15 & 29.05933 & $2-p t$ \\
\hline 33 & 1957 & 969.1966 & 33 & 27.60738 & $2-p t$ \\
\hline 34 & 2149 & 1064.221 & 22 & 32.77774 & $4-p t$ \\
\hline 35 & 2262 & 1120.147 & 38 & 23.82996 & $2-p t$ \\
\hline 36 & 2340 & 1158.751 & 19 & 32.86841 & $4-p t$ \\
\hline 37 & 2497 & 1236.453 & 31 & 32.41895 & $8-p t$ \\
\hline 36 & 2501 & 1238.433 & 38 & 21.70056 & $4-p t$ \\
\hline 39 & 2589 & 1281.986 & 38 & 24.40426 & $B-p t$ \\
\hline 40 & 2635 & 1304.752 & 24 & 32.27486 & $B-p t$ \\
\hline 41 & 2783 & 1378 & 32 & 21.65064 & $4-p t$ \\
\hline 42 & 2950 & 1460.652 & 180 & 11.41258 & $e-p t$ \\
\hline 43 & 2972 & 1471.54 & 12 & 31.18048 & $2-p t$ \\
\hline 44 & 3493 & 1729.393 & 34 & 21.20913 & $8-p t$ \\
\hline 45 & 3562 & 1763.542 & 55 & 16.16036 & $4-p t$ \\
\hline 46 & 3771 & 1866.98 & 13 & 27.73501 & $4-p t$ \\
\hline
\end{tabular}

Fig. 2. Example of candidate peaks table displayed on monitor. 


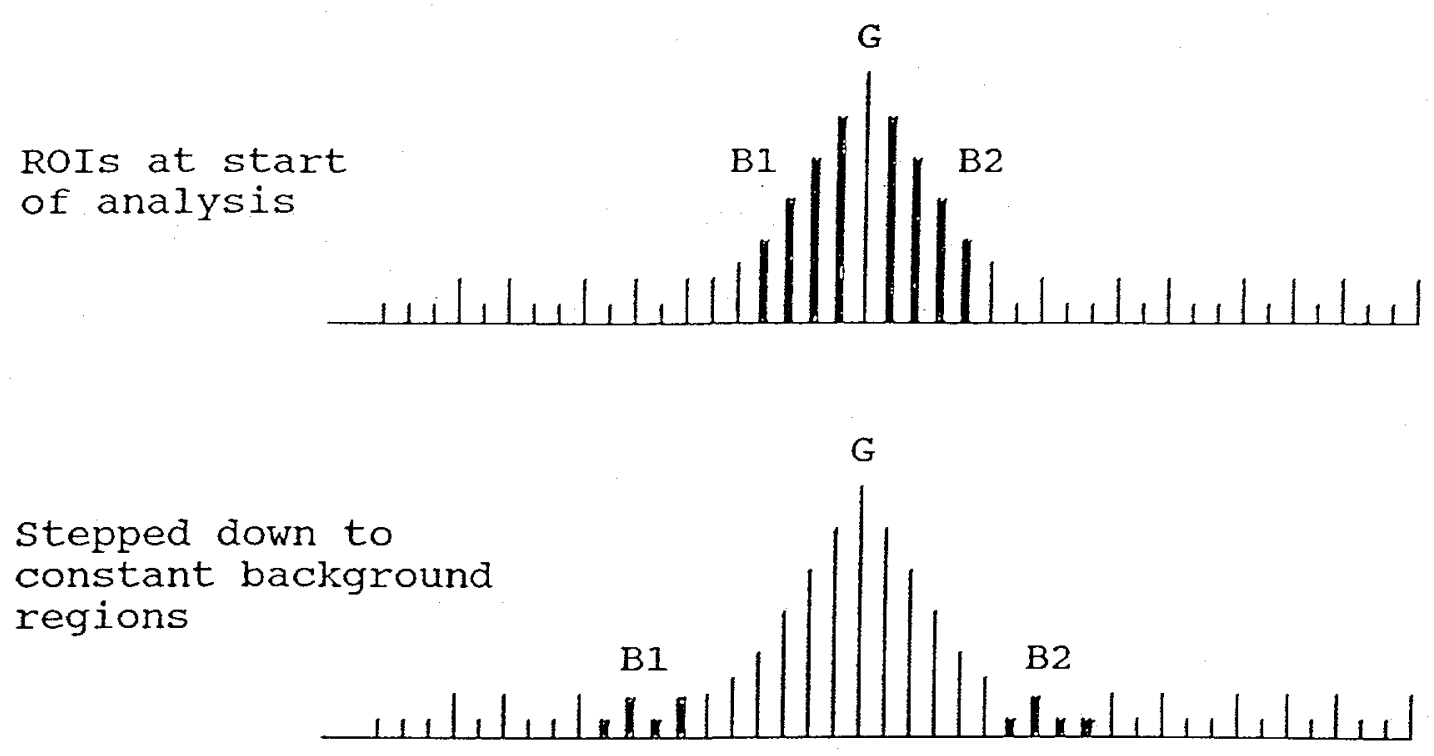

Adjusted for even

number of gross

channels

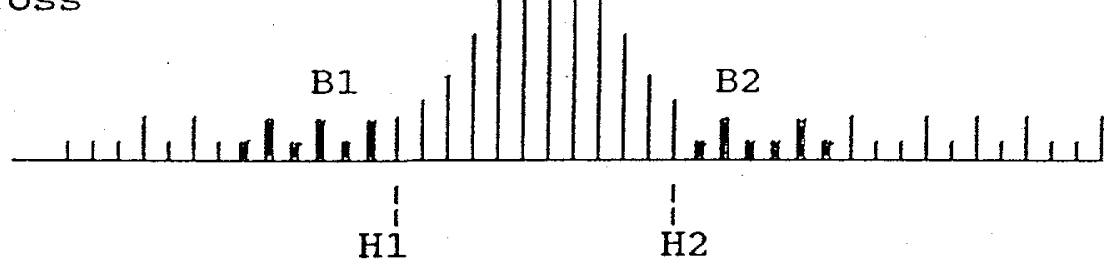

Fig. 3. Singlet analysis for ROIs of gross (G) and background (B1, B2) counts. The two background RoIs are found such their corresponding adjacent gross channels have counts that do not exceed their respective background channel averages by more than $2 \sigma$. 
(a) perfect resolution

b $[1-\mathrm{H}(\mathrm{E}-\mathrm{Eg})]$

step background

A $\delta(E-E g)$

full energy

peak

$\delta(\mathrm{E}-\mathrm{Eg})=\mathrm{dH}(\mathrm{E}-\mathrm{Eg}) / \mathrm{dE}$

b

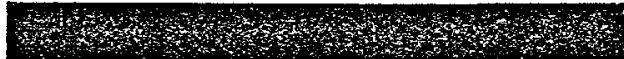

E

I

Eg

(b) actual resolution

A $f(E-E g)$

full energy

peak

b $[1-F(E-E g)]$

step background

$f(E-E g)=d F(E-E g) / d E$

b

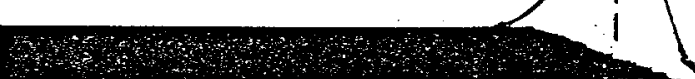

Eg

(c) flagged analyses (flag = negative tail)

Flag

-1
-2

-2
-3

$-4$

$-5$
Meaning

MDA forced/no peak

$$
\mathrm{F}<0
$$

$\mathrm{F} \ll 0.16,0.50,0.84$

$\operatorname{Sig} B-S i g A=0$

sigB-Cent $=0$
Response

None - MDA analysis FWHM big, cent est FWHM big, cent est overridden by $-2,3$ overridden by $-2,3$

Fig. 4. Detected gamma response function for (a) perfect solution and (b) actual solution, along with (c) flags indicating nature of analysis. It can be shown that convoluting $\delta\left(E^{\prime}-E g\right)$ and $H\left(E^{\prime}-E g\right)$ with $f\left(E-E^{\prime}\right)$ yields the $f(E-E g)$ and $F(E-E g)$ above. 
(a) Multiplet area

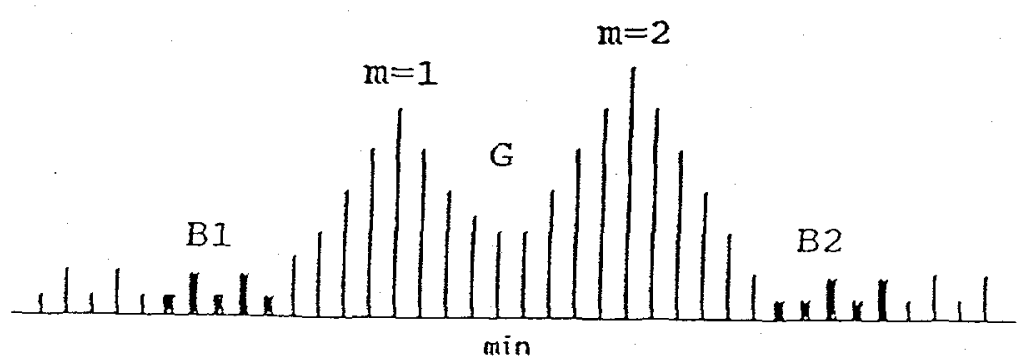

$$
A_{M}=G-\left(N_{M} / 2 N_{1}\right) B I-\left(N_{M} / 2 N_{2}\right) B 2
$$

(b) Peak areas

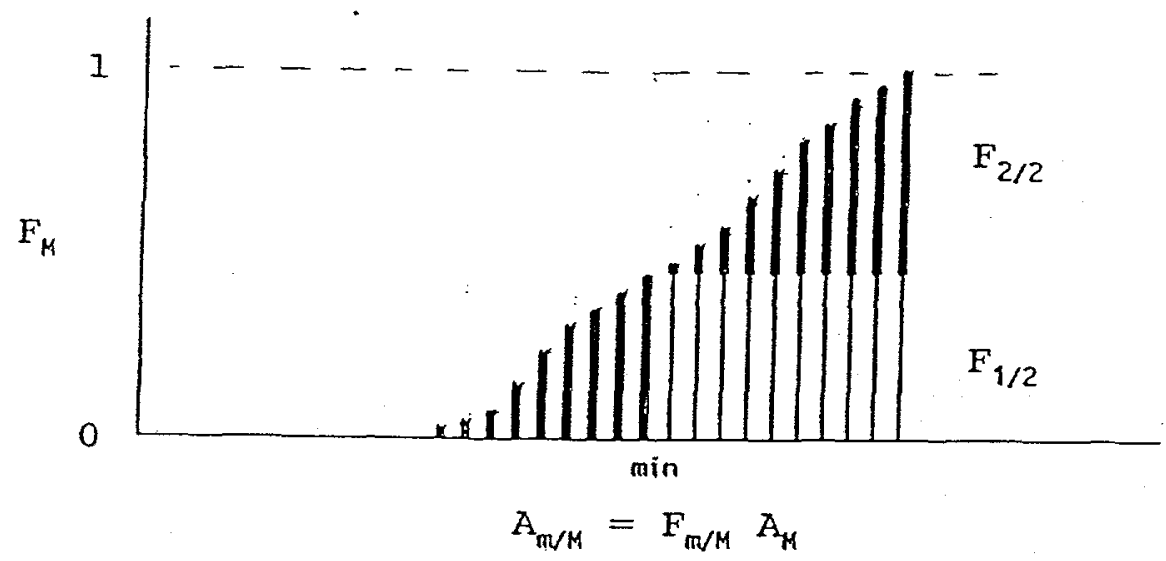

(c) Flagged analyses

$$
\begin{aligned}
& (F W H M=M+F l a g A / 10+F \operatorname{Fg} B / 100) \\
& (T a i I=m+F l a g A / 10+F l a g B / 100)
\end{aligned}
$$

Problem Flagl $\underline{\text { FlagB }}$ Response

$\begin{array}{llll}F_{m / M} \leq 0 & 1 & 0 & \text { Use linear background } B_{L} \\ B_{L}<0 & 1 & 1 & A_{m / M} \text { with warning } \\ A_{m / M}<0 & 2 & 1 & \text { Backgrounds adjacent minima } \\ A_{M} \leq 3 \sigma & 0,1,2 & 2 & \text { Use lower } B 1, B 2 \text { or } \text { fix } A<0\end{array}$

Fig. 5. Multiplet analysis: (a) calculation of total multiplet area $A_{M}$, similar to that for singlet; (b) individual peak areas $A_{m / M}$ calculated from $A_{M}$ and $F_{m / M} ;$ (c) flagged multiplet analyses for reconsideration. 


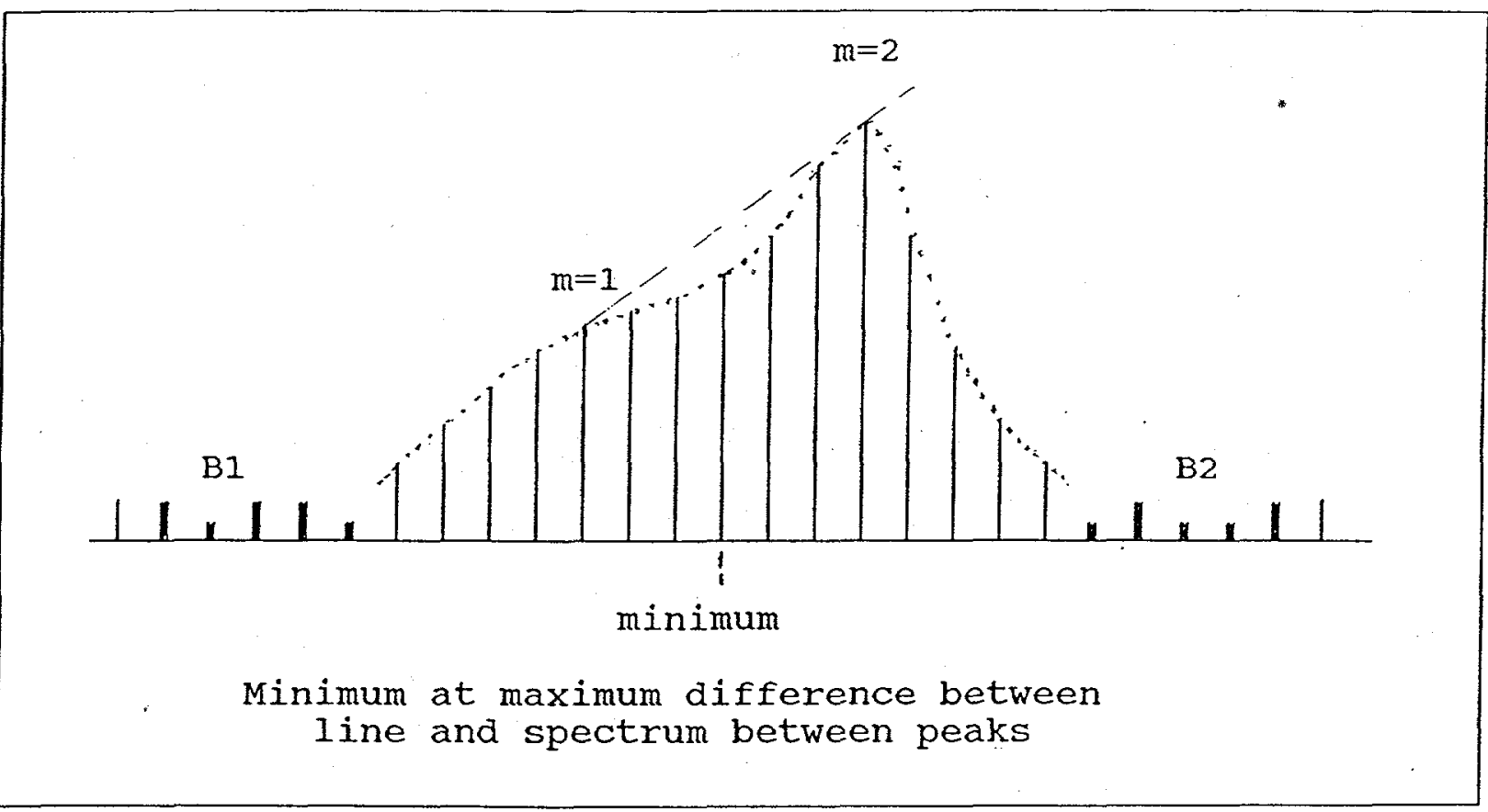

Fig. 6. Multiplet minimum for "shoulder doublet". 


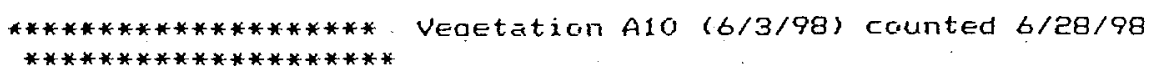

Sample Counting Informaticin

Sample dist file 6431vegs.chn

MCE nutiber 2

Segrient a

Start time 1413

Date 10JuLoz

Live time 63599.8 sec

Fieal tine 63931.9 ser

Sample Analysis Informatian

Start channel 50

End ehaninel 3950

Feat Eearch chanrels 8

Isotape ID $(+1-$ tieV $) 2$

Decay carrected to 25 days earlier

Activity unite (pCi madified per factars telaw) pCi/g

Numeratar factar $=3.83$

Denominator factor $=49.9$

Detectar Status Infarmatian

Det 4 with p4tack. EKG and pdet4cal.def

Configuratian $=1 \ldots$ (1) SFECIAL (2) DIAFEF (3) WELL (4) VIAL

Energy(kev) calitraticn: $\quad E N=.6390686+.4949195 *$ CHAN

FWHM(channel) calibration: FWHM = SQFi 8.019283 + 5.772945E-03 *CHAN)

Efficiency calitraticn: EFF = G*EXF(HYFEFEOLA * FOLYNOMIAL)*(1+FEFTUFEATION)

$G=$ glabal calibration factar $=.20397 \quad D=L N(G)=-1.589783$

HYFEFEOLA $=$ A*SOK $($ ENe + (LN(EN)-C) Ne) with ValuEs belaw:

$(A=-.5424688 \quad E=-.1952242 \quad C=5.166513$,

FOLYNOMIAL $=$ CO + C1*LN(EN) + C2*LN(EN) $=2+C 3 * L N(E N) \cdots 3$ with ValuEs bElaw:

$(\mathrm{CO}=2.791449 \mathrm{C} 1=-.670216 \mathrm{CP}=9.095154 \mathrm{E}-0 \mathrm{C} \mathrm{CB}=-3.105142 \mathrm{E}-03)$

$5000 \mathrm{keV}=$ crassciver between low EN (atave) and hiah EN (belaw) cases

$\left(\mathrm{CO}=0 \quad \mathrm{Cl}_{1}=0 \quad \mathrm{C2}=0 \mathrm{C3}=0\right)$

FEFTTUREATION $=F \cdot 0+F \cdot 1 * L N(E N)+F \cdot 2 * L N(E N) \cdots 2+F \cdot 3 * L N(E N)-3$ with, Values belaw: $\angle \mathrm{FO}=0 \mathrm{~F} 1=0 \mathrm{FC}=0 \mathrm{FB}=0$,

Fig. 8. Printout of input parameters ( 8.5 in. $x 11.0$ in. sheet) 


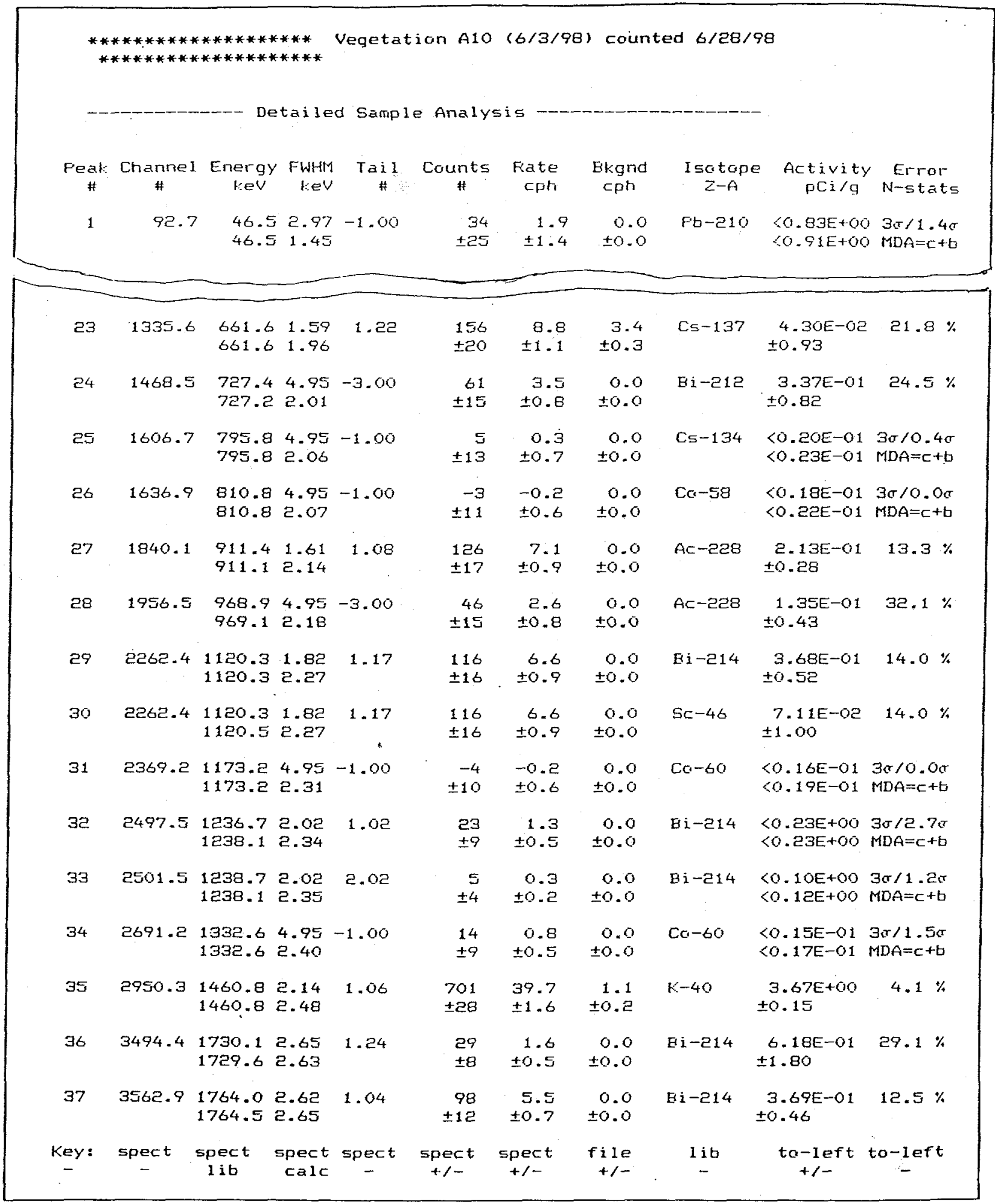

Fig. 9. Peak analysis printout table ( 8.5 in. $x 11.0$ in. sheets) 


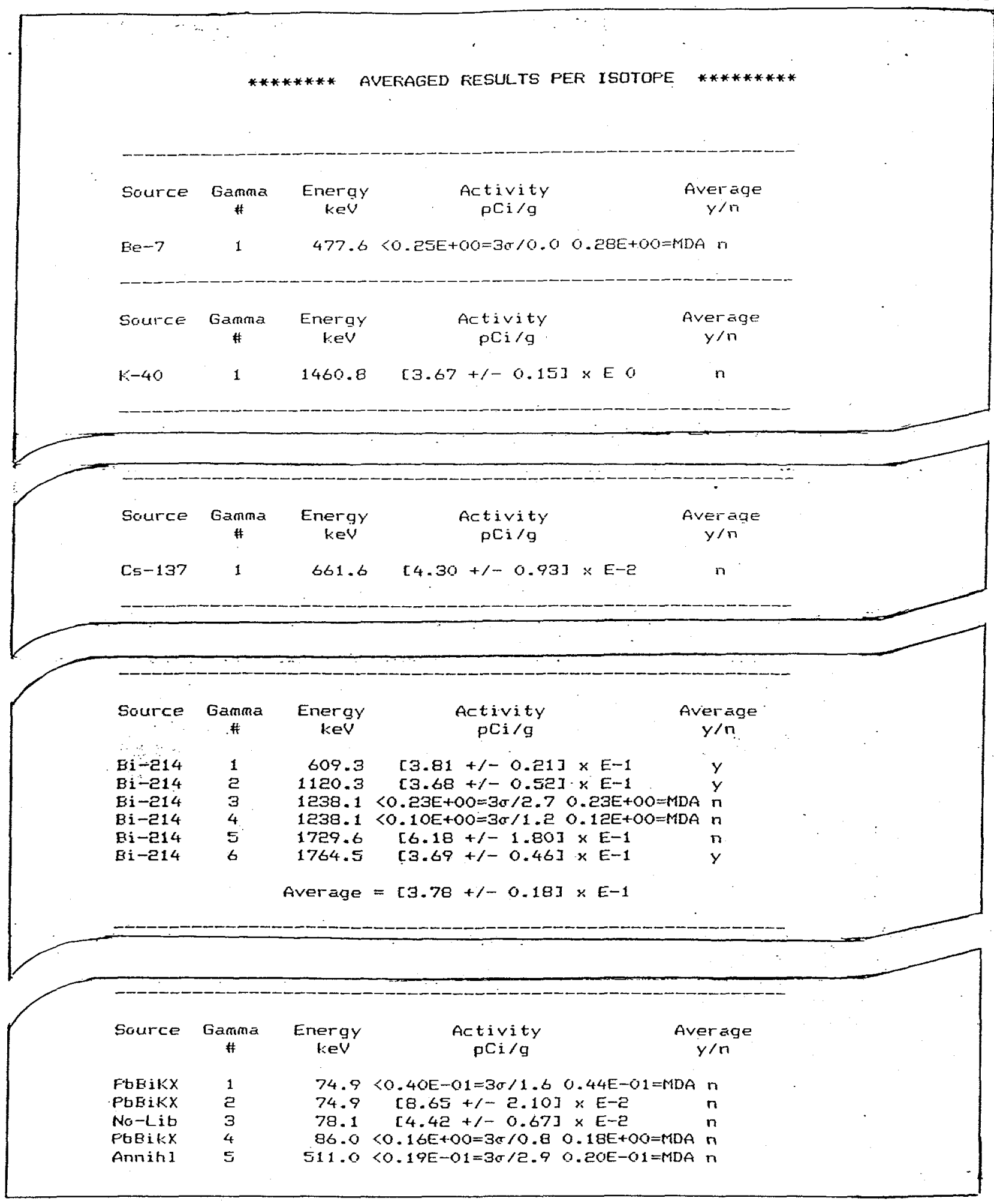

Fig. 10. GRABISOS isotope printout ( 8.5 in. $x 11.0$ in. sheets) 


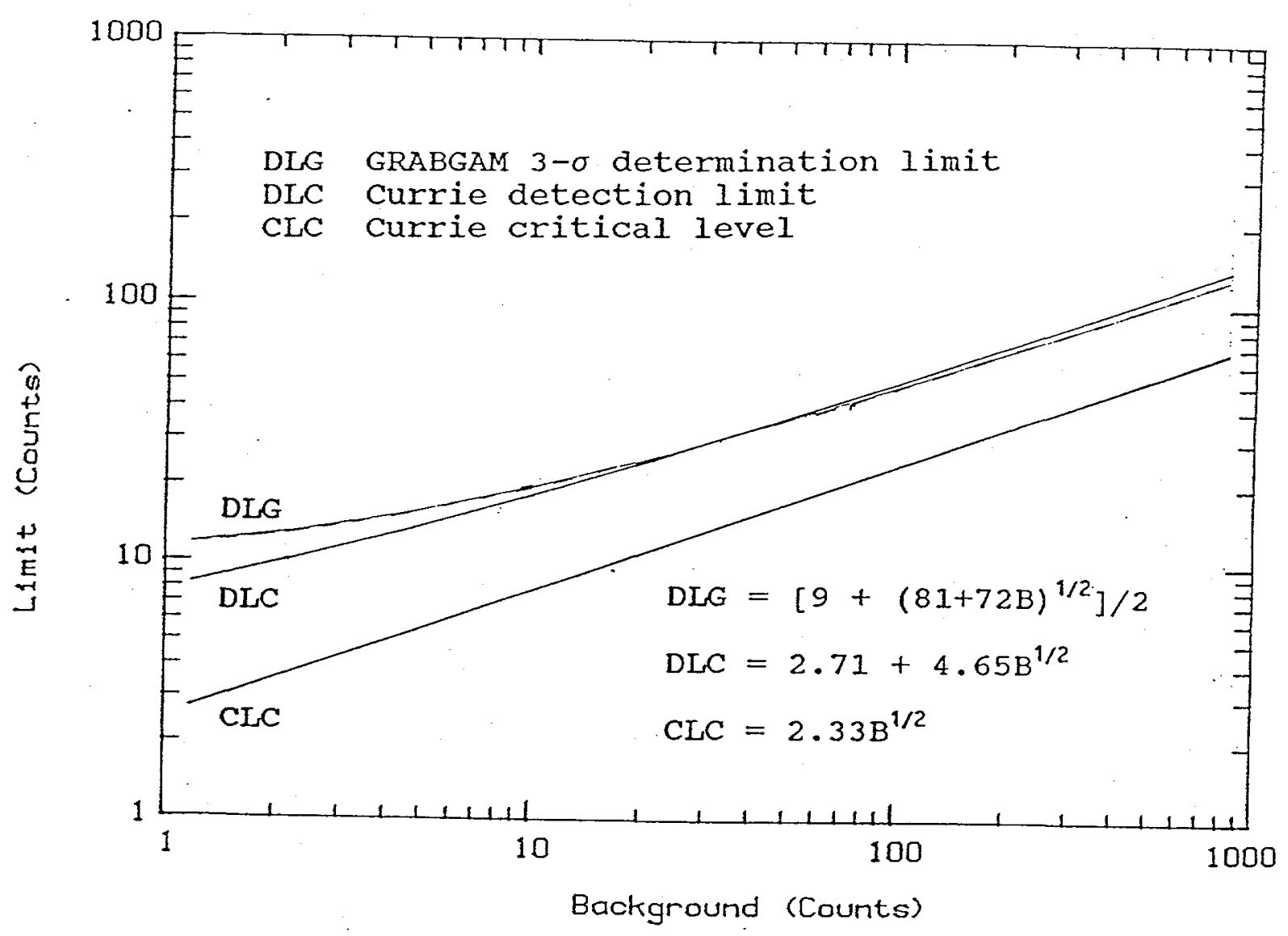

Fig. 11. Comparison of detection level scenarios. 
WSRC-TR-99-00187
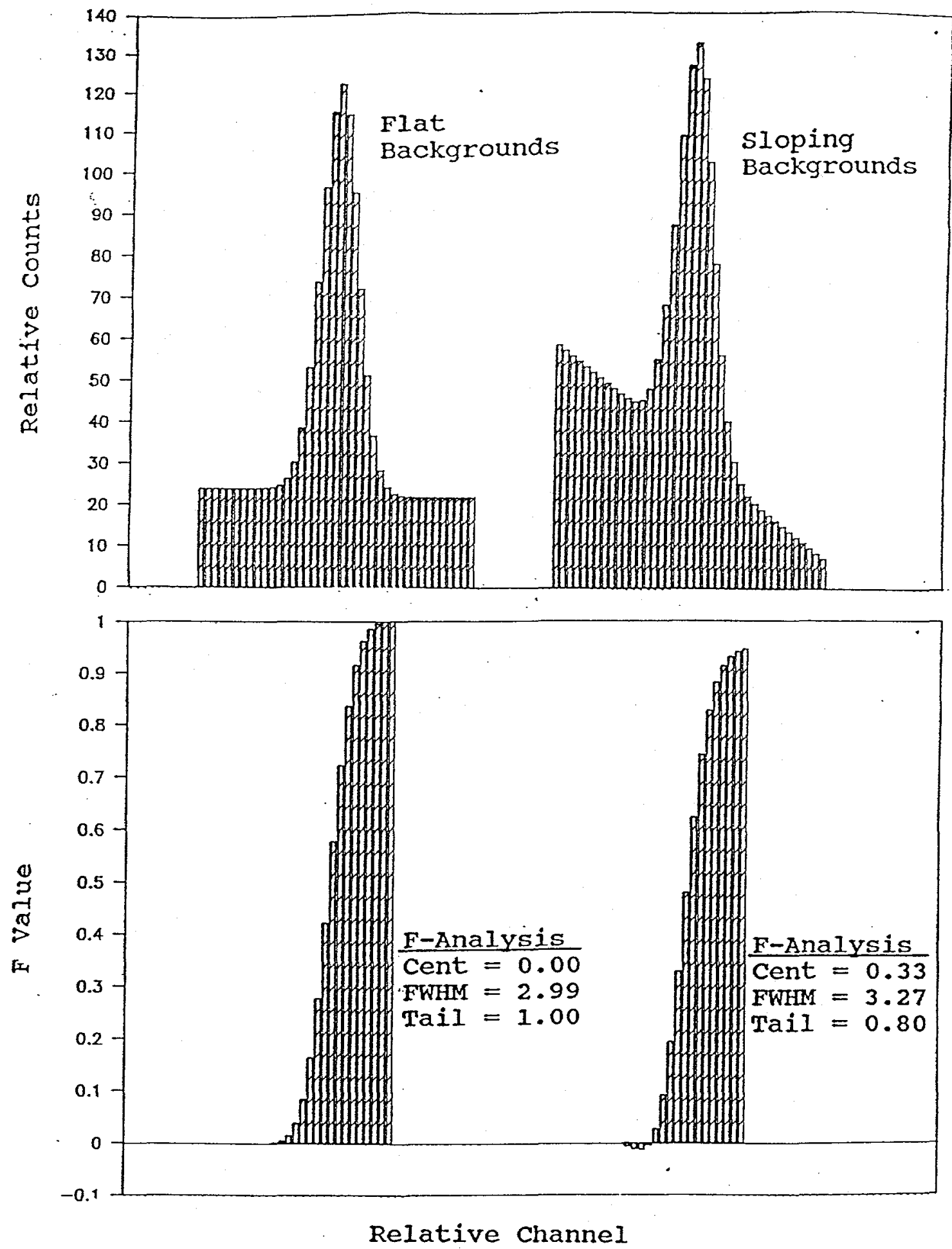

Fig. 12. Effect of sloping background on F-analysis for $v(E) \equiv 0$, per comparison of Gaussian peak (centroid $\equiv 0.00$, FWHM $\equiv$ 3.00 , tail $\equiv 1.00$ ) on flat and sloping backgrounds. 


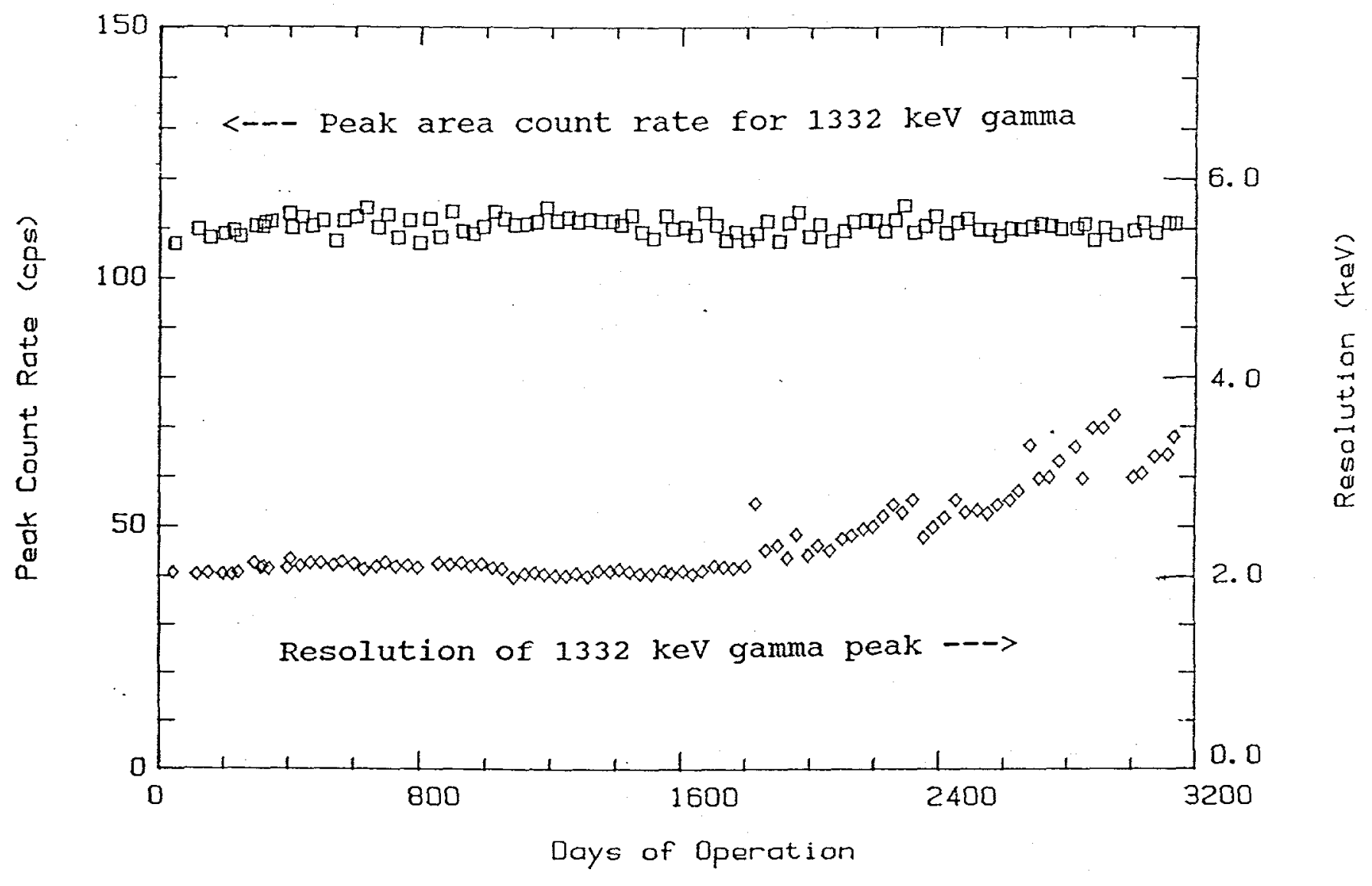

Fig. 13. Peak area count rate constancy per GRABGAM analysis, during resolution degradation. 


\section{APPENDIX A}

\section{RECENT MULTIPLET REFINEMENTS}

Two recent refinements for the multiplet analysis have been developed. The first addresses variable backgrounds in the GRABGAM code. The second is a new auxiliary program PEAKPART, which provides the user the option of refining the area partitioning for the multiplet peaks. Details of both are discussed below, and code listings are given in Appendix B.

\section{VARIABLE BACKGROUNDS}

A GRABGAM algorithm was developed to address variable backgrounds so that a more precise integral probability $F$ is utilized. As pointed out in the main text, the math for deducing the $F$ distribution over the gross region of a singlet or multiplet is equivalent; thus, the somewhat simpler notation for the singlet will be used in this discussion.

\section{General Nature of Algorithm}

The algorithm defines $z(E)=c+v(E)$ of Equation 6 as a third order polynomial in gamma energy, viz

$$
z(E)=c+v(E)=c_{0}+c_{1}\left(E-E_{L}\right)+c_{2}\left(E-E_{L}\right)^{2}+c_{3}\left(E-E_{L}\right)^{3} \quad(A-1)
$$

where $E_{1}$ is conveniently chosen to correspond to the background adjacent to the peak on its lower energy side, as shown in Figure A-I. With this substitution Equation 6 becomes

$$
\begin{aligned}
g(E)=A f(E-E g) & +b(1-F(E-E g)) \\
& +c_{0}+c_{1}\left(E-E_{L}\right)+c_{2}\left(E-E_{L}\right)^{2}+c_{3}\left(E-E_{L}\right)^{3}
\end{aligned}
$$

Integrating this equation over one channel yields

$$
\begin{aligned}
g_{j}=A\left(F_{j+1 / 2}-F_{j-1 / 2}\right) & +b_{c}-b_{c}\left(F_{j+1 / 2}+F_{j-1 / 2}\right) / 2 \\
& +c_{c 0}+c_{c 1}\left(j-j_{L}\right)+c_{c 2}\left(j-j_{L}\right)^{2}+c_{c 3}\left(j-j_{L}\right)^{3}
\end{aligned}
$$

where $c_{c 0}, c_{c 1}, c_{c 2}, c_{c 3}, j$ and $j_{L}$ are the equivalent coefficients and A-1 
energies for $z(E)$ in channel units. Thus, the resulting $F$-function expression of Equation 11 becomes

$$
\begin{aligned}
& F_{k+1 / 2}= \\
& \frac{\sum_{j=i}^{k}\left\{g_{j}-c_{c 1}\left(j-j_{L}\right)-c_{C 2}\left(j-j_{L}\right)^{2}-c_{c 3}\left(j-j_{L}\right)^{3}\right\}+b_{c} \sum_{j=i}^{k-1} F_{j+1 / 2}-(k-i+1)\left(b_{c}+c_{C 0}\right)}{A-b_{c} / 2}
\end{aligned}
$$

\section{Selection of Algorithm Parameters}

The background regions adjacent to the multiplet are fitted with straight lines given by

$$
z_{L}=a_{L 0}+a_{L 1}\left(j-j_{L}\right) \text { and } z_{R}=a_{R 0}+a_{R 1}\left(j-j_{L}\right)
$$

where the subscripts $\mathrm{L}$ and $\mathrm{R}$ refer to the background regions to the left and right of the gross peak region. The code normally uses 8 points in each background region for the fits, but if a nearby peak exists it will use fewer points but at least 3 . Also, if the magnitude of the slope $\left(\left|a_{L 1}\right|\right.$ or $\left.\left|a_{R 1}\right|\right)$ is less than its uncertainty $(1.5 \sigma)$, then the slope is set to zero and the constant term ( $\mathrm{a}_{\mathrm{L} 0}$ or $\left.\mathrm{a}_{\mathrm{RO}}\right)$ is the average of the points; this helps eliminate nonrepresentative erratic slopes that are based on poor counting statistics.

It is desired to fit the background under the multiplet as the third order polynomial of Equation $A-1$ in a consistent manner with the above Iinear adjacent background regions. In channel units, Equation $A-1$ becomes

$$
z=c_{c 0}+c_{c 1}\left(j-j_{L}\right)+c_{c 2}\left(j-j_{L}\right)^{2}+c_{c 3}\left(j-j_{L}\right)^{3}
$$

The notations $j_{L}$ and $j_{R}$, which denote the background channels adjacent to the gross peak region on its left and right sides, are useful in the development. Initially Equation A-6 is selected for a quadratic dependence with $c_{c 3}=0$, subject the following conditions:

$$
\begin{array}{rlrl}
z & =z_{R} & j & =j_{R} \\
d z / d j & =d z_{R} / d j & j & =j_{R} \\
d z / d j & =d z_{L} / d j & j & =j_{L}
\end{array}
$$


These conditions result in defining the coefficients in Equation A-6 as

$$
\begin{aligned}
& c_{C 0}=a_{R 0}+\left(a_{R 1}-a_{L 1}\right)\left(j_{R}-j_{L}\right) / 2 \\
& c_{C 1}=a_{L 1} \\
& c_{C 2}=\left(a_{R 1}-a_{L 1}\right) / 2\left(j_{R}-j_{L}\right) \\
& c_{C 3}=0
\end{aligned}
$$

which may be verified by substituting them into Equation $A-6$ and performing the calculations prompted by Equations A-7.

Selection of the step background $b_{c}$ must also be made. The algorithm calculates

$$
b_{c}=z_{L}-z \quad \text { for } j=j_{L}
$$

which is tested for the condition

$$
0 \leq b_{c} \leq b_{c \max }
$$

where the range defines realistic values for $b_{c}$. (An estimate for $\mathrm{b}_{\text {cmax }}$ will be discussed later in this appendix). If $b_{c}$ lies between the these limits, then the quadratic $z$ is used to model the variable background. For other cases the cubic representation of $z$ is deduced subject to the following conditions:

$$
\begin{array}{rlrl}
z & =z_{R} & j & =j_{R} \\
d z / d j & =d z_{R} / d j & j & =j_{R} \\
z & =z_{L}-b_{k} & j & =j_{L} \\
d z / d j & =d z_{L} / d j & j & =j_{L}
\end{array}
$$

where $b_{k}$ replaces $b_{c}$ as

$$
\begin{aligned}
\mathrm{b}_{c}-->b_{k} & =0 & \text { for } & b_{c}<0 \\
b_{k} & =b_{c \max } & \text { for } & b_{c}>b_{c \max }
\end{aligned}
$$


The conditions of Equation A-10 result in defining the coefficients in Equation $A-6$ as

$$
\begin{aligned}
& c_{c 0}=a_{L 0}-b_{k} \\
& c_{C 1}=a_{L 1} \\
& c_{C 2}=3\left(a_{R 0}-a_{L 0}+b_{k}\right) /\left(j_{R}-j_{L}\right)^{2}+2\left(a_{R 1}-a_{L 1}\right) /\left(j_{R}-j_{L}\right) \\
& c_{C 3}=-2\left(a_{R 0}-a_{L 0}+b_{k}\right) /\left(j_{R}-j_{L}\right)^{3}-\left(a_{R 1}-a_{L 1}\right) /\left(j_{R}-j_{L}\right)^{2}
\end{aligned}
$$

which may be verified by substituting them into Equation $A-6$ and performing the calculations prompted by Equation $A-10$. In these limiting cases for $b_{c}$, the true nature of the step background may be obscured by a larger magnitude of the variable background component, whereby unrealistic values of $b_{c}$ could result. By requiring $0 \leq \mathrm{b}_{\mathrm{c}} \leq \mathrm{b}_{\mathrm{cmax}}$, such values are eliminated.

\section{optimization of F-Function and Net Area A}

The final F-function is made self-consistent as an integral probability function by requiring that $\mathrm{F}=1$ when calculated for the total gross region. The net peak-region area calculated using the B1, G, and B2 ROIs described in the main text is not strictly accurate for a multiplet, although singlets are estimated well with this approach. Thus, for a multiplet this area estimate is refined by iteratively finding the area $A$ that causes Equation A-4 to yield $F=1$ for the total gross peak region. Typically, the resulting $A$ is within a few percent of the B1/G/B2 initial estimate. However, it has been noted that it is possible (although rare) that the iteration can cause unrealistic negative $A$; these cases default to the originally calculated $A$ and use the $F l a g B=2$ analysis, but rerunning GRABGAM with a better choice of FWHM may eliminate the negative A possibility altogether.

Figure A-2 illustrates how the step background components of a multiplet can cause the $B 1 / G / B 2$ estimate to be in error. In addition the shape of the background function $z(E)$ of Equation A-1 also impacts the peak areas of the multiplet. Thus, the Ffunction approach for determining the multiplet background is preferred.

\section{Selection of $b_{c m a x}$}

The step background $\mathrm{b}_{\mathrm{c}}$ beneath a peak is due to incomplete energy conversion within the active volume of the HPGe detector and forward compton scattering. Thus, $b_{c}$ depends both on the detector size and the sample geometry. When the code determines $b_{c}$ 
such that $0 \leq b_{c} \leq b_{c \max }$, the $b_{c}$ is assumed to be adequate as it is physically reasonable. For cases where $b_{c}$ is only a small component of the background, the code may initially estimate an artificial $b_{c}$ that lies outside the physically reasonable range; subsequently $b_{c}$ is fixed at either 0 or $b_{\text {cmax }}$ as discussed earlier while the larger component of the background is fitted to the cubic polynomial of Equation $A-6$. It is clear that $b_{c}$ cannot be less than zero, which is an easily defined limit. It is also clear that $b_{c}$ must not exceed some $b_{c m a x}$; however, experimental measurements are needed to define $\mathrm{b}_{\mathrm{cmax}}$.

Ideally, $b_{c \max }$ should be defined for each detector and sample geometry; however, such an effort is not practical. For GRABGAM, $a$ study of $b_{c m a x}$ for various detectors and geometries yielded the empirical relation

$$
\mathrm{b}_{\mathrm{cmax}}=0.04(100 / \mathrm{E})(\mathrm{A} / \mathrm{W})
$$

where $\mathrm{E}$ is the gamma energy in $\mathrm{keV}, \mathrm{A}$ is the area of the peak, and $W$ is the effective channel width of the peak that reproduces the peak height as $A / W$. A reasonable approximation is $W=F W H M$, and GRABGAM uses the calculated value FWHM ${ }^{*}$, which is discussed in the main text. Measurements of $b$ for singlet peaks are given in Figure $A-3$, relative to the $b_{c \max }$ defined in Equation A-13. For multiplets, the same equation is used, as $b_{c m a x}$ includes contributions from all peaks in the multiplet, where $A$ is their summed areas yielding $A / W$ as their summed composite height.

\section{Multiplet Printout Table}

With these recent improvements GRABGAM now prints a detailed multiplet table, as illustrated in Figure A-4. This table immediately precedes the peak analysis table, as described in Figure 9. The table gives the maximum, bounding minima, area, energy, and isotope identification for each peak of the all multiplets detected in the spectrum. The bounding minima, minl and min2, have different formats, $x \times x x, x$ and $x x x x \cdot x y$, whereby the $x \times x x . x$ denotes the channel number and $y$ is a flag indicating how the minimum is determined, as denoted in Figure A-4.

The multiplet information provides the user with guidelines for any further evaluation of the multiplet, including application of the area partitioning program PEAKPART, which is discussed next. 


\section{REFINEMENT FOR PEAK AREA PARTITIONING}

The auxiliary program PEAKPART was developed to provide the option of refining the peak partitioning of GRABGAM for multiplets. As discussed in section III.C, GRABGAM calculates a peak area within a multiplet as the area $A_{m}$ bounded by its adjacent minima. This is not the actual area $X_{m}$ of peak, because $A_{m}$ does not contain all of $x_{m}$ and includes contributions from other peaks in the multiplet. Thus, the $A_{m}$ estimate for peak area $x_{m}$ is in error due to "cross talk" with other peaks of the multiplet.

The peak area $\mathrm{X}_{\mathrm{m}}$ is distributed within the $\mathrm{M}$ peak regions of the multiplet, whereby a fraction $F_{\mathrm{km}}$ is included in the region $\mathrm{k}$ for an area $F_{\mathrm{km}} X_{\mathrm{m}}$. We note that the peak fractions sum to 1 , viz

$$
\sum_{k=1}^{M} F_{k m}=1
$$

From Figure $A-5$, it is recognized that the GRABGAM peak areas $A_{k}$ may be expressed as a set of linear equations,

$$
A_{k}=\sum_{m=1}^{M} F_{k m} X_{m}
$$

which for $\mathrm{M}=3$ are given by

$$
\begin{aligned}
& A_{1}=F_{11} X_{1}+F_{12} X_{2}+F_{13} X_{3} \\
& A_{2}=F_{21} X_{1}+F_{22} X_{2}+F_{23} X_{3} \\
& A_{3}=F_{31} X_{1}+F_{32} X_{2}+F_{33} X_{3}
\end{aligned}
$$

Thus, if the $F_{k m}$ are known then the actual areas $X_{m}$ may be determined from the $A_{k}$ values.

The $F_{k m}$ can be defined by assuming that each multiplet peak $m$ is Gaussian with known centroid $\mu_{\mathrm{m}}$ and width parameter $\sigma$. For the $\mathrm{X}_{\mathrm{m}}$ peak, its area fraction within the minima-bounded peak region $\mathrm{k}$ is given by

$$
F_{k m}=\int_{I_{k}}^{h_{k}} 1 /(2 \pi)^{1 / 2} \exp \left[-\left(x-\mu_{m}\right)^{2} / 2 \sigma^{2}\right] d x
$$

where the lower and upper integral limits $l_{k}$ and $h_{k}$ correspond to the minima that bound region $k$. For mathematical purposes, the

$$
A-6
$$


values of $l_{1}$ and $h_{M}$ are effectively treated as $-\infty$ and $+\infty$ to assure that all peak fractions add to 1 as provided in Equation $(A-14)$. The $\mu_{m}$ are determined using the four contiguous channels that contain the highest net counts per the F-function background subtraction within region $m$; however, if this estimate is not within \pm 0.5 channel of the location determined by the peak find algorithm, the peak find average location is used. The $\sigma$ is estimated from the measured FWHM of nearby singlet peaks within the spectrum or from prior calibrations.

It should be noted that the $x_{m}$ solved from the linear equations, such as Equation $A-16$, satisfy the following condition

$$
\sum_{m=1}^{M} X_{m}=\sum_{m=1}^{M} A_{m}
$$

so that the total multiplet area is not changed by the analysis. The preceding equation is proved by summing the $A_{k}$ as given in Equation $A-15$, viz

$$
\sum_{k=1}^{M} A_{k}=\sum_{k=1}^{M} \sum_{m=1}^{M} F_{k m} X_{m}=\sum_{m=1}^{M}\left(\sum_{k=1}^{M} F_{k m}\right) X_{m}=\sum_{m=1}^{M} X_{m}
$$

where Equation $A-14$ is substituted for the $F_{k m}$ summation. Thus, transformation from $A_{m}$ to $X_{m}$ does not alter the total area of the multiplet; it simply redistributes this area among the peaks.

The accuracy of the resulting $x_{m}$ depends primarily on the accuracy of the $\mu_{m}$ and $\sigma$. By contrast, the minima channels $l_{k}$ and $h_{k}$ that bound the $A_{k}$ are inconsequential because the corresponding $F_{k m}$ will correctly address whatever values are used for $l_{k}$ and $h_{k}$, provided that the $\mu_{m}$ and $\sigma$ are accurate. At the same time, when $l_{k}$ and $h_{k}$ correspond to accurate minima, the peak "cross talk" between the $A_{m}$ regions tends to be minimized, so that the initial estimate for $A_{m} \approx X_{m}$ is better. This was the original GRABGAM basis for partitioning the peak areas of a multiplet. Now PEAKPART maY be used to refine these estimates as appropriate.

PEAKPART analysis examples are given in Figure A-6, as based on data from $F$ igure $A-4$. Here the $\left[F_{i j}\right]$ matricies are displayed to illustrate the peak overlap, which is greater when the off-diagonal elememts are larger. Each case illustrates that the total multiplet area is not altered by the repartitioning, as predicted by Equation $A-18$. Also it is noted that the individual $x_{m} \approx A_{m}$ within the statistical error for these low-level multiplets, and the corresponding $\mathrm{x}_{\mathrm{m}} / \mathrm{A}_{\mathrm{m}}$ must be significantly different than 1 to display a significant difference in the integer values of $x_{m}$ and $A_{m}$, which are presented in the figure. 


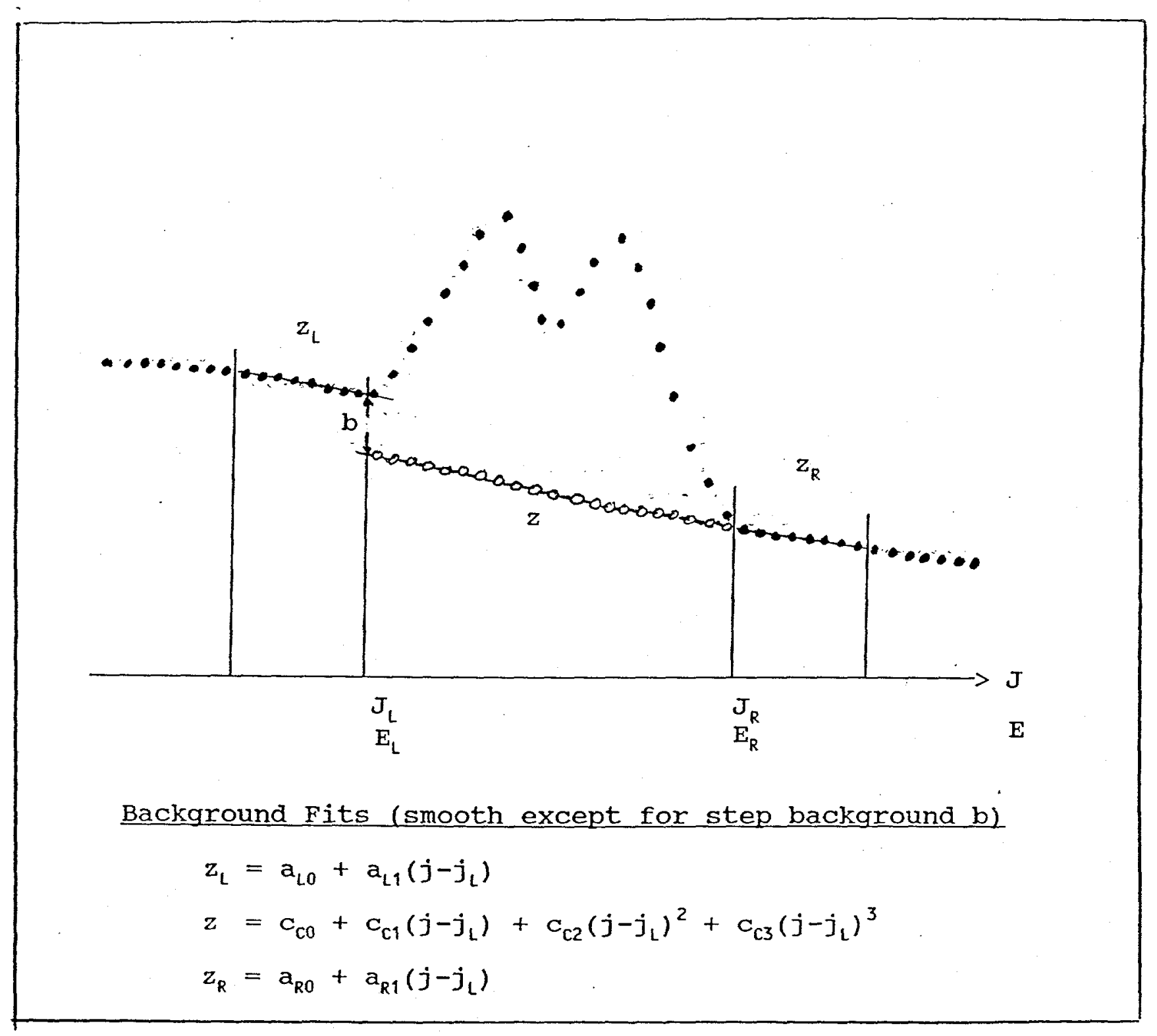

Fig. A-1. Features of Background Model 


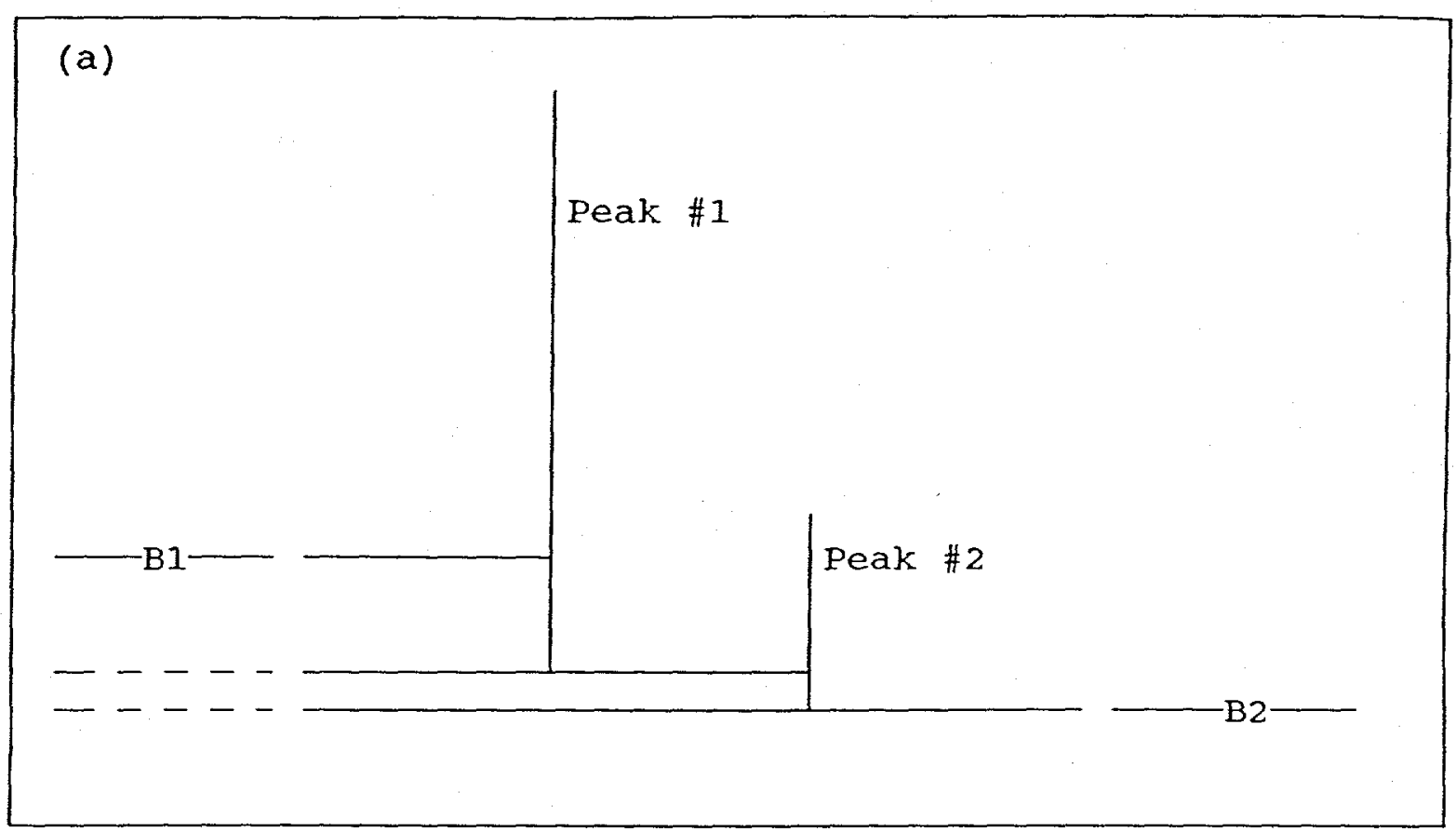

(b)

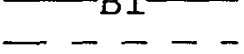

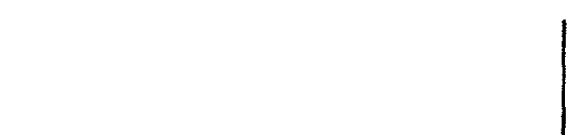

Peak \#1

$-\cdots$

$\mathrm{B} 2$

Fig. A-2. Actual Multiplet Background vs B1/B2 Estimate

Perfect resolution is used for clarity in the above examples. Note that the B1 and B2 backgrounds are the same in both cases, but the $\mathrm{B1} / \mathrm{B} 2$ estimate is greater than the actual background for case (a) and smaller for case (b). 


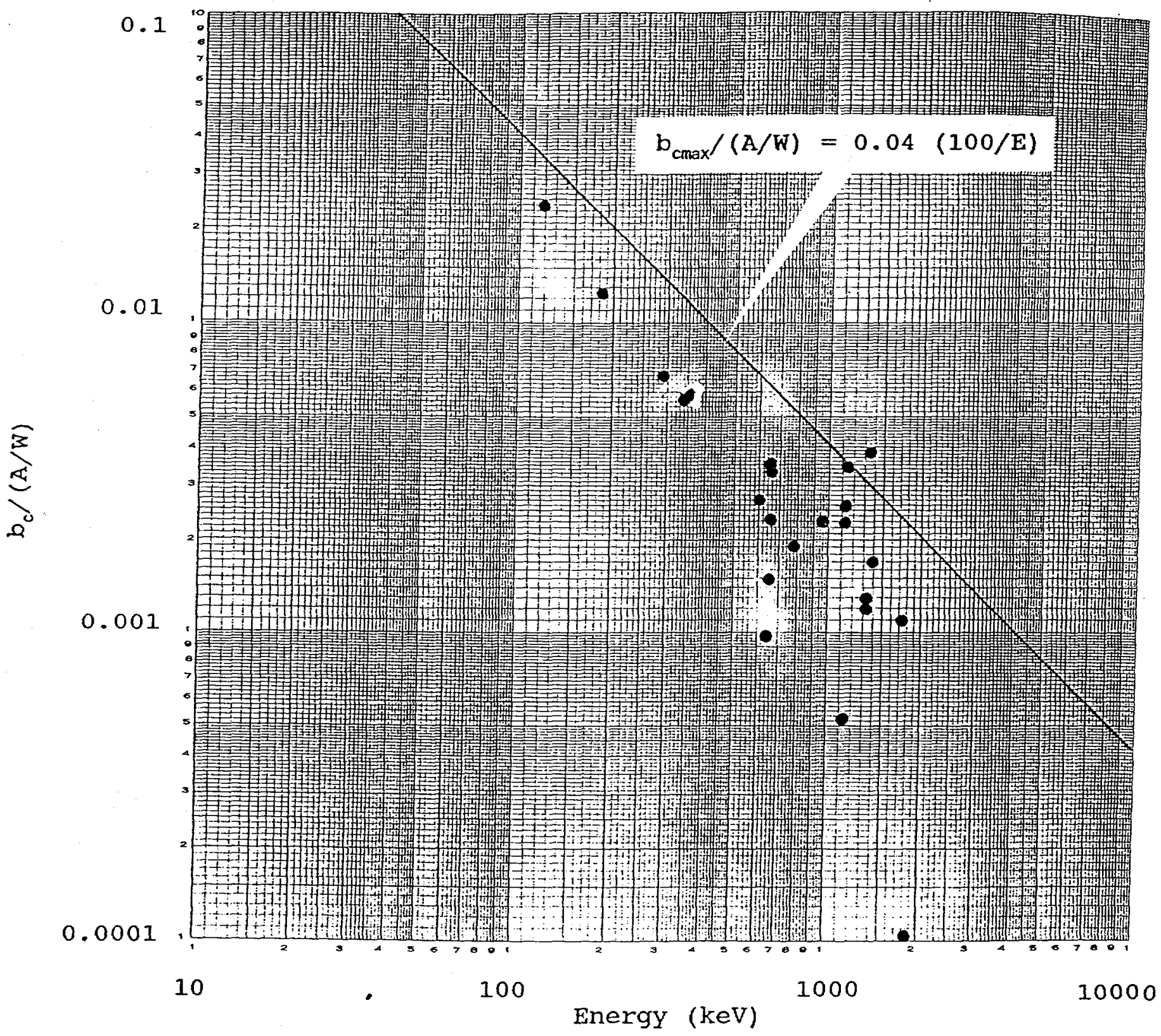

Fig. A-3 Empirical Relation for $b_{c \max }$

The plotted values of $b_{c} /(A / W)$ are for detectors with resolution of $\sim 2 \mathrm{keV}$ for the $1332 \mathrm{keV}$ gamma. (Note that in the present work $W=$ FWHM in channels). The range of values for the 662,1173 , and $1332 \mathrm{keV}$ gammas correspond to detectors with standard HPGe efficiencies of 20-160\%. The general trend over the entire energy range is dominated by large Marinelli water standards counted by a $160 \%$ HPGe. 
Multiplet Feat: Details

\begin{tabular}{|c|c|c|c|}
\hline $\begin{array}{l}\text { Feak: } \\
\text { \# }\end{array}$ & $\min 1$ & $\begin{array}{c}\text { Channe } 1 \\
\text { max }\end{array}$ & mine \\
\hline 1 & 147.5 & $15 \mathrm{C} .5$ & 154.51 \\
\hline 2 & 154.5 & 157.4 & 161.50 \\
\hline 1 & 468.5 & 473.4 & 476.51 \\
\hline e & 476.5 & 479.5 & 483.50 \\
\hline 1 & 1112.5 & 1118.8 & 1119.53 \\
\hline 2 & 1119.5 & 1122.5 & 1127.50 \\
\hline 1 & 1422.5 & 1428.7 & 1429.53 \\
\hline e & 1429.5 & 1430.3 & 1435.50 \\
\hline 1 & 1570.5 & 1576.9 & 1578.53 \\
\hline e & 1578.5 & 1579.5 & 1580.53 \\
\hline 3 & 1580.5 & 1581.5 & 1586.50 \\
\hline 1 & 2695.5 & 2702.7 & 2703.53 \\
\hline 2 & 2703.5 & 2706.6 & 2712.50 \\
\hline
\end{tabular}

$\begin{array}{cccc}\begin{array}{c}\text { Area }+1-\text { Errar } \\ \text { caunts }+1-\text { caunts }\end{array} & \begin{array}{c}\text { Energy } \\ \text { keV }\end{array} & \begin{array}{c}\text { Isatape } \\ Z-A\end{array} \\ 68+1- & 26 & 75.1 & \text { FbEikX } \\ 37+1- & 19 & 77.6 & \text { Na-Lib } \\ 109+1- & 32 & 239.0 & \text { Fb-212 } \\ 50+1- & 21 & 242.0 & \text { Fb-214 } \\ 5+1- & 4 & 568.4 & \text { Cs-134 } \\ 35+1- & 13 & 570.3 & \text { Cs-134 } \\ 10+1- & 5 & 726.7 & \text { Bi-212 } \\ 16+1- & 6 & 727.5 & \text { Ei-212 } \\ 10+1- & 6 & 802.4 & \text { Cs-134 } \\ 6+1- & 5 & 803.7 & \text { Cs-134 } \\ 7+1- & 5 & 804.7 & \text { Bi-214 } \\ 7+1- & 3 & 1377.2 & \text { Ei-214 } \\ 17+1- & 5 & 1379.2 & \text { Bi-214 }\end{array}$

Fig. A-4. GRABGAM Multiplet Printout

Note that MIN2 format $\mathrm{xxxx} . \mathrm{xy}$. provides channel number as $x \times x x . x$, while $y$ equals $o$ for end minimum, 1 for absolute minimum, 2 for relative minimum, and 3 for inverse weighted minimum. 
GRABGAM

Multiplet

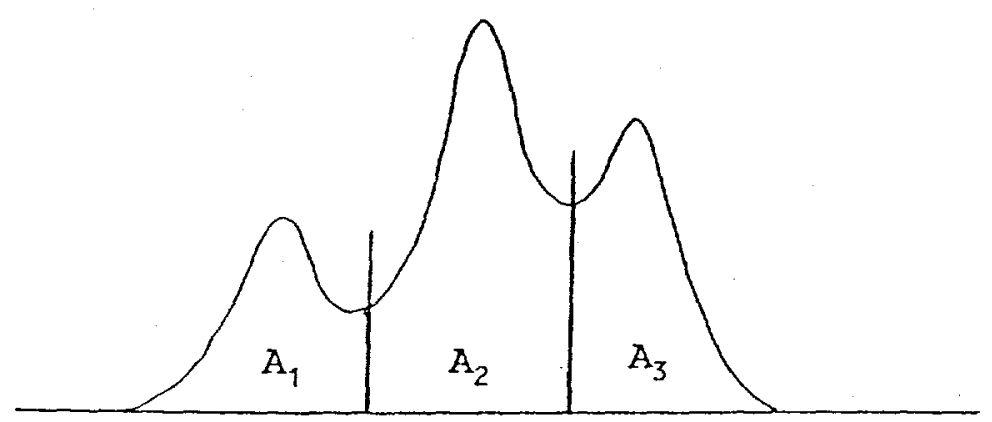

Peak 1

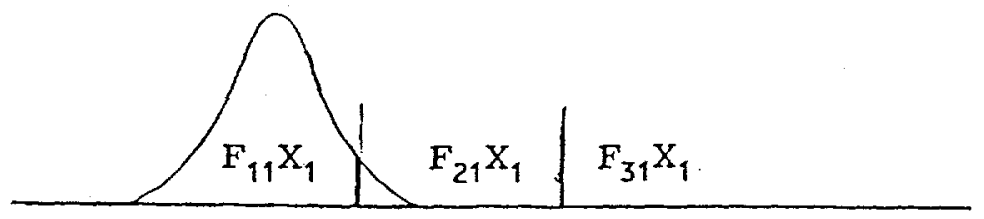

Peak 2

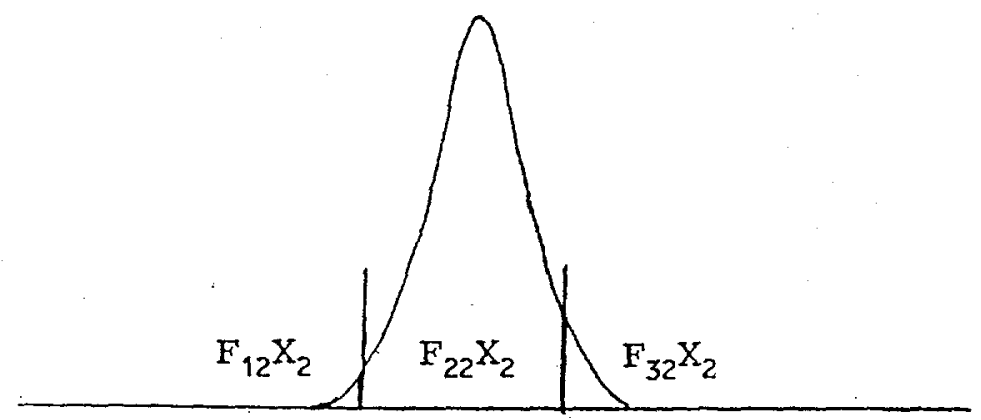

Peak 3

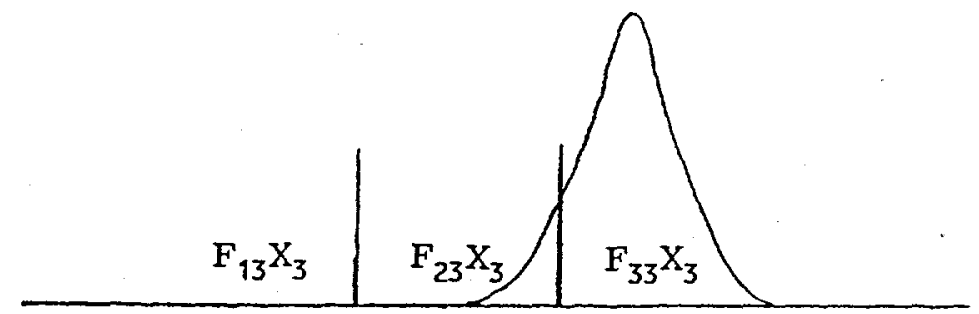

Fig. A-5. GRABGAM Multiplet Areas $A_{m}$ and Actual Areas $X_{m}$ Note that summing the $F_{m j} X_{j}$ area components for each $A_{m}$ yields the linear relations in Equation $\mathrm{A}-16$. 


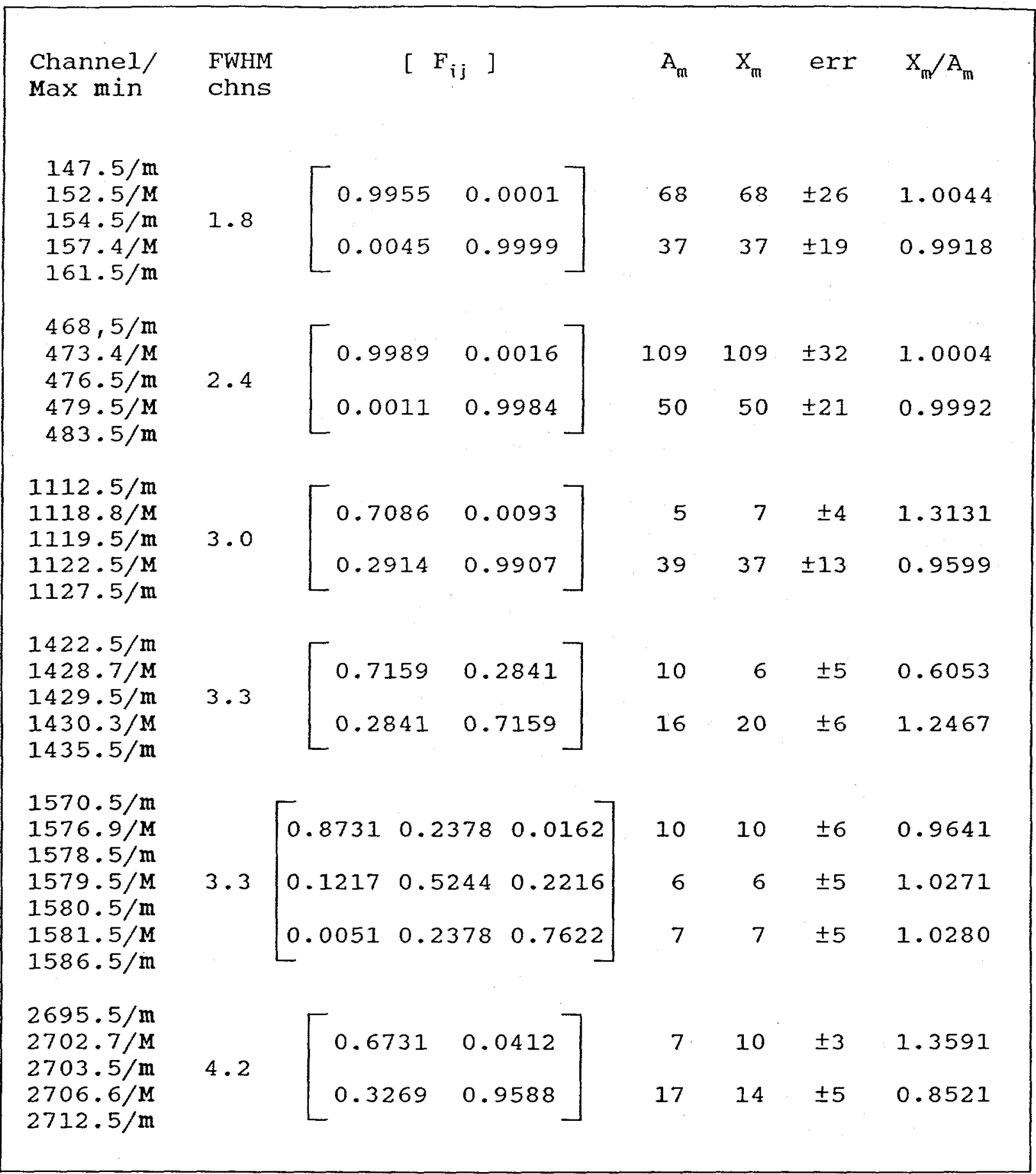

Fig. A-6. Examples of PEAKPART results

Results are for multiplets given in Fig. A-4. Note that the $\mathrm{X}_{\mathrm{m}} \approx \mathrm{A}_{\mathrm{m}}$ within the statistical error for these low-level cases. Also note that $\Sigma X_{m}=\Sigma A_{m}$ for each multiplet. 


\author{
APPENDIX B \\ GRABGAM CODE LISTINGS
}

\title{
INTRODUCTION
}

Listings of source codes associated with GRABGAM are provided in this appendix. The BASIC codes are operable as BASICA or GWBASIC versions. Modification to later BASIC versions or FORTRAN has not been necessary, although future efforts in these directions would be useful for further evolution of the code. The present BASIC codes have been compiled for faster execution. Typically a GRABGAM analysis may be completed within 30 seconds using a pentium computer. As some of the code operations refer to disk drive $B$, the user may wish to develop DOS batch files with ASSIGN or SUBST commands to conveniently address this drive. below:

The code listings provided are given in the order categorized

\begin{tabular}{lll}
\multicolumn{1}{c}{ Category } & \multicolumn{1}{c}{ Code } & Page \\
Auxiliary/Setup & & \\
& ISOLIBAS & $\mathrm{B}-4$ \\
& DETLIBAS & $\mathrm{B}-6$ \\
& MERGBACK & $\mathrm{B}-9$ \\
& MERGCALB & $\mathrm{B}-13$ \\
Execution/GRABGAM & GRABDKR1 & $\mathrm{B}-27$ \\
& GRABDKR2 & $\mathrm{B}-39$ \\
Appendage/Supplement & GRABISOS & $\mathrm{B}-54$ \\
& GRABBACK & $\mathrm{B}-60$ \\
& GRABCALB & $\mathrm{B}-67$ \\
& GRABDIAG & $\mathrm{B}-81$ \\
& GRABPLOT & $\mathrm{B}-85$ \\
& PEAKPART & $\mathrm{B}-92$ \\
Development/Analysis & BDATRANS & $\mathrm{B}-96$ \\
& GEFFCX1 & $\mathrm{B}-99$ \\
& TEFFPERF & $\mathrm{B}-102$
\end{tabular}

\section{BACKGROUND INFORMATION}

The codes of the first three categories are discussed in the main text and in Appendix $A$, while the three codes of the last category are discussed in this section.

$$
\mathrm{B}-1
$$


BDATRANS is a skeleton code that was used to develop the first five Appendage/Supplement codes listed above. Primarily this code reads in the files generated by GRABGAM for supplementary analysis. Thus, BDATRANS is the basis on which the other supplementary codes were developed, and it can be used for development of any new supplementary codes in the future.

GEFFCX1 and TEFFPERF are codes used in fitting efficiency data to a function dependent on both gamma energy and vial height. Such efficiency options are discussed and referenced in the main text. ${ }^{3}$ Given a set of experimentally measured efficiencies as a function of energy (E) and vial height (h), it is desired to fit these data to some efficiency function $\epsilon(E, h)$. In actuality, it is more convenient to use $\mathrm{x}=\ln (\mathrm{E})$ and fit a function $\epsilon(\mathrm{x}, \mathrm{h})$.

For a given geometry, it has been noted that the energy- or $x$-dependent efficiency may be fitted to a hyperbola in a In $(\epsilon)$ vs $\ln (E)=x$ plot, $v i z$

$$
\ln (\epsilon)=A\left[B^{2}+(x-C)^{2}\right]^{1 / 2}+D
$$

Thus, such a relation should be reasonable for the efficiency of each vial height, as well as the average efficiency for the vial height cases. If we measure the efficiency of a particular energy as a function of vial height, it is similarly noted that the efficiency may be approximated as

$$
\epsilon=\epsilon_{0} /\left(\mathrm{h}+\mathrm{h}_{0}\right)^{2}
$$

Averaging Equation B-2 over the different energy cases also yields a similar approximation.

GEFFCXI is a least-squares program for fitting the $\mathrm{h}$-averaged efficiencies to Equation B-1. The E-averaged efficiencies can be fitted to Equation $B-2$ by plotting $\epsilon^{-1 / 2}$ vs $h$ and extracting $h_{0}$ as the $h$-intercept and $\left(\epsilon_{0}\right)^{-1 / 2}$ as the slope; or a least-squares fit for a straight line may be used. Then, we may combine Equations $B-1$ and $\mathrm{B}-2$ to yield an approximate efficiency of

$$
\epsilon_{A}(x, h)=G \exp \left\{A\left[B^{2}+(x-C)^{2}\right]^{1 / 2}\right\} /\left(h+h_{0}\right)^{2}
$$

where $G$ represents constants $D$ and $\epsilon_{0}$ of Equations $B-1$ and $B-2$. 
TEFFPERF refines the approximate efficiency $\epsilon_{A}(x, h)$. First, all constants $A, B, C$, and $h_{0}$ are accepted from the preceding analysis, and then Equation $B-3$ is force fitted to all the experimental measurements $\epsilon_{\mathrm{m}}(\mathrm{x}, \mathrm{h})$ to obtain the best fitted value of $G$. Next, the relative perturbations $p(x, h)$ between $\epsilon_{m}(x, h)$ and $\epsilon_{\mathrm{A}}(\mathrm{x}, \mathrm{h})$ are calculated as

$$
p(x, h)=\epsilon_{m}(x, h) / \epsilon_{A}(x, h)-1
$$

Then, TEFFPERF performs a least-squares polynomial fit to $p(x, h)$ as $\mathrm{p}_{\mathrm{F}}(\mathrm{x}, \mathrm{h})$ or explicitly

$$
\begin{aligned}
p_{F}(x, h)=a_{00}+ & a_{10} x+a_{01} h+a_{20} x^{2}+a_{11} x h+a_{02} h^{2} \\
& +a_{30} x^{3}+a_{21} x^{2} h+a_{12} x h^{2}+a_{03} h^{3}
\end{aligned}
$$

The final fitted efficiency $\epsilon(x, h)$ is then calculated as the product of Equations $B-3$ and $B-5$, viz

$$
\epsilon(\mathrm{x}, \mathrm{h})=\epsilon_{\mathrm{A}}(\mathrm{x}, \mathrm{h})\left[1+\mathrm{p}_{\mathrm{F}}(\mathrm{x}, \mathrm{h})\right]
$$

\section{LISTING INFORMATION}

Each code listing is presented with lines grouped according to function. A sequential outline of the code precedes each listing, describing main program functions and subroutines with regard to line numbers. Some of the codes could be edited for bogus Iines and nonessential printout; such lines are identified in the sequential outlines when appropriate. Also, some of the dimensioned variables (defined in DIM statements) may need to have their array sizes increased in the future. 
ISOLIBAS: Program structure Reference

Main

<-- Subroutines and [files]

$2-100 /$ DIM Init

8005-8050/READ data <--- 20000-23000 DATA on gammas/isotopes <--- Create B:ISOLIBRY.LIB 
2 REM ISOLIBAS. BAS

50 CLS

70 PRINT"Isotope libraries being stored in b: (RAM disk)"

100 DIM ISOS(250), ISOTH(250), ISOEM (250), ISOGAM(250), MDA (250)

BO05 OPEN "B:ISOLIBRY.LIB" FOR OUTPUT AS \#3

8010 FOR ISO $=1$ TO 250

8015 READ ISOS (ISO), ISOTH (ISO), ISOEN (ISO), ISOGAM(ISO), MDA (ISO)

8020 WRITE \#3, ISOS(ISO), ISOTH (ISO), ISOEN (ISO), ISOGAM (ISO), MDA (ISO)

8030 IF ISOS(ISO) = "limit " THEN ISO $=250$

8040 NEXT ISO

8050 CLOSE \#3

20000 REM - library of isotope data by gama enegry order - lines 20000-23000

20001 'isotope, half-life(d), energy, igamma, ma

20046 DATA "Pb-210", 8145.1,46.5201,4.050,1

20059 DATA "AM-241", 157861,59.3571,35.91, 0

20063 DATA "Th-234",24.101,63.2901,4.471, 0

20075 DATA "PbBiKX", 1.00e6, 74.9001,74.03,0

20086 DATA "PbBikX", 1.00e6,86.0001,21.49,0

20087 DATA "Eu-155",1741.1,86.5431,30.81,0

20088 DATA "Cd-109",464.01,88.0301,3.611,0

20093 DATA "Th-234", 1632e9,92.5901,5.161,0

20105 DATA "Eu-155",1741.1,105.308,20.51,0

20121 DATA "Eu-152",4868,6,121.782,28.32,0

20122 DATA "Co-57",270.91,122.063,85.59,0

20123 DATA "EL-154",3127.1,123.141,40.51,0

20129 DATA "AC-228",511e10,129.201,2.929,0

20134 DATA "Ce-144",284.31,133.544,10.81,0

20136 DATA "CO-57",270.91,136.476,10.61,0

20144 DATA "U-235",2571e8, 143.761,10.93,0

20145 DATA "Ce-141",32.501,145.441,48.44,0

20163 DATA "U-235",2571e8,163.401,5.001,0

20166 DATA "Ce-139",137.71,165.851,79.95,0

20185 DATA "U-235",2571e8,185.715,57.51,0

20186 DATA "Ra-226",5.84e5,186.211,3.281,0

20205 DATA "U-235",2571e8,205.301,5.031,0

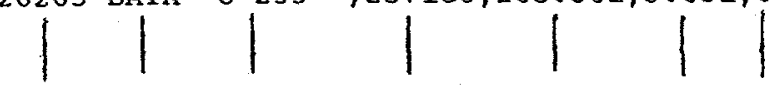

21120 DATA "Bi-214",5.84e5,1120.29,15.71,0

21121 DATA "SC-46",83.851,1120.52,99.99,0

21155 DATA "Bi-214",5.84e5,1155.19,1.701,0

21173 DATA "CO-60",1924.1,1173.21,99.91,1

21238 DATA "Bi-214",5.84e5,1238.11,5.941,0

21274 DATA "Eu-154",3127.1,1274.45,35.50,0

21275 DATA "Na-22 ",950.41,1274.51,99.95,0

21280 DATA "Bi-214", 5.84e5, $1280.96,1.481,0$

21292 DATA "Fe-59",44.496,1291.60,43.21,0

21333 DATA "Co-60 ", 1924.1,1332.56,99.98,1

21365 DATA "CS $134 ", 753.11,1365.01,3.401,0$

21377 DATA "Bi-214",5.84e5, 1377.82,5.061,0

21384 DATA "Agl10m", $249.76,1384.31,24.28,0$

21385 DATA "Bi-214", 5.84e5,1385.21,0.776,0

21402 DATA "Bi-214", 5.84e5, 1401.51,1.386, 0

21408 DATA "Eu-152", 4868.6,1408.01,20.85,0

21409 DATA "Bi-214",5.84e5,1408.11,2.477,0

21461 DATA "K-40" "467e12,1460.75,10.71, 0

21496 DATA "AC-228",511e10,1495.81,0.900,0

21509 DATA "Bi-214", 5.84e5,1509.21,2.192,0

21583 DATA "Bi-214",5.84e5, 1583.21,0.717,0

21588 DATA "AC-228",511e10,1588.21,3.201,0

21593 DATA "DX2614",511e10,1593.21,100.1,0

21596 DATA "Ia-140", $1.6758,1596.49,95,49,0$

21620 DATA "Bi-2.12",511e10,1620.51,2.751,0

21630 DATA "AC-228",511e10,1630.51,1.949,0

21661 DATA "Bi-214",5.84e5,1661.28,1.150,0

21691 DATA "Sb-124",60.201,1690.98,47.31,0

21729 DATA "Bi-214",5.84e5,1729.61,2.971, 0

21765 DATA "Bi-214",5.84e5,1764.49,17.01,

21836 DATA "Y -88 ", 106.66,1836.01,99.35,0

21838 DATA "Bi-214", 5.84e5, $1838,36,0.385$, 0

21847 DATA "Bi-214", 5.84e5,1847.42,2,091,0

21873 DATA "Bi-214",5.84e5,1873.16,0.227,0

23000 DATA "limit ", 1.0000,5000.01,1.000,0 
DETLIBAS: Program structure Reference

Main <-- Subroutines and [files]

\author{
2-24/DIM Init \\ 9000-9100/READ data <-- 50000-50538 DATA on det vial effs \\ <--- Create B:DETLIBRY. LIB
}

$$
\mathrm{B}-6
$$


2 REM DETLIBAS.BAS

5 PRINT

6 PRINT "Detector calibrations for vials being stored in b: (RAM disk)"

7 PRINT

$22 \operatorname{DIM} \operatorname{GOEFF}(5,3), \operatorname{HOEFF}(5,3), \operatorname{AOEFF}(5,3), \operatorname{BOEFF}(5,3), \operatorname{KOEFF}(5,3)$

23 DIM CEOHO $(5,3)$, CEIHO $(5,3), \operatorname{CEOH}(5,3), \operatorname{CE} 2 H O(5,3), \operatorname{CEIHI}(5,3), \operatorname{CEOH} 2(5,3)$

24 DIM CE3HO $(5,3), \operatorname{CE} 2 \mathrm{H} 1(5,3), \operatorname{CE} 1 \mathrm{H} 2(5,3), \operatorname{CEOH} 3(5,3)$

9000 OPEN "B:DETLIBRY.LIB" FOR OUTPUT AS \#3

9010 FOR $I=1$ TO 5

9020 FOR $J=1$ TO 3

$9030 \operatorname{READ} \operatorname{GOEFF}(I, J), \operatorname{AOEFF}(I, J), \operatorname{BOEFF}(I, J), \operatorname{KOEFF}(I, J), \operatorname{HOEFF}(I, J)$

9035 WRITE $3, \operatorname{GOEFF}(I, J), \operatorname{AOEFF}(I, J), \operatorname{BOEFF}(I, J), \operatorname{KOEFF}(I, J), \operatorname{HOEFF}(I, J)$

9040 READ CEOHO (I,J)

9045 WRITE \#3, CEOHO (I,J)

9050 READ CE 1 HO $(I, J)$, CEOH $1(I, J)$

9055 WRITE \#3,CE1HO $(I, J), C E O H 1(I, J)$

9060 READ CE2HO (I,J), CEIHI (I,J), CEOH2 $(I, J)$

9065 WRITE \#3, CE2HO (I,J), CEIHI (I,J), CEOH2 (I,J)

9070 READ CE3HO(I,J), CE2H1 (I,J), CE1H2 (I,J), CEOH3 (I,J)

9075 WRITE \#3, CE3HO(I,J), CE2H1 (I,J), CE1H2 (I,J), CEOH3 (I,J)

$9080 \mathrm{NEXT} \mathrm{J}$

$9090 \mathrm{NEXT} I$

9100 CLOSE \#3

50000 REM - library, for vial efficiency parameters

50110 REM - old bottom - large vials

50111 REM G A B . C HO

50112 DATA $4.4014,-1.0759, .23537,4.7811,7.521$

50113 REM EOHO E1HO EOH1 E2HO E1H1 EOH2

50114 DATA $-1.0715, .66925,-.11622,-.13165,3.8465 e-2,-8.1974 e-3$

50115 REM E3HO E2H1 E1H2 EOH3

50116 DATA $8.1961 e-3,-2.9106 e-3,9.0012 e-4,4.1102 e-4$

50118 REM

50120 REM - old bottom - medium vials

50121 REM G A B A C HO

50122 DATA $4.2723,-1.1133, .20449,4.6917,5.39$

50123 REM EOHO E1HO EOHI E2HO E1HI EOH2

50124 DATA $-1.5687, .90226,-.28041,-.16506,6.3938 e-2,5.5751 \mathrm{e}-2$

50125 REM E3HO E2H1 EXH2 EOH3

50126 DATA $9.6486 \mathrm{e}-3,-4.4284 \mathrm{e}-3,2.4211 \mathrm{e}-3,-1.6689 \mathrm{e}-2$

50128 REM

50130 REM - old bottom - small vials

50131 REM G A A B A C HO

50132 DATA $5.7074,-1.1126, .21211,4.6839,6.003$

50133 REM EOHO E1HO EOH1 E2HO E1H1 EOH2

50134 DATA $-2.8370,1.1014,-.30294,-.20342,5.7149 e-2,3.6757 \mathrm{e}-2$

50135 REM E3HO E2H1 E1H2 EOH3

50136 DATA $1.2026 e-2,-3.6859 e-3,-4.7735 e-4,-3.1522 e-3$

50138 REM

50210 REM - bottom - large vials

50211 REM G A B C HO

50212 DATA $5.7118,-.95483, .24005,4.6652,7.397$

50213 REM EOHO E1HO EOHI E2HO EIHI EOH2

50214 DATA $-.84914, .53672,-.16315,-.10173,3.5614 \mathrm{e}-2,3.8510 \mathrm{e}-3$

50215 REM E3HO E2H1 E1H2 EOH3

50216 DATA $5.9538 e-3,-1.8056 e-3,9.0641 e-5,-8.4979 e-5$

50218 REM

50220 REM - bottom - medium vials

50221 REM G A B B C

50222 DATA $5.5596,-.99324, .11750,4.6283,5.654$

50223 REM EOHO E1HO EOH1 E2HO E1H1 EOH2

50224 DATA $-1.0950, .61684,-.18324,-.10899,2.9329 \mathrm{e}-2, .039674$

50225 REM E3HO E2H1 E1H2 EOH3

50226 DATA $6.0818 e-3,-1.1207 e-3,1.4525 e-3,-1.0103 e-2$

50228 REM

50230 REM - bottom - small vials

50231 REM G A A B A

50232 DATA $6.9078,-1.0034, .14180,4.6445,6.062$

50233 REM EOHO E1HO EOH1 E2HO E1H1 EOH2

50234 DATA $-1.3356, .84971,-.35531,-.16112,7.3339 \mathrm{e}-2,3.2921 \mathrm{e}-2$

50235 REM E3HO E2H1 E1H2 EOH3

50236 DATA $9.5563 e-3,-3.9038 e-3,-2.5714 e-3,-1.0877 e-3$

50238 REM 


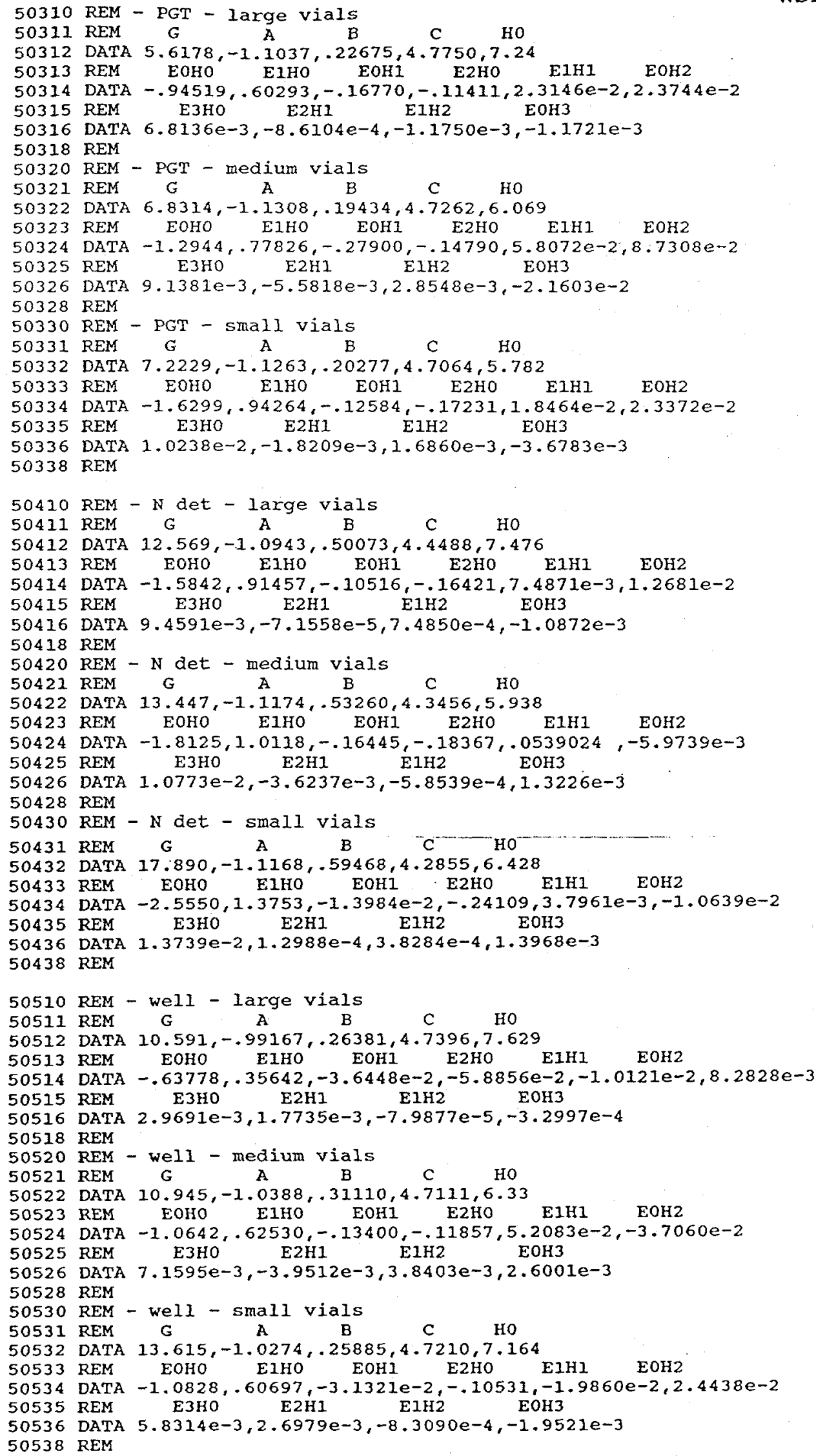




\section{MERGBACK: Program structure Reference}

Main $<--$ Subroutines and [files]

$5-50 /$ Print instr 100-230/Print bkg <--- 6000-6100/Select and print file $<---$ backgnd. BKG

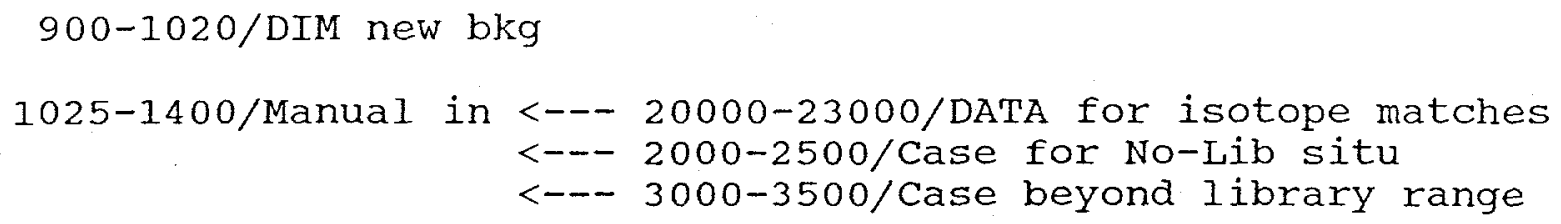

$1900 / \mathrm{STOP}$ 
5 REM - mergback

25 CLS

50 INPUT'Use $(\wedge)$ - or $(\operatorname{Ctrl})$-(PrtSc) as needed in this program - press enter to $p$ roceed";22

100 CLS:PRINT

200 PRINT: INPUT"Desire to print anY background files before begin $(Y / n)$ "iYE\$

210 PRINT

220 IF YES="Y" THEN GOSUB 6000

230 IF YE $\$=" Y$ " THEN GOTO 200

900 CIS

1000 INPUT"Live count time (sec)";LTIME :PRINT

1005 INPUT"Energy identification search $(\mathrm{e} .9+1 /-2.0 \mathrm{keV})$ ": EFIND

1006 PRINT

1010 BADDER $=0$

1020 DIM BNERGY (100), BRATE(100), BERR(100), BISO\$(100)

1025 INPUT"Energy (keV) of background peak (5000 to end) "; EB:BADDER=BADDER+I

1030 READ ISO\$, ISOTH, ISOEN, ISOGAM, MDA

1040 IF ISO\$="Iimit " THEN BADDER =BADDER-1: GOTO 1400

1070 IF EB-ISOEN > EFIND THEN 1030

1075 IF ISOEN-EB > EFIND THEN GOSUB 2000

1077 IF ISOEN-EB > EFIND THEN INPUT"Energy (keV) of background peak (5000 to end )": $\mathrm{EB}$ : BADDER=BADDER+1:GOTO 1070

1080 INPUT" Counts"; COUNTS : BRATE (BADDER) =COUNTS/LTIME

1090 INPUT" क erYOr" ; PERROR: BERR (BADDER) =PERROR $\star B R A T E(B A D D E R) / 100$

1100 BISO $($ BADDER $)=$ ISO $\$$ : BNERGY $($ BADDER $)=$ ISOEN

1125 PRINT

1200 READ ISO\$, ISOTH, ISOEN, ISOGAM, MDA

1202 IF ABS (EB-ISOEN) <= EFIND THEN BADDER=BADDER+1:GOTO 1080

1210 INPUT"Energy (keV) of background peak (5000 to end) ";EB:BADDER=BADDER+1

1300 GOTO 1040

1400 IF EB<5000 THEN GOSUB 3000:REM - include backgrounds beyond last library pe ak

1490 CLS

1500 PRINT: PRINT"Sumary of inputs"

1501 PRINT

1505 PRINT"Peak Isotope Energy Rate Error"

1506 PRINT" \# Z-A keV cph N-stats"

1507 PRINT

1510 FOR $I=1$ TO BADDER

1515 IF BNERGY(I)=0 THEN 1550:REM - this takes care of last faked high energy

1520 PRINT USING "\#\#";I;:PRINT" ";BISOS(I);:PRINT USING"\#\#\#\#\#\#.\#";BNERGY(

I) ;

1530 PRINT USING "\#\#\#\#\#.\#";BRATE(I) *3600;:PRINT USING"\#\#\#•\#"; $100 *$ BERR(I)/BRATE

(I) : : PRINT" \& "

1540 IF CSRIIN > 23 THEN INPUT"press enter to continue"; PAGE\$:CLS

1550 NEXT I

1560 PRINT:INPUT"Corrections to above data $(y / n)$ "; YES:IF YE $\$<" n " T H E N$ GOSUB 7000

1570 IF YES<>"n" THEN 1490

1600 GOSUB $4000:$ REM put data out to file

1650 GOSUB 8000 : REM hardcopy of results

1700 PRINT:INPUT"Desire to print any background files before finish $(y / n)$ ";YE\$

1710 PRINT

1720 IF YE $\$=" Y "$ THEN GOSUB 6000

1730 IF YE $\$=" Y$ " THEN GOTO 1700

1900 STOP

2000 REM - sub for nonlibrary backgrounds

2030 BNERGY (BADDER) $=E B$

2040 INPUT" Counts"; COUNTS : BRATE (BADDER) =COUNTS/LTIME

2050 INPUT" error" ; PERROR: BERR (BADDER) $=$ PERROR $*$ BRATE $($ BADDER $) / 100$

2060 BISOS (BADDER) $=$ "No-Lib"

2080 PRINT

2500 RETURN 
3000 REM - sub for background peaks beyond library

3020 GOTO 3050

3030 PRINT

3040 INPUT"Energy (keV) of background peak (5000 to end) ";EB:IF EB=5000 THEN 350

0

3050 BADDER=BADDER+1

3060 BNERGY $(B A D D E R)=E B$

3070 INPUT"Counts"; COUNTS: BRATE (BADDER) $=$ COUNTS/LTIME

3080 INPUT" क error" ; PERROR: BERR (BADDER) =PERROR $\star B R A T E(B A D D E R) / 100$

3090 BISO\$ (BADDER) $="$ NO-Lib"

3100 GOTO 3030

3500 RETURN

4000 REM - sub to put data on file

4010 PRINT: INPUT"Name of disk file (-........BKG) "; BKFILES

4020 CLS: PRINT"File name is : ";BKFILE\$

4025 PRINT: INPUT"File name acceptable ( $y=$ proceed/n=rename) "; YE\$

4027 IF YES $<>$ "Y"THEN 4010

4030 OPEN BKFILES FOR OUTPUT AS \#2

4040 FOR I=1 TO BADDER

4050 WRITE \#2, BNERGY (I), BRATE (I), BERR (I)

4060 NEXT I

4070 CLOSE \#2

4100 RETURN

6000 CLS:PRINT:INPUT"Name of background file (-...-.BKG) ";FILEBKS

6005 PRINT:PRINT

6010 PRINT "Peak Energy Rate Error "

6015 PRINT " \# $\mathrm{keV} \mathrm{cph}$ \%

6016 PRINT

6020 OPEN FILEBKS FOR INPUT AS \#2

$6030 \quad \mathrm{CBACK}=1$

6040 IF EOF(2) THEN GOTO 6070

6050 INPUT \#2,BNERGY, BRATE, BERR

6055 PRINT USING"\#\#\#";CBACK; : PRINT USING" \#\#\#\#\#\# .\#" ; BNERGY

\#\#\#\#";3600*BRATE；:PRINT USING"\#\#\#\#\#.\#";100*BERR .../BRATE

;:PRINT USING" \#\#\#

$6060 \mathrm{CBACK}=\mathrm{CBACK}+1$

6065 GOTO 6040

6070 CLOSE \#2

6100 RETURN

7000 REM - subroutine to correct inputs

7005 ENERGY $=0:$ COUNTS $=0:$ PERROR $=0$

7010 PRINT: INPUT"Select peak number to correct"; PEAK: PRINT

7015 BRATE $=$ BRATE (PEAK)

7020 PRINT"Press enter for parameters that need no correction"

7030 INPUT"EnergY (keV) "; ENERGY: IF ENERGY=0 THEN 7050

7040 BNERGY $($ PEAK) $=$ ENERGY

7050 INPUT" COUnts"; COUNTS: IF COUNTS $=0$ THEN 7070

7060 BRATE $($ PEAK $)=$ COUNTS $/$ LTIME

7065 IF BRATE $>0$ THEN BERR (PEAK) =BERR (PEAK) *BRATE (PEAK) $/$ BRATE

7070 INPUT"Error \& "; PERROR: IF PERROR =0 THEN 7090

$7080^{\circ}$ BERR $($ PEAK $)=$ PERROR $*$ BRATE $($ PEAK $) / 100$

7090 RETURN

8000 REM - hardcopy of results

8010 PRINT: INPUT"Hardcopy title" ; TITLE\$

8020 LPRINT TITLE\$ : LPRINT

8030 LPRINT BKFILE\$ : LPRINT

8100 LPRINT: LPRINT"SumnarY of inputs"

8101 LPRINT

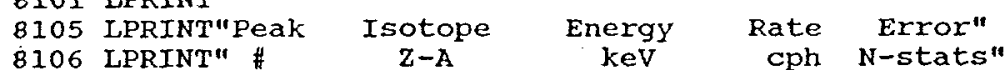

8107 LPRINT

8110 FOR $I=1$ TO BADDER

8115 IF BNERGY $(I)=0$ THEN 8150:REM-this takes care of last faked high energy

8120 LPRINT USING "\#\#\#";I;:LPRINT" ";BISOS(I);:LPRINT USING"\#\#\#\#\#\#.\#";BNER

$G Y(I)$;

8130 LPRINT USING "\#\#\#\#\#.\#";BRATE(I)*3600;:LPRINT USING"\#\#\#•\#";100*BERR(I)/BRA

TE (I) ; : LPRINT" \&"

8150 NEXT I

8200 RETURN 
20000 REM - library of isotope data by gamma enegry order - Iines 20000-23000

20001 'isotope, half-Iife (d), energy, igamma, mda

20046 DATA "Pb-210", 8145.1,46.5201,4.050,1

20063 DATA "Th-234",24.101,63.2901,4.471,0

20075 DATA "PbBiKX", 1.00e6, 74.9001,74.03,0

20086 DATA "PbBikX", 1.00e6,86.0001,21.49,0

20087 DATA "Eu-155", 1741.1,86.5431,30.81,0

20088 DATA "Cd-109",464.01,88.0301,3.611,0

20093 DATA "Th-234",1632e9,92.5901,5.161,0

20105 DATA "Eu-155",1741.1,105.308,20.51,0

20122 DATA "CO-57",270.91,122.063,85.59,0

20123 DATA "Eu-154",3127.1,123.141,40.51,0

20129 DATA "AC-228",511e10,129.201,2.929,0

20134 DATA "Ce-144",284.31,133.544,10.81,0

20136 DATA "Co-57",270.91,136.476,10.61,0

20144 DATA "U-235",2571e8,143.761,10.93,0

20145 DATA "Ce-141",32.501, 145.441,48.44,0

20166 DATA "Ce-139",137.71, 165.851,79.95,0

20185 DATA "U-235 ",2571e8,185.715,57.51,0

20186 DATA "Ra-226",5.84e5,186.211,3.281,0

20210 DATA "AC-228",511e10,209.501,4.553,0

20238 DATA "Pb-212",511e10,238.625,44.61,0

20271 DATA "Rn-219",7952,6,271.231,9.901,0

20279 DATA "Hg-203", 47.001, 279.191,81.55,0

20295 DATA "Pb-214",5.84e5,295.201,20.01,0

20320 DATA "CR-51",27.701,320.081,9.831,0

20328 DATA "AC-228", 511e10,328.801,3.346,0

20338 DATA "AC-228",511e10,338.401,11.10,0

20352 DATA "Pb-214",5.84e5,351.921,38.91,0

20364 DATA "I-13I ",8.0401,364.481,81.24,0

20392 DATA "Sn-113",115.01,391.691,64.16,0

20409 DATA "AC-228",511e10,409.501,2.233,0

20427 DATA "Sb-125",996.45,427.891,29.44,0

20462 DATA "AC-228",511e10,462.801,4.641,0

20477 DATA "Be-7 ",53.301,477.591,10.31, I

20487 DATA "La-140",1.6758,487.029,45.51,0

20497 DATA "Ru-103",39.351,497.080,89.51,0

20510 DATA "TI-208",511e10,510.801,21.61,0

20511 DATA "Annihl", 1.00e6,511,006,200.1,0

20514 DATA "Sr-85",64.851,513.996,98.01,0

20537 DATA "Ba-140", 12.789,537.321,24.39,0

20583 DATA "TI-208",511e10,583,139,74.71,0

20601 DATA "Sb-125",996.45,600.557,17.78,0

20603 DATA "Sb-124",60.201,602.731,97.81,0

20605 DATA "Cs-134",753.11,604.699,97.56,0

20609 DATA "Bi-214",5.84e5,609.312,43.31,0

20622 DATA "Ru-106",368.21,621.841,9.812,0

20662 DATA "Cs-137",11021,,661.638,84.13,1

20724 DATA " $\mathrm{Zr}-95$ ",64.021,724.199,44.11, 0

20727 DATA "Bi-212",511e10,727.171,7.161,0

20757 DATA "Zx-95 ",64.021,756.729,54.51,0

20765 DATA "Nb-95 ".34.971,765.791,99.79,0

20768 DATA "Bi-214",5.84e5,768.356,5.041,0

20795 DATA "AC-228",511e10,795.001,4.843, 0

20796 DATA "Cs-134",753.11,795.845,85.44,0

20835 DATA "Mn-54",312.71,834.827,99.98,0

20860 DATA "TI-208", 1.4e10,860.564,12.01,0

20889 DATA "SC-46",83.851,889.258,99.98,0

20898 DATA "Y-88. ", 106.66,898.021,95.01, 0

20911 DATA "AC-228",511e10,911.070,26.35,0

20969 DATA "AC-228",511e10,969.111, 15.66,0

21001 DATA "Pa-234",1632e9,1001.03,.5901,0

21116 DATA " $\mathrm{Zn}-65 ", 244.11,1115.52,50.74,0$

21120 DATA "Bi-214",5.84e5,1120.29,15.71,0

21121 DATA "SC-46",83.851,1120.52,99.99,0

21173 DATA "CO-60",2924.1,1173.21,99.91,1

21238 DATA "Bi-214", 5.84e5, 1238.11,5.941,0

21274 DATA "Eu-154",3127.1,1274.45,35.50,0

21333 DATA "CO-60 ", 1924.1,1332.56,99.98, 1

21461 DATA "K-40 ",467e12,1460.75,10.71,0

21593 DATA "DE2614",511e10,1593.21, 100.1,0

21596 DATA "La-140", 1.6758, 1596.49,95.49,0

21620 DATA "Bi-212",511e10,1620.51,2.751,0

21630 DATA "AC-228",511e10,1630.51,1.949,0

21691 DATA "Sb-124",60.201,1690.98,47.31,0

21765 DATA "Bi-214", 5.84e5,1764.49,17.01,0

21836 DATA "Y-88 ", 106.66,1836.01,99.35, 0

23000 DATA "limit ", 1.0000,5000.01,1.000,0 


\section{MERGCALB: Program structure Reference}

Main

<-- Subroutines and [files]

$5-28 /$ Setup DIM

31-32/File effs <--- 9000-9200/Vial efficiency functions $<--$ B:DETLIBRY. LIB

40-63/Ref eff <--- 46000-46090/Detector selection

<--- 46100-46200/Geometry selection

<--- 46500-46690/Special samples

$<---46700-46760 /$ Air "diapers"

$<---46800-46850 /$ Well samples

$<--46900-46990 /$ Vials

$<---47000-47200 /$ File geom $<---$ detreff. DCF

<-- 60000-60140/Eff cal table

64-170/Anal menu (options 1-5 below)

$$
\begin{aligned}
& \text { 180/1-eff } \quad<---40-63 / \text { GOTO for new ref det } \\
& \text { 190/2-plot <--- 56000-56900/LogEff vs logE screen graph } \\
& \text { <-- 58000-58900/Plot ref eff } \\
& \text { 200/3-eff dat <--- 20000-20500/Input measured efficiencies } \\
& \text { <-- 21000-21100/Order by energy } \\
& \text { 210/4-eff fit <--- 600-etc/GOTO for analyzing new data } \\
& \text { 220/5-exit <--- 990/GOTO for STOP execution } \\
& 230 / \mathrm{N} \text {-menu } \quad \text {--- 100/GOTO for menu 64-170 on non-option } \mathrm{N}
\end{aligned}
$$

650-677/Plot drawing instructions

$$
\begin{aligned}
680-798 / \text { Draw eff } & <--551000-51900 / \text { LogEff vs LogE screen graph } \\
& <---50000-50900 / \text { Plot measured efficiencies } \\
& <--55000-58900 / \text { Plot ref eff } \\
& <---52000-52030 / \text { Plot } 3 \text { hyperbola fit points } \\
& <---52200-52290 / \text { Move red point to curve max } \\
& <---52100-52130 / \text { Erase point } \\
& <---52000-52030 / \text { Draw point }
\end{aligned}
$$




\section{MERGCALB: Program structure Reference (continued)}

Main

$<--$ Subroutines and [files]

680-798/Draw eff

(cont'd)

800-865/Norm eff

<--- 52300-52330/Move yellow point to sym pt <--- 52100-52130/Erase point <-- 52000-52030/Draw point

<-- 52400-52390/Move green point to asympt $<--52100-52130 /$ Erase point $<--52000-52030 /$ Draw point

<--- 52500-52590/Draw hyperbola guidelines <-- 52600-25690/Erase hyperbola guidelines <--- 15000-15090/LnEff-LnE units for 3 points <-- 53000-53900/Plot resulting hyperbola eff <--- 51000-51900/LogEff-LogE graph <-- 50000-50900/Plot measured effs

<--- 42000-42900/Exam hyperbola vs meas effs $<--$ 53000-53900/Replot per dev=0 normalize <--- 51000-51900/LogEff-LogE graph <--- 50000-50900/Plot measured effs

870-890/Refine A <--- 10000-10500/Least-squares hyperbola fit <-- 11000-1110/Chi-sq fit results

<-- 53000-53900/Plot resulting final eff $<--$ 51000-51900/LogEff-LogE graph <-- 50000-50900/Plot measured effs

<--- 42000-42900/Exam hyperbola vs meas effs

$890-915 /$ Refine B

<--- 16000-16300/L-S cubic fit to residuals <--- 17000-17170/Trianglize matrix <--- 18000-18100/Solve cubic coeffs <--- 19000-19100/Chi-sq fit results

<--- 53000-53900/Plot resulting final eff <--- 51000-51900/LogEff-LogE graph <--- 50000-50900/Plot measured effs

--- 42000-42900/Exam final fit vs meas effs

$920-939 / 0 K$ menu

<--- 650-etc/GOTO back at draw hyperbola

<--- 870-etc/GOTO back at L-S hyperbola fit

$<--$ 900-etc/GOTO back at L-S cubic fit

$<--910-e t c /$ GOTO back to redraw final plot

<--- 938-etc/GOTO continue - fit oK

940-970/Output <--- 34000-34100/Parameters set for output

<-- 35000-35500/Create efficiency file $<--$ detreff. DCF

<--- 36000-36900/Print efficiency summary

$990 /$ STOP

$B-14$ 


\section{MERGCALB: Program structure Reference} (continued)

Lines not used in execution

61000-61020/Calendar data

62000-62020/Attenuation data

$\mathrm{B}-15$ 
5 REM - MERGCALB. BAS

10 CLS:PRINT" MERGCALB.BAS - setting up records"

18 DIM A (3), TC $(3,3), T D(3), T N(3,3)$

19 DIM ENATT (21), MUATT (21)

20 DIM MONTH (12), GAMRATE (25), EFFCAL (25), ERRCAL (25), J (25), ECAL (25), SUMCOR (25)

21 DIM Hi (100), H2 (100), RATERR (100)

22 DIM $\operatorname{GOEFF}(5,3), \operatorname{HOEFF}(5,3), \operatorname{AOEFF}(5,3), \operatorname{BOEFF}(5,3), \operatorname{KOEFF}(5,3)$

23 DIM CEOHO $(5,3), \operatorname{CE} I H O(5,3), \operatorname{CEOH} 1(5,3), \operatorname{CE} 2 \mathrm{HO}(5,3), \operatorname{CE} 1 \mathrm{H} 1(5,3), \mathrm{CEOH} 2(5,3)$

$24 \operatorname{DIM} C \operatorname{CEHO}(5,3), \operatorname{CE} 2 \mathrm{H} 1(5,3), \operatorname{CE} 1 \mathrm{H} 2(5,3), \operatorname{CEOH} 3(5,3)$

25 DIK YLOC (20), DETNAMS(10), BNERGY (100), BRATE (100), BERR (100), DETLABS(10)

26 DIM ISOTH (100), MDA (100), ACTRAT (100), LIBEN (100), SBRATE (100), SBERR (100)

27 DIM RATE (100), ENERGY (100), ISOEN (100), ISOID\$(100), ISO\$(100), ISOGAM (100)

28 DIM NPC (4096), AREA (100), EAREA (100), LOCH (100), FWHM (100), TAIL(I00), CENT(100)

31 GOSUB 9000:REM read in detector efficiency parameters for vials

32 DETNAM $(1)=$ "Old Botton Detector":DETNAM $(2)=$ "New Bottom Detector":DETNAM\$(3)=

"PGT Detector":DETNAM $(4)=" N-5 i d e$ Detector": DETNAM $\$(5)=$ "Well Detector"

$40 \mathrm{CLS}$

46 GOSUB $46000:$ REM - get efficiency parameters - part 1

47 PRINT: INPUT"Repeat this frame due to input errors $(y / n)$ " FRAMERS:IF FRAMERS=" $Y^{\prime \prime}$ THEN CLS:GOTO 40

50 GOSUB $46100: R E M$ - get efficiency parameters - part 2

51 PRINT:INPUT"Repeat this frame due to input errors ( $y / n)$ ";FRAMERS:IF FRAMERS=" $Y^{\prime \prime}$ THEN CLS : GOTO 50

58 DEF FNEFFA $(E N)=$ GOEFF*EXP $(A O E F F \star S Q R(B O E F F \wedge 2+U O E F F \star(L O G(E N)-K O E F F) \wedge 2) \star(C O E F F+C 1$ $E F F \star I O G(E N)+C 2 E F F \star L O G(E N) \wedge 2+C 3 E F F \star L O G(E N) \wedge 3)+.5 *(1+S G N(E N-E N X)) *(D O E F F+D 1 E F F \star L O G$ $(E N)+D 2 E F F \star \operatorname{LOG}(E N) \wedge 2+D 3 E F F \star \operatorname{LOG}(E N) \wedge 3))$

$59 \mathrm{DEF}$ FNEFFB (EN) $=1+\mathrm{POEFF}+\mathrm{P} 1 \mathrm{EFF} \star \mathrm{LOG}(\mathrm{EN})+\mathrm{P} 2 \mathrm{EFF} \star \mathrm{LOG}(\mathrm{EN}) \wedge 2+\mathrm{P} 3 \mathrm{EFF} \star \operatorname{LOG}(\mathrm{EN}) \wedge 3$

60 DEF FNEFF (EN) =FNEFFA (EN) *FNEFFB (EN)

61 INPUT"DO you wish to see EFF VS EN data for standard energies (Y/n)";EFFVEHS:

CLS: IF EFFVENS $>$ "Y" THEN GOTO 64

62 GOSUB $60000:$ REM check on efficiency data EFF VS EN

63 IF NEWEFF\$="Y" THEN CLS:GOTO 46:REM replace efficiency data case

$64 \mathrm{CLS}$

100 CLS:REM - main menu option for plot

105 PRINT"Currently selected detector : "; DETNAMS (DETN) : PRINT: PRINT

110 PRINT" Menu for plot of detector efficiencies":PRINT

120 PRINT" $\quad$ (1) select different detector"

130 PRINT" (2) Plot selected detector alone"

140 PRINT" (3) Input data for new calibration"

150 PRINT" (4) Analyze data for new calibration file"

160 PRINT" $\quad$ (5) Exit program - finished":PRINT

170 INPUT"Option" $O P$

180 IF $O P=1$ THEN 40

190 IF OP=2 THEN GOSUB 56000:GOSUB 58000:LOCATE 24,4:INPUT"OK(press enter)";ZZ:S CREEN 2:SCREEN $0:$ GOTO 100

200 IF OP=3 THEN GOSUB 20000:GOTO 100

210 IF OP=4 THEN GOTO $600: R E M$ - if $O p=4$ then continue on

220 IF OP=5 THEN 990

230 GOTO 100:REM - catch all for incorrect option

600 REM - plot initial results and continue analysis

605 GOSUB 51000:REM - set up graph paper

610 GOSUB 50000:REM - plot data points

615 GOSUB 58000:REM plot selected existing case

620 LOCATE 24,4

630 INPUT"OK (press enter) "; YES: PRINI

645 SCREEN 2:SCREEN 0

650 CLS:PRINT"Calibration curve fitting":PRINT

$651 \mathrm{~S}=0$

655 PRINT" First order fit with hyperbola"

660 PRINT" (Will apply second order cubic later) ": PRINT: PRINT

665 PRINT" Instructions: ": PRINT

666 PRINI" (1) Turn on Num Lock to use arrows"

667 PRINT"

668 PRINT"

669 PRINT"

670 PRINT"

(2) Select options below while looking at graph"

(x)ed point - adjust to curve max estimate"

(y)ellow point - adjust to origin point of hyperbola"

(g) reen point - adjust to asymptote point of hyperbola"

671 PRINT"

672 PRINT"

673 PRINT"

674 PRINT"

675 PRINT"

(d) raw lines - examine above settings"

(e) rase lines - as needed for new (d) cases"

(f) infohed - clean replot with calib curve"

676 PRINT"

677 PRINT"

3) Move a point in (2) with number pad arrows (5 = finished)"

(4) Draw hyperbola characterist1c 1 ines (2-d and 2-e)"

(5) Plot resulting callbration curve $(2-f)^{*}$

(6) Repeat this process until satisfactory curve fit":PRINT 
680 INPUT"To begin, press enter" $; z Z$

685 RED $=2: Y E L L O W=3:$ GREEN $=1$

$690 X R=120: Y R=40: X Y=120: Y Y=20: X G=250: Y G=160$

700 GOSUB 51000 : GOSUB 50000 : GOSUB 58000

$710 \quad \mathrm{XP}=\mathrm{XR}: \mathrm{YP}=\mathrm{YR}$ : COLOUR=RED:GOSUB $52000: \mathrm{REM}$ - point plot with no error

$712 X P \cong X Y: Y P=Y Y: C O L O U R=Y E L L O W: G O S U B 52000$

$714 X P=X G: Y P=X G: C O L O U R=G R E E N: G O S U B \quad 52000$

720 RYGDEF $\$=$ INKEY $\$$ IF RYGDEF $\$="$ "THEN 720

725 IF RYGDEF $\$=" r$ " THEN GOSUB 52200

730 IF RYGDEF $\$=" Y$ " THEN GOSUB 52300

735 IF RYGDEF $\$=" g$ " THEN GOSUB 52400

740 IF RYGDEF $\$=" d "$ THEN GOSUB 52500

745 IF RYGDEF $\$=$ "e" THEN GOSUB 52600

750 IF RYGDEF $\langle>$ " f"THEN .720

755 REM - now ready to plot calib curve (hyperbola)

760. XEN $=X R: Y E F F=Y R: G O S U B$ 15000: LNENR=LNEN: LNEFFR=LNEFF

$765 X E N=X Y: Y E F F=Y Y:$ GOSUB $15000:$ LNENY $=$ LNEN $:$ LNEFFY $=$ LNEFF

$770 \mathrm{XEN}=\mathrm{XG}: \mathrm{YEFF}=\mathrm{YG}: \mathrm{GOSUB}$ 15000: LNENG $=$ LNEN:LNEFFG=LNEFF

$775 \mathrm{D}=\mathrm{LNEFFY}: \mathrm{A}=(\mathrm{LNEFFG}-\mathrm{LNEFFY}) /($ LNENG-LNENY $): \mathrm{B}=(\mathrm{LNEFFY}-\mathrm{LNEFFR}) / \mathrm{A}: \mathrm{C}=\mathrm{LNENR}$

$776 \quad A(0)=I: A(1)=0: A(2)=0: A(3)=0: S P=0$

780 GOSUB 53000:REM - plot hyperbola

797 LOCATE 24,4

798 INPUT"Satisfactory $(Y / n) "$ "YES:TF XE\$="n" THEN CLS:GOTO 700

800 GOSUB 42000:REM - compare data analysis results for hyperbola

855 PRINT:INPUT"Desire to renormalize to make average deviation zero ( $Y / n$ ) "; YES:

IF YE\$<>"Y" THEN 870

$860 \mathrm{D}=\mathrm{D}+$ TOTDEV/NCAL: GOSUB $53000:$ LOCATE 24,4

865 INPUT"OK(press enter)"; ZZ:GOSUB 42000

870 PRINT:INPUT"Desire LSQ-fit to hyperbola ( $y / n$ ) " $Y$ Y $\$: I F$ YE\$<> "Y" THEN 900

875 GOSUB 10000:REM LSQ-fit to hyperbola

880 GOSUB 53000:IOCATE 24,4

890 INPUT"OK (press - enter)" ; $2 Z:$ GOSUB 42000

900 PRINT:INPUT"APplY LSQ cubic fit to perturbations from hyperbola (Y/n)";YES:I F YE\$<> "Y". THEN 920

905 GOSUB I6000: REM LSQ cublc fit to hyperbola perturbations

910 GOSUB $53000:$ LOCATE 24,4

915 INPUT"OK(press enter)";zz:GOSUB 42000

920 PRINT:INPUT"Press enter to continue";ZZ:CLS

925 PRINT" MENU FOR REFIT OPTIONS": PRINT

926 PRINT" Note: Refit options (1-3) remove existing cubic ISQ"

927 PRINT" perturbation fit, which can be raplacod within"

928 PRINT" these options if desired":PRINT:PRINT

929 PRINT" Refit beginning previous fit sequence at: ": PRINT

930 PRINT" (1) Hyperbola drawing on screen"

931 PRINT" (2) Hyperbola LSQ selection"

932 PRINT" (3) Cubic LSQ perturbation selection"

933 PRINT" (4) No refit yet - view current fit and plot first"

934 PRINT" (5) None of the above - current fit acceptable":PRINT

935 INPUT"Option"; OP: IF OP>3 THEN 938

$936 A(0)=I: A(1)=0: A(2)=0, A(3)=0$

870,900

938 IF OP=4 THEN 910

939 EFFCAL\$="No efficiency file made":REM - will change if and when file made

940 CLS: PRINT"

941 PRINT" (1) Disk file and printout"

942 PRINT" (2) Printout only"

943 PRINT" (3) Disk file only"

944 PRINT" (4) No more output - exit program":PRINT

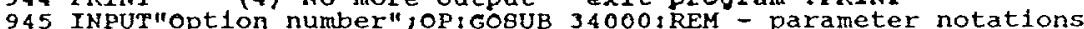

946 IF OP=I THEN GOSUB 35000: GOSUB 36000: GOTO 940

! 947 IF OP=2 THEN GOSUB 36000: GOTO 940

948 IF OP=3 THEN GOSUB 35000:GOTO 940

970 SCREEN 2:SCREEN 0

990 STOP

9000 REM sub from line 31 - read in detector data

9005 OPEN "B:DETLIBRY.LIB" FOR INPUT AS \#3

9010 FOR $I=1$ TO 5

9020 FOR $J=1$ TO 3

9030 INPUT $\# 3, \operatorname{GOEFF}(I, J), \operatorname{AOEFF}(I, J), \operatorname{BOEFF}(I, J), \operatorname{KOEFF}(I, J), \operatorname{HOEFF}(I, J)$

9040 INPUT $\# 3$, CEOHO $(I, J)$

9050 INPUT $3, \mathrm{CE} 1 \mathrm{HO}(I, J), \mathrm{JEOH} 1(I, J)$

9060 INPUT $3, \mathrm{CE} 2 \mathrm{HO}(I, J), \mathrm{CE} 1 \mathrm{H} 1(I, J), \mathrm{CEOH} 2(I, J)$

9070 INPUT $\$ 3, C E 3 H O(I, J), C E 2 H 1(I, J), C E 1 H 2(I, J), C E O H 3(I, J)$

9080 NEXT J

9090 NEXT I

9095 CIOSE 3

$9 I 00 \quad I=0: J=0$

9200 RETURN 
10000 REM-sub for least squares fit to hyperbola

10010 REM - calculate initial so

10020 GOSUB 11000: REM calc s=chi-2

10030 SO $=S$

10040 INPUT"Increment divisor (usually 2) ";INCR

10100 REM - calculate 1st and 2 nd derivitives for minimum cases

$10110 \mathrm{DSDD}=0: \mathrm{D} 2 \mathrm{SDD} 2=0: \mathrm{DSDA}=0: \mathrm{D} 2 \mathrm{SDA} 2=0$

$10120 \mathrm{DSDB}=0: \mathrm{D} 2 \mathrm{SDB} 2=0: \mathrm{DSDC}=0: \mathrm{D} 2 \mathrm{SDC} 2=0$

10130 FOR $K=1$ TO NCAL

$10140 \quad X K=\operatorname{LOG}(\operatorname{ECAL}(\mathrm{K})): \mathrm{YK}=\operatorname{LOG}(\operatorname{EFFCAL}(\mathrm{K}))$

$10150 \quad E Y K=E R R C A L(K) / E F F C A L(K): W T K=E Y K \wedge-2$

$10160 \quad \mathrm{DYK}=\mathrm{D}+\mathrm{A} * \mathrm{SQR}\left(\mathrm{B}^{\wedge} 2+(\mathrm{C}-\mathrm{XK})^{\wedge} 2\right)-\mathrm{YK}$

10170 YKROOT $=S Q R\left(B^{\wedge} 2+(C-X K) \wedge 2\right)$

10180 DSDD $=\mathrm{DSDD}+\mathrm{WTK} * \mathrm{DYK}$

10190 D2SDD2 $=$ D2SDD2 +WTK

$10200 \mathrm{DSDA}=\mathrm{DSDA}+\mathrm{WTK} * \mathrm{YKROOT} * \mathrm{DYK}$

$10210 \mathrm{D} 2 \mathrm{SDA} 2=\mathrm{D} 2 \mathrm{SDA} 2+\mathrm{WTK} *$ YKROOT^2

10220 DSDB=DSDB+WTK*B* $((D-Y K) / Y K R O O T+A)$

$10230 \mathrm{D} 2 S \mathrm{SB} 2=\mathrm{D} 2 \mathrm{SDB} 2+\mathrm{WTK} *\left((\mathrm{D}-\mathrm{YK}) \star(\mathrm{C}-\mathrm{XK}) \wedge 2 / \mathrm{XKROOT}^{\wedge} 3+\mathrm{A}\right)$

$10240 \mathrm{DSDC}=\mathrm{DSDC}+\mathrm{WTK} *(\mathrm{C}-\mathrm{XK}) *((\mathrm{D}-\mathrm{YK}) / \mathrm{YKROOT}+\mathrm{A})$

10250 D2SDC2 $=D 2 S D C 2+W T K \star\left((D-Y K) \star B^{\wedge} 2 / Y K R O O T^{\wedge} 3+A\right)$

10260 NEXT K

$10270 \mathrm{D}=\mathrm{D}-\mathrm{DSDD} / \mathrm{D} 2 S \mathrm{DD} 2 / \mathrm{INCR}$

$10280 \mathrm{~A}=\mathrm{A}-\mathrm{DSDA} / \mathrm{D} 2 \mathrm{SDA} 2 / \mathrm{INCR}$

$10290 \mathrm{~B}=\mathrm{B}-\mathrm{DSDB} / \mathrm{D} 2 \mathrm{SDB} 2 / \mathrm{INCR}$

$10300 \mathrm{C}=\mathrm{C}-\mathrm{DSDC} / \mathrm{D} 2 \mathrm{SDC} 2 / \mathrm{INCR}$

10310 GOSUB 11000:REM - calc new s with above parameters

10320 IF S>SO THEN PRINT:PRINT"Use increment factor $>$ ";INCR:GOTO 10040

10330 IF ABS (S-SO)>.001*SO THEN SO=S:GOTO 10110

10400 REM print results

10410 CLS

10420 PRINT" Fit to hYperbola LNEFF $=\mathrm{D}+\mathrm{A} * \mathrm{SQR}\left(\mathrm{B}^{\wedge} 2+(\mathrm{C}-\mathrm{INEN})^{\wedge} 2\right)$

10440 PRINT"D $=$ ";D

10445 PRINT"A $=" ; A$

10450 PRINT"B $="$ ";

10455 PRINT"C = ";C;" or "; $\operatorname{EXP}(\mathrm{C}) ; " \mathrm{keV} ":$ PRINT

10460 PRINT"Chi-2 = "is

10465 PRINT"Points fitted $=$ "iNCAL:PRINT

10470 INPUT"Press enter to continue"; $\mathrm{ZZ}$

10500 RETURN

11000 REM sub to calculate $s=\mathrm{chi}-2$

$11020 \mathrm{~S}=0$

11030 FOR $K=1$ TO NCAI

$11040 \mathrm{XK}=$ LOG $(\operatorname{ECAL}(K)): Y K=$ LOG $(\operatorname{EFFCAL}(K))$

11050 EYK=ERRCAL $(K) / E F F C A L(K): W T K=E Y K^{\wedge}-2$

$11060 \mathrm{DYK}=\mathrm{D}+\mathrm{A} * \mathrm{SQR}\left(\mathrm{B}^{\wedge} 2+(\mathrm{C}-\mathrm{XK}) \wedge 2\right)-\mathrm{YK}$

$11070 \mathrm{~S}=S+W T K * D Y K^{\wedge} 2$

11080 NEXT K

11100 RETURN

15000 REM - sub to convert pc-grid to lneff vs Inen

15010 LNEN $=((100-19+\mathrm{XEN}) / 100) * \operatorname{LOG}(10)$

$15020 \mathrm{LNEFF}=((100-\mathrm{YEFF}) / 100+\operatorname{LGEFMD}) * \operatorname{LOG}(10)$

15090 RETURN

16000 REM LSQ cubic fit to deviations from hyperbola

$16001 \mathrm{M}=3$

16002 FOR $I=1$ TO $M$

$16003 \mathrm{TD}(I)=0$

16004 FOR $J=1$ TO $M$

16005 TC $(I, J)=0$

16006 NEXT J

16007 NEXT I

16010 FOR $\mathrm{K}=1$ TO $\mathrm{NCAL}$

$16020 \quad \mathrm{XK}=\operatorname{LOG}(\mathrm{ECAL}(\mathrm{K})): \mathrm{YHY} P K=\mathrm{D}+\mathrm{A} \star \mathrm{SQR}\left(\mathrm{B}^{\wedge} 2+(\mathrm{C}-\mathrm{XK}) \wedge 2\right)$

$16025 Y K=($ LOG (EFFCAL (K) ) -D) / (YHYPK-D)

$16030 \mathrm{EYK}=($ ERRCAL $(\mathrm{K}) / \mathrm{EFFCAL}(\mathrm{K})) /(\mathrm{YHYPK}-\mathrm{D}): \mathrm{WTK}=\mathrm{EYK}^{\wedge}-2$

16040 FOR $\mathrm{I}=0$ TO $\mathrm{M}$

$16050 \mathrm{TD}(\mathrm{I})=\mathrm{TD}(\mathrm{I})+\mathrm{WTK} \star \mathrm{YK} \star X K \wedge I$

16060 FOR $\mathrm{J}=0$ TO $M$

$16065 \operatorname{TC}(I, J)=\mathrm{TC}(I, J)+W T K * X K \wedge(I+J)$

16070 NEXT $J$

16080 NEXT I

16085 NEXT K

16090 GOSUB 17000

16100 GOSUB 18000

16110 GOSUB 19000

16200 PRINT: INPUT"Press enter to proceed";ZZ

16300 RETURN 


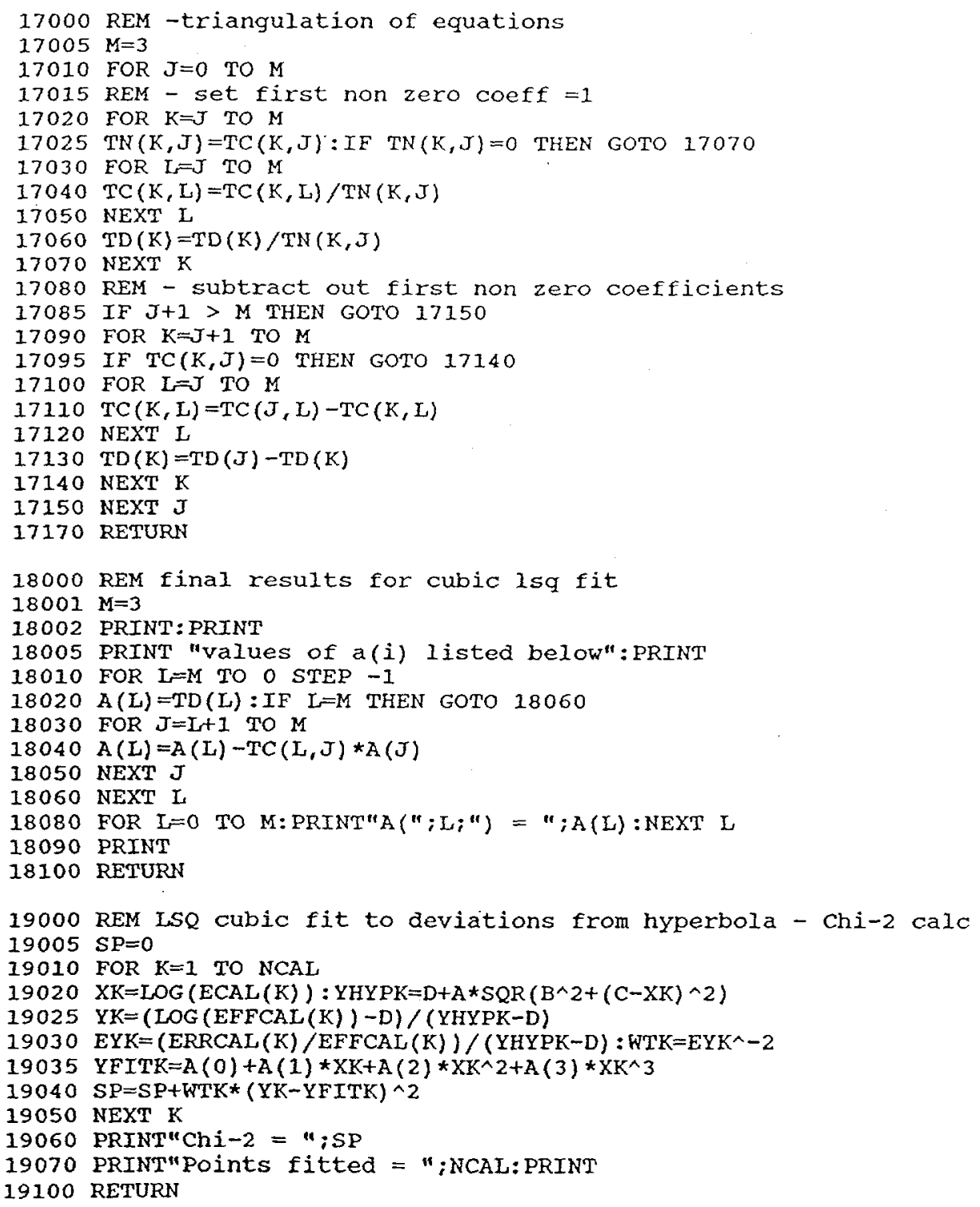


20000 REM- sub to input data for new calib

$20010 \mathrm{CLS}$

20020 PRINT"Select input form of calibration data": PRINT:PRINT

20030 PRINT" (1) Absolute efficiencies": RRINT

20040 PRINT" (2) Efficiency ratios to currently selected detector"

20041 PRINT" (";DETNAM\$ (DETN);")":PRINT

20045 PRINT" (3) None of above - need select different detector fixst":PRINT:PR INT

20050 INPUT"OptION" ; OP:IF OP=3 THEN RETURN

20055 NCAL $=0$

20060 CLS

20070 INPUT"Energy in keV (o if done)";EN:IF EN=0 THEN 20140

20080 NCAL $=N C A L+1: E C A L(N C A L)=E N:$ PRINT

20090 IF OP $=1$ THEN INPUT"EfficienCY"; EFFCAL(NCAL)

20100 IF OP=1 THEN INPUT"ErrOY";ERRCAL(NCAL)

20110 IF OP=2 THEN INPUT"Ratio" ; RATO: EFFCAL (NCAL) =RATO FNEFF (EN)

20120 IF OP=2 THEN INPUT"Error" ;ERATO:ERRCAL(NCAL) =ERATO*FNEFF(EN)

20130 GOTO 20060

20140 CLS:GOSUB 21000:REM - bubble sort of entries

20150 PRINT" Summary of inputs":PRINT

20155 PRINT"Number Energy Efficiency

20156 PRINT" \# 20160 FOR K=I TO NCAL keV \#

Ratio"

\#":PRINT

20170 PRINT USING"\#\#"; K;

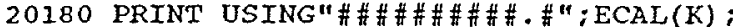

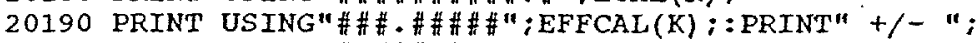

20200 PRINT USING"\#.\#\#\#\#";ERRCAL $(\mathrm{K})$;

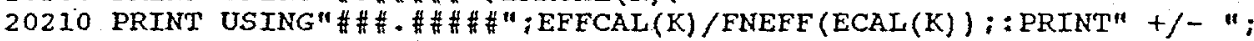

20220 PRINT USING" \#\#\#\#\#";ERRCAL(K)/FNEFF(ECAL(K))

20230 NEXT K

20240 PRINT: INPUT"Need correction $(y / n)$ "; YE\$

20250 INPUT"Print screen as needed - before pressing enter to proceed" ;ZZ

20260 IF YES=" $n$ " THEN 20500

20270 CLS

20280 PRINT" Corrections Menu": PRINT

20285 PRINT" (1) Delete entry"

20290 PRINT" (2) Add entry"

20300 PRINT" (3) Edit entry":PRINT

20310 INPUT"Option": OPE

20320 IF OPE $<>1$ THEN 20380

20330 PRINT:INPUT"Peak number to delete" ; NDEL:NCAI=NCAL-1

20340 FOR K=NDEL TO NCAL

$20350 \operatorname{ECAL}(K)=\operatorname{ECAL}(K+1): \operatorname{EFFCAL}(K)=\operatorname{EFFCAL}(K+1): \operatorname{ERRCAL}(K)=\operatorname{ERRCAL}(K+1)$

20360 NEXT K

20370 GOTO 20140

20380 IF OPE $=2$ THEN 20060

20390 IF OPE $<3$ THEN 20270

20400 PRINT:INPUT"Peak to edit";NED:PRINT

20410 PRINT"Note 0 entries mean no change": PRINT

20420 INPUT"EnergY (keV) "; EN : IF EN>0 THEN ECAL(NED) =EN

20430 IF OP=1 THEN INPUT"EffiCienCY";EFF: IF EFF>0 THEN EFFCAL(NED) =EFF

20440 IF OP=1 THEN INPUT"ErrOY"; EROR:IF ERR>0 THEN ERRCAL(NED)=EROR

20450 IF OP=2 THEN INPUT"Ratio"; RATO:IF RATO>0 THEN EFFCAL(NED)=RATO*FNEFF(EN)

20460 IF OP=2 THEN INPUT"ErrOY"; ERATO: IF ERATO>0 THEN ERRCAL(NED)=ERATO*FNEFF(EN )

20470 GOTO 20140

20500 RETURN

21000 REM - bubble sort to order en with eff and err

21010 FOR $K=1$ TO NCAL-1

21020 FOR $J=1$ TO NCAL-K

21030 IF $\operatorname{ECAL}(J+1)>\operatorname{ECAL}(\mathcal{J})$ THEN 23070

$21040 \operatorname{ECAL}=\operatorname{ECAL}(J+1): \operatorname{ECAL}(J+1)=\operatorname{ECAL}(J): \operatorname{ECAL}(J)=\operatorname{ECAL}$

$21050 \operatorname{EFFCAL}=\operatorname{EFFCAL}(J+1): \operatorname{EFFCAL}(J+1)=\operatorname{EFFCAL}(J): \operatorname{EFFCAL}(J)=\operatorname{EFFCAL}$

$21060 \operatorname{ERRCAL}=\operatorname{ERRCAL}(J+1): \operatorname{ERRCAL}(J+1)=\operatorname{ERRCAL}(J): \operatorname{ERRCAL}(J)=\operatorname{ERRCAL}$

21070 NEXT $J$

21080 NEXT $K$

21100 RETURN

34000 REM - transform detector parameters to usual notation

$34040 \quad G O E F F=E X P(D): A O E F F=A: B O E F F=B:$ UOEFF $=1: K O E F F=C$

$34050 \mathrm{COEFF}=\mathrm{A}(0): \mathrm{C} 1 \mathrm{EFF}=\mathrm{A}(1): \mathrm{C} 2 \mathrm{EFF}=\mathrm{A}(2): \mathrm{C} 3 \mathrm{EFF}=\mathrm{A}(3)$

$34060 \mathrm{ENX}=5000: \mathrm{DOEFF}=0: \mathrm{D} 1 \mathrm{EFF}=0: \mathrm{D} 2 \mathrm{EFF}=0: \mathrm{D} 3 \mathrm{EFF}=0$

34070 POEFF $=0: P 1 E F F=0: P 2 E F F=0: P 3 E F F=0$

34100 RETURN 
35000 REM - make detector calibration file

35010 PRINT: PRINT

35020 INPUT"Entire detector calibration file label (- - - - - . DCF) ";EFFCALS

35030 PRINT:PRTNT"File label is ";EFFCAL\$;:INPUT" OK(Y/n)";YE\$:IF YE\$ $>$ "Y" THEN

COTO 35010

35080 PRINT: INPUT"Examine transformed data before making file $(y / n) " ; Y E S$

35090 IF YES $<$ "Y" THEN 35200

35100 Crs

35110 GOSUB 60000:REM eff check list

35120 PRINT:INPUT"Stili wish to make file $(y / \pi)$ ";YES

35130 IF YE $\$=" n "$ THEN EFFCALS="NO efficiency file made" : GOTO 35500

35200 OPEN EFFCALS FOR OUTPUT AS 3

35210 WRITE $\$ 3$, GOEFF, AOEFF, BOEFF, UOEFE, KOEFF, COEFF, C1EFF, C2EFF, C3EFF

35220 WRITE 3 , ENX, DOEFF, DIEFF, D2EFF, D3EFF, POEFF, PIEFF, P2EFF, P3EFF

35230 CLOSE 3

35500 RETURN

36000 REM - sub to printout results

36010 CLS: INPUT"Line feed printer as needed, and press enter to print"; $z Z$

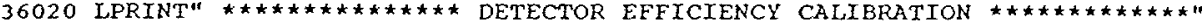

36030 LPRINT:LPRINT

36040 LPRINT"Title: ";NACALS:LPRINT

36050 LPRINT"Calibration file generated: ";EFFCALS:LPRINT

36330 REM - this segment on file DETPRINT. BAS in A-format

36335 LPRINT

36355 LPRINT"

36370 LPRINT

36380 LPRINT"Efficiency calibration: EFF $=G * E X P$ (HYPERBOLA * POLYNOMIAL)* $(1+$ PERT URBATION)"

36385 LPRINT

36390 IPRTNT

F)

36395 LPRINT

36400 LPRINT"

36410 LPRINT*

36415 LPRINT

36420 LPRINT"

ues below:"

36430 LPRINT"

$G=$ global calibration factor $=$ ";GOEFF;" $D=\operatorname{LN}(G)=$ ":LOG(GOEF

HYPERBOLA $=A \star S Q R\left(B^{\wedge} 2+(\operatorname{LN}(E N)-C) \wedge 2\right)$ with values below:

$(A=$ ( $A O E F F ; " B=" ; B O E F F ; " C=$ ";KOEFF;")"

POLYNOMIAL $=C 0+C 2 * \operatorname{LN}(E N)+C 2 * \operatorname{LN}(E N) \wedge 2+C 3 * \operatorname{LN}(E N) \wedge 3$ with val

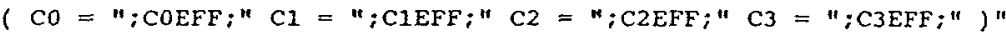

36432 LPRINT*

w) cases"

";ENX;" $\mathrm{keV}=$ crossover between low EN (above) and high EN (belo

36434 LPRINT"

$(\mathrm{co}=$ ":TOEFF;" $\mathrm{C} 1=$ ";TIEFF;" $\mathrm{C} 2=$ ":T2EFF;" $\mathrm{C} 3=$ ":T3EFF;" )"

36435 LPRINT

36440 LPRINT"

PERTURBATION $=P O+P 1 * L N(E N)+P 2 * I N(E N) \wedge 2+P 3 * I N(E N) \wedge 3$ with $v$

alues below:"

36450 LPRINT"

$(\mathrm{PO}=$ ";POEFF;" $\mathrm{P1}=$ ";P1EFF;" $\mathrm{P2}=$ ":P2EFF;" P3 = ";P3EFF;" )"

36460 LPRINT

36470 LPRINT*

36480. TPRINT

36505 LPRINI"Comparison of measured (Eff) and calculated (Hypeff) results"

36506 LPRINT:LPRINT

36507 LPRINT" Peak Energy Eff Hypeff Diff"

36508 LPRINT" \# keV \# \# \# \#PRINT

36509 TOTDEV $=0:$ RMSDEV $=0$

36510 FOR $K=1$ TO NCAL

36512 LNEN $=$ LOG $(\operatorname{ECAL}(\mathrm{K}))$

$36515 \operatorname{LNEFF}=D+A * \operatorname{SQR}\left(B^{\wedge} 2+(\operatorname{LNEN}-C) \wedge 2\right) *(A(0)+A(1) * \operatorname{LNEN}+A(2) * \operatorname{LNEN} \wedge 2+A(3) * \operatorname{LNEN} \wedge 3)$

36520 DEVEFF $=$ LOG (EFFCAL (K) )-LNEFF

36525 TOTDEV=TOTDEV+DEVEFF : RMSDEV=RMSDEV+DEVEFF^ 2

36530 LPRINT USING" \#"

36531 LPRINT USING"

.36532 LPRINT USING"

36533 LPRINT USING"

36534 LPRINT USING" \#\# \#\#":100*DEVEFF

36540 NEXT $K$

36545 LPRINT:LPRINT"RMS deviation = ;:LPRINT USING"\#\#.\#";100*SQR (RMSDEV/NCAL)

;:LPRINT" \&"

36550 LPRINT:LPRINT"Average deviation = ": :LPRINT USING"\#\#-\#\#";100*TOTDEV/NCAL;

:LPRINT" है"

36560 LPRTNT: LPRINT"Chi-2 for hyperbola $=$ "iS:IF S=0 THEN 36580

36570 LPRINT"SQR (Chi-2/n-r) = "iSQR (S/(NCAL -4))

36580 LPRINT:LPRINT"Chi-2 for cubic perturbation = ":SP:IF SP=0 THEN 36600

36590 IPRINT"SQR (Chi-2/n-r) $=$ "iSQR (SP/ (NCAL-4))

36600 LPRINT

36610 LPRINT"

36620 LPRINT: LPRINT

36655 LPRINT"Number

36656 LPRINT" \#

36660 FOR $K=1$ TO NCAL

(

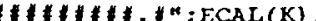

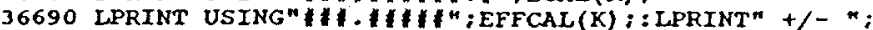

36700 LPRINT USING" : IIIF"; ERRCAL $(\mathrm{X})$ :

36710 LPRINT USING" II I INI";EFFCAL(K)/FNEFF(ECAL(K)): :LPRINTN +/- ";

36720 LPRINT USING" IIf " IERRCAL(K)/FNEFF(ECAL(K))

36730 NEXT $K$

36900 RETURN 
42000 REM- sumary of hyperbola fit - tabular

42801 CLS:SCREEN 2 :SCREEN 0

42805 PRINT"Comparison of measured (Eff) and calculated (Hypeff) results"

42806 PRINT: PRINT

42807 PRINT"Peak Energy Eff Hypeff Diff"

42808 PRINT"

42809 TOTDEV $=0:$ RMSDEV $=0$

42810 FOR $K=1$ TO NCAL

42812 LNEN $=$ LOG $(E C A L(K))$

$42815 \operatorname{LNEFF}=D+A * \operatorname{SQR}\left(B^{\wedge} 2+(\operatorname{LNEN}-C) \wedge 2\right) *(A(0)+A(1) \star \operatorname{LNEN}+A(2) \star \operatorname{INEN\wedge } 2+A(3) * \operatorname{LNEN\wedge } 3)$

42820 DEVEFF $=$ LOG $($ EFFCAL $(K))$ - LNEFF

42825 TOTDEV=TOTDEV+DEVEFF: RMSDEV=RMSDEV+DEVEFF^ 2

42830 PRINT USING"

42831 PRINT USING"

42832 PRINT USING"

42833 PRINT USING"

42834 PRINT USING"

42840 NEXT $K$

42845 PRINT:PRINT"RMS deviation = ": :PRINT USING" $\# \#$ - \#":100*SQR(RMSDEV/NCAL) $:: \mathrm{P}$ RINT"

42850 PRINT:PRINT"Average deviation $="::$ PRINT USING"\#\#.\#\#":100*TOTDEV/NCAL;:PR

INT" \&"

42900 RETURN

46000 REM - subroutine from line 46 - detector efficiencies - part 1

46005 DETLABS (6) ="<normal >": OTHERDETS="<normal >. DCF"

46010 PRINT "Efficiency calibration - select detector below"

46030 PRINT

46040 PRINT " $\quad$ (1) Bottom-old"

46045 PRINT " (2) Bottom-new"

46050 PRINT " (3) PGT-top"

46055 PRINT " $\quad$ (4) N-side"

46060 PRINT" $\quad$ (5) Well"

46062 PRINT " (6) Other"

46065 PRINT

46070 INPUT"Detector number" : DETN

46090 RETURN

46100 REM - subroutine from line 47 - detector efficiencies - part 2

46105 CLS: OPTDT6 $=0$

$46110 \mathrm{GOEFF}=1: \mathrm{AOEFF}=1: \mathrm{BOEFF}=1: \mathrm{UOEFF}=0: \mathrm{COEFF}=1: \mathrm{ClEFF}=0: \mathrm{C} 2 \mathrm{EFF}=0: \mathrm{C} 3 \mathrm{EFF}=0$

46115 POEFF $=0: P I E F F=0: P 2 E F F=0: P 3 E F F=0: D O E F F=0: D 1 E F F=0: D 2 E F F=0: D 3 E F F=0: E N X=5000$

46117 IF DETN $=6$ THEN GOSUB 47000

46118 PRINT:IF OPTDT6=1 THEN GOSUB 46500

46119 IF OPTDT $6>0$ THEN 46200

46120 PRINT"Efficiency calibration data for ";DETNAMS(DETN)

46130 PRINT

46140 PRINT" (1) Special samples (manual input)"

46145 PRINT" . (2) Diaper samples (auto input)"

46150 PRTNT" (3) Well samples (auto input)"

46160 PRINT" (4) Vial samples (auto input)"

46165 PRINT

46170 INPUT"Calibration case number" ;OPNUM: PRINT

46180 ON OPNUM GOSUB $46500,46700,46800,46900$

46190 REM eff sub-parts $2 \mathrm{a} 2 \mathrm{~b} 2 \mathrm{c} 2 \mathrm{a}$

46200 RETURN

46500 REM - manual input efficiencies - part 2a of efficiency calcs/1ine46180 46505 INPUT'Type of fit - (0) None<eff=1> (1) Polynomial, (2) Hyperbola, (3) Bot h ": PHB: PRINT

46510 ON PHB GOTO $46600,46530,46520$

46515 IF $\mathrm{PHB}=0$ THEN $A O E F F=0:$ GOTO 46690

$46520 \mathrm{PRINT"LN}(E F F)=D+A * \operatorname{SOR}\left(\mathrm{B}^{\wedge} 2+(\operatorname{LN}(E)-C) \wedge 2\right) *(C O+C 1 * \operatorname{LN}(E)+C 2 * \operatorname{LN}(E) \wedge 2+$

$\mathrm{C} 3 * \operatorname{LN}(\mathrm{E}) \wedge 3)^{\prime \prime}$

46525 IF PHB $=3$ THEN GOTO 46535

46530 PRINT"LN(EFF) $=D+A * S Q R\left(B^{\wedge} 2+(L N(E)-C) \wedge 2\right) ": P R I N T$

46535 UOEFF $=1$

46540 INPUT" D" ; DAEFF :GOEFF=EXP (DAEFF)

46550 INPUT" A" ; AOEFF

46560 INPUT" B" :BOEFF

46570 INPUT" C": KOEFF

46590 IF $\mathrm{PHB}=3$ THEN GOTO 46620

46595 IF $P H B=2$ THEN GOTO 46690

46600 PRINT"LN $(E F F)=C 0+C 1 * \operatorname{LN}(E)+C 2 * \operatorname{LN}(E) \wedge 2+C 3 * \operatorname{LN}(E) \wedge 3 " ; \operatorname{PRINT}$

46610 UOEFF $=0$

46612 INPUT" Crossover energy (keV)..... if none enter o ";ENX:IF ENX=0 THEN ENX

$=5000$

46614 PRINT" Coefficients below crossover point"

46630 INPUT"

46640 INPUT"

46650 INPUT"

46651 IF ENX

46652 PRINT"

46655 INPUT"

46660 INPUT"

46665 INPUT"

46665 INPUT"
46670 INPUT"

46690 RETURN

CO" : COEFF

CI" : CIEFF

$\mathrm{C} 2^{n} ; \mathrm{C} 2 \mathrm{EFF}$

C3"; C3EFF: IF PHB=3 THEN GOTO 46690

5000 THEN GOTO 46690

Coefficients above crossover point"

CO" ; TOEFF: DOEFF=TOEFF-COEFF

CI" : T1EFF:DIEFF $=$ TIEFF-CIEFF

C2";T2EFF : D2EFF=T2EFF-C2EFF

C3n ;T3EFF: D3EFF=T3EFF-CJEFF 
46700 REM - diaper coefficients effs - part 2b of efficiency calib/line 46180 46710 IF DETN=1 THEN COEFF $=-32.9019: \mathrm{C} 1 \mathrm{EFF}=15.5286: \mathrm{C} 2 \mathrm{EFF}=-2.63121: \mathrm{C} 3 \mathrm{EFF}=.137454$ 46720 IF DETN=2 THEN COEFF $=-33.7619: \mathrm{C} 1 \mathrm{EFF}=15.949: \mathrm{C} 2 \mathrm{EFF}=-2.69313: \mathrm{C} 3 \mathrm{EFF}=.141663$ 46730 IF DETN=3 THEN COEFF $=-44.2381: \mathrm{C} 1 \mathrm{EFF}=21.0238: \mathrm{C} 2 \mathrm{EFF}=-3.50398: \mathrm{C} 3 \mathrm{EFF}=.183542$ 46740 IF DETN=4 THEN PRINT"not available - make another choice" 46750 IF DETN=5 THEN $C O E F F=-30.373: C 1 E F F=14.4228: C 2 E F F=-2.4183: C 3 E F F=.125452$ 46760 RETURN

46800 REM - well coefficients effs - part 2c of efficiency calib/line 46180 46810 IF DETN $>5$ THEN PRINT "NOT APPLICABLE - MAKE ANOTHER CHOICE"

46820 UOEFF $=1: A O E F F=-.921 * \operatorname{SQR}(1.6952): \operatorname{BOEFF}=\operatorname{SQR}(1.21 / 1.6952): \mathrm{KOEFF}=\operatorname{LOG}(60)$

46830 GOEFF $=\operatorname{EXP}(.921 * .9)$

46850 RETURN

46900 REM - vial coefficients effs - part 2 d of efficiency calib/line 46180

46910 PRINT"Vial sizes": PRINT

46911 PRINT" (1) Large"

46912 PRINT" (2) Medium"

46913 PRINT" (3) Smali" : PRINT

46920 INPUT"Vial size number"; VIALN: PRINT

46930 INPUT"Vial sample height (mm) "; HMM:H=HMI/IO

46940 UOEFF $=1:$ : OEFF $=$ AOEFF $(D E T N$, VIALN $): B O E F F=B O E F F(D E T N$, VIALN $):$ KOEFF $=$ KOEFF (DETN ,V IALN)

46950 POEFF $=$ CEOHO $(D E T N$, VIALN $)+C E O H 1(D E T N$, VIALN $) * H+C E O H 2($ DETN, VIALN $) * H^{\wedge} 2+C E O H 3(D E$ TN, VIALN) * $\mathrm{H}^{\wedge} 3$

46955 P1EFF $=$ CEIHO $($ DETN , VIALN $)+C E 1 H 1($ DETN , VIALN $)$ * H+CE1H2 (DETN, VIALN $) * H^{\wedge} 2$

$46960 \mathrm{P} 2 \mathrm{EFF}=\mathrm{CE} 2 \mathrm{HO}(\mathrm{DETN}, \mathrm{VIALN})+\mathrm{CE} 2 \mathrm{HI}(\mathrm{DETN}, \mathrm{VIALN}) * \mathrm{H}$

46965 P3EFF $=$ CE3HO (DETN, VIAIN)

46970 GOEFF=GOEFF (DETN, VIALN $) /(H+\operatorname{HOEFF}(D E T N, \operatorname{VIALN}))^{\wedge} 2$

46975 DAEFF $=$ LOG (GOEFF)

46990 RETURN

47000 REM- sub for detector $\# 6$ (other detector)

47001 ON ERROR GOTO 47120

47002 CLS

47003 INPUT"Descriptive name of detector"; DETNAMS(6):PRINT: PRINT

47015 PRINT"Detector efficiency options": PRINT

47020 PRINT" (1) Manual input (includes eff=1 case)

47030 PRINT" (2) File input":PRINT

47040 INPUT"Option"; OPTDT6

47050 IF OPTDT6 $<>2$ THEN 47200

47060 PRINT:PRINT

47070 INPUT"Detector calibration file (-.-.-. DCF) ";OTHERDET\$

47080 OPEN OTHERDET\$ FOR INPUT AS \#3

47090 INPUT \#3, GOEFF, AOEFF, BOEFF, UOEFF, KOEFF, COEFF, C1EFF, C2EFF, C3EFF

47100 INPUT \$3,ENX, DOEFF, DIEFF, D2EFF, D3EFF, POEFF, PIEFF, P2EFF, P3EFF

47110 CLOSE \#3

47120 IF ERR=53 THEN PRINT: INPUT"Above file not found. Press return for retry"; $\mathrm{Z}:$ CLS:RESUME 47000

47200 RETURN

50000 REM - sub to plot data points

50010 FOR $\mathrm{K}=1$ TO NCAL

$50020 \mathrm{XEN}=19+100 * \operatorname{LOG}(\operatorname{ECAL}(\mathrm{K})) / \operatorname{LOG}(10)-100$

50030 YEFF $=100-100 *$ ( IOG(EFFCAL(K))/LOG (10) - LGEFMD)

50040 YEFFA $=100-100 *(\operatorname{LOG}(\operatorname{EFFCAL}(\mathrm{K})+\operatorname{ERRCAL}(\mathrm{K})) /$ LOG $(10)$ - LGEFMD )

50050 YEFFB $=100-100 *(\operatorname{LOG}(\operatorname{EFFCAL}(\mathrm{K})-\operatorname{ERRCAL}(K)) /$ LOG $(10)$ - LGEFMD $)$

50060 LINE $(X E N-1, Y E F F-1)-(X E N+1, Y E F F+1), 3, B: R E M$ point plotted

50070 LINE (XEN, YEFFA) - (XEN, YEFFB), 3:REM error plotted

50080 NEXT K

50900 RETURN 
51000 REM - subroutine for graph paper

51600 REM - plot initial results and continue analysis

51610 SCREEN $1:$ CLS

51620 COLOR 8,0

51625 MINEFF $=1:$ MAXEFF $=0$

51630 FOR $K=1$ TO NCAL: REM find graph limits

51632 IF EFFCAL (K) >MAXEFF THEN MAXEFF $=\operatorname{EFFCAL(K)}$

51634 IF EFFCAL (K) $\angle M I N E F F$ THEN MXNEFF $=\operatorname{EFFCAL(K)}$

51636 NEXT K

51640 LGEFMD $=($ LOG $($ MAXEFF $)+\operatorname{LOG}($ MINEFF $)) /(2 *$ LOG $(10)): R E M$ mid $y-a x$ is

$51650 \operatorname{LINE}(19,0)-(319,199), 1, B: \operatorname{REM}$ draw axis frame

$51651 \operatorname{LINE}(119,0)-(119,199), 1$

51652 LINE $(219,0)-(219,199), 1$

51654 IF LGEFMD = INT (IGEFMD) THEN YGR1=100:YGR2=100: $\operatorname{LTNE}(19,100)-(319,100), 1: G 0$

To 660

51655 YGR1 $=\operatorname{INT}(100+100 *($ LGEFMD-INT (LGEFMD) $)$

51656 IF GRI<199 THEN $\operatorname{LINE}(19$, YGR1)-(319, YGR1), 1

51657 YGR2 $=$ YGR $1-100$

51658 IF YGR2>0 THEN LINE(19,YGR2)-(319,YGR2), 1

51660 FOR XXGRID=19 TO 219 STEP 100

51662 FOR XGRID $=1$ TO 10

51664 XTIC $=\operatorname{INT}(100 * \operatorname{LOG}($ XGRID)/LOG $(10)+.5)+$ XXGRID

51666 LINE (XTIC, 0)-(XTIC, 5), 1

51667 LINE (XTIC, 199)-(XTIC, 194), 1

51668 NEXT XGRID

51669 NEXT XXGRID

51670 FOR YYGRID=YGR1+100 TO YGR2 STEP - 100

51671 FOR YGRID=1 TO 10

51672 YTIC=YYGRID - INT (100*IOG (YGRID)/LOG $(10)+.5)$

51673 IF YTIC > 199 THEN 51677

51674 IF YTIC $<0$ THEN 51677

$51675 \operatorname{LINE}(29$, YTIC) $-(24$, YTIC $), 1$

51676 LINE (319, YTIC)-(314, YTIC), 1

51677 NEXT YGRID

51678 NEXT YYGRID

51900 RETURN

52000 REM - sub to draw point

$52010 \operatorname{LINE}(X P-1, Y P-1)-(X P+1, Y P+1)$, COLOUR, BF

52030 RETURN

52100 REM - sub to erase point

52110 LINE $(X P-1, Y P-1)-(X P+1, Y P+1), 0, B F$

52130 RETURN

52200 REM - sub to move red point for max of hyperbola

52210 VECT $\$=$ INKEY $\$$ : IF VECT $\$="$ " THEN 52210

52220 IF INT(VAL(VECTS)/2) < VAL(VECT\$)/2 THEN 52270

$52225 X P=X R: Y P=Y R: G O S U B 52100$

52230 IF VECT $\$=" g$ " THEN YR=YR-1:XP=XR:YP=YR: COLOUR=RED:GOSUB 52000:GOTO 52210

52235 IF VECT $\$=" 2$ " THEN $Y R=Y R+1: X P=X R: Y P=Y R: C O L O U R=R E D: G O S U B$ 52000:GOTO 52210

$52240 \quad X P=X Y: Y P=Y Y:$ GOSUB 52100

52245 TF VECT $=" 6$ " THEN 52260

$52250 \mathrm{XR}=\mathrm{XR}-1: \mathrm{XP}=\mathrm{XR}: \mathrm{YP}=\mathrm{YR}:$ COLOUR=RED: GOSUB 52000

$52255 X Y=X Y-I: X P=X Y: Y P=Y Y: C O I O U R=Y E I T O W: G O S U B \quad 52000:$ GOTO 52210

$52260 X R=X R+1: X P=X R: Y P=Y R: C O I O U R=R E D: G O S U B \quad 52000$

$52265 X Y=X Y+1: X P=X Y: Y P=Y Y: C O L O U R=Y E L I O W: G O S U B \quad 52000:$ GOTO 52210

52270 IF VECT\$<> " 5 ." THEN 52210

52290 RETURN

52300 REM - sub to move yellow point for origin of hyperbola

52310 VECT $\$=$ INKEY $\$$ IF VECT $\$=N$ THEN 52310

52320 IF INT (VAL (VECT\$)/2) < VAL(VECT\$)/2 THEN 52370

$52325 X P=X Y: Y P=X Y: G O S U B 52100$

52330 IF VECT $\$=" B "$ "THEN $Y Y=Y Y-1: X P=X Y: Y P=Y Y: C O L O U R=Y E L L O W: G O S U B$ 52000:GOTO 52310

52335 IF VECT $\$=2 "$ THEN $Y Y=Y Y+1: X P=X Y: Y P=Y Y: C O L O U R=Y E L L O W: G O S U B$ 52000:GOTO 52310

$52340 \quad X P=X R: Y P=Y R: G O S U B \quad 52100$

52345 IF VECT $\$=164$ THEN 52360

$52350 X R=X R-1: X P=X R: Y P=X R: C O L O U R=R E D: G O S U B 52000$

$52355 X Y=X Y-1: X P=X Y: Y P=Y Y: C O L O U R=Y E L L O W: G O S U B \quad 52000:$ GOTO 52310

$52360 X R=X R+1: X P=X R: Y P=Y R: C O L O U R=R E D: G O S U B \quad 52000$

$52365 X Y=X Y+1: X P=X Y: Y P=Y Y: C O I O U R=Y E L L O W: G O S U B \quad 52000: G O T O 52310$

52370 TF VECTS $>$ "5". THEN 52310

52390 RETURN

$52400 \mathrm{REM}$ - sub to move green point for asymptote of hyperbola

52410 VECT $\$=$ INKEY $\$$ IF VECT\$=" THEN 52410

52420 IF INT(VAL(VECT\$)/2) < VAL (VECT\$) $/ 2$ THEN 52470

$52425 X P=X G: Y P=Y G: G O S U B \quad 52100$

52430 IF VECT $=" B^{\prime \prime}$ "THEN YG=YG-1:XP=XG: YP=YG:COLOUR=GREEN : GOSUB $52000: G 0 T 052410$

52435 IF VECT $\$=2 "$ THEN YG $=Y G+1: X P=X G: Y P=Y G:$ COLOUR=GREEN : GOSUB 52000:GOTO 52410

52445 IF VECT $\$=" 6 "$ THEN 52460

52450 XG=XG-1:XP=XG:YP=YG:COLOUR=GREEN:GOSUB 52000 : GOTO 52410

$52460 X G=X G+1: X P=X G: Y P=Y G:$ COLOUR=GREEN : GOSUB 52000 : GOTO 52410

52470 IF VECT\$<>"5" THEN 52410

52490 RETURN 
52500 REM - sub to draw hyperbola characteristics

52510 LINE (XR, YR) - (XY, YY), GREEN

$52520 \operatorname{LINE}(X Y, Y Y)-(X G, Y G), G R E E N$

$52530 \quad X R E=X R: Y R E=Y R: X Y E=X Y: Y Y E=Y Y: X G E=X G: Y G E=Y G$

52590 RETURN

52600 REM - sub to erase hyperbola characteristics

52610 LINE (XRE, YRE) - (XYE, YYE), 0

52620 LINE (XYE, YYE) - (XGE, YGE) 0

52690 RETURN

53000 REM - sub to plot hyperbola calib

53780 CIS:GOSUB 51000:GOSUB 50000

53785 FOR $X E N=20$ TO 318

53787 LNEN $=((100-19+\mathrm{XEN}) / 100) \star \operatorname{LOG}(10)$

$53788 \mathrm{LNEFF}=\mathrm{D}+\mathrm{A} \star S Q R\left(\mathrm{~B}^{\wedge} 2+(\operatorname{LNEN}-C) \wedge 2\right) *\left(\mathrm{~A}(0)+\mathrm{A}(1) \star \operatorname{LNEN}+\mathrm{A}(2) * \operatorname{LNEN}^{\wedge} 2+A(3) * \operatorname{LNEN}^{\wedge} 3\right)$

53789 YEFF $=100-100 *$ (LNEFF/LOG (10) - LGEFMD)

53790 IF $Y E F F>198$ THEN 53795

53791 IF $Y E F F<I$ THEN 53795

53792 PSET (XEN, YEFF) RED

53795 NEXT XEN

53796 GOSUB 50000

53900 RETURN

56000 REM - subroutine for graph paper

56600 REM - plot initial results and continue analysis

56610 SCREEN 1:CIS

56620 COLOR 8,0

56625 MINEFF $=1:$ MAXEFF $=0$

56630 MAXEFF $=$ FNEFF $(100)$

56632 MINEFF=MAXEFF $/ 30$

56640 LGEFMD $=($ LOG $($ MAXEFF $)+\operatorname{LOG}($ MINEFF $)) /(2 *$ LOG $(10)):$ REM mid $Y$-axis

$56650 \operatorname{LINE}(19,0)-(319,199), 1, \mathrm{~B}:$ REM draw axis frame

56651 LINE $(119,0)-(119,199), 1$

$56652 \operatorname{LINE}(219,0)-(219,199), 1$

56654 IF LGEFMD $=$ INT (LGEFMD) THEN YGRI=100:YGR2=100: LINE $(19,100)-(319,100), 1: G 0$

TO 56660

56655 YGRI $=$ INT $(100+100 *($ LGEFMD-INT(LGEFMD) )

56656 IF GR1<199 THEN LINE(19,YGR1)-(319,YGR1), I

56657 YGR2 $=$ YGR $1-100$

56658 IF YGR2>0 THEN $\operatorname{LINE}(19, Y G R 2)-(319, Y G R 2), 1$

56660 FOR XXGRID $=19$ TO 219 STEP 100

56662 FOR XGRID=2 TO 10

56664 XTIC $=$ INT $(100 *$ LOG $($ XGRID $) / \operatorname{LOG}(10)+.5)+$ XXGRID

56666 LINE (XTIC, 0)-(XTIC, 5), I

56667 LINE (XTIC, 199)-(XTIC, 194), 1

56668 NEXT XGRID

56669 NEXT XXGRID

56670 FOR YYGRID=YGR1+100 TO YGR2 STEP - 100

56671 FOR YGRID=1 TO 10

56672 YTIC $=$ YYGRID - INT (100*LOG (YGRID)/LOG $(10)+.5$ )

56673 IF YTIC $>199$ THEN 56677

56674 IF YTIC < 0 THEN 56677

56675 LINE (19, YTIC)-(24, YTIC), 1

56676 LINE (319, YTIC)-(314,YTIC), 1

56677 NEXT YGRID

56678 NEXT YYGRID

56900 RETURN

58000 REM - sub to plot FNEFF

58780 RED $=2$

58785 FOR XEN $=20$ TO 318

58787 LNEN $=((100-19+$ XEN $) / 100) *$ LOG $(10)$

58788 LNEFF $=$ LOG (FNEFF (EXP (LNEN))

58789 YEFF $=100-100 *$ (LNEFF/LOG $(10)$ - LGEFMD)

58790 IF YEFF $>198$ THEN 58795

58791 IF YEFF $<1$ THEN 58795

58792 PSET (XEN, YEFF), RED

58795 NEXT XEN

58900 RETURN

60000 REM temp check on eff

60005 PRINT"Efficiency (EFF) per standard energy (EN) for ":EFFCALS

60006 PRINT

60010 PRINT "EN", "EFF"

60011 PRINT"k "EV" " "EFF"

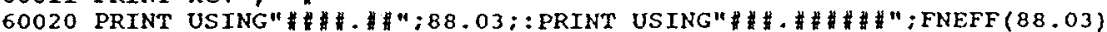

60030 PRINT USING" \#\#.\#";122.06;:PRINT USING"\#\#\#\#\#\#";FNEFF(122.06)

60040 PRINT USING"\#\#.\#";165.85;:PRINT USING"\#\#.\#\#\#" ;FNEFF(165.85)

60050 PRINT USING"

60060 PRINT USING"

60070 PRINT USING"

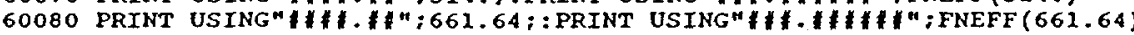

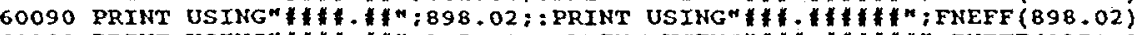

60100 PRINT USING"

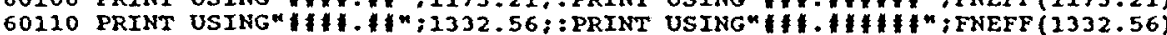

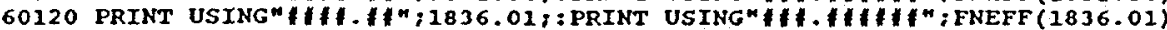

60130 PRINT: INPUT" Ready to proceed - press enter.", $z z$

60140 RETURN 
61000 REM month days data

61010 DATA $31,28,31,30,31,30$

61020 DATA $31,31,30,31,30,31$

62000 REM - data for mass atten coeffs in barns/atom - convert to cm-1 by $62010 \mathrm{REM}$ - multiplying by $0.008297 \times 5.35 \mathrm{gm} / \mathrm{cm} 3$

62020 REM Energy (keV) b/atom, etc

62030 DATA $15,11000,20,5070,30,1680,40,746,50,400,60,243,80,115$

62040 DATA $100,66.4,150,29.6,200,20.0,300,13.5,400,11.2,500,9.87$

62050 DATA $600,8.96,800,7.73$

62060 DATA $1000,6.89,1500,5.60,2000,4.92,3000,4.24,4000,3.95,5000,3.81$ 
WSRC-TR-99-00187

GRABDKR1: Program structure Reference

Main

s-- Subroutines and [files]

$1-12 / D I M$ and COMMON

16-18/CRT \#1: printer

19-38/CRT \#2: intro

$29 /$ Peak initl

31/Detrs : Efficy <--- 9000-9200/Vial Data

$<---[B: D E T L I B R Y$.LIB]

32/Detrs : Names

39/CRT \#3: Info <--- 5000-5190/User background and rates

40-47/CRT \#4: Energy <--- 40000-40100/E vs chn

: FWHM <-- 43000-43100/E VS FWHM

: Detrs <-- 46000-46090/Detector selection

50-51/CRT \#5: Efficy <--- 46100-46200/Driver for choices

$<--47000-47200 /$ Other Detector

- [backgnd. BKG]

<-- [detreff. DCF]

(-- 46500-46690/Manual input

$<--46700-46760 /$ Air filters

<-- 46800-46850/Well samples

<-- 46900-46990/Vial samples

58-63/Efficy: Functs <--- 60000-60140/CRT effs VS Es

64-298/CRT \#6: Spect <- [ [spectrum. CHN] leader

: Analys <-- 1000-1999/parameter selection <-- 11000-11500/Print input data

300-390/Spect : Readin <--- [spectrum. CHN] spectrum counts/chn

: Peaks <-- 2000-2900/Find peak driver

<-- 12000-12120/3-rope/CRT peak init

<-- 12400-12430/2-ch rope filter

<-- 12500-12530/4-ch rope filter

<--- 12600-12630/8-ch rope filter

<--- 12200-12290/Peak resolver

$400 /$ Chain GRABDKR2

$500 /$ stop 
1 'VERSION GRABDKRI

$2 \operatorname{DIM} H 1(150), \mathrm{H} 2(150), \operatorname{GOEFF}(5,3), \operatorname{HOEFF}(5,3), \operatorname{AOEFF}(5,3), \operatorname{BOEFF}(5,3), \operatorname{KOEFF}(5,3), A(2$

0), MINXM(20), MCENT (20)

3 COMMON HI ( ), H2 (), GOEFF( ), HOEFF(), AOEFF(), BOEFF(), KOEFF(), A (), MINXM(), MCENT()

4 DIM CEOHO $(5,3), \operatorname{CE} 1 \mathrm{HO}(5,3), \operatorname{CEOHI}(5,3), \operatorname{CE} 2 \mathrm{HO}(5,3), \operatorname{CE} 1 \mathrm{H} 1(5,3), \mathrm{CEOH} 2(5,3), \mathrm{CE} 3 \mathrm{HO}(5$,

3), $\operatorname{CE} 2 \mathrm{H} 1(5,3), \operatorname{CE} 1 \mathrm{H} 2(5,3), \operatorname{CEOH} 3(5,3), \operatorname{GEOM} \$(10)$

5 COMMON CEOHO(), CE1HO(), CEOH1(), CE2HO(), CE1H1(), CEOH2(), CE3HO(), CE2H1(), CEIH2() , $\mathrm{CEOH} 3(), \mathrm{GEOMS()}$

6 DIM YLOC (20), DETNAM\$ (10), BNERGY (150), BRATE (150), BERR (150), DETLAB\$(10), ISOTH(25 0), MDA (250), ISOACT (250), IIBBEN (250), SBRATE (150), SBERR (150)

7 COMMON YIDC(), DETNAMS(), BNERGY (), BRATE(), BERR(), DETIABS(), ISOTH(), MDA(), ISOACT () , LIBEN (), SBRATE(), SBERR()

8 DIM RATE (150), ENERGY (150), ISOEN (250), ISOID\$(250), ISO\$ (250), ISOGAM (250), NPC (409

6), AREA (150), EAREA (150), LOCH(150), TAIL (150), FWHM(150), CENT (150)

9 COMMON RATE(), ENERGY(),ISOEN(), ISOIDS(), ISOS(), ISOGAM(),NPC(), AREA(), EAREA(),L OCH(), TAIL(), FWIM(), CENT(), FACILITY \$, DETLABS, DETN, LIBRY \$

10 COMMON LTIME, RTIME, STTIME, STDATES, LOCH\&, NPC, COENC, CIENC, TDAYS, RUNITS, SAMBAC, S TCH, ENCH, CRES, HCRES, EFIND, SBRATE, RATE, RATERR, SBERR, CENT , FWHM, TAIL, AREA, RTCN, ACTR AT , EAREA, IP, SENSIT, COFWHM, CIFWHM, ANAMES, RTCNS , AUNIT\$

11 COMMON GOEFF, AOEFF, BOEFF, UOEFF, KOEFF, COEFF, COEFF, CIEFF, C2EFF, C3EFF, EN, ENX

12 COMMON DOEFF, D1EFF, D2EFF, D3EFF, POEFF, P1EFF, P2EFF, P3EFF, FETHICK

16 CLS

17 INPUT"Printer used... (1) IBM (2) TOSHIBA"; PRUSED: PRINT: PRINT

18 INPUT"Do you need a form feed on printer first $(y / n)$ ";FEYES:IF FFYE\$ $<>$ " $n$ " THEN LPRINT CHR\$(12):REM - far away from next lprint statement

19 CLS

20 PRINT: PRINT: PRINT

21 PRTNT"

22 PRINT"

GRABGAM $\quad * \star \star * \star * \star * \star * \star * \|:$ PRINT:PRINT

Gamma Ray BASIC Generated At MCA/PC":PRINT:PRINT: PRINT

23 PRINT" Overview of Operations":PRINT

24 PRINT" 1 . Insert diskette with data files.":PRINT

25 PRINT" 2. Enter all data on following Input Frames.":PRINT

26 PRINT" 3. Assure input data correct before leaving each Input Frame. ": $P$

RINT

27 PRINT" 4. Analysis will take about 2 min per $4000 \mathrm{ch}$ spectrum. ":PRINT

28 PRINT" 5. Next prompt will appear below after data libraxies read.":PRI NT

$29 \mathrm{IP}=0: \mathrm{PEAK}=0: \mathrm{B} 1=0: \mathrm{G}=0: \mathrm{B} 2=0$

31 GOSUB 9000:REM read in detector efficiency parameters for vials

32 DETNAM $(1)=$ "OId Bottom Detector":DETNAM $(2)=$ "New Bottom Detector": DETNAM $\$(3)=$ "PGT Detector": DETNAM\$ (4)="N-side Detector":DETNAM\$ (5)="Well Detector"

38 INPUT"Press enter for Input Frame";PAGE\$:CLS

39 GOSUB 5000 REM-background/sample menu

40 GOSUB 40000:REM - get energy calibration parameters

41 DEF FNENC (CHAN) $=$ COENC + CIENC*CHAN

42 PRINT

43 GOSUB 43000:REM - get FWHM calibration parameters

44 DEF FNFWHM (CHAN) $=$ SQR ( COFWHM + C1FWHM $*$ CHAN )

45 PRINT

46 GOSUB 46000:REM - get efficiency parameters - part 1

47 PRINT: INPUT"Repeat this frame due to input errors $(y / n)$ "FRAMERS:IF FRAMERS=" $Y^{\prime \prime}$ THEN CLS: GOTO 40

50 GOSUB 46100:REM - get efflclency parameters - part 2

51 PRINT: INPUT"Repeat this frame due to input errors $(Y / n)$ "; FRAMERS:IF FRAMERS=" $Y^{\prime \prime}$ THEN CLS:GOTO 50

58 DEF FNEFFA $(E N)=\operatorname{GOEFF} \star \operatorname{EXP}\left(A O E F F \star S Q R\left(B O E F F^{\wedge} 2+U O E F F \star(L O G(E N)-K O E F F) \wedge 2\right) *(C O E F F+C 1\right.$ $E F F$ LOG $(E N)+C 2 E F F \star L O G(E N) \wedge 2+C 3 E F F \star L O G(E N) \wedge 3)+.5 *(1+\operatorname{SGN}(E N-E N X)) *(D O E F F+D 1 E F F \star L O G$ $(E N)+D 2 E F *$ LOG $(E N) \wedge 2+D 3 E F F \star L O G(E N) \wedge 3))$

59 DEF FNEFFB (EN) $=1+$ POEFF+P1EFF $\star$ LOG $(E N)+P 2 E F F * L O G(E N) \wedge 2+P 3 E F F \star L O G(E N) \wedge 3$

60 DEF FNEFF (EN) =FNEFEA (EN) * FNEFFB (EN)

61 INPUT"Do you wish to see EFF Vs EN data for standard energles $(y / n)$ ";EFFVEN\$:

CLS:IF EFFVENS $<>~ " Y "$ THEN GOTO 65

62 GOSUB 60000:REM "check on efficlency data EFF VE EN

63 IF NEWEFFS=" $Y$ " THEN CLS:GOTO 46:REM replace efficlency data case 
64 CLS

65 INPUT" (1) SPECTRUM FILE (-- .CHN) ";SP\$:YLOC(1)=CSRLIN-1:REM pick up from i nputs editing routine in 1000

68 'SINCE BASIC CANNOT HANDLE 4 BYTE INTEGERS, INTEGER4 DATA IS READ

69 'AS 1-BYTE STRINGS AND CONVERTED TO REAL BY THE FOLLOWING

70 OPEN SPS AS \#I LEEN $=32$ :'PICKUP HEADER RECORD

80 FIELD \#1, 2 AS FLAG\$, 2 AS MCBNUM\$, 2 AS SEG\$;, 2 AS PCOUNT\$, 4 AS RTIME\$,

4 AS LTYME $\$, 8$ AS STDATE\$, 4 AS STTIME\$, 2 AS STCHAN\$, 2 AS NUMCHAN\$

90 GET H 1

100 PRINT" THE MCB IS NUMBER"; CVI (MCBNUM\$)

102 PRINT" THE MCB SEGMEMT ";CVI (SEG\$)

110 PRINT" THE ACQUISITION DATE WAS" :STDATES

120 PRINT" THE ACQUISITION TIME WAS ":STTIME\$

$130 \mathrm{~B} 1 \%=\mathrm{ASC}(\operatorname{MID} \$(\operatorname{RTIME} \$, 1,1)): \mathrm{B} 1 \mathrm{H}=\mathrm{B} 1 \%$

$140 \mathrm{~B} 2 \%=\mathrm{ASC}(\operatorname{MID} \$(\operatorname{RTIME}, 2,1)): \mathrm{B} 2 \mathrm{H}=\mathrm{B} 2 \mathrm{z}$

$150 \mathrm{~B} 3 \mathrm{q}=\operatorname{ASC}(\operatorname{MID} \$(\operatorname{RTIME} \$, 3,1)): \mathrm{B} 3 \#=\mathrm{B} 3 \%$

$160 \mathrm{~B} 4 \%=\mathrm{ASC}(\operatorname{MID} \$(\operatorname{RTIME} \$, 4,1)): \mathrm{B} 4=\mathrm{B} 4 \%$

170 REMEMBER THE TIMES ARE IN 20 MILLISECOND TICS

175 RTIME $=(\mathrm{B} 1 \#+256 * \mathrm{~B} 2 \#+65536 ! * \mathrm{~B} 3 \#+16777216 \# * \mathrm{~B} 4 \#) * .02$

178 PRINT" THE REAL TIME WAS : ";RTIME

180 REM PRINT" THE REAL TIME WAS : ";FNCV4\# (B1\%, B2\%,B3\%, B4\%)*.02

$190 \mathrm{~B} 1 \%=\mathrm{ASC}(\mathrm{MID} \$($ LTIME $\$, 1,1)): \mathrm{B} 1 *=\mathrm{B} 1 \%$

$200 \mathrm{~B} 2 \mathrm{q}=\mathrm{ASC}(\mathrm{MID} \$(\operatorname{LTIME} \$, 2,1)): \mathrm{B} 2 \mathrm{\#}=\mathrm{B} 2 \mathrm{q}$

$210 \mathrm{~B} 3 \%=\mathrm{ASC}(\operatorname{MID}\{(\operatorname{LTIME}, 3,1)): \mathrm{B} 3 \#=\mathrm{B} 3 \%$

$220 \mathrm{~B} 4 \%=\operatorname{ASC}(\operatorname{MID} \$(\operatorname{LTIME} \$, 4,1)): \mathrm{B} 4 \#=\mathrm{B} 4 \%$

230 'REMEMBER THE TIMES ARE IN 20 MILLISECOND TICS

235 LTIME $=($ B1\#+256*B2\#+65536!*B3\#+16777216\#*B4\#)*.02

236 PRINT" THE LIVE TIME WAS : "; LTIME

240 REM PRINT" THE LIVE TIME WAS : ";FNCV4\# (B1\%,B2\%, B3\%, B4\%)*.02

241 LTIME $=(B 1 \#+256 * B 2 \#+65536 ! * B 3 \#+16777216 \# * B 4 \#) * .02$

250 STCHAN\% $=$ CVI (STCHAN\$)

260 NUMCHAN $=$ CVI (NUMCHANS)

270 LASTCHAN $=$ STCHAN\% + CVI (NUMCHAN\$) -1

280 CLOSE \#1

285 IF CORRIN>0 THEN LOCATE YLOC $(0), 1:$ GOTO 1520:REM jump back to input section

290 'NOW REOPEN WITH NEWLENGTH AND GET CHANNEL COUNTS

298 GOSUB 1000:REM - input parameters (last section) and print inputs (al1)

300 OPEN SP\$ AS \#I LEN $=4$

310 FIELD \#1, 1 AS FI\$, 1 AS F2\$, 1 AS F3\$, 1 AS F4\$

320 FOR $I=S T C H$ TO ENCH

330 GET 1 , $\mathrm{I}+8$ 'SKIP OVER HEADER

$340 \mathrm{~B} 1 \%=\mathrm{ASC}(\mathrm{F} 1 \$): \mathrm{B} 2 \%=\mathrm{ASC}(\mathrm{F} 2 \$): \mathrm{B} 3 \%=\mathrm{ASC}(\mathrm{F} 3 \$)$

$341 \mathrm{BI}=\mathrm{B} 1 \%: \mathrm{B} 2 \#=\mathrm{B} 2 \%: \mathrm{B} 3 \#=\mathrm{B} 3 \%$

345 COUNT $=B 2 \#+256 * B 2 \#+65536 ! * B 3 \#$

350 REM COUNT\# = FNCV3\# $(\mathrm{B} 2 \%, \mathrm{~B} 2 \%, \mathrm{~B} 3 \%)$

$355 \mathrm{NPC}(\mathrm{I})=$ COUNT \#

357 GOSUB 2000:REM - identify peaks while read spectrum above

358 IF YNCHS $\longleftrightarrow$ " $Y$ " THEN GOTO 380

360 PRINT"CHANNEL $=$ "; I-1;TAB (20); "COUNT $=n$;

370 PRINT USING "\#\#\#\#\#\#\#\#";COUNT\#

380 NEXT

390 CLOSE \#1

400 CHAIN "grabdkr2"

500 STOP 
1000 REM SUB for problem Input parametexs

1002 PRINT

1004 INPUT" (2) SAMPLE NAME : " ANAME $\$$ :YLOC(2)=CSRLIN-1:IF CORRIN>0 THEN LOCATE Y LOC (0) 1: GOTO 1520

1006 INPUT" (3) SAMPLE AGE (daYS): "; TDAYS:YLOC(3)=CSRLIN-I:IF CORRIN>O THEN LOCA TE YLOC (0), 1:GOTO 1520

1015 PRINT

1020 INPUT " (4) ACTIVITY UNITS (eg nCi/cc)" ;AUNITS:YLOC(4)=CSRLIN-I:IF IEN (AUNI T\$) $>=8$ THEN GOTO 1028

1022 SPARE $\$="$ ":SLH $=(8-\operatorname{LEN}($ AUNITS) $) / 2: \operatorname{ISLH}=\mathrm{INT}($ SLH $)$

1024 IF SLH=ISIH THEN SLI=ISLH:SL2=ISIH:GOTO 1026

1025 SLI=ISLH+1:SL2 $=$ ISLH

1026 FOR $\mathrm{SX}=1$ TO SL1:AUNIT\$=SPARE\$+AUNIT\$:NEXT SX

1027 FOR $S X=1$ TO SL2:AUNIT $\$=A U N I T \$+S P A R E S: N E X T$ SX

1028 IF CORRIN>0 THEN LOCATE XIOC(0), $1:$ GOTO 1520

1030 PRINT"-- Activity in pCi converted to above units with factors below"

1040 INPUT" (5) NUMERATOR FACTOR (eg $1.0 \mathrm{E}-06$ fOr UCi) "; UNUM:YLOC (5) =CSRLIN-1: IF CORRIN>0 THEN LOCATE YLOC (0), 1: GOTO 1520

1050 INPUT" (6) DENOMINATOR FACTOR (eg sample volume) "; UDEM: YLOC (6) =CSRLIN-1:IF CORRIN $>0$ THEN LOCATE YLOC (0), I:GOTO 1520

1060 RUNITS=UNUM/ (UDEM*.037) :REM raw rate in cps - also in 1 ine 1525

1070 PRINT

1310 PRINT"-- Peak analysis parameters below"

1330 INPUT" (7) START CHANNEL (eg 50) "; STCH:YLOC (7)=CSPLIN-1: IF CORRIN>0 THEN IO CATE YLOC (0), 1:GOTO 1520

1340 INPUT" (8) END CHANNEL (eg 3950) ": ENCH: YLOC(8)=CSRLIN-I:IF CORRIN>0 THEN LO CATE YLOC(0) 1:GOTO 1520

1350 INPUT" (9) SEARCH CHANNELS PER PEAK (eg 8)";CRES:HCRES=CRES/2:YLOC $(9)=$ CSRLI N-1:IF CORRIN $>0$ THEN IOCATE XLOC (0), 1:GOTO 1520

1360 INPUT " $(10)+/-$ KEV FOR PEAK ID (eg 2)";EFIND: YLOC $(10)=$ CSRLIN-1:IF CORRIN $>0$ THEN LOCATE YIOC (0), 1: GOTO 1520

1500 REM check inputs scheme

1510 PRINT

1520 INPUT" Correct above inputs by number (o for no corrections) "; CORRIN:YLOC(0)

$=$ CSRLIN-1

1525 RUNITS=UNUM/(UDEM*.037) :REM raw rate in cps - also in line 1060

1530 IF CORRIN $=0$ THEN GOTO 1700

1540 IF CORRIN > 10 THEN LOCATE YLOC(0), 1: GOTO 1520

1550 LOCATE YIOC(CORRIN) 1

1560 ON CORRIN GOTO $65,1004,1006,1020,1040,1050,1330,1340,1350,1360$

1700 INPUT"Include screen print of each channel (y/usually $n$ ) "; YNCHS

1800 GOSUB 11000: REM printout of data id for sample

1999 RETURN 
2000 REM sub to identify peaks

2010 IF I-STCH $=23$ THEN GOSUB 12000

2020 IF I-STCH $<=23$ THEN 2900:REM return

$2030 \mathrm{~B} 1 \mathrm{R} 8=-\mathrm{NPC}(I-24)+\mathrm{BIR} 8+\mathrm{NPC}(I-20)$

2040 GR8 $=-\mathrm{NPC}(I-16)+\mathrm{GR} 8+\mathrm{NPC}(I-8)$

$2050 \mathrm{~B} 2 \mathrm{R} 8=-\mathrm{NPC}(\mathrm{I}-4)+\mathrm{B} 2 \mathrm{R} 8+\mathrm{NPC}(\mathrm{I})$

2060 BIR4 $=-\mathrm{NPC}(I-18)+\mathrm{B} 1 \mathrm{R} 4+\mathrm{NPC}(I-16)$

$2070 \mathrm{GR4}=-\mathrm{NPC}(I-14)+\mathrm{GR} 4+\mathrm{NPC}(\mathrm{I}-10)$

$2080 \mathrm{~B} 2 \mathrm{R} 4=-\mathrm{NPC}(I-8)+\mathrm{B} 2 \mathrm{R} 4+\mathrm{NPC}(I-6)$

2090 BIR2 $=-\mathrm{NPC}(I-I 5)+\mathrm{BIR} 2+\mathrm{NPC}(I-14)$

$2200 \mathrm{GR} 2=-\mathrm{NPC}(\mathrm{I}-13)+\mathrm{GR} 2+\mathrm{NPC}(\mathrm{I}-11)$

$2110 \mathrm{~B} 2 \mathrm{R} 2=-\mathrm{NPC}(I-I 0)+\mathrm{B} 2 \mathrm{R} 2+\mathrm{NPC}(I-9)$

$2210 S A 8=3:$ IF $G R 8+B 1 R 8+B 2 R 8>0$ THEN $S A 8=3 * S Q R(G R 8+B 1 R 8+B 2 R 8)$

2220 SA4 $=3:$ IF GR4+BIR4+B2R4>0 THEN SA4=3*SQR (GR4+B1R4+B2R4)

$2230 \quad S A 2=3:$ IF $G R 2+B 1 R 2+B 2 R 2>0$ THEN $S A 2=3 * S Q R(G R 2+B 1 R 2+B 2 R 2)$

2240 A $8=G R 8-B 1 R 8-B 2 R 8$

2250 A $4=\mathrm{GR} 4-\mathrm{B} 1 \mathrm{R} 4-\mathrm{B} 2 \mathrm{R} 4$

2260 A2 $=$ GR2 $-B 1 R 2-B 2 R 2$

2300 IF IP $\angle I$ THEN IP $=1: A 2 M A X=0: A 4 M A X=0: A 8 M A X=0: P E A K 2=0: P E A K 4=0: P E A K 8=0$

2400 IF A2>SA2 THEN GOSUB 12400: GOTO 2900

2410 IF PEAK2 $=1$ THEN PRINT IP;" ";X2PK, FNENC (X2PK), A2MAX, PERA2, "2-pt":LOCH (IP) $=$ $\mathrm{X} 2 \mathrm{PK}$ : GOSUB $12200: \mathrm{IP}=\mathrm{IP}+1: \mathrm{PEAK} 2=0: A 2 \mathrm{MAX}=0: \mathrm{PEAK} 2 \mathrm{~T}=1:$ GOTO 2900

2420 IF PEAK2T $=1$ AND A4>SA4 THEN 2900

2430 IF PEAK2T $=1$ AND $A 8>S A 8$ THEN 2900

2440 PEAK2T=0

2500 IF A4>SA4 THEN GOSUB 12500:GOTO 2900

2510 IF PEAK4=1 THEN PRINT IP;" ";X4PK, FNENC (X4PK), A4MAX, PERA4, "4-pt":LOCH (IP) = $\mathrm{X} 4 \mathrm{PK}: \mathrm{GOSUB} 12200: I P=I P+1: \mathrm{PEAK} 4=0: \mathrm{A} 4 \mathrm{MAX}=0: \mathrm{PEAK} 4 \mathrm{~T}=1:$ GOTO 2900

2520 IF PEAK4T=1 AND. A8>SA8 THEN 2900

2530 PEAK $4 \mathrm{~T}=0$

2600 IF A8>SA8 THEN GOSUB 12600:GOTO 2900

2610 IF PEAK8=1 THEN PRINT IP;" ";X8PK, FNENC (X8PK), A8MAX, PERA8, "8-pt":LOCH (IP) = $X 8 P K:$ GOSUB $12200: I P=I P+1: P E A K 8=0: A 8 M A X=0$

2900 RETURN 
5000 REM - sub for sample/background/analysis menus

5010 PRINT"Select type of analysis below": PRINT

5020 PRINT" (1) Results with background subtraction (usual case)"

5030 PRINT" (2) Results without background subtraction (last resort)"

5080 PRINT: INPUT" Analysis number" :SAMBAC

5085 DETLAB $\$(1)=$ "OLDBOTTM" : DETLAB $\$(2)=" N E W B O T T M ":$ DETLAB $\$(3)="$ PGTDETOR" :DETLAB $\$(4$

)$=$ "NSIDEDET" : DETLAB $\$(5)=$ "WELLDETR"

5090 PRINT: PRINT

5100 PRINT"Select sample type per appropriate countrate units":PRINT

5110 PRINT"

(1) Normal low level activities - rates in cph"

5120 PRINT" (2) Calibration standards - rates in cps"

5130 PRINT"

(2) Calibration standards - rates in

5140 INPUT"Sample type" : SOP

5150 RTCN $=3600:$ RTCN $\$=" \mathrm{Cph"}$

5160 IF SOP $=2$ THEN RTCN=1:RTCN $\$=" C p s "$

5170 IF SOP=3 THEN RTCN=60:RTCN $\$=" \mathrm{cpm} "$

5175 PRINT:PRINT:INPUT"Repeat this frame due to input errors $(\mathrm{Y} / \mathrm{n})$ ": YES

5180 CLS:IF YES<> "n" THEN 5010

5190 RETURN

9000 REM sub from Iine 31 - read in detector data

9005 OPEN "B:DETLIBRY.LIB" FOR INPUT AS \#3

9010 FOR $\mathrm{I}=1$ TO 5

9020 FOR $\mathrm{J}=1$ TO 3

9030 INPUT \#3, GOEFF(I,J), $\operatorname{AOEFF}(I, J), \operatorname{BOEFF}(I, J), \operatorname{KOEFF}(I, J), \operatorname{HOEFF}(I, J)$

9040 INPUT \#3, CEOHO (I,J)

9050 INPUT \# $3, \mathrm{CE} 1 \mathrm{HO}(\mathrm{I}, \mathrm{J}), \mathrm{CEOH} 1(\mathrm{I}, \mathrm{J})$

9060 INPUT $\# 3, \operatorname{CE} 2 H O(I, J), \operatorname{CE} 1 H 1(I, J), C E O H 2(I, J)$

9070 INPUT \#3, CE3HO $(I, J), \operatorname{CE} 2 H 1(I, J), \operatorname{CE} 1 H 2(I, J), \operatorname{CEOH} 3(I, J)$

9080 NEXT J

9090 NEXT I

9095 CLOSE \#3

$9100 \quad I=0: J=0$

9200 RETURN 
11000 REM - sub from sub 1000 - sample info printout

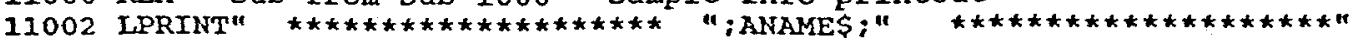

11003 LPRINT: LPRINT: LPRINT

11010 LPRINT"

Sample counting Information

11020 LPRINT

11030 LPRINT"

11040 LPRINT

11050 LPRINT"

sample disk file ";SP\$

11060 LPRINT"

11070 LPRINT

11080 LPRINT"

11090 LPRINT"

11100 LPRINT

11110 LPRINT"

11120 LPRINT"

11130 LPRINT:LPRINT: LPRINT

11140 LPRINT"

11150 L.PRINT

11160 LPRINT"

11170 LPRINT"

11180 LPRINT

11185 LPRINT

11190 IPRINT"

MCB number ";CVI (MCBNUM\$)

Segment "; CVI (SEG\$)

11195 LPRINT

11200 LPRINT"

11205 LPRINT

11207 LPRINT"

11208 LPRINT

11210 LPRINT"

11220 LPRINT"

start time "; STTIME\$

Date ":STDATE $\$$ : BGDATE $\$=S T D A T E \$$

Live time ";LTIME;" sec"

Real time ";RTIME;" sec"

11230 LPRINT"

11240 LPRINT: LPRINT

11250 LPRINT"

11260 LPRINT

11270 LPRINT" "DETNAM (DETN);" with ":DETLAB\$(6);".BKG and ";OTHERDET\$

11280 LPRINT: LPRINT

11285 LPRINT:IF OPTDT6>0 THEN OPNUM $=1$

11290 LPRINT"Configuration = ";OPNUM;"....(1) SPECIAL (2) DIAPER (3) WELL (4) VI

AL"

11300 LPRINT

11310 IF OPNUM $<4$ THEN GOTO 11350

11320 LPRINT"Vial size = ":VIALN;"....... (1) Large (2) Medium (3) Small"

11330 LPRINT"Sample height $(\mathrm{mm})=$ "iHMM:LPRINT

11335 LPRINT

11350 LPRINT"Energy (keV) calibration: $\quad$ EN $="$;COENC;" + ";CIENC;"*CHAN"

11355 LPRINT

11360 LPRINT"FWHM(channel) calibration: FWHM = SQR(";COFWHM;" + ";C1FWHM;"*CHAN

)"

11370 LPRINT

11380 LPRINT"Efficiency calibration: EFF $=$ G*EXP (HYPERBOLA * POLYNOMIAL) * $(I+P E R T$ URBATION) "

11385 LPRINT

11390 LPRINT"

F)

11395 LPRINT

11400 LPRINT"

11410 LPRINT"

11415 LPRINT

11420 LPRINT" ues below: "

$G=$ global calibration factor $=" ; G O E F F " D=L N(G)=": \operatorname{LOG}($ GOEF

11430 LPRINT"

11432 LPRINT"

W) cases"

11434 LPRINT"

HYPERBOLA $=A * S Q R\left(B^{\wedge} 2+(\operatorname{LN}(E N)-C)^{\wedge} 2\right)$ with values below:

$(\mathrm{A}=$ ";AOEFF;" $\mathrm{B}=$ "; BOEFF;" $\mathrm{C}=$ ";KOEFF;")"

POLYNOMIAL $=\mathrm{C} 0+\mathrm{C} 1 * \operatorname{LN}(E N)+\mathrm{C} 2 * \operatorname{LN}(E N) \wedge 2+\mathrm{C} 3 * \operatorname{LN}(E N) \wedge 3$ with val

$(\mathrm{CO}=" ; \mathrm{COEFF} ; " \mathrm{C} 1=$ ";C1EFF;" $\mathrm{C} 2=" ; \mathrm{C} 2 \mathrm{EFF} ; " \mathrm{C} 3=" ; \mathrm{C} 3 \mathrm{EFF} ; ") "$

":ENX:" $\mathrm{keV}=$ crossover between low EN (above) and high EN (belo

$(\mathrm{CO}=$ ";TOEFF;" $\mathrm{Cl}=$ ";T1EFF;" $\mathrm{C2}=$ ";T2EFF;" C3 = ";T3EFF;" )"

11435 LPRINT

11440 LPRINT"

alues below:"

11450 LPRINT"

PERTURBATION $=\mathrm{P0}+\mathrm{P} 1 \star \operatorname{LN}(E N)+\mathrm{P} 2 \star \operatorname{LN}(E N) \wedge 2+\mathrm{P} 3 \star \operatorname{LN}(E N) \wedge 3$ with $\mathrm{v}$

$(\mathrm{PO}=$ "; POEFF;" $\mathrm{P1}=$ ";P1EFF;" $\mathrm{P2}=$ ";P2EFF;" $\mathrm{P} 3=$ ";P3EFF;" $) "$

11460 LPRINT: LPRINT: LPRINT

11500 RETURN 
12000 REM subroutine from 2000 subroutine

12010 FOR $K R=0$ TO 3

$12020 \mathrm{~B} 1 \mathrm{R} 8=\mathrm{B} 1 \mathrm{R} 8+\mathrm{NPC}(\mathrm{STCH}+\mathrm{KR})$

$12030 \mathrm{~B} 2 \mathrm{R} 8=\mathrm{B} 2 \mathrm{R} 8+\mathrm{NPC}(\mathrm{STCH}+20+\mathrm{KR})$

12040 NEXT KR

12050 FOR $\mathrm{KR}=0$ TO $7: \mathrm{GR} 8=\mathrm{GR} 8+\mathrm{NPC}(\mathrm{STCH}+8+\mathrm{KR}): \mathrm{NEXT} \mathrm{KR}$

12060 B1R $4=\mathrm{NPC}(\mathrm{STCH}+6)+\mathrm{NPC}(\mathrm{STCH}+7)$

$12070 \quad \mathrm{~B} 2 \mathrm{R} 4=\mathrm{NPC}(\mathrm{STCH}+16)+\mathrm{NPC}(\mathrm{STCH}+17)$

12080 FOR KR $=0$ TO $3: G R 4=G R 4+N P C(S T C H+10+K R): N E X T$ KR

$12090 \mathrm{~B} 1 \mathrm{R} 2=\mathrm{NPC}(\mathrm{STCH}+9)$

12100 B2R2 $=\mathrm{NPC}(\mathrm{STCH}+14)$

12110 GR2 $=\mathrm{NPC}(\mathrm{STCH}+11)+\mathrm{NPC}(\mathrm{STCH}+12)$

12115 PRINT:PRINT"peak channel KeV Area s-error Rope" :

PRINT

12120 RETURN

12200 REM - sub to test if new resolved peak found

12210 IF ABS(LOCH(IP) -LOCH (IP-1))>.47*FNFWHM(IOCH(IP)) THEN GOTO 12290

$12220 \mathrm{LOCH}(\mathrm{IP}-1)=\mathrm{INT}((\mathrm{LOCH}(\mathrm{IP}-1)+\mathrm{LOCH}(\mathrm{IP})) / 2): I P=I P-1$

12230 PRINT IP, LOCH(IP), "Above nonresolved peaks combined as one"

12290 RETURN

12400 REM - sub from Iine 2400

12410 PEAK2 $=1: A 4 M A X=0: A 8 M A X=0: P E A K 4=0: P E A K 8=0$

12420 IF A2>A2MAX THEN X2PK $=\mathrm{T}-12: \mathrm{A} 2 \mathrm{MAX}=\mathrm{A} 2: \mathrm{PERA} 2=100 * \mathrm{SA} 2 /(3 * \mathrm{~A} 2)$

12430 RETURN

12500 REM - sub from line 2500

12510 PEAK4 $=1: A 8 M A X=0: P E A K 8=0$

12520 IF A4>A4MAX THEN X4PK=I-12:A4MAX=A4:PERA4=100*SA4/(3*A4)

12530 RETURN

12600 REM - sub from line 2600

12610 PEAK8=1

12620 IF $A 8>A 8 M A X$ THEN $X 8 \mathrm{PK}=I-12: \mathrm{A} 8 \mathrm{MAX}=\mathrm{A} 8: \mathrm{PERA} 8=100 * \mathrm{SA} 8 /(3 * \mathrm{~A} 8)$

12630 RETURN 
40000 REM - subroutine from line 40 - energy calibrations 40005 PRINT

40010 PRINT"Energy calibration - enter two peaks as below"

40020 INPUT" LOW ENERGY (eg 661.638 keV) ";ELOW

40030 INPUT" LOW CHANNEL (eg 1321.20) ";CLOW

40040 INPUT" HIGH ENERGY (eg $1332.56 \mathrm{keV}$ ) ";EHIGH

40050 INPUT" HIGH CHANNEL (eg 2665.12) ";CHIGH

$40060 \mathrm{C} 1 \mathrm{ENC}=(\mathrm{EHIGH}-\mathrm{ELOW}) /(\mathrm{CHIGH}-\mathrm{CLOW})$

40070 COENC $=$ ELOW - CIENC $*$ CLOW

40100 RETURN

43000 REM - sub from line 43 - FWHM data

43010 PRINT" FWHM calibration - 2 input cases "

43020 INPUT" LOW ENERGY (eg $100 \mathrm{keV})$ "; ELOW

43030 INPUT" LOW FWHM (eg $1.5 \mathrm{keV}$ ) "; FWHMLO

43040 INPUT" HIGH ENERGY (eg $1500 \mathrm{keV}$ ) ";EHIGH

43050 INPUT" HIGH FWIM (eg $2.5 \mathrm{keV}$ )":FWHMHI

43060 CIFWHM $=($ FWHMHI^2-FWHMLO^2) $/($ EHIGH-ELOW $)$

43070 COFWHM $=$ FWHMIO^2 - C1FWHM $*$ ELOW

43080 C1FWHM $=$ C1FWHM $/$ CIENC

43090 COFWHM $=$ COFWHM $/ \mathrm{C} 1 \mathrm{ENC}^{\wedge} 2$

43100 RETURN

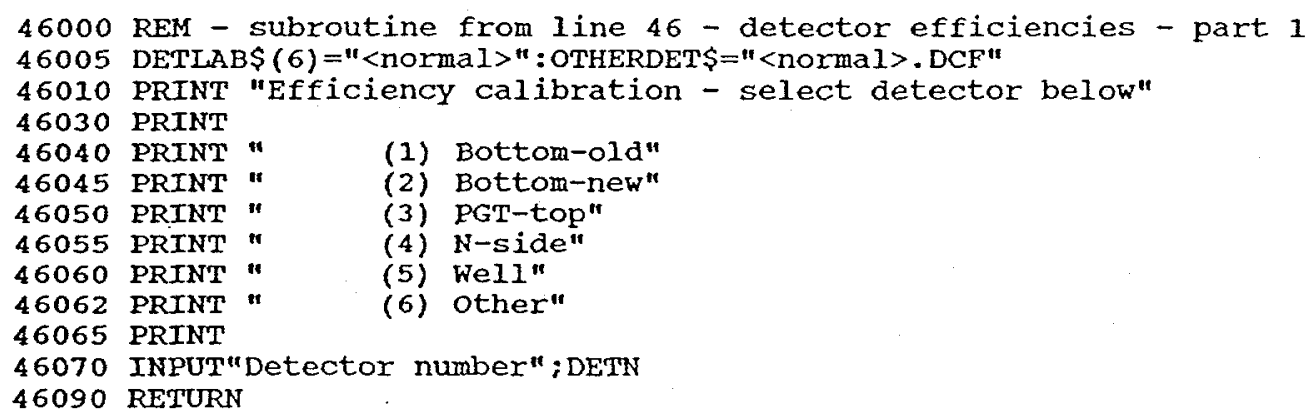


46100 REM - subroutine from line 47 - detector efficiencies - part 2

46105 CLS : OPTDT6=0

46110 GOEFF $=1: \AA O E F F=1: B O E F F=1: U O E F F=0: C O E F F=1: C 1 E F F=0: C 2 E F F=0: C 3 E F F=0$

46115 POEFF $=0:$ P1EFF $=0:$ P2EFF $=0:$ P3EFF $=0: D O E F F=0: D 1 E F F=0: D 2 E F F=0: D 3 E F F=0: E N X=5000$

46117 TF DETN $=6$ THEN GOSUB 47000

46118 PRINT:IF OPTDT6 $=1$ THEN GOSUB 46500

46119 IF OPTDT6>0 THEN 46200

46120 PRINT"Efficiency calibration data for "; DETNAMS(DETN)

46130 PRINT

46140 PRINT"

46145 PRINT"

46150 PRINT"

(1) Special samples (manual input)"

46160 PRINT"

46165 PRINT

46170 INPUT"Calibration case number"; OPNUM: PRINT

46180 ON OPNUM GOSUB $46500,46700,46800,46900$

46190 REM eff sub-parts $2 \mathrm{a} \quad 2 \mathrm{~b} \quad 2 \mathrm{C} \cdot 2 \mathrm{~d}$

46200 RETURN

46500 REM - manual input efficiencies - part 2a of efficiency calcs/line 46180

46505 INPUT"Type of fit - (0) None<eff=1> (1) Polynomial, (2) Hyperbola, (3) Bot h "; PHB: PRINT

46510 ON PHB GOTO $46600,46530,46520$

46515 IF $P H B=0$ THEN AOEFF $=0:$ GOTO 46690

46520 PRINT"IN $(E F F)=D+A * S Q R\left(B^{\wedge} 2+(\operatorname{LN}(E)-C)^{\wedge} 2\right) *(C O+C I * L N(E)+C 2 * I N(E) \wedge 2+$ $\left.C 3 * \operatorname{LN}(E)^{\wedge} 3\right)^{\prime \prime}$

46525 IF $\mathrm{PHB}=3$ THEN GOTO 46535

46530 PRINT"LN $(E F F)=D+A * S Q R\left(B^{\wedge} 2+(\operatorname{LN}(E)-C)^{\wedge} 2\right) ":$ PRINT

46535 UOEFF $=1$

46540 INPUT" D" ; DAEFF: GOEFF=EXP (DAEFF)

46550 INPUT" $A ":$ :AOEFF

46560 INPUT" B" ; BOEFF

46570 INPUT" C" ; KOEFF

46590 IF PHB $=3$ THEN GOTO 46620

46595 IF $P H B=2$ THEN GOTO 46690

46600 PRINT"LN(EFF) $=C 0+C 1 * L N(E)+C 2 * L N(E)^{\wedge} 2+C 3 * \operatorname{LN}(E)^{\wedge} 3 ": P R I N T$

46610 UOEFF $=0$

46612 INPUT" Crossover energy (keV) .... if none enter 0 ";ENX:IF ENX=0 THEN ENX

$=5000$

46614 PRINT" Coefficients below crossover point"

46620 INPUT"

46630 INPUT"

46640 INPUT"

46650 INPUT"

46651 IF ENX

46652 PRINT"

46655 INPUT!

46660 INPUT"

46665 INPUT"

46670 INPUT"

Coefficients be
CO"; COEFF

$C I "$; CIEFE

$\mathrm{C} 2$ " ; C2EFE

C3" ; C3EFF:IF PHB=3 THEN GOTO 46690

46690 RETURN

5000 THEN GOTO 46690

Coefficients above crossover point"

CO" : TOEFF : DOEFF $=$ TOEFF-COEFF

CI" ; T1EFF : DIEFF=T1EFF-CIEFF

$\mathrm{C} 2$ " :T2EFF:D2EFF=T2EFF-C2EFF

C3" ;T3EFF : D3EFF=T3EFF-C3EFF 
46700 REM - diaper coefficients effs - part $2 \mathrm{~b}$ of efficiency calib/line 46180 46710 IF DETN=1 THEN COEFF $=-32.9019: \mathrm{C} 1 E F F=15.5286: \mathrm{C} 2 \mathrm{EFF}=-2.63121: \mathrm{C} 3 \mathrm{EFF}=.137454$ 46720 IF DETN=2, THEN $C O E F F=-33.7619: C 1 E F F=15.949: \mathrm{C} 2 \mathrm{EFF}=-2.69313: \mathrm{C} 3 \mathrm{EFF}=.141663$ 46730 IF DETN=3 THEN COEFF $=-44.2381: \mathrm{C} 1 E F F=21.0238: \mathrm{C} 2 \mathrm{EFF}=-3.50398: \mathrm{C} 3 \mathrm{EFF}=.183542$ 46740 IF DETN=4 THEN PRINT"not available - make another choice" 46750 IF DETN=5 THEN COEFF $=-30.373: \mathrm{C} 1 \mathrm{EFF}=14.4228: \mathrm{C} 2 \mathrm{EFF}=-2.4183: \mathrm{C} 3 \mathrm{EFF}=.125452$ 46760 RETURN

46800 REM - well coefficients effs - part $2 \mathrm{c}$ of efficiency calib/line 46180 46810 IF DETN $>5$ THEN PRINT "NOT APPLICABLE - MAKE ANOTHER CHOICE"

$46820 \mathrm{UOEFF}=1: \mathrm{AOEFF}=-.921 \star \operatorname{SQR}(1.6952): \mathrm{BOEFF}=\operatorname{SQR}(1.21 / 1.6952): \mathrm{KOEFF}=\operatorname{LOG}(60)$ $46830 \mathrm{GOEFF}=\mathrm{EXP}(.921 * .9)$

46850 RETURN

46900 REM - vial coefficients effs - part $2 d$ of efficiency calib/line 46180

46910 PRINT"Vial sizes": PRINT

46911 PRINT" (1) Large"

46912 PRINT" (2) Medium"

46913 PRINT" (3) Small" : PRINT

46920 INPUT"Vial size number" ; VIALN: PRINT

46930 INPUT"Vial sample height (mm) ";HMM:H=HMM/10

46940 UOEFF=1:AOEFF=AOEFF (DETN, VIALN) :BOEFF=BOEFF (DETN, VIALN) $: \operatorname{KOEFF}=\operatorname{KOEFF}(\mathrm{DETN}, \mathrm{V}$

IAIN)

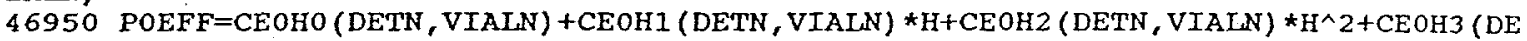

TN, VIALN) *H^3

46955 PIEFF $=$ CE1HO (DETN, VIALN) +CEIH1 (DETN, VIALN) *H+CE1H2 (DETN, VIALN) *H^2

$46960 \mathrm{P} 2 \mathrm{EFF}=\mathrm{CE} 2 \mathrm{HO}(\mathrm{DETN}, \mathrm{VIALN})+\mathrm{CE} 2 \mathrm{HI}(\mathrm{DETN}, \mathrm{VIALN}) \star_{\mathrm{H}}$

46965 P3EFF $=$ CE3HO (DETN, VIALN)

46970 GOEFF=GOEFF (DETN, VIALN $) /(\text { H+HOEFF }(\text { DETN, VIALN }))^{\wedge} 2$

46975 DAEFF $=$ LOG (GOEFF)

46990 RETURN 
47000 REM- sub for detector 6 (other detector)

47001 ON ERROR GOTO 47120

47002 CIS

47003 INPUT"Descriptive name of detector";DETNAM\$(6) : PRINT: PRINT

47004 IF SAMBAC $<1$ THEN 47015

47005 ISAVE $=0$ :INPUT"Background file (-.......BKG) " DETLAB\$ (6): PRINT:PRINT

47006 FOR $I=1$ TO LEN (DETLAB $\$(6)$ )

47007 IF MTD\$(DETLAB $\$(6), I, 1)="$." THEN ISAVE $=\mathrm{I}-1$

47008 NEXT I

47009 IF ISAVE>0 THEN DETLAB $\$(6)=$ LEFT $\$$ (DETLAB $\$(6)$, ISAVE)

47010 OPEN DETLABS(6)+".BKG" FOR INPUT AS \#3

47011 CIOSE \#3

47015 PRINT"Detector efficiency options": PRINT

47020 PRINT" (1) Manual input (includes eff=I case)

47030 PRINT" (2) File input": PRINT

47040 INPUT"Option";OPTDT6

47050 IF OPTDT6 $<>2$ THEN 47200

47060 PRINT:PRINT

47070 INPUT"Detector calibration file (- - - . DCF)";OTHERDET\$

47080 OPEN OTHERDET\$ FOR INPUT AS \#3

47090 INPUT 3, GOEFF, AOEFF, BOEFF, UOEFF, KOEFF, COEFF, C1EFF, C2EFF, C3EFF

47100 INPUT 3,ENX, DOEFF, D1EFF, D2EFF, D3EFF, POEFF, P1EFF, P2EFF, P3EFF

47110 CLOSE $\# 3$

47120 IF ERR=53 THEN PRINT:INPUT"Above file not found. Press return for retry"; $\mathrm{Z}$ : CLS: RESUME 47000

47200 RETURN

60000 REM temp check on eff

60005 PRINT"Efficiency (EFF) per standard energy (EN) for ";DETNAMS(DETN)

60006 PRINT

60010 PRINT "EN" "EFF"

60011 PRINT"keV", " \#"

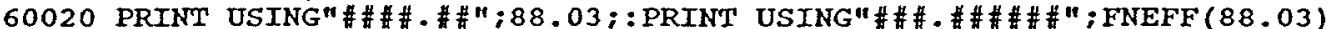

60030 PRINT USING" \#\#\#\#\#";122.06;:PRINT USING"\#\#苂\#\#\#\#"; FNEFF (122.06)

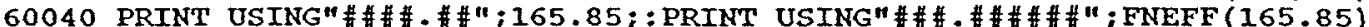

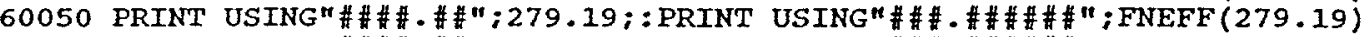

60060 PRINT USING"\#\#\#.\#\#";391.69;:PRINT USING"\#\#\#.\#\#\#\#\#\#;FNEFF (391.69)

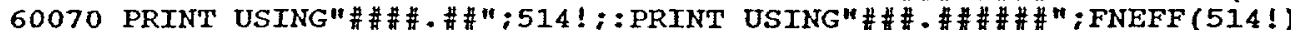

60080 PRINT USING"\#\#\#\#•\#";661.64;:PRINT USING"\#\#\#.\#\#\#\#\#;FNEFF(661.64)

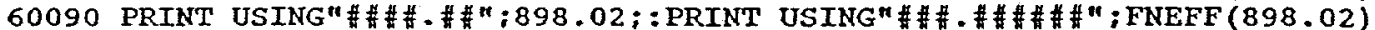

60100 PRINT USING"\#\#\#.\#\#";1173.21;:PRINT USING"\#\#\#.\#\#\#\#";FNEFF(1173.21)

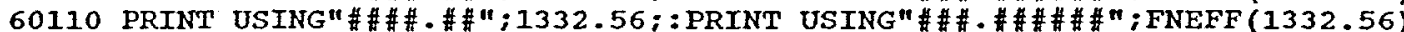

60120 PRINT USING"\#\#\#.\#\#";1836.01;:PRINT USING"\#\#\#\#\#\#\#\#;FNEFF (1836.01)

60130 INPUT"Need to re-enter new efficieny case $(y / n)^{\prime \prime N E W E F F S ~}$

60140 RETURN 


\section{GRABDKR2: Program structure Reference}

Main

<--- Subroutines and [files]

1-12/DIM and COMMON

30/Gammas: IsoIDs <--- 8000-8100/File read driver $<--[B:$ ISOLIBRY.LIB]

41-60/Functs: GRABDKRI

391-397/Header: Multiplets

398-400/Peaks : Analys Isotopes

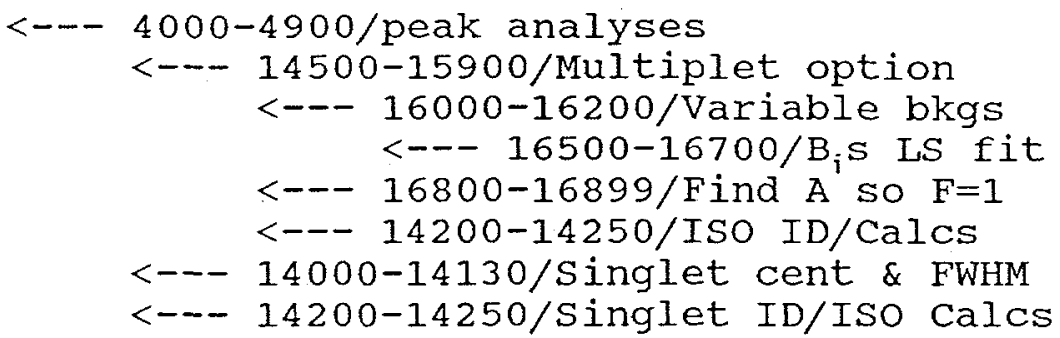

410-412/Debug : test

413/F-MDAs: print \#

450/MDAs : Analys <--- 3000-3400/merge peaks \& selected MDAs <-- 13000-13100/E to CHAN calc <-- 13300-13490/Selected MDAs calcs

460/Bkgnd : Option --- 5200-5400/User file read driver <--- [backgnd. BKG]

461-467/Peaks : Header

475-485/Peaks : Print <--- 3500-3690/Print peak table data <--- 3900-3990/Notations for " \pm " <-- 3800-3830/REM tests

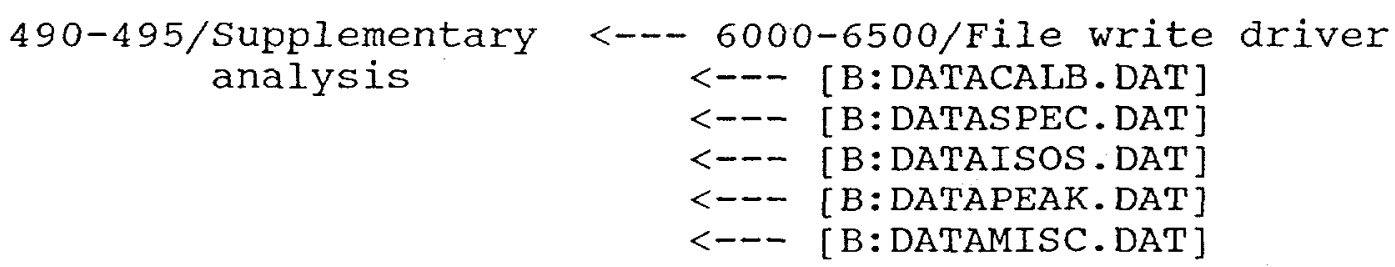

$500 /$ Stop

B-39 
1 'VERSION GRABDKR2. BAB 3/12/99 fiX

$2 \operatorname{DTM} H 1(150), H 2(150), \operatorname{GOEFF}(5,3), \operatorname{HOEFF}(5,3), \operatorname{AOEFF}(5,3), \operatorname{BOEFF}(5,3), \operatorname{KOEFF}(5,3), A(2$

0), MINXM (20), MCENT (20)

3 COMMON HI (), H2 (), GOEFF(), HOEFF(), AOEFF(), BOEFF(), KOEFF(), A(), MINXM(), MCENT()

$4 \operatorname{DIM} \operatorname{CEOHO}(5,3), \operatorname{CE} 1 \mathrm{HO}(5,3), \operatorname{CEOH} 1(5,3), \operatorname{CE} 2 \mathrm{HO}(5,3), \operatorname{CE} 1 \mathrm{H} 1(5,3), \operatorname{CEOH} 2(5,3), \operatorname{CE} 3 \mathrm{HO}(5$,

3) $, \operatorname{CE} 2 \mathrm{H} 1(5,3), \operatorname{CE} 1 \mathrm{H} 2(5,3), \operatorname{CEOH} 3(5,3), \operatorname{GEOM} \$(10)$

5 COMMON $\operatorname{CEOHO}(), \operatorname{CE} 1 \mathrm{HO}(), \operatorname{CEOH} 1(), \operatorname{CE} 2 \mathrm{HO}(), \operatorname{CE} 1 \mathrm{H} 1(), \operatorname{CEOH} 2(), \operatorname{CE} 3 \mathrm{HO}(), \operatorname{CE} 2 \mathrm{H} 1(), \operatorname{CE} 1 \mathrm{H} 2()$ , $\mathrm{CEOH} 3()$, GEOM $\$()$

6 DTM YLOC (20), DETNAM\$ (10), BNERGY (150), BRATE (150), BERR (150), DETLABS (10), ISOTH (25

0), MDA (250), ISOACT (250), LIIBEN (250), SBRATE (150), SBERR(150)

7 COMMON YLOC (), DETNAM\$ (), BNERGY (), BRATE (), BERR(), DETLAB\$ (), ISOTH (), MDA (), ISOACT

(), $\operatorname{LIBEN}()$, SBRATE(), SBERR()

8 DIM RATE (150), ENERGY (150), ISOEN (250), ISOID\$(250), ISOS(250), ISOGAM(250), NPC(409

6), AREA (150), EAREA (150), LOCH (150), TAIL (150), FWIHM(150), CENT (150)

9 COMMON RATE(), ENERGY (), ISOEN(), ISOID ()$, \operatorname{ISO}(), \operatorname{ISOGAM}(), \operatorname{NPC}(), \operatorname{ArEA}(), \operatorname{EAREA}(), L$ OCH (), TAIL (), FWHM (), CENT (), FACILITY\$, DETLAB\$, DETN, LIBRY\$

10 COMMON LTIME, RTIME, STTIME, STDATE $\$$, LOCH\%, NPC, COENC, CIENC, TDAYS, RUNITS, SAMBAC, S TCH, ENCH, CRES, HCRES, EFIND, SBRATE, RATE, RATERR, SBERR, CENT , FWHM, TAIL, AREA, RTCN, ACTR AT, EAREA, IP, SENSIT, COFWHM, C1FWHM, ANAMES, RTCNS, AUNITS

11 COMMON GOEFF, AOEFF, BOEFF, UOEFF, KOEFF, COEFF, COEFF, C1EFF, C2EFF, C3EFF, EN, ENX

12 COMMON DOEFF, DIEFF, D2EFF, D3EFF, POEFF, P1EFF, P2EFF, P3EFF, FETHICK

30 GOSUB 8000:REM read in isotope data

41 DEF FNENC $($ CHAN $)=$ COENC + C1ENC $*$ CHAN

44 DEF FNFWHM (CHAN) $=$ SQR ( COFWHM + C1FWHM $*$ CHAN )

58 DEF FNEFFA (EN) $=$ GOEFF*EXP $\left(A O E F F * S Q R\left(B O E F F^{\wedge} 2+U O E F F *(L O G(E N)-\operatorname{KOEFF}) \wedge 2\right) *(\mathrm{COEFF}+\mathrm{C} 1\right.$ $E F F \star I O G(E N)+C 2 E F F \star L O G(E N) \wedge 2+C 3 E F F \star L O G(E N) \wedge 3)+.5 \star(1+S G N(E N-E N X)) *(D O E F F+D 1 E F F \star L O G$ $(E N)+D 2 E F F * I O G(E N) \wedge 2+D 3 E F F * L O G(E N) \wedge 3))$

59 DEF FNEFFB (EN) $=1+P 0 E F F+P 1 E F F \star L O G(E N)+P 2 E F F \star L O G(E N) \wedge 2+P 3 E F F \star L O G(E N) \wedge 3$

60 DEF FNEFF $($ EN $)=$ FNEFFA $(E N) \star F N E F F B(E N)$

391 LPRINT:REM 2/4/99 earlier lines 391-397 now 461-467 to allow below

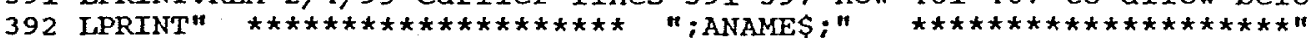

393 LPRINT:LPRINT: LPRINT" -

394 LPRINT: LPRINT

395 LPRINT" Peak

396 LPRINT" \# minl max min2

Area $t /-$ Error

counts $t /-$ counts

Energy

$\mathrm{keV}$

Isotope"

397 LPRINT

398. IP=IP-1:REM correct rope search number of peaks

400 GOSUB $4000:$ REM - peak areas and isotope calcs

410 FOR XP=NMDA+1 TO KPMAX

411 REM IF ABS (ENERGY (XP)-250) < 50 THEN PRINT"Line $411 \mathrm{xp/energY/area";XP,} \mathrm{ENERG}$ $Y(X P), A R E A(X P): R E M$ debug exploration $12 / 98$

412 NEXT XP

413 PRINT:PRINT"MDAs Flagged in Isotope Library = NMDA =" ;NMDA

450 GOSUB 3000:REM - merge identified peaks and MDA cases

455 REM PRINT"Iine 455 peak 25 area = ";AREA(25):REM debug exploration 12/98

460 IF SAMBAC=1 THEN GOSUB 5200:REM - input background data

461 LPRINT

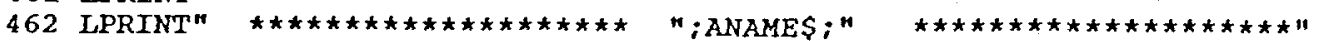

463 LPRINT:LPRINT:LPRINT" - Detailed Sample Analysis

464 LPRINT: LPRINT

465 LPRINT "Peak Channel Energy FWHM Tail counts Rate Bkgnd Isotope Acti

vity Error"

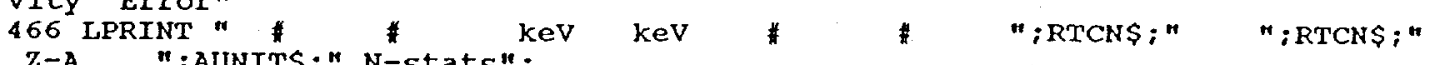

467 LPRINT

475 GOSUB $3500:$ REM - output first results table

480 LPRINT "Key: spect spect spect spect spect spect file lib toleft to-left";

485 LPRINT " -

$1-$

lib calc $-+1-+1-$

$+/-$

$-$

$+$

490 PRINT: INPUT"Desire Supplementary Analyses $(y / n)^{\prime \prime} ; Y E \$$

495 IF YE\$=" $Y$ " THEN GOSUB 6000:REM - make flles for supplementary analyses

500 STOP 


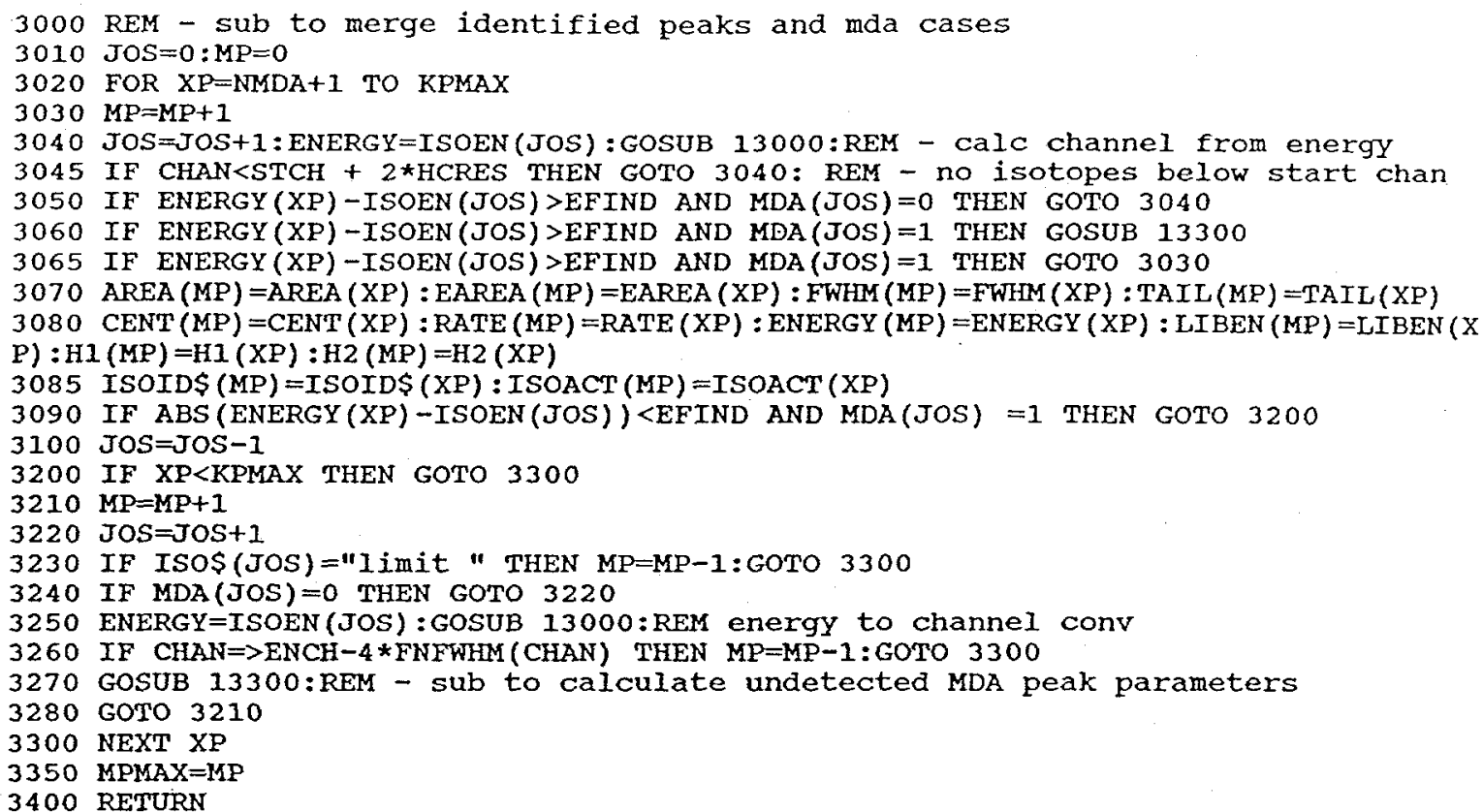




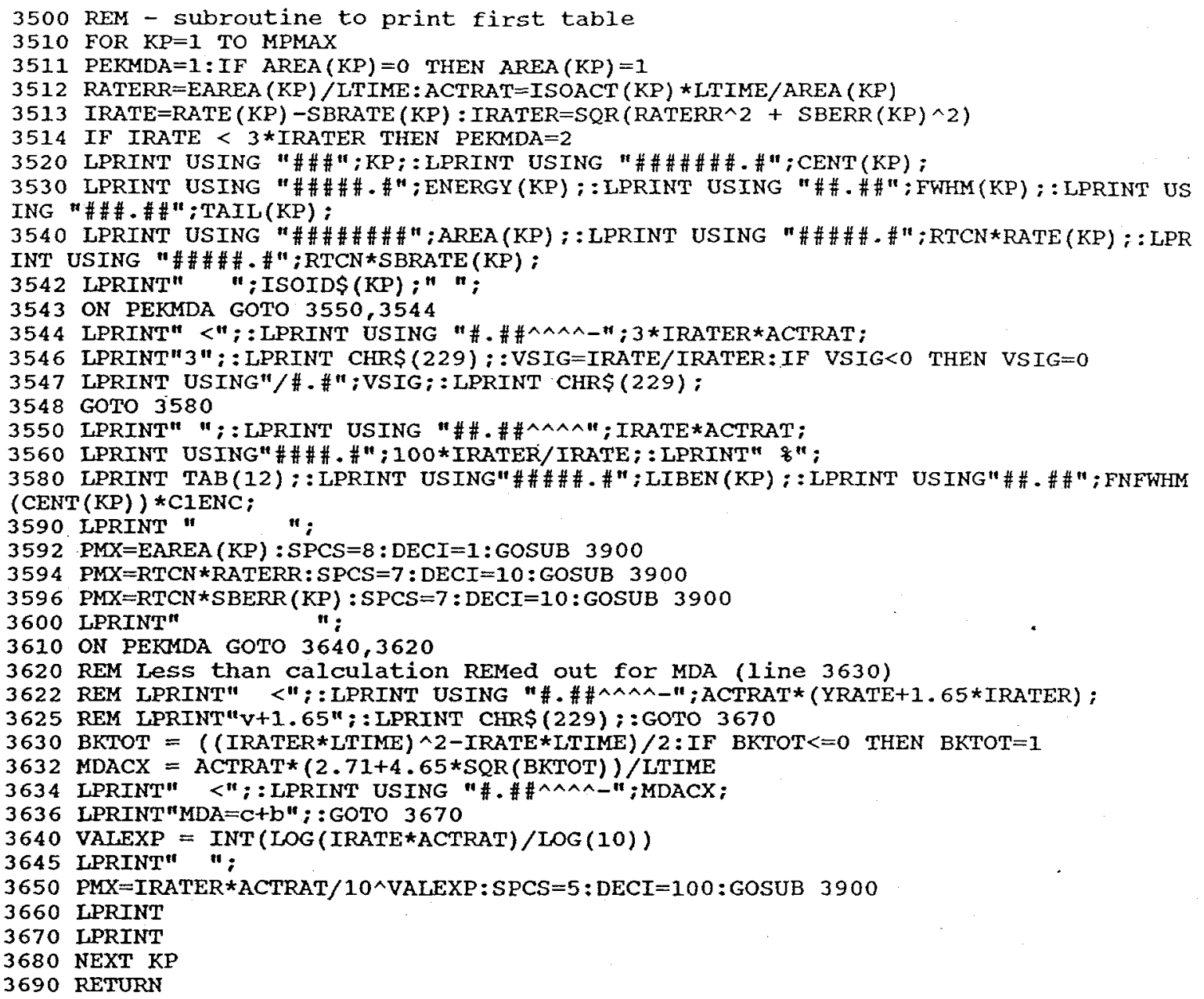




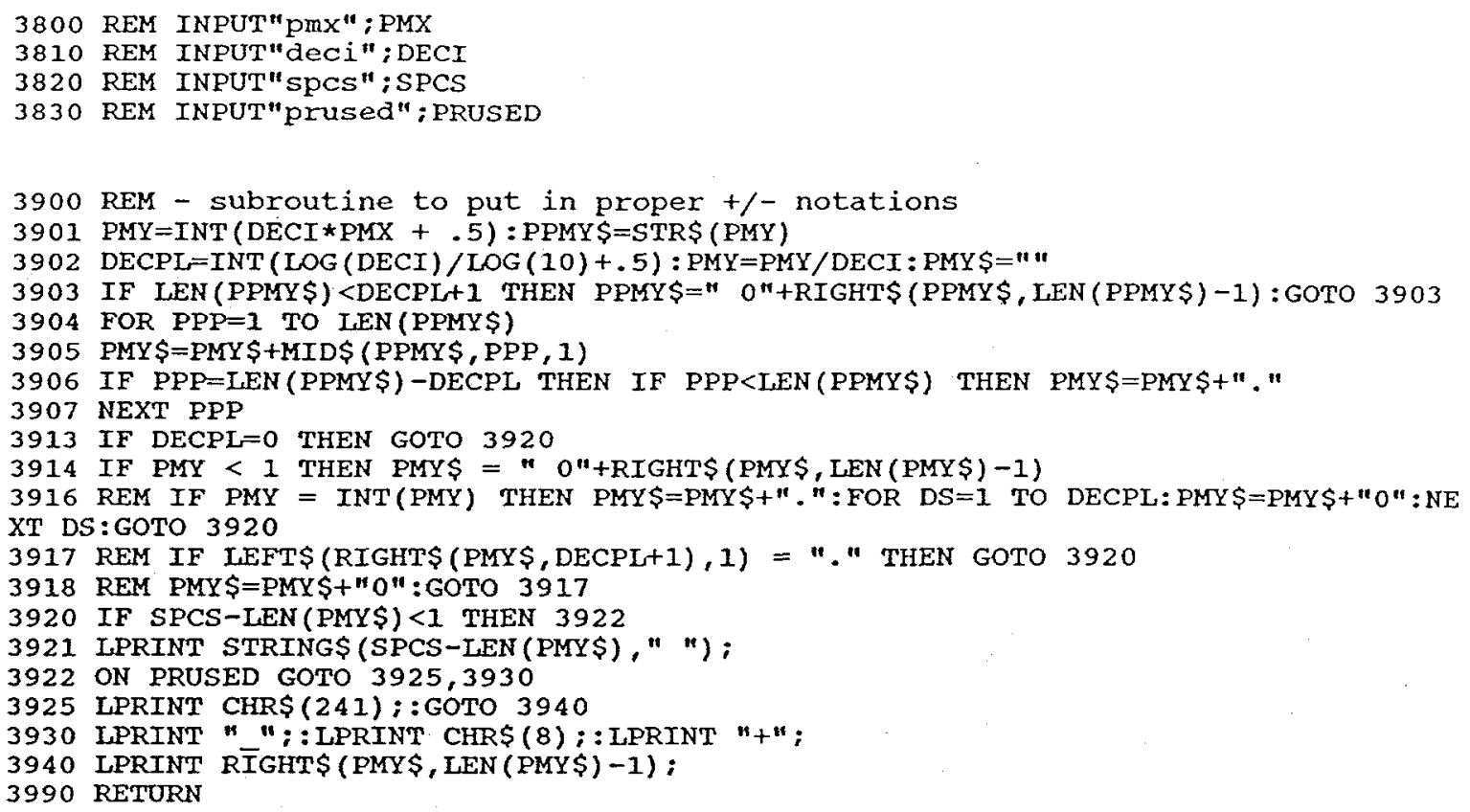


4000 REM examine detected peaks in detail

$4001 \mathrm{KP}=\mathrm{NMDA}: \mathrm{ISO}=1$

4002 FOR JP=1 TO IP

4003 IF ABS (LOCH (JP+1)-LOCH (JP)) <3.5*FNFWHM(LOCH(JP)) THEN GOSUB 14500:GOTO 4500

$4012 \mathrm{~B} 1=0: \mathrm{B} 2=0:$ HCRES $=\operatorname{INT}(\operatorname{FNFWHM}(\operatorname{LOCH}(\mathrm{JP}))+.5): \operatorname{IF}$ HCRES $<3$ THEN HCRES=3

$4014 \mathrm{MAX} 3=0$

4015 FOR $\mathrm{L}=\mathrm{LOCH}(\mathrm{JP})-2 * \mathrm{HCRES}$ TO $\mathrm{LOCH}(\mathrm{JP})+2 *$ HCRES

$4016 S \mathrm{SUM} 3=\mathrm{NPC}(\mathrm{L}-1)+\mathrm{NPC}(\mathrm{L})+\mathrm{NPC}(\mathrm{L}+1)$

4017 IF SUM $3>$ MAX3 THEN MAX3 $=$ SUM $3:$ MAXL $=\mathrm{L}$

4018 NEXT L

4020 FOR $I=1$ TO HCRES

$4030 \mathrm{~B} 1=\mathrm{B} 1+\mathrm{NPC}(\mathrm{LOCH}(\mathrm{JP})-\mathrm{L})$

$4040 \mathrm{~B} 2=\mathrm{B} 2+\mathrm{NPC}(\mathrm{IOCH}(\mathrm{JP})+\mathrm{L})$

4050 NEXT L

$4060 \mathrm{~L} 1=\mathrm{LOCH}(\mathrm{JP})-\mathrm{HCRES}: \mathrm{L} 2=\mathrm{LOCH}(\mathrm{JP})+\mathrm{HCRES}$

$4070 \mathrm{H} 1=\mathrm{LOCH}(\mathrm{JP})-1: \mathrm{H} 2=\mathrm{LOCH}(\mathrm{JP})+1$

$4080 \mathrm{REM}$ - find constant b1 background region

$4090 \mathrm{NLI}=\mathrm{NPC}(\mathrm{LI}-1): \mathrm{NH} 1=\mathrm{NPC}$ (H1)

$4100 \mathrm{~B} 1=\mathrm{NL} 1+\mathrm{B} 1-\mathrm{NH} 1: \mathrm{B} 1 \mathrm{AVE}=\mathrm{B} 1 / \mathrm{HCRES}$

4110 IF (NH1-B1AVE) $>2 * S Q R$ (NH1+B1AVE/HCRES) THEN L1=L1-1:H1=H1-1:GOTO 4090

4120 REM - find constant b2 background region

$4130 \mathrm{NL} 2=\mathrm{NPC}(\mathrm{L} 2+1): \mathrm{NH} 2=\mathrm{NPC}(\mathrm{H} 2)$

$4140 \mathrm{~B} 2=\mathrm{NL} 2+\mathrm{B} 2-\mathrm{NH} 2: \mathrm{B} 2 \mathrm{AVE}=\mathrm{B} 2 \% \mathrm{HCRES}$

4150 IF (NH2-B2AVE) $>2 * \mathrm{SQR}$ (NH2+B2AVE/HCRES) THEN L2=L $2+1: \mathrm{H} 2=\mathrm{H} 2+1:$ GOTO 4130

4155 IF H2-H1+1 < $2 *$ HCRES THEN H1=MAXL-HCRES-1:H2=MAXL+HCRES

4160 IF $(\mathrm{H} 2-\mathrm{H} 1+1) / 2<\mathrm{INT}((\mathrm{H} 2-\mathrm{H} 1+1) / 2)$ THEN H $1=\mathrm{H} 1-1$

$4170 \mathrm{~L} 1=\mathrm{H} 1-(\mathrm{H} 2-\mathrm{H} 1+1) / 2: \mathrm{L} 2=\mathrm{H} 2+(\mathrm{H} 2-\mathrm{H} 1+1) / 2$

$4175 B 1=0: G=0: B 2=0$

4180 FOR $\mathrm{L}=\mathrm{L} 1$ TO $\mathrm{HI}-1$

$4190 \mathrm{BI}=\mathrm{B} 1+\mathrm{NPC}(\mathrm{L})$

4200 NEXT L

4210 FOR $\mathrm{I}=\mathrm{H} 1$ TO $\mathrm{H} 2$

$4220 \mathrm{G}=\mathrm{G}+\mathrm{NPC}(\mathrm{L})$

4230 NEXT $L$

4240 FOR $\mathrm{L}=\mathrm{H} 2+1$ TO $\mathrm{L} 2$

$4250 \mathrm{~B} 2=\mathrm{B} 2+\mathrm{NPC}(\mathrm{L})$

4260 NEXT I

4270 IF $(\mathrm{G}-\mathrm{B} 1-\mathrm{B} 2)<3 * \mathrm{SQR}(\mathrm{G}+\mathrm{B} 1+\mathrm{B} 2)$ THEN GOTO 4500

4275 IF MAXL=MAXLP THEN GOTO 4500

$4280 \mathrm{KP}=\mathrm{KP}+1$

4285 MAXLP=MAXL

4300 AREA $(K P)=G-B 1-B 2: \operatorname{EAREA}(K P)=S Q R(G+B 1+B 2)$

4310 A=AREA (KP)

4320 GOSUB 14000:REM centroid and fwhm

4330 FWHM $(\mathrm{KP})=$ FWHM : TAIL $(\mathrm{KP})=$ TAIL: CENT $(\mathrm{KP})=$ CENT $: \mathrm{H} 1(\mathrm{KP})=\mathrm{H} 1: \mathrm{H} 2(\mathrm{KP})=\mathrm{H} 2$

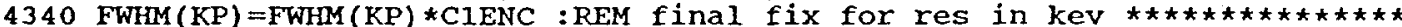

4350 RATE $(K P)=$ AREA $(K P) /$ LTIME

4360 ENERGY $(\mathrm{KP})=$ FNENC $($ CENT $(\mathrm{KP}))$

4370 GOSUB 14200 : REM isotope ident and calcs

4380 IF ABS (ENERGY (KP) -ISOEN (ISO+1)) <EFIND THEN ISO=ISO+1: GOTO 4280

4500 NEXT JP

4550 KPMAX $=$ KP

4900 RETURN 


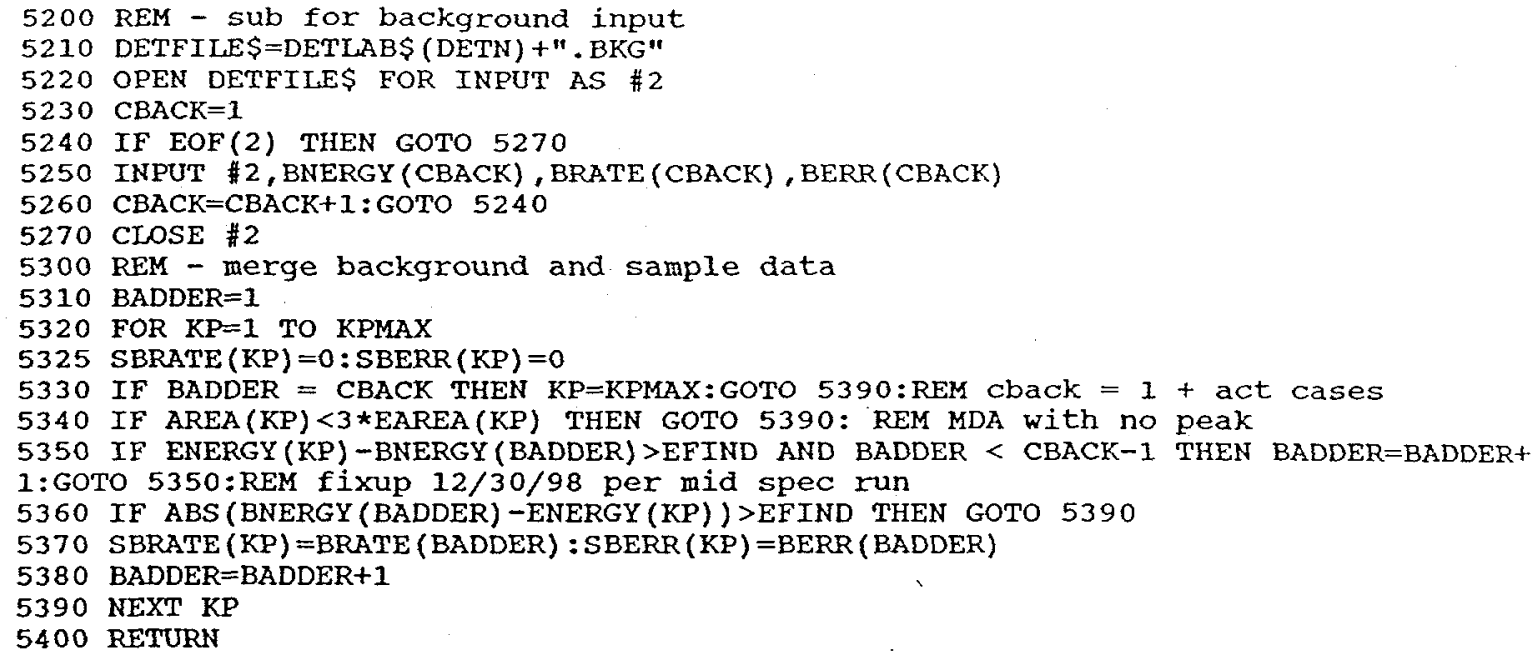




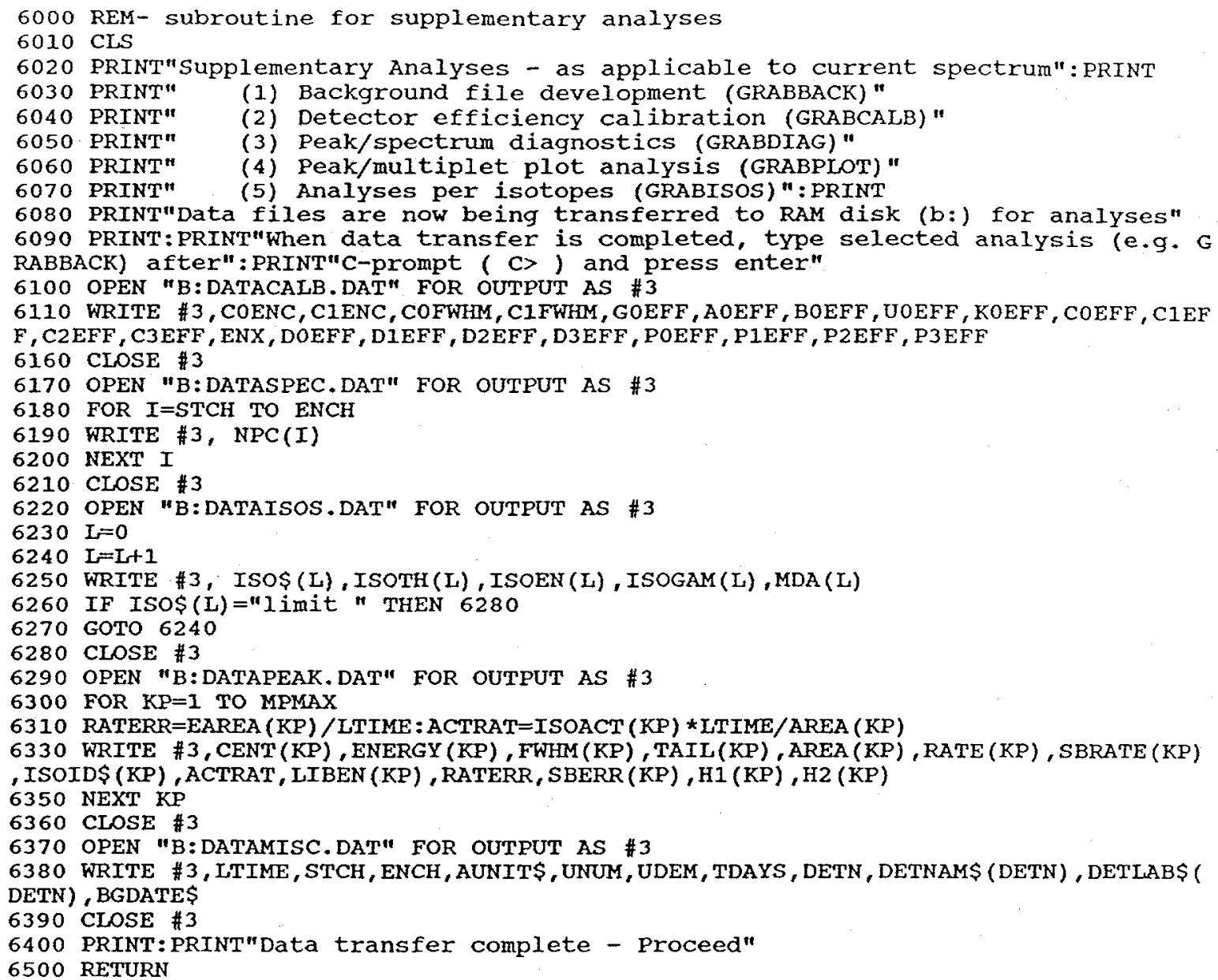




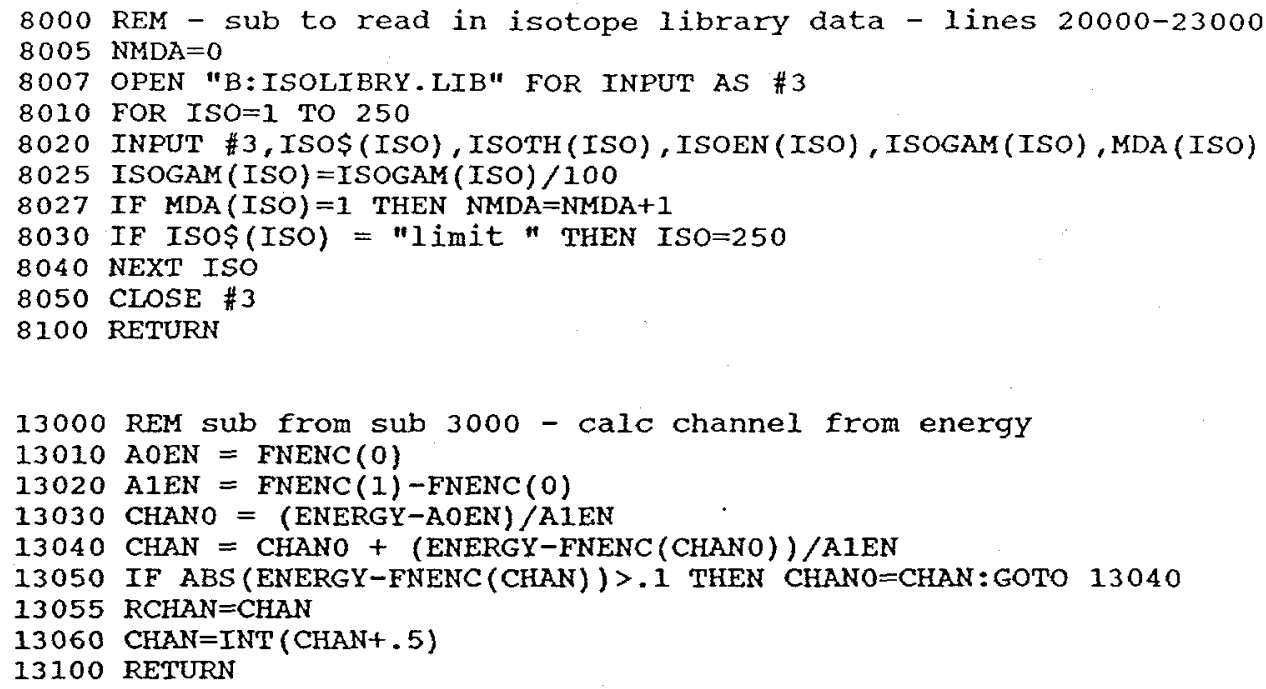


14000 REM subroutine from subroutine 4000 - centroid and fwhm for peaks found

$14010 \mathrm{BCl}=\mathrm{B} 1 /(\mathrm{H} 1-\mathrm{L} 1): \mathrm{BC} 2=\mathrm{B} 2 /(\mathrm{L} 2-\mathrm{H} 2)$

$14020 \mathrm{FI}=0: G L=0: L=0: D B C F I=0: F L A G A=0: F L A G B=0: F L A G C=0$

14030 FOR LI $=\mathrm{H} 1$ TO $\mathrm{H} 2$

$14035 \mathrm{~L}=\mathrm{L}+1$

$14040 \mathrm{GL}=\mathrm{GI}+\mathrm{NPC}(\mathrm{LL})$

$14050 \mathrm{FI}=(\mathrm{GI}-\mathrm{L} * \mathrm{BC} 1+\mathrm{DBCFI}) /(\mathrm{A}-(\mathrm{BCI}-\mathrm{BC} 2) / 2)$

14060 IF FL $>=.16$ AND FI $<=.16$ THEN SIGA=LL- $(1 /(F L-F I)) *(F L-.16): F L A G A=1$

14070 IF FL $>=.5$ AND FI $<=.5$ THEN CENT $=L L-(1 /(F L-F I)) *(F L-.5): F L A G C=1$

14080 IF $F L>=.84$ AND FI $<=.84$ THEN SIGB $=L L-(1 /(F L-F I)) *(F L-.84): F I A G B=1$

$14090 \mathrm{FI}=\mathrm{FL}: \mathrm{DBCFI}=\mathrm{DBCFI}+(\mathrm{BC} 1-\mathrm{BC} 2) * \mathrm{FI}$

14100 NEXT LL

14110 FWHM $=(2.355 / 2) *($ SIGB-SIGA $)$

14115 IF SIGB-SIGA $=0$ THEN TAIL $=-4:$ GOTO 14125

14116 IF SIGB-CENT=0 THEN TAIL $=-5:$ GOTO 14125

14120 TAIL $=$ (CENT-SIGA) / (SIGB-CENT)

14125 IF $\mathrm{FL}<0$ THEN FWHM $=\mathrm{H} 2-\mathrm{H} 1+1:$ TAII $=-2: \mathrm{CENT}=(\mathrm{H} 1+\mathrm{H} 2) / 2$

14127 IF FLAGA $*$ FLAGB $*$ FLAGC $=0$ THEN FWHM $=\mathrm{H} 2-\mathrm{HI}+1: \mathrm{TAIL}=-3: \mathrm{CENT}=(\mathrm{H} 1+\mathrm{H} 2) / 2$

14130 RETURN

14200 REM subroutine from sub 4000 - isotope id and calcs

14210 IF (ENERGY (KP) -ISOEN (ISO)) > EFIND THEN ISO=ISO+1: GOTO 14210

14220 IF ABS (ENERGY (KP) -ISOEN(ISO)) >EFIND THEN ISOIDS(KP)="NO-LIb": ISOACT (KP) = RATE (KP) *RUNITS/FNEFF (ENERGY (KP)) : GOTO 14250

$14230 \operatorname{ISOID}(\mathrm{KP})=\operatorname{ISO} \$(\operatorname{ISO}): \operatorname{LIBEN}(\mathrm{KP})=\operatorname{ISOEN}(\mathrm{ISO}): \operatorname{MDA}(\operatorname{ISO})=0$

14235 REM** case for two or more acceptable ids of peak - fixup in line 4380

14240 ISOACT $(\mathrm{KP})=\operatorname{RATE}(\mathrm{KP}) *(2 \wedge($ TDAYS/ISOTH $($ ISO $))) *$ RUNITS/ (ISOGAM (ISO) *FNEFF (ISOEN (ISO)) )

14250 RETURN 





$14860 \mathrm{NEXT} I$,

14861 IF MINXM(XMULT+1)-LOCPO-.5> 1 AND LOCPI+.5-MINXM(XMULT+1) > 1 THEN 14870: REM abs minimum found $2 / 9 / 99$ rev

14862 IF MINX1-LOCPO-.5 > 1 AND LOCP1+.5-MINX1 > 1 THEN MINXM(XMULT+1)=MINX1:GOT O 14870:REM rel minimum found $2 / 9 / 99$ rev

$14863 \operatorname{MINXM}(X M U L T+1)=\operatorname{INT}(($ LOCPO $*$ NPC $($ LOCPI $)+L O C P I * N P C(L O C P O)) /(N P C(L O C P O)+N P C(L$ $O C P 1\})+.5)+.53:$ REM inverse average minimum/ $0.532 / 9 / 99$

14864 IF MINXM (XNULT+1)-LOCPO-.5<.5 THEN MINXM (XNULT+I) =LOCPO+1.53:REM 3/12\%99

14865 IF LOCP1+.5-MINXM (XMULT+1)<.5 THEN MINXM $(X M U L T+1)=$ LOCP1- $47:$ REM 3/12/99

14870 NEXT XMULT

14879 REM

14880 REM - find total area of multiplet

$14885 \mathrm{G}=0$

14890 FOR $\mathrm{I}=\mathrm{H} 1$ TO $\mathrm{H} 2$

$14900 \mathrm{G}=\mathrm{G}+\mathrm{NPC}(\mathrm{L})$

14910 NEXT L

$14920 \mathrm{H} 12=\mathrm{H} 2-\mathrm{H} 1+1$

14925 FLAGA $=0:$ FLAGB $=0: F L A G C=0$

$14930 \mathrm{~A}=\mathrm{G}-.5 *(\mathrm{~B} 1 / \mathrm{CHB} 1+\mathrm{B} 2 / \mathrm{CHB} 2) * \mathrm{H} 12: \mathrm{ERRA}=\mathrm{SQR}\left(\mathrm{G}+.25 *\left(\mathrm{~B} 1 / \mathrm{CHB} 1 \wedge 2+\mathrm{B} 2 / \mathrm{CHB} 2^{\wedge} 2\right) \star \mathrm{H} 12^{\wedge} 2\right)$

14931 IF $A>3 *$ ERRA THEN 14950

14932 IF $\mathrm{B} 1 / \mathrm{CHB1}>\mathrm{B} 2 / \mathrm{CHB} 2$ THEN $\mathrm{B1}=\mathrm{B2}: \mathrm{CHB1}=\mathrm{CHB2}: \mathrm{REM}-\min$ background

14933 IF $\mathrm{B} 2 / \mathrm{CHB} 2>\mathrm{B} 1 / \mathrm{CHB} 1$ THEN $\mathrm{B} 2=\mathrm{B} 1: \mathrm{CHB} 2=\mathrm{CHB1}$

14934 CHB12 $=\mathrm{CHB} 1+\mathrm{CHB} 2$

$14935 \mathrm{~A}=\mathrm{G}-\mathrm{H} 12 *(\mathrm{~B} 1+\mathrm{B} 2) /(\mathrm{CHB} 12): \mathrm{ERRA}=\mathrm{SQR}(\mathrm{G}+(\mathrm{B} 1+\mathrm{B} 2) *(\mathrm{H} 12 /(\mathrm{CHB12})) \wedge 2)$

14936 FLAGB $=2$

14940 REM if $a<3 *$ erra then goto end of subroutine

14949 REM

14950 REM - get fractional areas by integral technique

14951 ASAVE $=\AA$ : REM $3 / 12 / 99$

14955 FOR LL $=0$ TO $20: A(L L)=0:$ NEXT LL

$14960 \mathrm{BCl}=\mathrm{B} 1 /(\mathrm{CHB} 1): \mathrm{BC} 2=\mathrm{B} 2 /(\mathrm{CHB} 2)$

14965 PWTCH=0:WTCH=0:REM INITILIZE FOR PEAK C.G. 2/9-10/99

14970 IF FLAGB $=2$ THEN $F I=0: G L=0: L=0: D B C F I=0:$ GOTO 14975:REM sloping bkgnd fix 149

$7112 / 21 / 98$ except for $F L A G B=2$ of $12 / 30 / 98$

14971 GOSUB 16000:REM sloping bkgnd fix 12/21/98

14972 FI=0:GL=0:L=0:DBCFI=0:REM sloping bjond $\mathrm{fix} 12 / 21 / 98$

14973 PFI=0:PGI=0:PDBCFI=0:REM add $\mathrm{dF} / \mathrm{dB}$ info $12 / 29 / 98$

14975 XMULT=1:REM - will shift back to zero start later - lines

14980 FOR LL=H1 TO H2

$14990 \mathrm{~L}=\mathrm{L}+1$ : REM channel $\mathrm{L}$ relative to $\mathrm{H} 1-1$ origin as 0

15000 IF FLAGB=2 THEN GIFGL+NPC $\left(L_{1}\right)$ : GOTO 15005:REM sloping background fix 15001

$12 / 21 / 98$ except for $F I A G=2$ of $12 / 30 / 98$

$15001 \mathrm{GL}=\mathrm{GL}+\mathrm{NPC}$ (LL) $-\mathrm{SLB} 12 * \mathrm{~L}-\mathrm{QUD} 12 * \mathrm{~L}^{\wedge} 2-\mathrm{CUB1} 2 * \mathrm{~L}^{\wedge} 3:$ REM sloping bkgnd $\mathrm{fix} 1 / 29 / 99$

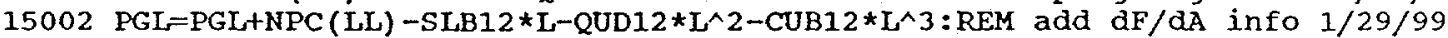

15005 IF FIAGB=2 AND $(\mathrm{A}-(\mathrm{BCl}-\mathrm{BC}) / 2)=0$ THEN FL=GL-L*BC1+DBCFI:GOTO 15020 ELSE GO To 15010:REM slope 12/21 except for $F L A G B=2$ of $12 / 30 / 98$

15006 IF $(A-B D E L T A / 2)=0$ THEN FI $=G L-L * C B C+D B C F I: R E M$ slope bk $1 / 13 / 99$

15007 IF $(P A-B D E L T A / 2)=0$ THEN PFL=PGL-I*CBC+PDBCFI:GOTO 15020:REM 1/13/99

15008 IF $(A-B D E L T A / 2)=0$ THEN GOTO 15020:REM 1/13/99

15010 IF FLAGB=2 THEN FL= (GL-L*BC1+DBCFI $) /(\mathrm{A}-(\mathrm{BC} 1-\mathrm{BC} 2) / 2)$ : GOTO 15020:REM sloping

b 15011 12/21/98 except for FLAGB $=2$ of $12 / 30 / 98$

15011 FL $=(G L-L \star C B C+D B C F I) /(A-B D E L T A / 2): R E M$ sloping b fix $12 / 21 / 98$

$15012 \mathrm{PFL}=(\mathrm{PGL}-\mathrm{L} * \mathrm{CBC}+\mathrm{PDBCFI}) /(\mathrm{PA}-\mathrm{BDELTA} / 2): \mathrm{REM} \mathrm{dF} / \mathrm{dA} 1 / 13 / 99$

15020 IF LL $M$ MNXM (XMULT) THEN A (XMULT)=FI:REM XMULT=XMULT+1 1ine 15024 2/10/99

15021 IF ABS (LL-CENT (KP+XMULT-1) $<2$ THEN PWTCH=PWTCH+LL* (FL-FI):REM CP $2 / 9-10$

15022 IF ABS (LI-CENT (KP+XMULT-1)) < 2 THEN WTCH=WTCH+FL-FI:REM peak Cp 2/9-10/9

15023 IF LL $>$ MINXM (XMULT) AND WTCH>0 THEN MCENT (XMULT-1) =PWTCH/WTCH:REM peaK C.g. $2 / 9-10 / 99$

15024 IF LL $>$ MINXM (XMULT) THEN PWTCH=0:WTCH=0:XMULT=XMULT+1:REM C.9. 2/9-10/99

15030 IF FLAGB=2 THEN FI=FL:DBCFI=DBCFI+(BCi-BC2)*FI:GOTO 15040:REM sloping $B$ is 
$03112 / 21 / 98$ except for FLAGB=2 of $12 / 30 / 98$

15031 FI=FL:DBCFI=DBCFI+(BDELTA $)$ *FI

15032 PFI=PFL: PDBCF $I=$ PDBCFI+ (BDELTA $)$ *PFI: REM 1/13/99

$15040 \mathrm{NEXT}$ LL

15041 IF FLAGB=2 THEN GOTO 15045: REM fixup 12/30/98

15042 IF PFI-FI=0 THEN GOTO 15045:REM 3/2/99 zero divide fix 1 ine 16820

15043 IF ABS(FI-1)>.001 THEN GOSUB 16800:GOTO 14972:REM find FI=1 12/29

15045 A (NMULT) $=F L: A(0)=0:$ REM - nail down these

15049 REM

15050 REM - rearrange above axeas which are one-sided integrals

15060 FOR XMULT=0 TO NMULT-1

15065 IF A(NMULT) $=0$ THEN A (NMULT) $=1$

15070 A $($ XMULT $)=(A(X M U L T+1)-A(X M U L T)) / A($ NMULT $):$ REM ASSURED NORMALTZATION

15075 IF $A$ (XMULT) $<=0$ THEN FIAGA $=1$

15080 NEXT XMULT

15090 REM above a( ) is oth order multiplet analysis (TD( ) for A() later)

15480 FOR XMULT $=0$ TO NMULT-1

15482 IF ABS (MCENT (XMULT)-CENT(KP+XMULT)) <. 5 THEN GOTO 15490:REM 2/9+3/12/99

$15485 \mathrm{CXM}=\mathrm{CENT}(\mathrm{KP}+\mathrm{XMULT}):$ REM rev $2 / 9 / 99$

15486 MCENT (XMULT) $=(\mathrm{CXM}-.5) * \mathrm{NPC}(\mathrm{CXM}-.5)+(\mathrm{CXM}+.5) * \mathrm{NPC}(\mathrm{CXM}+.5): \mathrm{REM}$ add $2 / 9 / 99$

15487 IF NPC $(C X M-.5)+N P C(C X M+.5)=0$ THEN MCENT (XMULT) $=$ CXM:GOTO $15490:$ REM $3 / 2 / 99$

$15488 \operatorname{MCENT}($ XMULT $)=\operatorname{MCENT}(X M U L T) /(\operatorname{NPC}(\mathrm{CXM}-.5)+\operatorname{NPC}(\mathrm{CXM}+.5)): \operatorname{REM}$ add $2 / 9 / 99$

15490 NEXT XMULT

15500 REM setup to print results

15510 FOR XMULT $=0$ TO NMULT-1

15515 CENT $($ KP $)=$ MCENT (XMULT)

15520 ENERGY (KP) = FNENC (CENT (KP))

15521 IF FLAGA=0 THEN 15530:REM - otherwise negative or zero a()

15522 GXMULT=0:MINXMQ $=\operatorname{INT}(\operatorname{MINXM}(X M U L T)+1): M I N X M P=I N T(M I N X M(X M U L T+1))$

15523 FOR LL=MINXMQ TO MINXMP:GXMULT=GXMULT+NPC(LL) :NEXT LL

$15524 \mathrm{~B} 1 \mathrm{XM}=\mathrm{BC} 1+(\mathrm{BC} 2-\mathrm{BC} 1) *(\mathrm{MINXMQ}-\mathrm{H} 1) /(\mathrm{H} 2-\mathrm{H} 1)$

$15525 \mathrm{~B} 2 \mathrm{XM}=\mathrm{BC} 1+(\mathrm{BC} 2-\mathrm{BC1}) *(\mathrm{MINXMP}-\mathrm{H} 1) /(\mathrm{H} 2-\mathrm{H} 1)$

$15526 \mathrm{BXM}=.5 *(\mathrm{~B} 1 \mathrm{XM}+\mathrm{B} 2 \mathrm{XM})$ * (MINXMP-MINXMQ +1$): \Upsilon F \quad \mathrm{BXM}<0$ THEN FLAGB=1

15527 AREA $(K P)=$ GXMULT-BXM $: \operatorname{RATE}(\mathrm{KP})=\operatorname{AREA}(\mathrm{KP}) /$ LTIME $: \operatorname{EAREA}(\mathrm{KP})=\operatorname{SQR}($ GXMULT+ABS $(B X M))$

15528 IF AREA(KP) $<0$ AND FLAGA=1 THEN B1XM=NPC (MINXMQ-1):B2XM=NPC (MINXMP+1):FLAGA $=2:$ GOTO 15526

15529 GOTO 15560

15530 AREA $(\mathrm{KP})=\mathrm{A}(\mathrm{XMULT}) * \mathrm{~A}: \mathrm{RATE}(\mathrm{KP})=\mathrm{AREA}(\mathrm{KP}) / \mathrm{LTIME}$

15535 REM IF ABS (ENERGY (KP) - 250) < 50 THEN PRINT"Line $15535 \mathrm{jp} / \mathrm{kp} / \mathrm{energY/area)} \mathrm{";}$ JP, KP, ENERGY (KP), AREA (KP) : REM $12 / 98$ debugger

15536 REM IF JP=11 THEN INPUT"continue $(y / n)$ or $c t 1-b k "$;YES:REM debugger 12/98

15540 EAREA $($ KP $)=$ ERRA $* \operatorname{SQR}(A(X M U L T))$

15560 FWHM $($ KP $)=$ NMULT+FLAGA $/ 10+$ FLAGB $/ 100:$ TAIL $(\mathrm{KP})=\mathrm{XMULT}+1+\mathrm{FLAGA} / 10+\mathrm{FLAGB} / 100$

15565 IF FLAGA $>0$ THEN FLAGA=1

15569 IF AREA (KP) =0 THEN AREA (KP) =1:RATE (KP)=AREA (KP) /LTIME

15570 GOSUB $14200:$ REM iso ident

15573 HIEND $=0:$ IF MINXM (XMULT) $=\mathrm{H} 1-1$ THEN H1END $=.5:$ REM $3 / 8 / 99$

$15574 \mathrm{H} 2 \mathrm{END}=0$ :IF MINXM (XMULT+1) $=\mathrm{H} 2$ THEN H2END=.5:REM 3/8/99 and 15575

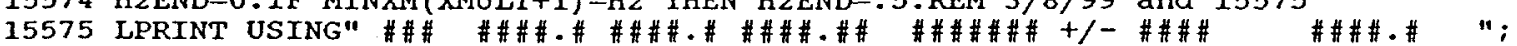
XMULT+1, MINXM (XMULT) -H1END, MCENT (XMULT), MINXM (XMULT+1)+H2END, AREA (KP), EAREA (KP), ENERGY (KP) ;

15576 LPRINT ISOIDS(KP):REM Iines 15575-15576 added 2/4/99 for mult params

15580 IF ABS (ENERGY (KP) -ISOEN (ISO+I)) <EFIND THEN ISO=ISO+1:KP=KP+1:GOTO 15515

$15590 \mathrm{KP}=\mathrm{KP}+1: \mathrm{JP}=\mathrm{JP}+1$

15600 NEXT XMULT

15605 LPRINT:REM 2/4/99 for multiplet parameters

$15610 \mathrm{KP}=\mathrm{KP}-1: \mathrm{JP}=\mathrm{JP}-1$

15900 RETURN 
16000 REM - Subroutine for Sloping Background Calculations 12/21/98

16005 MAXBDEL $=.04 *(100 /$ MENERGY $) *(\mathrm{~A} / \mathrm{MFWHM})$

16010 REM - set up $B i$ region straight-1ine fit

16020 LCHB1=8:IF (H1-LOCH (JP-1)-HCRES) <8 THEN LCHB1=HI-LOCH(JP-1)-HCRES

16025 IF LCHBI<3 THEN LCHBI $=3$

16030 XISLOW $=\mathrm{H} 1-\mathrm{LCHB} 1: \mathrm{XISHI}=\mathrm{H} 1-1$

16040 GOSUB 16500

$16050 \mathrm{C} 1 \mathrm{~B}=\mathrm{ACONST}: \mathrm{SL1B}=\mathrm{BSLOPE}$

16060 REM - set up $B 2$ region straight-line fit

16070 LCHB2 $=8:$ IF (LOCH (JP+NMULT) -H2-HCRES) $<8$ THEN LCHB2 $=$ LOCH (JP+NMULT) -H2-HCRES

16075 IF LCHB2 $<3$ THEN LCHB2 $=3$

16080 XISLOW $=\mathrm{H} 2+1: \mathrm{XISHI}=\mathrm{H} 2+$ LCHB2

16090 GOSUB 16500

$16100 \mathrm{C} 2 \mathrm{~B}=\mathrm{ACONST}: \mathrm{SL} 2 \mathrm{~B}=\mathrm{BSLOPE}$

16110 QUD12 $=.5 *($ SL2B-SL1B $) /(\mathrm{H} 2-\mathrm{H} 1+2):$ REM $1 / 13 / 99$

16120 B1FITO=CIB: REM relative origin at $\mathrm{H} 1-1$ as 0

$16130 \mathrm{~B} 2 \mathrm{FITO}=\mathrm{C} 2 \mathrm{~B}: \mathrm{REM}$ relative origin at $\mathrm{H} 1-1$ as 0

$16135 \mathrm{~B} 2 \mathrm{FITR}=\mathrm{C} 2 \mathrm{~B}+\mathrm{SL} 2 \mathrm{~B} *(\mathrm{H} 2-\mathrm{H} 1+2): \mathrm{REM}$ at right of peak or $\mathrm{h} 2+1$

16140 SLB12=SLIB:REM changed $1 / 14 / 99$

$16150 \mathrm{BDELTA}=\mathrm{C} 1 \mathrm{~B}-\mathrm{C} 2 \mathrm{~B}-\mathrm{QUD} 12 *(\mathrm{H} 2-\mathrm{H} 1+2) \wedge 2: \mathrm{REM} 1 / 13 / 99$

16155 REM BDSTEP=. I *BDELTA: IF BDSTEP=0 THEN BDSTEP=1: rem $1 / 13 / 99$

16156 ADSTEP $=.01 * A:$ REM $1 / 13 / 99$

$16157 \mathrm{CBC}=\mathrm{B} 1 \mathrm{FITO}$

16158 CUB12=0:REM add $1 / 29 / 99$

16160 IF BDELTA=>0 AND BDELTA<=MAXBDEL THEN GOTO 16171

16161 IF BDELTA<0 THEN BDELTA=0:REM 1/29/99 QUD12=0:SLB12=(B2FITR-B1FITO+BDELTA) $/(\mathrm{H} 2-\mathrm{H} 1+2):$ REM $1 / 19 / 99$

16162 IF BDELTA>MAXBDEL THEN BDELTA=MAXBDEL:REM 1/29/99 QUD12=0:SLB12=(B2FITR-B1 FITO+BDELTA) /(H2-H1+2):REM 1/19/99.

16163 QUDI $2=3 *(\mathrm{C} 2 \mathrm{~B}-\mathrm{C} 1 \mathrm{~B}+\mathrm{BDELTA}) /(\mathrm{H} 2-\mathrm{H} 1+2)^{\wedge} 2+2 *(\mathrm{SL} 2 \mathrm{~B}-\mathrm{SLIB}) /(\mathrm{H} 2-\mathrm{H} 1+1): \mathrm{REM} 1 / 29 / 99$

$16164 \mathrm{CUB12}=-2 *(\mathrm{C} 2 \mathrm{~B}-\mathrm{C} 1 \mathrm{~B}+\mathrm{BDELTA}) /(\mathrm{H} 2-\mathrm{H} 1+2) \wedge 3-(\mathrm{SL} 2 \mathrm{~B}-\mathrm{SLIB}) /(\mathrm{H} 2-\mathrm{H} 1+1) \wedge 2: \mathrm{REM} 1 / 29 / 99$

16165 REM PBDELTA=BDELTA+BDSTEP: rem $1 / 13 / 99$

16170 REM PSLB12=(B2FITR-B1FIT0+PBDELTA $) /(\mathrm{H} 2-\mathrm{H} 1+2): \mathrm{rem} 1 / 13 / 99$

$16171 \mathrm{PA}=\mathrm{A}+$ ADSTEP:REM $1 / 13 / 99$

16200 RETURN 


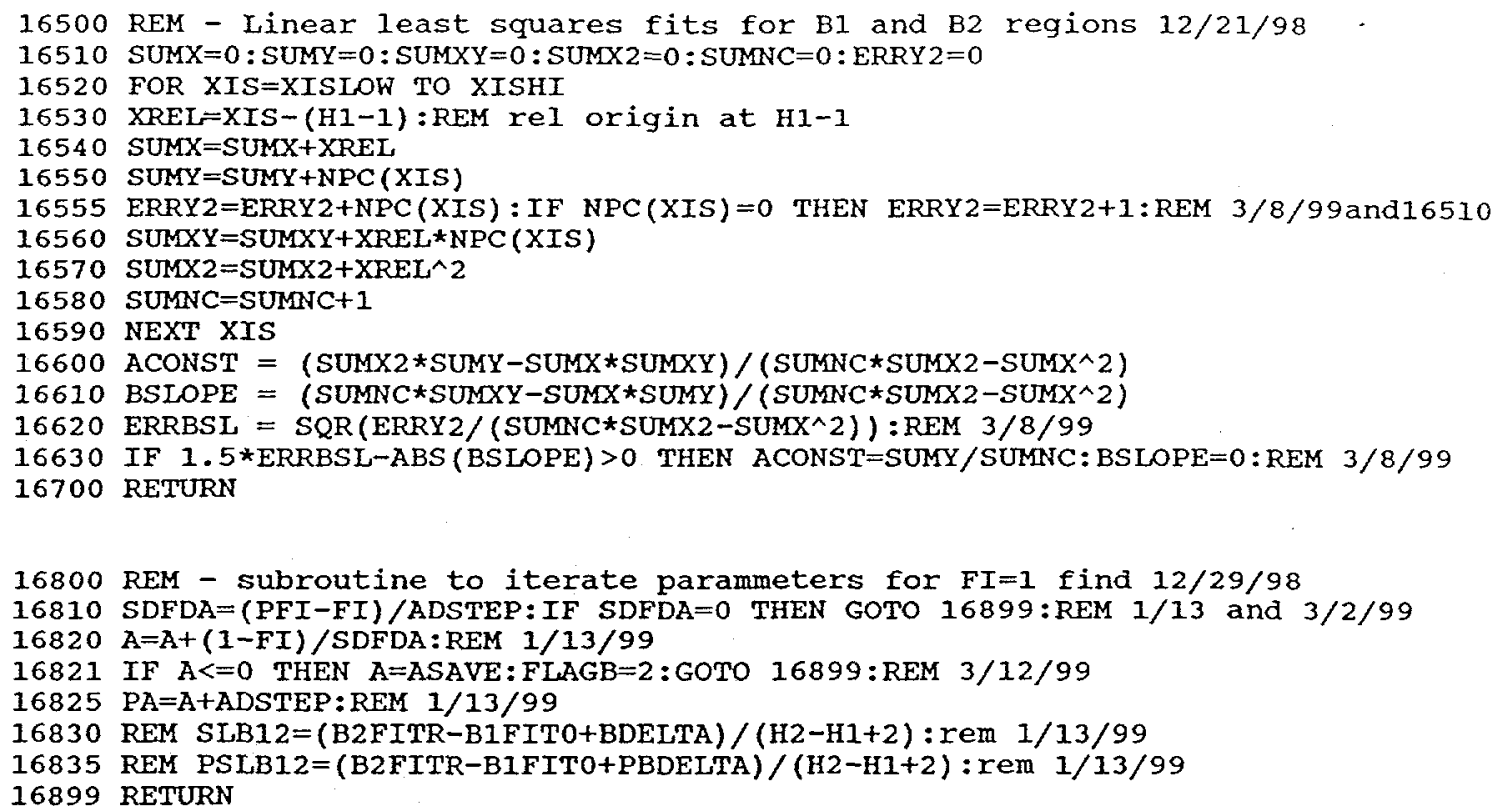




\section{GRABISOS: Program structure Reference}

Main

$$
5-28 / \text { DIM setup }
$$

30-35/Input data

$$
\begin{aligned}
&<-- \text { 1000-1100/Miscellaneous data } \\
&<--- \text { B:DATAMISC.DAT } \\
&<--- \text { 2000-2200/Efficiency data } \\
&<--- \text { B:DATACALB.DAT }
\end{aligned}
$$

$41-65 /$ Eff Formula

70-95/Input data

$$
\begin{gathered}
<--3000-3100 / \text { Gamma peaks } \\
<--- \text { B: DATAPEAK. DAT }
\end{gathered}
$$

$97-98 /$ Print header

100-250/Sort peak A <--- 20000-21000/Bubble sort exchanger

300-360/Sort peak Z <--- 20000-21000/Bubble sort exchanger

400-470/Sort peak E <--- 20000-21000/Bubble sort exchanger

500-705/Examine peaks

710-790/Average peaks

800-900/Print summary <--- 30000-30100/Peak formater

980-990/Continue/STOP <--- 9000-9100/Supplementary analysis menu

\section{Lines not used in execution}

4000-4100/Spectrum input of B:DATASPEC.DAT

5000-5080/Isotope data input of B:DATAISOS.DAT

6000-6100/Background input of backgnd. BKG

7000-7200/Efficiency parameters of DETLIBRY.LIB

8000-8100/Isotope Iibrary of B:DETLIBRY.LIB

13000-13100/Energy to channel transformer

60000-60140/Efficiency vs energy table for calib gammas

$$
\text { B-54 }
$$


5 REM file GRABISOS. BAS

6 PRINT"Reading in data files": PRINT

20 DIM ANUM(150), AVES(150), ACT (150), ERRACT (150)

21 DIM HI (150), H2 (150), RATERR(150)

$22 \operatorname{DIM} \operatorname{GOEFF}(5,3), \operatorname{HOEFF}(5,3), \operatorname{AOEFF}(5,3), \operatorname{BOEFF}(5,3), \operatorname{KOEFF}(5,3)$

$23 \operatorname{DIM}$ CEOHO $(5,3), \operatorname{CE} 1 H O(5,3), \operatorname{CEOH} 1(5,3), \operatorname{CE} 2 \mathrm{HO}(5,3), \operatorname{CE} 1 \mathrm{H} 1(5,3), \operatorname{CEOH} 2(5,3)$

24 DIM CE3HO $(5,3), \operatorname{CE} 2 H 1(5,3), \operatorname{CE} 1 \mathrm{H} 2(5,3), \mathrm{CEOH} 3(5,3)$

25 DIM YLOC (20), DETNAM\$ (10), BNERGY (150), BRATE (150), BERR (150), DETLAB $\$(10)$

26 DIM ISOTH (250), MDA (250), ACTRAT (150), LIBEN (250), SBRATE (150), SBERR (150)

27 DIM RATE (150), ENERGY (150), ISOEN (250), ISOID\$(250), ISO\$(250), ISOGAM(250)

28 DIM NPC (4096), AREA(150), EAREA (150), IOCH(150), FWHM(150), TAIL(150), CENT(150)

30 GOSUB 1000:REM read file B:DATAMISC. DAT

35 GOSUB 2000: REM read file B:DATACALB. DAT

41 DEF ENENC $($ CHAN $)=$ COENC+CIENC $\star$ CHAN

44 DEF FNFWHM (CHAN) $=$ SQR $($ COFWHM + CIFWHM $\star$ CHAN $)$

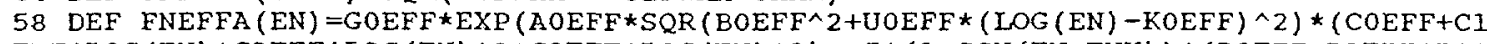
$E F F \star L O G(E N)+C 2 E F F \star L O G(E N) \wedge 2+C 3 E F F \star L O G(E N) \wedge 3)+.5 \star(1+S G N(E N-E N X)) \star(D O E F F+D L E F F * L O G$ (EN) $+\mathrm{D} 2 E F F * \operatorname{LOG}(E N) \wedge 2+D 3 E F F \star \operatorname{LOG}(E N) \wedge 3))$

$59 \mathrm{DEF}$ FNEFFB (EN) $=1+P O E F F+P 1 E F F \star \operatorname{LOG}(E N)+P 2 E F F \star L O G(E N) \wedge 2+P 3 E F F \star L O G(E N) \wedge 3$

60 DEF FNEFF (EN) =FNEFFA (EN) *FNEFFB (EN)

61 REM INPUT"Do you wish to see EFF VS EN data for standard energies $(Y / n) " ; E F F V$ EN\$:CLS:IF EFFVEN\$ <> "Y" THEN GOTO 65

62 REM GOSUB 60000:REM check on efficiency data EFF vS EN

65 REM - tempory continue

70 GOSUB 3000:REM read file B:DATAPEAK. DAT

75 REM GOSUB 4000:REM read file B:DATASPEC.DAT

80 REM GOSUB 5000:REM read file B:DATAISOS.DAT

85 REM GOSUB 6000:REM read file DETFILE\$.BKG

90 REM GOSUB 7000:REM read file B:DETLIBRY.LIB

95 REM gosub 8000:rem read file B:ISOLIBRY.LIB (when needed for B:DATAISOS.DAT)

97 INPUT"Hit form feed before proceeding";ZZ:PRINT

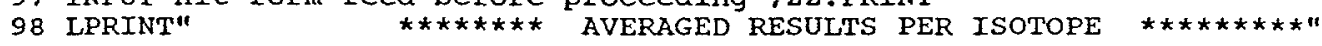

100 REM-get A numbers

105 ISOTOT $=0$

110 FOR $\mathrm{KP}=1$ TO MPMAX

120 FOR $\mathrm{J}=5$ TO 1 STEP -1

130 ANUM=VAL (RIGHT\$ (ISOIDS (KP) , J))

135. IF ANUM>300 THEN ANUM (KP) $=1000: \mathrm{J}=1:$ GOTO 160

140 IF ANUM>0 THEN ANUM (KP) $=$ ANUM: $J=1:$ ISOTOT=ISOTOT+1: GOTO 160

150 IF $\mathrm{J}=1$ THEN ANUM $(\mathrm{KP})=1000$

160 NEXT J

170 NEXT KP

200 PRINT"Bubble sorting on $A^{\prime \prime}:$ REM - bubble sort on anum

210 FOR J=MPMAX TO 2 STEP -1

220 FOR $K=$ MPMAX TO MPMAX-J+2 STEP - I

230 IF ANUM(K) <ANUM(K-1) THEN GOSUB 20000

240 NEXT K

250 NEXT J

300 PRINT"Bubble sorting on isotope name":REM - followup bubble sort on isotope name (in case two isos have same $A$ )

310 FOR $J=$ ISOTOT TO 2 STEP -1

320 FOR $\mathrm{K}=\mathrm{ISOTOT}$ TO ISOTOT-J+2 STEP -1

330 IF ANUM $(K)<>$ ANUM $(K-1)$ THEN 350

340 IF ISOID\$(K)<ISOID\$(K-I) THEN GOSUB 20000

350 NEXT $K$

360 NEXT J

400 PRINT"Bubble sorting on isotope energY":REM - followup bubble sort to assure energies monotonic

410 FOR $\mathrm{J}=$ ISOTOT TO $2 \mathrm{STEP}-1$

420 FOR K=ISOTOT TO ISOTOT $-\mathrm{J}+2$ STEP -1

430 IF ANUM (K) $>$ ANUM (K-1) THEN 460

440 IF ISOIDS(K) $>$ ISOID $(K-1)$ THEN 460

450 IF LIBEN (K) < LIBEN $(K-1)$ THEN GOSUB 20000

460 NEXT $K$

470 NEXT J 
500 REM - commence examining tables for averages

505 NEWISOS $=1$

510 FOR $J=1$ TO MPMAX

515 IF NEWISOS $=0$ THEN 550

518 NUMGAM $=1$

520 CLS

525 IF J>ISOTOT THEN PRINT"Sumary of left over peaks": PRINT:GOTO 540

530 PRINT"Sumuary results for "; ISOIDS(J) : PRINT

540 PRINT"Gamma Energy FWHM Tail Rate Bkgnd Activity"

545 PRINT" \# $\mathrm{keV}$ keV \# $\mathrm{cph}$ cph ";AUNIT\$:PRINT

550 ACT (J) =ACTRAT (J) * (RATE (J) -SBRATE (J))

$560 \operatorname{ERRACT}(J)=\operatorname{ACTRAT}(J) \star \operatorname{SQR}(\operatorname{RATERR}(J) \wedge 2+\operatorname{SBERR}(J) \wedge 2)$

570 PRINT USING"

580 PRINT USING" \#\#\#-\#\#";FWHM(J);:PRINT USING"\#\#耕" ;TAIL(J);

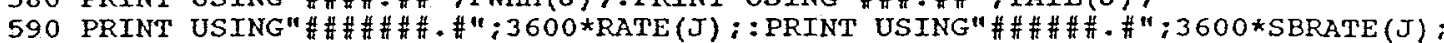

600 IF ACT $(J)<3 *$ ERRACT $(J)$ THEN 620

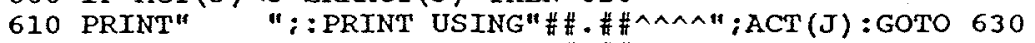

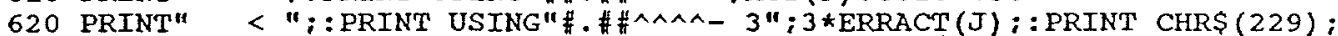

622 VSIG $=A C T(J) / E R R A C T(J): I F$ VSIG $<0$ THEN VSIG $=0$

625 PRINT USING"/\#., ";VSIG;:PRINT CHR\$ (229)

630 PRINT ISOIDS $(J)$;:PRINT USING"\#\#\#\#\#\#・\#":LIBEN(J):

640 PRINT USING"\#\#\#\#, \# ; CIENC*FNFWHM (CENT(J));:PRINT"

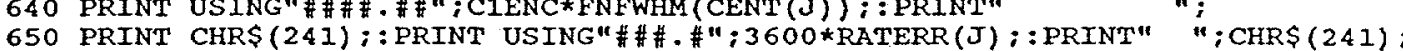

660 PRINT USING"\#\#\#" \#;3600*SBERR(J);

670 IF ACT $(J)<3 *$ ERRACT $(J)$ THEN 681

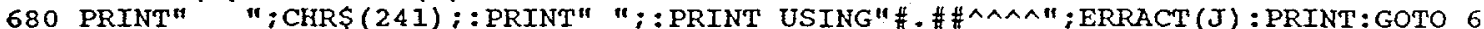

90

681 REM LESSTH=ACT $(J)+1.65 * \operatorname{ERRACT}(J):$ IF ACT $(J)<0$ THEN LESSTH $=1.65 \star E R R A C T(J)$

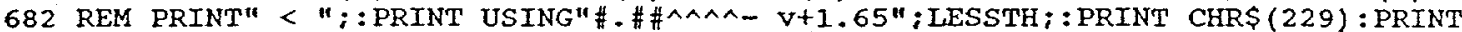

683 REM lines 681-682 less than calculation removed

: 684 IRATE=ACT (J)/ACTRAT (J) : IRATER=ERRACT (J)/ACTRAT (J)

685 BKTOT $=($ (IRATER*LTIME) $\wedge 2-$ IRATE*ITIME $) / 2: I F$ BKTOT $<=0$ THEN BKTOT=1

$686 \mathrm{MDACX}=$ ACTRAT $(\mathrm{J}) *(2.71+4.65 * \operatorname{SQR}(\mathrm{BKTOT})) /$ LTIME

687 PRINT" < ";: PRINT USING"\#.\#\#A^^^— MDA=C+b";MDACX: PRINT

690 IF $J=$ MPMAX THEN 710

700 IF ISOID $(J)=$ ISOID $(J+1)$ THEN NUMGAM=NUMGAM+1:NEWISOS=0: GOTO 900

705 IF J>ISOTOT THEN NUMGAM=NUMGAM+I:NEWISOS=0:GOTO 900

710 INPUT"Average above results $(Y / n) ": Y E \$: I F$ NUMGAM=1 THEN YE $\$=n$ "

715 IF YE $\$=" n$ " THEN 800

718 AVEACT $=0:$ WTACT $=0$

720 FOR $\mathrm{L}=\mathrm{J}+1$-NUMGAM TO $\mathrm{J}$

730 PRINT" Include gamma

740 IF AVE $\$(L)<>" y "$ THEN 780

760 AVEACT=AVEACT + ACT $(L) *(1 / \operatorname{ERRACT}(L))^{\wedge} 2$

770 WTACT $=$ WTACT $+(1 / \operatorname{ERRACT}(\mathrm{L}))^{\wedge} 2$

780 NEXT L

790 AVEACT $=$ AVEACT/WTACT: $A C T E R R=S Q R(1 /$ WTACT $)$ 


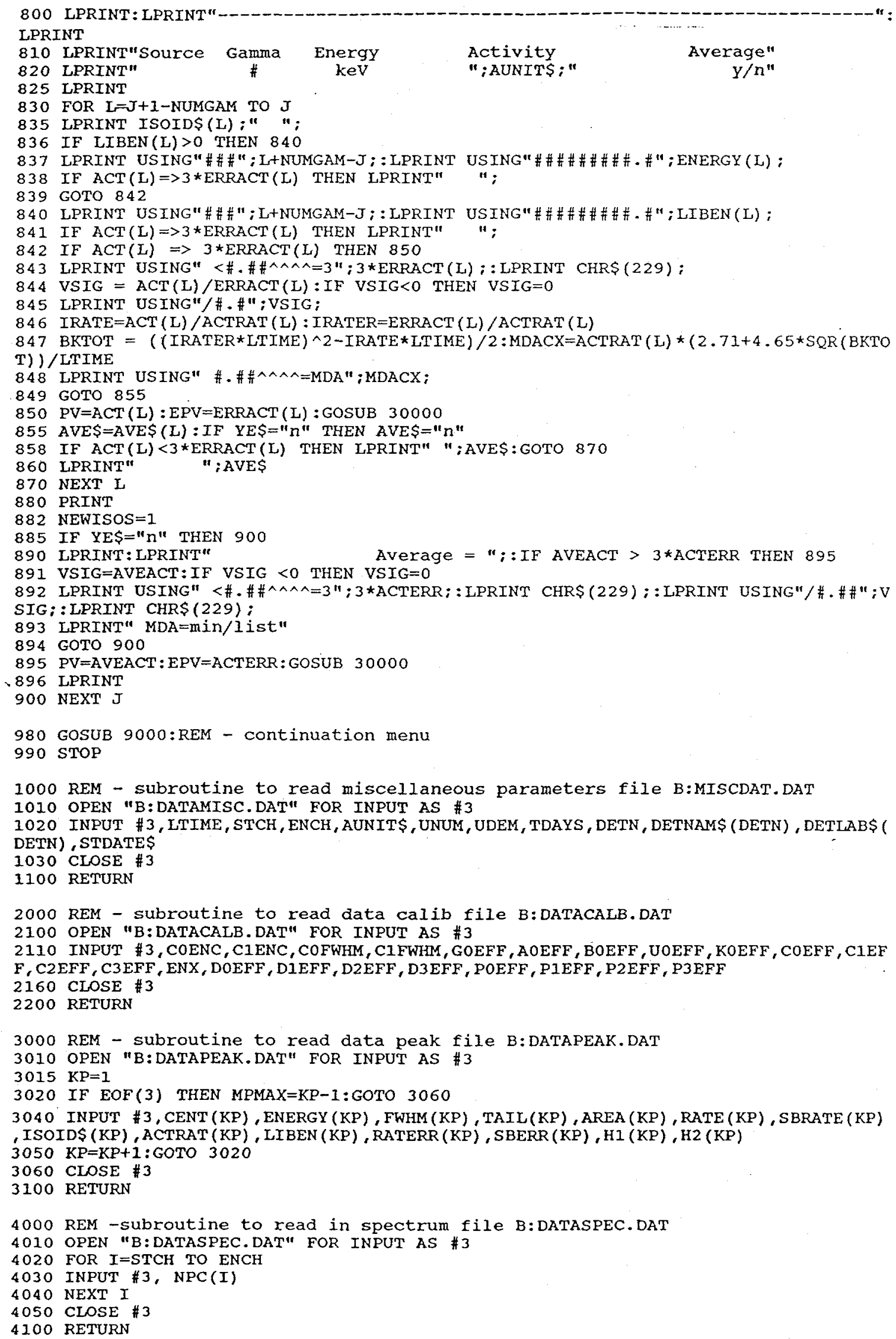


5000 REM - subroutine to read in isotope library file B:DATAISOS.DAT

5010 OPEN "B:DATAISOS.DAT" FOR INPUT AS \#3

$5020 \quad I=0$

$5030 \mathrm{~L}=\mathrm{L}+1$

5040 INPUT \#3, ISOS(L), ISOTH (L), ISOEN(L), ISOGAM(L), MDA(L)

5050 IF ISO\$(L)="I imit " THEN 5070

5060 GOTO 5030

5070 CLOSE \#3

5080 RETURN

6000 REM - subroutine to read in background library

6010 DETFILES=DETIAB $\$($ DETN $)+"$. BKG"

6020 OPEN DETFILE\$ FOR INPUT AS \#2

6030 CBACK $=1$

6040 IF EOF (2) THEN BAMAX $=\mathrm{CBACK}-1$ : GOTO 6070

6050 INPUT \#2, BNERGY (CBACK), BRATE (CBACK), BERR (CBACK)

$6060 \mathrm{CBACK}=\mathrm{CBACK}+1: \mathrm{GOTO} 6040$

6070 CLOSE \#2

6100 RETURN

7000 REM - subroutine to read in detector library B:DETLIBRY.LIB

7005 OPEN "B:DETLIBRY.LIB" FOR INPUT AS \#3

7010 FOR $I=1$ TO 5

7020 FOR $J=1$ TO 3

7030 INPUT \#3, GOEFF (I,J), $\operatorname{AOEFF}(I, J), \operatorname{BOEFF}(I, J), \operatorname{KOEFF}(I, J), \operatorname{HOEFF}(I, J)$

7040 INPUT \#3, CEOHO $(I, J)$

7050 INPUT \# $3, \mathrm{CE} 1 \mathrm{HO}(I, J), \mathrm{CEOH} 1(I, J)$

7060 INPUT 3, CE2HO $(I, J), C E I H I(I, J), C E O H 2(I, J)$

7070 INPUT $H_{3}, \mathrm{CE} 3 \mathrm{HO}(I, J), \mathrm{CE} 2 \mathrm{H} 1(I, J), \mathrm{CE} 1 \mathrm{H} 2(I, J), \mathrm{CEOH} 3(I, J)$

7080 NEXT J

7090 NEXT I

7095 CLOSE \#3

$7100 \quad I=0: J=0$

7200 RETURN

8000 REM - subroutine to read in isotope library data B:ISOLIBRY. LIB

8001 REM - note that B:DATAISOS.DAT is used instead usually

8005 NMDA $=0$

8007 OPEN "B:ISOLIBRY.LIB" FOR INPUT AS \#3

8010 FOR ISO $=1$ TO 100

8020 INPUT $\# 3$, ISOS(ISO), ISOTH(ISO), ISOEN (ISO), ISOGAM(ISO), MDA (ISO)

8025 ISOGAM (ISO) =ISOGAM (ISO) $/ 100$

8027 IF MDA (ISO) $=1$ THEN NMDA $=$ NMDA +1

8030 IF ISOS(ISO) = "limit " THEN ISO $=100$

8040 NEXT ISO

8050 CIOSE \#3

8100 RETURN

9000 REM- subroutine for supplementary analyses

9005 OPEN "B:DETLIBRY. LIB" FOR INPUT AS \#3

$9010 \mathrm{CLS}$

9020 PRINT"Supplementary Analyses - as applicable to current spectrum": PRINT

9030 PRINT"

9040 PRINT"1

(1) Background file development (GRABBACK) "

9050 PRINT" (3) Peak/spectrum diagnostics (GRABDIAG)"

9060 PRINT" (4) Peak/multiplet plot analysis (GRABPLOT)"

9070 PRINT" (5) Analyses per isotopes (GRABISOS) ":PRINT

9080 PRINT"Data files are now being transferred to RAM disk (b:) for analyses"

9090 PRINT: PRINT"Type selected analysis (e.g. GRABBACK) after":PRINT"C-prompt (

C>, and press enter"

9095 CLOSE \#3

9100 RETURN

13000 REM sub from sub 3000 - calc channel from energy

13010 AOEN $=$ FNENC $(0)$

13020 A1EN $=$ FNENC $(1)-$ FNENC $(0)$

13030 CHANO $=($ ENERGY - AOEN $) / A I E N$

13040 CHAN $=$ CHANO $+($ ENERGY - FNENC $($ CHANO $)) / A 1 E N$

13050 IF ABS (ENERG $X-$ FNENC (CHAN) ) >. I THEN CHANO=CHAN : GOTO 13040

13055 RCHAN $=$ CHAN

13060 CHAN $=$ INT $($ CHAN +.5$)$

13100 RETURN 
20000 REM-bubble sort flip-flopper

20010 ANUM $=$ ANUM $(K):$ ANUM $(K)=\operatorname{ANUM}(K-1):$ ANUM $(K-1)=$ ANUM

20020 ENERGY $=\operatorname{ENERGY}(\mathrm{K}): \operatorname{ENERGY}(\mathrm{K})=\operatorname{ENERGY}(\mathrm{K}-1): \operatorname{ENERGY}(\mathrm{K}-1)=\operatorname{ENERGY}$

$20030 \operatorname{LIBEN}=\operatorname{LIBEN}(K): \operatorname{LIBEN}(K)=\operatorname{LIBEN}(K-1): \operatorname{LIBEN}(K-1)=\operatorname{LIBEN}$

20040 RATE $=\operatorname{RATE}(K): \operatorname{RATE}(K)=\operatorname{RATE}(K-1): \operatorname{RATE}(K-1)=\operatorname{RATE}$

$20050 \operatorname{RATERR}=R A T E R R(K): \operatorname{RATERR}(K)=\operatorname{RATERR}(K-1): \operatorname{RATERR}(K-1)=\operatorname{RATERR}$

20060 SBRATE $=S B R A T E(K): \operatorname{SBRATE}(K)=\operatorname{SBRATE}(K-1): \operatorname{SBRATE}(K-1)=S B R A T E$

$20065 \operatorname{SBERR}=\operatorname{SBERR}(\mathrm{K}): \operatorname{SBERR}(\mathrm{K})=\operatorname{SBERR}(\mathrm{K}-1): \operatorname{SBERR}(\mathrm{K}-1)=\operatorname{SBERR}$

20070 ACTRAT $=A C T R A T(K): \operatorname{ACTRAT}(K)=\operatorname{ACTRAT}(K-1): \operatorname{ACTRAT}(K-1)=A C T R A T$

20080 ISOIDS=ISOIDS $(K): \operatorname{ISOIDS}(K)=\operatorname{ISOID}(K-1): \operatorname{ISOID} \$(K-1)=\operatorname{ISOID} \$$

20090 FWHM $=$ FWHM $(K): \operatorname{FWHM}(\mathrm{K})=\mathrm{FWHM}(\mathrm{K}-1): \operatorname{FWHM}(\mathrm{K}-1)=\mathrm{FWHM}$

20100 TAIL $=$ TAIL $(K): \operatorname{TAIL}(K)=\operatorname{TAIL}(K-1): \operatorname{TAIL}(K-1)=$ TAIL

$20110 \operatorname{CENT}=\operatorname{CENT}(K): \operatorname{CENT}(K)=\operatorname{CENT}(K-1): \operatorname{CENT}(K-1)=\mathrm{CENT}$

21000 RETURN

30000 REM - subroutine for printout - works for positive value pv +/- epv 30010 PVEX=INT (LOG (PV) /LOG (10)):PVARG = PV/10^PVEX

30020 EPVARG $=P V A R G \star E P V / P V$

30030 LPRINT" [ ";:LPRINT USING"\# -\#"; PVARG; :LPRINT" + $/$ - ";

30040 LPRINT USING"\#.\#";EPVARG;:LPRINT"] x E";:LPRINT PVEX;

30100 RETURN

60000 REM temp check on eff

60005 PRINT"Efficiency (EFF) per standard energy (EN) for ";DETNAMS(DETN)

60006 PRINT

60010 PRINT "EN", "EFF"

60011 PRINT"keV"," \#"

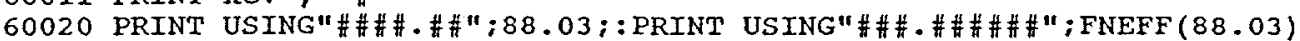

60030 PRINT USING"\#\#\#\#\#\#";122.06;:PRINT USING" \#\#\#\#\#\#\#\#";FNEFF(122.06)

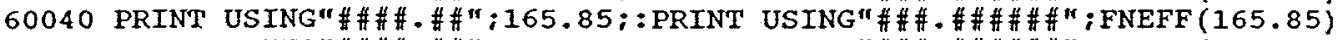

60050 PRINT USING"\#\#\#.\#\#":279.19;:PRINT USING"\#\#\#.\#\#\#\#\#";FNEFF (279.19)

60060 PRINT USING"\#\#\#\#.\#\#"; 391.69; :PRINT USING"\#\#\# .\#\#\#\#\#\#; FNEFF (391.69)

60070 PRINT USING" \#\#\#\#\#\#";514!;: PRINT USING"\#\#\#.\#\#\#\#\#"; FNEFF (514!)

60080 PRINT USING"\#\#\#\#\#\#";661.64;:PRINT USING"\#\#\#•\#\#\#\#\#";FNEFF(661.64)

60090 PRINT USING"\#\#\#.\#\#"; 898.02 ;:PRINT USING"\#\#\#\#\#\#\#\#"; FNEFF (898.02)

60100 PRINT USING"\#\#\#.\#\#";1173.21;:PRINT USING"\#\#\#.\#\#\#\#\#\#;FNEFF(1173.21)

60110 PRINT USING"\#\#\#\#\#\#";1332.56: :PRINT USING"\#\#\#•\#\#\#\#\#";FNEFF(1332.56)

60120 PRINT USING"\#\#\#\#\#\#"; 1836.01; : PRINT USING"\#\#\#.\#\#\#\#\#";FNEFF(1836.01)

60130 INPUT"Press return to proceed" $; z z$

60140 RETURN 
GRABBACK: Program structure Reference

Main

$5-28 /$ DIM setup

30-35/Input data

$41-65 /$ Eff Formula

70-95/Input data

$$
\begin{aligned}
<-- & 1000-1100 / \text { Miscellaneous data } \\
& <--- \text { B:DATAMISC.DAT } \\
<--- & \text { 2000-2200/Efficiency data } \\
& <--- \text { B:DATACALB.DAT }
\end{aligned}
$$

--- Subroutines and [files]

<--- 3000-3100/Gamma peaks <-- B:DATAPEAK. DAT

<-- 6000-6100/Existing background --- backgnd. BKG

100-140/Spectrum bkg

<--- 980/option GoTo to exit program

145-210/Create file <--- new backgnd. BKG

212-213/Print header

215-247/Dev-merge bkg

$\begin{aligned}<-- & 20000-21000 / \text { File copier } \\ & <--- \text { new backgnd. BKG } \\ & <---980 / \text { option GOTO to exit program }\end{aligned}$

250-490/Setup merge (-- new backgnd. BKG

495-496/Match keV

500-610/Merge bkgs

620-670/Print merge

700-708/OK merge menu

710-715/Menu options

<-- 980/option GOTO to exit program

<-- 30000-31000/Backup old bkg file <-- backgnd. BUB

<-- 20000-21000/File copier <--- new backgnd. BKG

720-725/Peak edit <-- 40000-41000/Delete questionable peaks 729-850/Print \& save <-- new backgnd. BKG

980-990/Continue/STOP <---9000-9100/Supplementary analysis menu

$$
B-60
$$




\title{
GRABBACK: Program structure Reference (continued)
}

\author{
Lines not used in execution \\ 4000-4100/Spectrum input of B:DATASPEC.DAT \\ 5000-5080/Isotope data input of B:DATAISOS.DAT \\ 7000-7200/Efficiency parameters of DETLIBRY.LIB \\ $8000-8100 /$ Isotope library of B:DETLIBRY.LIB \\ 13000-13100/Energy to channel transformer \\ 60000-60140/Efficiency vs energy table for calib gammas
}


5 REM file GRABBACK. BAS

10 PRINT: PRINT"Reading in data files"

15 PRINT:PRINT"Check printer if need form feed"

21 DIM H1 (100), H2 (100), RATERR(100)

$22 \operatorname{DIM} \operatorname{GOEFF}(5,3), \operatorname{HOEFF}(5,3), \operatorname{AOEFF}(5,3), \operatorname{BOEFF}(5,3), \operatorname{KOEFF}(5,3)$

23 DIM CEOHO $(5,3), \operatorname{CE} 1 \mathrm{HO}(5,3), \mathrm{CEOHI}(5,3), \mathrm{CE} 2 \mathrm{HO}(5,3), \mathrm{CE} I \mathrm{H} 1(5,3), \mathrm{CEOH} 2(5,3)$

24 DIM CE3HO $(5,3), \operatorname{CE} 2 \mathrm{H} 1(5,3), \operatorname{CE} 1 \mathrm{H} 2(5,3), \operatorname{CEOH} 3(5,3)$

25 DIM YLOC (20), DETNAM\$ (10), BNERGY (100), BRATE (100), BERR (100), DETLAB\$ (10)

26 DIM ISOTH (100), MDA (100), ACTRAT (100), LIBEN(100), SBRATE (100), SBERR(100)

27 DIM RATE(100), ENERGY (100), ISOEN(100), ISOID\$(100), ISO\$(100), ISOGAM(100)

28 DIM NPC (4096), AREA (100), EAREA (100), LOCH (100), FWHM (100), TAIL (100), CENT (100)

30 GOSUB 1000:REM read file B:DATAMISC.DAT

35 GOSUB 2000:REM read file B:DATACALB.DAT

41 DEF FNENC $($ CHAN $)=C O E N C+C I E N C * C H A N$

44 DEF FNFWHM (CHAN) $=S Q R$ (COFWHM + CIFWHM $*$ CHAN)

$58 \mathrm{DEF}$ FNEFFA $(\mathrm{EN})=\mathrm{GOEFF} * \operatorname{EXP}(\mathrm{AOEFF} * \mathrm{SOR}(\mathrm{BOEFF} \wedge 2+\mathrm{UOEFF} *(\mathrm{LOG}(\mathrm{EN})-\mathrm{KOEFF}) \wedge 2) *(\mathrm{COEFF}+\mathrm{CI}$ $E F *$ LOG $(E N)+C 2 E F F * L O G(E N) \wedge 2+C 3 E F E * L O G(E N) \wedge 3)+.5 *(1+\operatorname{SGN}(E N-E N X)) *(D O E F F+D I E F F * I O G$ $(E N)+D 2 E F F * L O G(E N) \wedge 2+D 3 E F F * L O G(E N) \wedge 3))$

$59 \mathrm{DEF} \quad \mathrm{FNEFFB}(\mathrm{EN})=1+\mathrm{POEFF}+\mathrm{P} 1 \mathrm{EFF} \star \mathrm{LOG}(\mathrm{EN})+\mathrm{P} 2 \mathrm{EFF} \star \mathrm{LOG}(\mathrm{EN}) \wedge 2+\mathrm{P} 3 \mathrm{EFF} * \mathrm{LOG}(\mathrm{EN}) \wedge 3$

60 DEF $\operatorname{FNEFF}($ EN $)=$ FNEFFA $(E N) *$ FNEFFB (EN)

61 REM INPUT"Do you wish to see EFF VS EN data for standard energies $(y / n)$ ";EFFV EN\$:CLS:IF EFFVEN\$ $>$ "Y" THEN GOTO 65

62 REM GOSUB 60000:REM check on efficiency data EFF vS EN

65 REM - tempory continue

70 GOSUB 3000:REM read file B:DATAPEAK.DAT

75 REM GOSUB 4000:REM read file B:DATASPEC.DAT

80 REM GOSUB 5000:REM read file B:DATAISOS.DAT

85 GOSUB 6000:REM read file DETFILES.BKG

90 REM GOSUB 7000 : REM read file B:DETLIBRY. LIB

95 REM gosub 8000:rem read file B:ISOLIBRY.LIB (when needed for B:DATAISOS.DAT)

100 REM - make background file for this sample

101 CLS

102 PRINT"Examine normal printout for sample vs current background": PRINT

105 BKG $=$ RIGHTS (STR\$ (DETN), 1) +LEFT\$ (STDATE\$, 7)+". BKG"

110 PRINT"Proposed background label "; BKG\$:PRINT

115 INPUT"Desire different background label $(\mathrm{y} / \mathrm{n})$ "; YES:IF YE\$=" $n$ " THEN 125

120 PRINT:INPUT"Background file label (-.--_--.BKG)";BKG\$

125 PRINT

130 INPUT"Make above background file from sample rates $(y / n)$ ";YE\$:PRINT

140 IF YE\$<>"Y" THEN PRINT"No changes made in current file ":DETFILE\$:PRINT:INPU T"Press enter to proceed" ; $\mathrm{ZZ}:$ GOTO 980

145 NEWBKG=0

150 OPEN BKG\$ FOR OUTPUT AS \#2

155 FOR $\mathrm{KP}=1$ TO MPMAX

160 IF AREA (KP) <3*RATERR (KP) *LTIME THEN 200

170 ENERGY $=$ LIBEN $(\mathrm{KP})$

180 IF ISOID\$(KP) $=$ "NO-Lib" THEN ENERGY=ENERGY (KP)

190 WRITE \#2, ENERGY, RATE (KP), RATERR (KP) : NEWBKG=NEWBKG+1

200 NEXT KP

210 CLOSE \#2

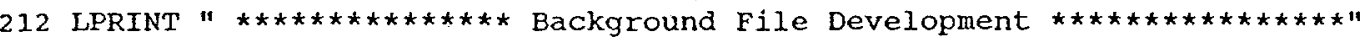

213 LPRINT: LPRINT

$215 \mathrm{CLS}$

220 PRINT:PRINT"The following options can be used with ";BKG\$:PRINT

222 PRINT"

(1) Initial background data case - setup user analysis file"

224 PRINT"

(2) Examine for merge/average with existing user analysis file"

225 PRINT

226 IF DETFILE\$="missing" THEN PRINT"Option (1) defaulted - no user analysis fil

e found": GOTO 235

227 PRINT"Recommend option (2) - user analysis file ";DETFILE\$;" found"

228 PRINT

229 INPUT"Option" ; OPNO

230 IF OPNO=2 THEN GOTO 250

235 PRINT:INPUT"Assign a user analysis file (eg yourDETR. BKG) ";DETFILES

240 GOSUB 20000:REM COpy bkg\$ to detfiles

245 PRINT "New user file ";DETFILES;" created from ";BKG

247 GOTO 980 
250 PRINT:PRINT"Background file ";BKG\$;" can be merged/averaged with ";DETFILES

260 PRINT: PRINT"File merging in progress": PRINT

$300 \mathrm{REM}$ - arrange arrays for merge - slide down from top (100)

310 FOR I=BAMAX TO 1 STEP -1

320 BNERGY $(100-\operatorname{BAMAX}+\mathrm{I})=\operatorname{BNERGY}(\mathrm{I})$

330 BRATE $(100-B A M A X+I)=\operatorname{BRATE}(I)$

$340 \operatorname{BERR}(100-\operatorname{BAMAX}+I)=\operatorname{BERR}(\mathrm{I})$

350 NEXT I

360 OPEN BKG\$ FOR INPUT AS $\$ 2$

370 FOR $I=1$ TO NEWBKG

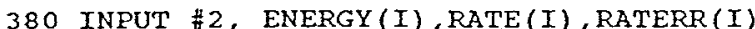

390 NEXT I

400 CLOSE

410 FOR I=NEWBKG TO 1 STEP - 1

420 ENERGY $(100-N E W B K G+I)=\operatorname{ENERGY}(I)$

430 RATE $(100-N E W B K G+I)=\operatorname{RATE}(I)$

$440 \operatorname{RATERR}(100-\mathrm{NEWBKG}+\mathrm{I})=\operatorname{RATERR}(\mathrm{I})$

450 NEXT I

490 PRINT:INPUT"Energy agreement (e.g. +/- $2 \mathrm{kEV}$ )";EFIND

495 LPRINT:LPRINT"Energy agreement for merged files = +/- ":EFIND;" keV"

496 LPRINT

500 REM - perform table merge

$505 \mathrm{NB}=100-\mathrm{NEWBKG}+1: \mathrm{J}=1$

510 FOR $I=100-B A M A X+1$ TO 100

515 IF $N B=101$ THEN 540

520 IF BNERGY(I) -ENERGY (NB) <=EFIND THEN 530

$521 \operatorname{ENERGY}(J)=\operatorname{ENERGY}(N B): \operatorname{RATE}(J)=\operatorname{RATE}(N B): \operatorname{RATERR}(J)=\operatorname{RATERR}(N B)$

$522 \operatorname{BNERGY}(J)=\operatorname{ENERGY}(\mathrm{NB}): \operatorname{BRATE}(J)=0: \operatorname{BERR}(J)=0$

$523 \mathrm{NB}=\mathrm{NB}+1: \mathrm{J}=\mathrm{J}+1: \mathrm{GOTO} 515$

530 IF BNERGY (I)-ENERGY (NB)<-EFIND THEN 540

$531 \operatorname{ENERGY}(J)=\operatorname{ENERGY}(N B): \operatorname{RATE}(J)=\operatorname{RATE}(N B): \operatorname{RATERR}(J)=\operatorname{RATERR}(N B)$

$532 \operatorname{BNERGY}(J)=\operatorname{BNERGY}(I): \operatorname{BRATE}(J)=\operatorname{BRATE}(I): \operatorname{BERR}(J)=\operatorname{BERR}(I)$

$533 \mathrm{NB}=\mathrm{NB}+1: \mathrm{J}=\mathrm{J}+1$ : GOTO 550

540 REM - line 530 conaition met

$541 \operatorname{ENERGY}(J)=\operatorname{BNERGY}(\mathrm{I}): \operatorname{RATE}(J)=0: \operatorname{RATERR}(J)=0$

$542 \operatorname{BNERGY}(J)=\operatorname{BNERGY}(I): \operatorname{BRATE}(J)=\operatorname{BRATE}(I): \operatorname{BERR}(\mathrm{J})=\operatorname{BERR}(\mathrm{I})$

$543 \mathrm{~J}=\mathrm{J}+1$

550 NEXT I

555 REM - below assures pick up upper energy cases missed in above loop

560 IF NB=101 THEN 610

570 FOR $\mathrm{MB}=\mathrm{NB}$ TO 100

$580 \operatorname{ENERGY}(J)=\operatorname{ENERGY}(M B): \operatorname{RATE}(J)=\operatorname{RATE}(M B): \operatorname{RATERR}(J): \operatorname{RATERR}(M B)$

590 BNERGY $(J)=\operatorname{ENERGY}(\mathrm{MB}): \operatorname{BRATE}(\mathrm{J})=0: \operatorname{BERR}(\mathrm{J})=0$

$595^{\circ} \mathrm{J}=\mathrm{J}+1$

600 NEXT MB

$610 \mathrm{JMAX}=\mathrm{J}-1$

620 REM - print out merged data below

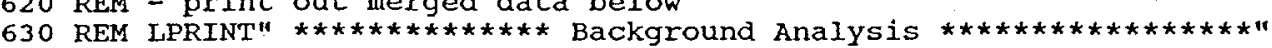

631 LPRINT: LPRINT:LPRINT

Data after Merger ":
633 LPRINT TAB(15) BKG\$ TAB(45) DETFILE\$:LPRINT

634 LPRINT"Peak Energy Rat

635 LPRINT"i

636 LPRINT

640 FOR $J=1$ TO JMAX

645 LPRINT USING" \#\#\#";J;

650 LPRINT USING"\#\#\#\#\#\#\#\#\#\#";ENERGY(J), 3600*RATE(J);:LPRINT" +/-";:LPRINT USING

"\#\#. " "; $3600 *$ RATERR(J):

655 IPRTNT USING" \#\#\#\#\#\#\#\#\# .\#";BNERGY(J), 3600*BRATE(J) ;:LPRINT" +/-";:LPRINT USIN G"\#\# . \#"; $3600 \star \operatorname{BERR}(\mathrm{J})$

670 NEXT J

700 REM - print out average merged data and dump to disk file

701 CLS

702 PRINT"Examine merged printout to decide appropriate option below":PRINT

703 PRINT" (1) Retain current ":DETFILE\$;" as background file"

704 PRINT" (2) Make new ";DETFILE\$;" from "; BKG\$; "file alone"

705 PRINT"

706 PRINT"

(3) Make new ":DETFILE\$;" from average of merged files" (i.e. ":BKG\$;" and current ":DETFILE\$;")": PRINT

707 PRINT" Note: questionable peaks can be removed in cases (2) or (3)":PRINT 708 INPUT"Select option";OPB 
710 IF OPB $=1$ THEN LPRINT:LPRINT"Current background file kept": LPRINT:GOTO $980^{\circ}$

711 IF $O P B=2$ THEN GOSUB 30000:REM - back up current detfiles if present

712 IF OPB $=2$ THEN GOSUB 20000:REM - new background data only

713 IF $O P B=2$ THEN PRINT"New "; DETFILES;" made from ";BKG\$;" alone":GOTO 720

714 IF OPB $<3$ THEN CLS:PRINT"Not a valid option - try again":PRINT:GOTO 700

715 GOSUB 30000:REM - make backup to current detfiles if present

720 CIS:PRINT"Exclusion of questionable peaks only removes ";BKG\$;" values"

721 PRINT:PRINT"Check peaks to delete $(y / n)$ in table generated below"

722 PRINT" (Note: New Rates = old Rates, if option \#2 was selected) ": PRINT

725 GOSUB 40000:REM - delete peaks subroutine

729 LPRINT: LPRINT: LPRINT

730 LPRINT" Data after averaging merged background files"

732 LPRINT: LPRINT

733 LPRINT"

734 LPRINT

735 LPRINT"

736 LPRINT"Peak

737 LPRINT" \#

- notes

s - - - - - - - - - -

738 LPRINT

740 OPEN DETFILES FOR OUTPUT AS \#2

$750 \mathrm{PX}=1$

760 FOR $J=1$ TO JMAX

770 IF $\mathrm{J}<>$ NPC (PX) THEN 780

771 IF OPB=2 THEN LPRINT USING"\#\#\#"; ;:LPRINT USING"\#\#\#\#\#\#.\#";ENERGY(J)::LPRINT

"This peak deleted" $: P X=P X+1$ : GOTO 820

772 IF BRATE(J) =0 THEN LPRINT USING"\#\#\#"; J;:LPRINT USING"\#\#\#\#\#\#・\#";ENERGY(J) ;:L PRINT" This peak deleted": $\mathrm{PX}=\mathrm{PX}+1:$ GOTO 820

773 LPRINT USING"\#\#\#"; J ; :LPRINT USING"\#\#\#\#\#\#・\#";BNERGY (J) ; :LPRINT" Deleted ";

774 LPRINT USING"\#\#\#\#•\#"; 3600*BRATE(J);:LPRINT" +/-";:LPRINT USING"\#\#・" ; 3600*B $\operatorname{ERR}(J)$;

775 LPRINT USING"\#\#\#\#\#\#"; 3600*BRATE (J);:LPRINT" +/-";:LPRINT USING"\#\#•\#";3600*B $\operatorname{ERR}(J)$

777 BNERGY=BNERGY $(J): \operatorname{BRATE}=\operatorname{BRATE}(\mathrm{J}): \operatorname{BERR}=\mathrm{BERR}(\mathrm{J}): \mathrm{PX}=\mathrm{PX}+1: \mathrm{GOTO} 810$

780 BNERGY $=.5 *(\operatorname{ENERGY}(J)+\operatorname{BNERGY}(J)): \operatorname{BRATE}=.5 *(\operatorname{RATE}(\mathrm{J})+\operatorname{BRATE}(J)): \operatorname{BERR}=.5 * \operatorname{SQR}(\mathrm{RATE}$ $\operatorname{RR}(\mathrm{J}) \wedge 2+\operatorname{BERR}(J) \wedge 2)$

782 IF OPB $=2$ THEN BERR $=$ BERR(J)

785 LPRINT USING"\#\#" ; J ; : LPRINT USING"\#\#\#\#\#\# .\#"; BNERGY;

790 LPRINT USING"\#\#\#\#.\#"; 3600*RATE (J);:ILPRINT" +/ ";:LPRINT USING"\#\#•\#";3600*RA TERR(J):

795 LPRINT USING"\#\#\#\#•\#"; 3600*BRATE(J);:LPRINT" +/-";:LPRINT USING"\#\#,\#";3600*B $\operatorname{ERR}(J)$;

800 LPRINT USING"\#\#\#\#+\#"; 3600*BRATE; : LPRINT" +/-";:LPRINT USING"\# \#\#"; 3600*BERR

810 WRITE $\# 2$, BNERGY, BRATE, BERR

820 LPRINT

830 NEXT

850 CLOSE \#2

980 GOSUB 9000:REM - continuation menu 990 STOP

1000 REM - subroutine to read miscellaneous parameters file B:MISCDAT.DAT 1010 OPEN "B:DATAMISC.DAT" FOR INPUT AS \#3

1020 INPUT \$3, LTIME, STCH, ENCH, AUNIT\$, UNUM, UDEM, TDAYS, DETN, DETNAM\$ (DETN), DETLAB\$( DETN), STDATES

1030 CLOSE \#3

1100 RETURN

2000 REM - subroutine to read data calib file B:DATACALB.DAT

2100 OPEN "B:DATACALB.DAT" FOR INPUT AS \#3

2110 INPUT \#3, COENC, CIENC, COFWHM, C1FWHM, GOEFF, AOEFF, BOEFF, UOEFF, KOEFF, COEFF, C1EF $F, C 2 E F F, C 3 E F F$, ENX, DOEFF, D1EFF, D2EFF, D3EFF, POEFF, P1EFF, P2EFF, P3EFF

2160 CLOSE \#3

2200 RETURN

3000 REM - subroutine to read data peak file B:DATAPEAK.DAT

3010 OPEN "B:DATAPEAK. DAT" FOR INPUT AS \#3

$3015 \mathrm{KP}=1$

3020 IF EOF(3) THEN MPMAX $=$ KP-1: GOTO 3060

3040 INPUT \#3, CENT (KP), ENERGY (KP), FWHM(KP), TAIL (KP), AREA (KP), RATE (KP), SBRATE (KP)

, ISOID\$(KP), ACTRAT (KP), LIBEN (KP), RATERR (KP), SBERR (KP), H1 (KP), H2 (KP)

$3050 \mathrm{KP}=\mathrm{KP}+1:$ :GOTO 3020

3060 CLOSE \#3

3100 RETURN 
4000 REM -subroutine to read in spectrum file B:DATASPEC.DAT

4010 OPEN "B:DATASPEC.DAT" FOR INPUT AS \#3

4020 FOR I=STCH TO ENCH

4030 INPUT \#3, NPC(I)

4040 NEXT I

4050 CLOSE \#3

4100 RETURN

5000 REM - subroutine to read in isotope library file B:DATAISOS. DAT

5010 OPEN "B:DATAISOS.DAT" FOR INPUT AS \#3

$5020 \mathrm{~L}=0$

$5030 \quad \mathrm{~L}=\mathrm{L}+1$

5040 INPUT \#3, ISOS(L), ISOTH (L), ISOEN (L), ISOGAM(L), MDA (L)

5050 IF ISO\$(L)="Iimit " THEN 5070

5060 GOTO 5030

5070 CLOSE \#3

5080 RETURN

6000 REM - subroutine to read in background library

6005 IF LEN (DETLAB (DETN))=0 THEN DETFILE\$="missing": GOTO 6100

6010 DETFILE $\$=D E T L A B \$(D E T N)+"$. BKG"

6020 OPEN DETFILES FOR INPUT AS \#2

6030 CBACK=1

6040 IF EOF (2) THEN BAMAX=CBACK-1: GOTO 6070

6050 INPUT \#2, BNERGY (CBACK), BRATE (CBACK), BERR (CBACK)

6060 CBACK $=C B A C K+1:$ GOTO 6040

6070 CLOSE \#2

6100 RETURN

7000 REM - subroutine to read in detector library B:DETLIBRY. LIB

7005 OPEN "B:DETLIBRY. LIB" FOR INPUT AS \#3

7010 FOR $I=1$ TO 5

7020 FOR $J=1$ TO 3

7030 INPUT \#3, $\operatorname{GOEFF}(I, J), \operatorname{AOEFF}(I, J), \operatorname{BOEFF}(I, J), \operatorname{KOEFF}(I, J), \operatorname{HOEFF}(I, J)$

7040 INPUT \#3, CEOHO $(I, J)$

7050 INPUT \#3, CE1HO $(I, J), \operatorname{CEOH} 1(I, J)$

7060 INPUT \#3,CE2HO (I,J), CE1HI (I,J), CEOH2 $(I, J)$

7070 INPUT $\$ 3, C E 3 H O(I, J), \operatorname{CE} 2 H 1(I, J), \operatorname{CE} 1 \mathrm{H} 2(I, J), \operatorname{CEOH3}(I, J)$

7080 NEXT J

7090 NEXT I

7095 CLOSE \#3

$7100 \quad I=0: J=0$

7200 RETURN

8000 REM - subroutine to read in isotope library data B:ISOLIBRY. LIB

8001 REM - note that B:DATAISOS.DAT is used instead usually

8005 NMDA $=0$

8007 OPEN "B:ISOLIBRY. LIB" FOR INPUT AS \#3

8010 FOR ISO $=1$ TO 100

8020 INPUT \#3,ISO\$(ISO), ISOTH (ISO), ISOEN (ISO), ISOGAM (ISO), MDA (ISO)

8025 ISOGAM(ISO) =ISOGAM (ISO) $/ 100$

8027 IF $\mathrm{MDA}$ (ISO) $=1$ THEN NMDA $=$ NMDA +1

8030 IF ISOS(ISO) = "limit " THEN ISO $=100$

8040 NEXT ISO

8050 CLOSE \#3

8100 RETURN

9000 REM- subroutine for supplementary analyses

9005 OPEN "B:DETLIBRY. LIB" FOR INPUT AS \#3

9010 CLS

9020 PRINT"Supplementary Analyses - as applicable to current spectrum":PRINT

9030 PRINT"

9040 PRINT"

(1) Background file development (GRABBACK)"

9050 PRINT"

(2) Detector efficiency calibration (GRABCALB)"

(3) Peak/spectrum diagnostics (GRABDIAG)"

9060 PRINT" (4) Peak/multiplet plot analysis (GRABPIOT)"

9070 PRINT" (5) Analyses pex isotopes (GRABISOS) ": PRINT

9080 PRINT"Data files are now being transferred to RAM disk (b:) for analyses"

9090 PRINT:PRINT"Type selected analysis (e.g. GRABBACK) after":PRINT"C-prompt (

C> ) and press enter"

9095 CLOSE \#3

9100 RETURN 
13000 REM sub from sub 3000 - calc channel from energy

13010 AOEN $=$ FNENC $(0)$

13020 AIEN $=$ FNENC $(1)-$ FNENC $(0)$

13030 CHANO $=($ ENERGY-AOEN $) /$ AIEN

13040 CHAN $=$ CHANO $+($ ENERGY-FNENC $($ CHANO $)) /$ AIEN

13050 IF ABS (ENERGY-FNENC (CHAN)) >. 1 THEN CHANO=CHAN : GOTO 13040

$13055 \mathrm{RCHAN}=\mathrm{CHAN}$

13060 CHAN $=$ INT $($ CHAN +.5$)$

13100 RETURN

20000 REM -subroutine for copying bkg\$ file to detfile\$/problem ends soon after 20010 OPEN BKG\$ FOR INPUT AS \#2

20020 FOR $\mathrm{KP}=1$ TO NEWBKG

20030 INPUT \#2, BNERGY (KP), BRATE (KP), BERR (KP)

20040 NEXT KP

20050 CLOSE \#2

20110 OPEN DETFILES FOR OUTPUT AS \#2

20120 FOR $\mathrm{KP}=1$ TO NEWBKG

20130 WRITE \#2, BNERGY (KP), BRATE (KP), BERR(KP)

20140 NEXT KP

20150 CLOSE \#2

20160 LPRINT:LPRINT"NeW user analysis file ";DETFILE\$

20170 LPRINT"made solely from copy of file ";BKG\$:LPRINT

21000 RETURN

30000 REM - subroutine to backup current detfiles if present

30010 IF DETFILE\$="missing" THEN GOTO 31000

30020 OPEN DETFILES FOR INPUT AS $\# 2$

30030 FOR I=I TO BAMAX

30040 INPUT $\# 2, \operatorname{NPC}(1000+I), N P C(2000+I), N P C(3000+I): R E M$ unused npc(n) locations

30050 NEXT I

30060 CLOSE \#2

30100 BACKUPBKG $=$ DETLAB $(D E T N)+"$. BUB"

30120 OPEN BACKUPBKG\$ FOR OUTPUT AS \#2

30130 FOR $I=1$ TO BAMAX

30140 WRITE \#2, NPC $(1000+I), N P C(2000+I), N P C(3000+I): R E M$ unused npc $(n)$ locations

30150 NEXT I

30160 CLOSE \#2

30170 LPRINT: LPRINT"Above background file ";DETFILE\$

30180 LPRINT"may be overwritten, as it is backed up as "; BACKUPBKG\$:LPRINT

31000 RETURN

40000 REM sub to delete questionable peaks

40010 PRINT: PRINT

40020 PRINT"

40030 PRINT TAB(15) BKG\$ TAB (45) DETFILES:PRINT

40040 PRINT"Peak Energy Rate Rate Dergy

lete"

40050 PRINT" keV

kev $\quad \mathrm{cph}$

$\mathrm{keV}$

$\mathrm{cph}$

Y

$/ n^{\prime \prime}$

40060 PRINT: $\mathrm{PX}=1$

40070 FOR $J=1$ TO JMAX

40080 PRINT USING"\#\#" ; J ;

40090 PRINT USING"\#\#\#\#\#\#\#\#\# \# ";ENERGY $(J), 3600 * R A T E(J) ;:$ PRINT" +/-";:PRINT USING" \#\#" " ; $3600 *$ RATERR (J) :

40100 PRINT USING"\#\#\#\#\#\#\#\#\#";BNERGY $(J), 3600 * \operatorname{BRATE}(J) ;:$ PRINT" +/-";:PRINT USING

"\#

40110 INPUT"

40120 NEXT J

41000 RETURN

60000 REM temp check on eff

60005 PRINT"Efficiency (EFF) per standard energy (EN) for "; DETNAMS (DETN)

60006 PRINT

60010 PRINT "EN" "EFF"

60011 PRINT"keV"," \#"

60020 PRINT USING"\#\#\#\#\#\#";88.03;:PRINT USING"\#\#\#\#\#\#\#\#";FNEFF(88.03)

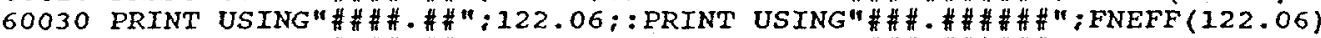

60040 PRINT USING"\#\#\#\#.\#\#"; 165.85 ; : PRINT USING"\#\#\#.\#\#\#\#\#";FNEFF (165.85)

60050 PRINT USING"\#\#\#\#\#\#":279.19;:PRINT USING"\#\#\#_\#\#\#\#\#"; FNEFF $(279.19)$

60060 PRINT USING"\#\#\#\#-\#\#"; 391.69; : PRINT USING"\#\#\#.\#\#\#\#\#";FNEFF (391.69)

60070 PRINT USING"\#\#\#\#, \#\#";514!;: PRINT USING"\#\#\#\#\#\#\#\#"; FNEFF(514!)

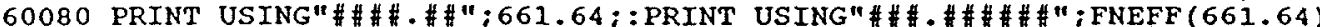

60090 PRINT USING"\#\#\#\#\#\#";898.02;: :PRINT USING"\#\#\#-\#\#\#\#\#";FNEFF(898.02)

60100 PRINT USING"\#\#\#.\#\#";1173.21;:PRINT USING"\#\#\#.\#\#\#\#\#";FNEFF (1173.21)

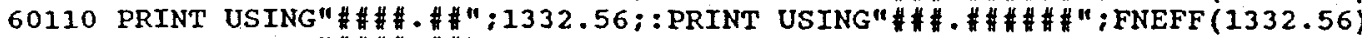

60120 PRINT USING"\#\#\#.\#\#"; 1836.01 ;:PRINT USING"\#\#.\#\#\#\#";FNEFF $(1836.01)$

60130 INPUT"Press return to proceed":ZZ

60140 RETURN 


\section{GRABCALB: Program structure Reference}

Main

5-28/DIM setup

30-35/Input data

41-65/Eff Formula

70-95/Input data

100-130/Calendar

135-140/Attenuation

145-260/Source Age

300-490/Calib peaks

500-510/Display peaks

520-530/Edit peaks

600-620/Plot calibs

$630-645 /$ Fixup summing
--- Subroutines and [files]

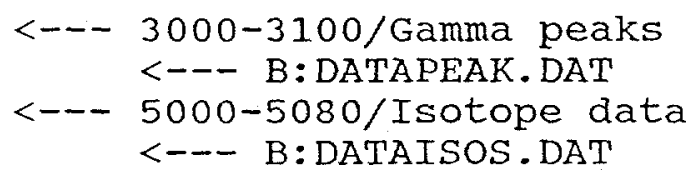

<--- 61000-61020/Calendar data

<-- 62000-62060/Ge coefficients

<-- 20000-21000/Dates to age calc

<-- 30000-30100/Peak listing

<-- 31000-31100/Corrections menu <-- 32000-32300/Add peak <--- 33000-33100/Delete peak <--- 34000-34100/Change peak <--- 30000-31100/List peaks

<--- 51000-51900/LogEff-LogE graph

<-- 50000-50900/Plot measured effs

<--- 40000-4090/Make summing corrections <-- 4000-4100/Get spectrum $<--$ B:DATASPEC. DAT

<-- 41000-41100/Atten-eff calcs

<-- 51000-51900/LogEff-LogE graph

<-- 50000-50900/Plot measured effs

650-677/Plot drawing instructions

680-798/Draw eff <-- 51000-51900/Logeff Vs LogE graph

<-- 50000-50900/Plot measured effs

$$
B-67
$$


GRABCALB: Program structure Reference (continued)

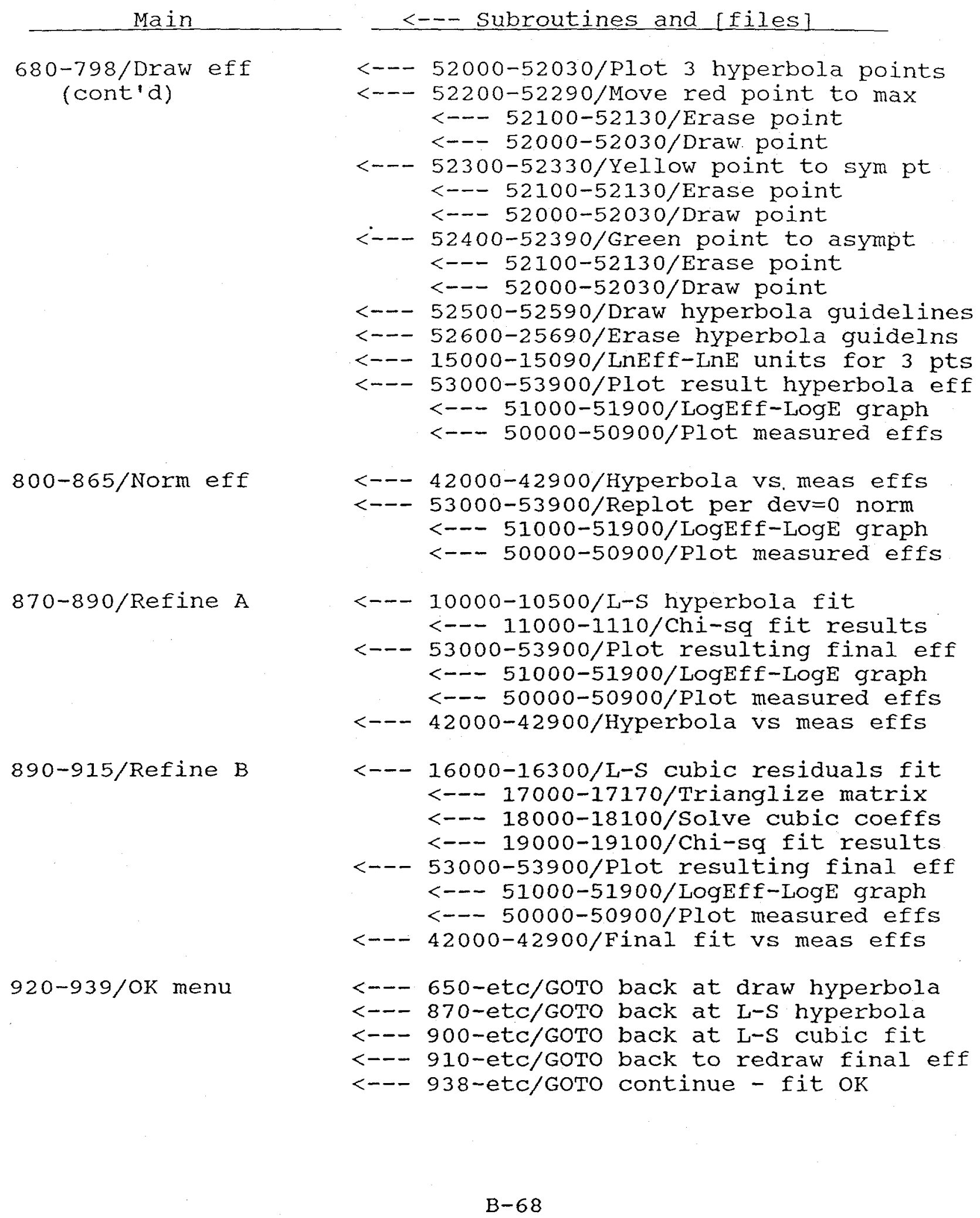




\section{GRABCALB: Program structure Reference (continued)}

Main

940-970/Output

Lines not used in execution

6000-6100/Background input of backgnd. BKG

7000-7200/Efficiency parameters of DETLIBRY.IIB

8000-8100/Isotope library of B:DETLIBRY.LIB

13000-13100/Energy to channel transformer

60000-60140/Efficiency Vs energy table for calib gammas 


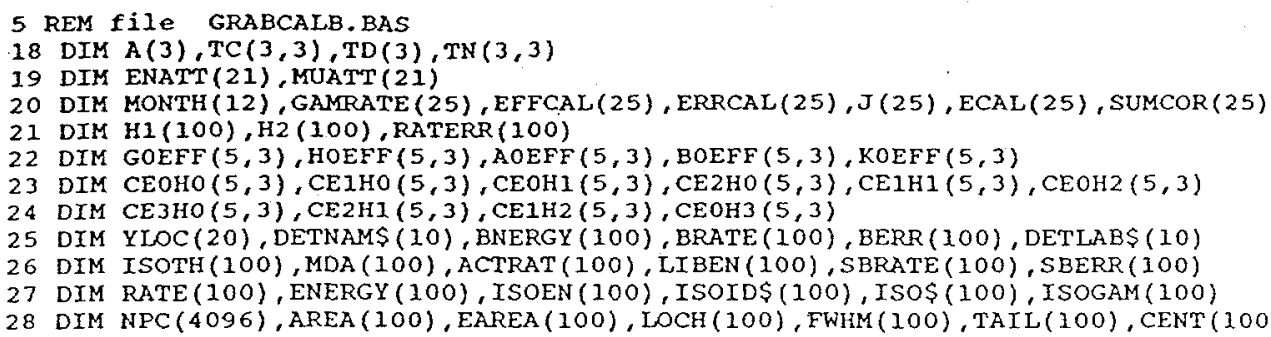

30 GOSUB 1000:REM read file B:DATAMISC.DAT

35 GOSUB 2000:REM read file B:DATACALB. DAT

41 DEF FNENC $($ CHAN $)=$ COENC + CIENC $\star$ CHAN

44 DEF FNFWHM (CHAN) $=S Q R(C O F W H M+C 1 F W H M * C H A N)$

58 DEF FNEFFA $(E N)=G O E F F \star E X P\left(A O E F F \star S Q R\left(B O E F F \wedge 2+U O E F F \star(L O G(E N)-K O E F F)^{\wedge} 2\right) \star(C O E F F+C 1\right.$

$E F F * L O G(E N)+C 2 E F F * \operatorname{LOG}(E N) \wedge 2+C 3 E F F * \operatorname{LOG}(E N) \wedge 3)+.5 *(1+S G N(E N-E N X) *(D O E F F+D I E F F * L O G$ $(E N)+D 2 E F F * L O G(E N) \wedge 2+D 3 E F F * \operatorname{LOG}(E N) \wedge 3))$

59 DEF FNEFFB $(E N)=1+P O E F F+P 1 E F F \star L O G(E N)+P 2 E F F \star L O G(E N) \wedge 2+P 3 E F F \star I O G(E N) \wedge 3$

60 DEF FNEFF (EN) $=$ FNEFFA (EN) $*$ FNEFFB (EN)

61 REM INPUT"Do you wish to see EFF VS EN data for standard energies ( $Y / n$ )";EFFV ENS:CLS:IF EFFVEN\$ $\langle>$ "Y" THEN GOTO 65

62 REM gOSUB 60000:REM check on efficiency data EFF VS EN

65 REM - tempory continue

70 GOSUB $3000:$ REM read file B:DATAPEAK.DAT

75 REM GOSUB 4000:REM read file B:DATASPEC.DAT

80 GOSUB 5000:REM read file B:DATAISOS.DAT

85 REM GOSUB 6000:REM read file DETFILE\$.BKG

90 REM GOSUB 7000:REM read file B:DETLIBRY. IIB

95 REM gosub B000:rem read file B:ISOLIBRY.LIB (when needed for B:DATAISOS.DAT)

100 REM-read in days of month data

105 MONTH $(0)=0$

110 FOR $I=1$ TO 12

120 READ MONTH (I) : MONTH (I) $=\operatorname{MONTH}(I)+\operatorname{MONTH}(I-1)$

130 NEXT I

135 REM - below reads in atennuation data

140 FOR $I=1$ TO $21: \operatorname{READ} \operatorname{ENATT}(I), \operatorname{BNATOM}: \operatorname{MUATT}(I)=.008297 * 5.35 * B N A T O M: N E X T$ I

$145 \mathrm{CLS}$

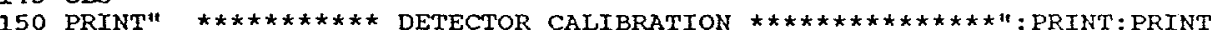

160. INPUT" Descriptive name for this calibration" "NACALS

170 PRINT"Calibration : ";NACAL\$

200 REM-select peaks and do experimental calibrations

210 PRINT"Enter decay information for standard": PRINT

220 PRINT" (1) Certification date (Mo-DY-Yr)"

230 PRINT" (2) Time since certification (Days)": PRINT

240 INPUT"Option";OPD: PRINT

250 IF OPD $=1$ THEN GOSUB 20000:GOTO 300

260 INPUT"DecaY time since standard certification (Days)";TDAY

300 REM - read in peaks and flag calibration candidates

310 PRINT: INPUT"Press enter to select calibration peaks ";

315 NCAL=0

320 FOR $J=1$ TO MPMAX

325 CLS

330 PRINT

340 PRINT"Isotope $=$ "iISOID\$(J)

350 PRINT"Energy = ";:PRINT USING" \#\#\#.\#";ENERGY $(J) ;:$ PRINT" keV"

355 PRINT

360 PRINT"Count rate = ";:PRINT USING" "\#\#\#\#\#\#";RATE(J);:PRINT" CPS"

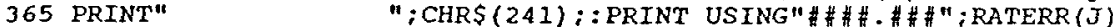

370 PRINT

380 INPUT"Use this peak as calibration $(Y / n)$ ": YE\$:PRINT

390 IF YES="n" THEN 490

395 NCAL $=$ NCAL+1:J $($ NCAL $)=J$

400 FOR $\mathrm{L}=1$ TO LMAX

410 IF ISOID\$(J) $<>$ ISO\$(L) THEN 440

420 ISOTH $=$ ISOTH (L)

$430 \quad L=$ LMAX

440 NEXT I

450 INPUT"Gammas/sec at certification date" :GAMRATE (NCAL)

$460 \operatorname{ECAL}(N C A L)=\operatorname{LIBEN}(J): \operatorname{IF} \operatorname{LIBEN}(J)=0$ THEN $\operatorname{ECAL}(N C A L)=\operatorname{ENERGY}(J)$

470 EFFCAL (NCAL) $=\operatorname{RATE}(J) * 2^{\wedge}($ TDAY $/$ ISOTH) $/$ GAMRATE $($ NCAL $)$

480 ERRCAL (NCAL) $=$ RATERR (J) *2^(TDAY/ISOTH)/GAMRATE (NCAL)

485 PRINT"Eff $=$ "; : PRINT USING" \#. \#\#\#";EFFCAL(NCAL)

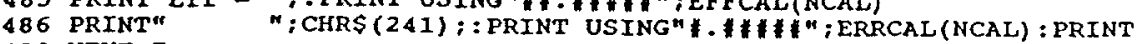

490 NEXT $J$ 
500 CLS:PRINT"Calibrations - Raw Data"

510 GOSUB 30000 : REM - list calibration points

520 INPUT"Desire corrections to input data $(Y / n)$; YES:PRINT

530 IF YE $\$=" Y$ " THEN GOSUB 31000:GOTO 500

600 REM - plot initial results and continue analysis

605 GOSUB 51000:REM - set up graph paper

610 GOSUB 50000:REM - plot data points

620 LOCATE 24,4

630 INPUT"Fix coinC-sum $(\mathrm{Y} / \mathrm{n})$ "; Y Y $\$$ : PRINT

635 FOR $K=1$ TO NCAL: $\operatorname{SUMCOR}(K)=I: N E X T K$

640 IF YE $\$=" Y$ " THEN SCREEN 2 : SCREEN $0:$ GOSUB 40000

645 SCREEN 2:SCREEN 0

650 CLS:PRINT"Calibration curve fitting": PRINT

$651 \mathrm{~S}=0$

655 PRINT" First order fit with hyperbola"

660 PRINT" (Will apply second order cubic later)":PRINT:PRINT

665 PRINT" Instructions: ": PRINT

666 PRINT" (1) Turn on Num Lock to use arrows"

667 PRINT"

(2) Select options below while looking at graph"

668 PRINT"

669 PRINT"

$(x)$ ed point - adjust to curve max estimate"

(y) ellow point - adjust to origin point of hyperbola"

670 PRINT"

(g) reen point - adjust to asymptote point of hyperbola"

671 PRINT"

(d) raw lines - examine above settings"

(e) rase lines - as needed for new (d) cases"

673 PRINT"

(f) inished - clean replot with calib curve"

674 PRINT"

675 PRINT"

(3) Move a point in (2) with number pad arrows $(5=$ finished)"

676 PRINT"

(4) Draw hyperbola characteristic lines (2-d and 2-e)"

677 PRINT"

(5) Plot resulting calibration curve (2-f)"

(6) Repeat this process until satisfactory curve fit":PRINT

680 INPUT"To begin, press enter"; $z Z$

685 RED $=2$ : YELLOW $=3$ : GREEN $=1$

$690 \mathrm{XR}=120: Y R=40: X Y=120: Y Y=20: X G=250: Y G=160$

700 GOSUB $51000:$ GOSUB 50000

$710 \mathrm{XP}=\mathrm{XR}: \mathrm{YP}=\mathrm{YR}: \mathrm{COLOUR}=\mathrm{RED}:$ GOSUB 52000:REM - point plot with no error

$712 \mathrm{XP}=\mathrm{XY}: \mathrm{YP}=\mathrm{YY}:$ COLOUR$=\mathrm{YEL}$ LOW $:$ GOSUB 52000

$714 X P=X G: Y P=Y G: C O L O U R=G R E E N: G O S U B 52000$

720 RYGDEF $\$=$ INKEY $\$$ : IF RYGDEF $\$="$ " THEN 720

725 IF RYGDEF $\$=" r$ " THEN GOSUB 52200

730 IF RYGDEF $\$=" y$ " THEN GOSUB 52300

735 IF RYGDEF $\$=" g$ " THEN GOSUB 52400

740 IF RYGDEF $\$=" d$ " THEN GOSUB 52500

745 IF RYGDEF $\$=" e$ " THEN GOSUB 52600

750 IF RYGDEF\$ $<>$ "E"THEN 720

755 REM - now ready to plot calib curve (hyperbola)

$760 X E N=X R: Y E F F=Y R: G O S U B$ 15000: LNENR $=$ INEN : LNEFFR $=$ LNEFF

$765 X E N=X Y: Y E F F=Y Y:$ GOSUB $15000:$ LNENY =LNEN : LNEFFY $=$ LNEFF

$770 \quad X E N=X G: Y E F F=Y G: G O S U B$ 15000:LNENG $=$ LNEN $:$ LNEFFG $=$ LNEFF

$775 D=$ LNEFFY : $A=($ LNEFFG-LNEFFY $) /($ LNENG-LNENY $): B=($ LNEFFY-LNEFFR $) / A: C=$ LNENR

$776 \quad A(0)=1: A(1)=0: A(2)=0: A(3)=0: S P=0$

780 GOSUB 53000:REM - plot hyperbola

797 LOCATE 24,4

798 INPUT"Satisfactory $(Y / n)$ ";YES:IF YE\$=" $n "$ THEN CLS:GOTO 700

800 GOSUB 42000:REM - compare data analysis results for hyperbola

855 PRINT:INPUT"Desire to renormalize to make average deviation zero $(\mathrm{Y} / \mathrm{n})$ "; YES:

IF YE\$C> "Y" THEN 870

860 D=D+TOTDEV/NCAL: GOSUB 53000: LOCATE 24,4

865 INPUT"OK(press enter)";ZZ:GOSUB 42000

870 PRINT: INPUT"Desire ISQ-fit to hyperbola $(y / n)$ "; YE\$:IF YES $>$ "Y" THEN 900 875 GOSUB 10000:REM LSQ-fit to hyperbola

880 GOSUB $53000:$ LOCATE 24,4

890 INPUT"OK(press enter)";zZ:GOSUB 42000

900 PRINT: INPUT"Apply LSQ cubic fit to perturbations from hyperbola (Y/n)";YES:I F YE\$ $\langle>" Y "$ THEN 920

905 GOSUB 16000: REM LSQ cubic fit to hyperbola perturbations

910 GOSUB $53000:$ LOCATE 24,4

915 INPUT"OK(press enter)"; $2 Z:$ GOSUB 42000 
920 PRINT:INPUT"Press enter to continue";ZZ:CLS

925 PRINT"

926 PRINT" Note: Refit options $(1-3)$ remove existing cubic LSQ"

927 PRINT" perturbation fit, which can be replaced within"

928 PRINT" these options if desired":PRINT:PRINT

929 PRINT" Refit beginning previous fit sequence at: ": PRINT

930 PRINT" (1) Hyperbola drawing on screen"

931 PRINT" (2) Hyperbola LSQ selection"

932 PRINT" (3) Cubic LSQ perturbation selection"

933 PRINT" (4) No refit yet - view current fit and plot first"

934 PRINT" (5) None of the above - current fit acceptable":PRINT

935 INPUT"Option";OP:IF OP>3 THEN 938

$936 \mathrm{~A}(0)=1: A(1)=0: A(2)=0: A(3)=0$

937 ON OP GOTO $650,870,900$

938 IF OP=4 THEN 910

939 EFFCALS="No efficiency file made":REM - will change if and when file made

940 CLS: PRINT't

941 PRINT"

FINAL DATA OUTPUT MENU": PRINT

942 PRINT

(1) Disk file and printout"

(2) Printout only"

943 PRINT" (3) Disk file only"

944 PRINT" (4) No more output - exit program":PRINT

945 INPUT"Option number";OP:GOSUB 44000:REM - parameter notations

946 IF $O P=1$ THEN GOSUB $45000:$ GOSUB $46000:$ GOTO 940

947 IF $O P=2$ THEN GOSUB $46000:$ GOTO 940

948 IF OP $=3$ THEN GOSUB 45000 : GOTO 940

970 SCREEN 2 :SCREEN 0

980 GOSUB 9000:REM - continuation menu

990 STOP

1000 REM - subroutine to read miscellaneous parameters file B:MISCDAT. DAT

1010 OPEN "B:DATAMISC.DAT" FOR INPUT AS \#3

1020 INPUT \#3, LTIME, STCH, ENCH, AUNIT\$, UNUM, UDEM, TDAYS, DETN, DETNAMS (DETN), DETIABS(

DETN , STDATE\$

1030 CLOSE \#3

1100 RETURN

2000 REM - subroutine to read data calib file B:DATACALB.DAT

2100 OPEN "B:DATACALB.DAT" FOR INPUT AS \#3

2110 INPUT \#3, COENC, C1ENC, COFWHM, C1FWHM, GOEFF, AOEFF, BOEFF, UOEFF, KOEFF, COEFF, C1EF

$F, C 2 E F F, C 3 E F F, E N X, D O E F F, D 1 E F F, D 2 E F F, D 3 E F F, P O E F F, P 1 E F F, P 2 E F F, P 3 E F F$

2160 CLOSE \#3

2200 RETURN

3000 REM - subroutine to read data peak file B:DATAPEAK.DAT

3010 OPEN "B:DATAPEAK.DAT" FOR INPUT AS \#3

$3015 \mathrm{KP}=1$

3020 IF EOF (3) THEN MPMAX $=K P-1:$ GOTO 3060

3040 INPUT $\#$, CENT (KP), ENERGY (KP), FWHM(KP), TAIL (KP), AREA (KP), RATE(KP), SBRATE (KP)

, ISOID\$(KP), ACTRAT (KP), LIBEN (KP), RATERR (KP), SBERR (KP) , H1 (KP), H2 (KP)

$3050 \quad \mathrm{KP}=\mathrm{KP}+1:$ GOTO 3020

3060 CLOSE \#3

3100 RETURN

4000 REM - subroutine to read in spectrum file B:DATASPEC.DAT

4005 TOTNPC $=0$

4010 OPEN "B:DATASPEC.DAT" FOR INPUT AS \#3

4020 FOR $I=S T C H$ TO ENCH

4030 INPUT \#3, NPC(I)

4035 TOTNPC $=$ TOTNPC+NPC (I)

4040 NEXT I

4050 CLOSE 3

4100 RETURN

5000 REM - subroutine to read in isotope library file B:DATAISOS.DAT

5010 OPEN "B:DATAISOS.DAT" FOR INPUT AS \#3

$5020 \mathrm{~L}=0$

$5030 \quad \mathrm{~L}=\mathrm{L}+1$

5040 INPUT 3 , ISO\$(L), ISOTH (L), ISOEN(L), ISOGAM(L),MDA(L)

5050 IF ISOS(L)="limit" THEN 5070

5060 GOTO 5030

5070 CLOSE 3

5075 LMAX $=$ I

5080 RETURN

6000 REM - subroutine to read in background library

6010 DETFILE\$=DETLAB\$ (DETN) +" . BKG"

6020 OPEN DETFILES FOR INPUT AS \#2

6030 CBACK $=1$

6040 IF EOF (2) THEN BAMAX $=$ CBACK-1: GOTO 6070

6050 INPUT 2 , BNERGY (CBACK), BRATE (CBACK), BERR (CBACK)

$6060 \mathrm{CBACK}=\mathrm{CBACK}+1:$ GOTO 6040

6070 CLOSE 12

6200 RETURN 
$7000 \mathrm{REM}$ - subroutine to read in detector library B:DETLIBRY.LIB

7005 OPEN "B:DETLIBRY.LIB" FOR INPUT AS \#3

7010 FOR $I=1$ TO 5

7020 FOR $\mathrm{J}=1$ TO 3

7030 INPUT \#3, $\operatorname{GOEFF}(I, J), \operatorname{AOEFF}(I, J), \operatorname{BOEFF}(I, J), \operatorname{KOEFF}(I, J), \operatorname{HOEFF}(I, J)$

7040 INPUT $\# 3$, CEOHO $(I, J)$

7050 INPUT $\$ 3, \mathrm{CE} 1 \mathrm{HO}(\mathrm{I}, \mathrm{J}), \mathrm{CEOH} 1(\mathrm{I}, \mathrm{J})$

7060 INPUT $3, C E 2 H O(I, J), C E 1 H 1(I, J), C E O H 2(I, J)$

7070 INPUT $\$ 3, \operatorname{CE} 3 \mathrm{HO}(I, J), \operatorname{CE} 2 \mathrm{H} 1(\mathrm{I}, J), \operatorname{CE} H \mathrm{H} 2(\mathrm{I}, J), \operatorname{CEOH} 3(\mathrm{I}, J)$

7080 NEXT J

7090 NEXT I

7095 CLOSE \#3

$7100 \quad I=0: J=0$

7200 RETURN

8000 REM - subroutine to read in isotope library data B:ISOLIBRY.LIB

8002 REM - note that B:DAXAISOS.DAT is used instead usually

8005 NMDA $=0$

8007 OPEN "B:ISOLIBRY.LIB" FOR TNPUT AS 3

8010 FOR ISO=1 TO 100

8020 INPUT \#3, ISOS (ISO), ISOTH (ISO), ISOEN (ISO), ISOGAM(ISO), MDA (ISO)

8025 ISOGAM $($ ISO) $=$ ISOGAM (ISO) $/ 100$

8027 IF MDA (ISO) $=1$ THEN NMDA $=N M D A+1$

8030 IF ISO\$(ISO) = "Iimit " THEN ISO $=100$

8040 NEXT ISO

8050 CLOSE \#3

8100 RETURN

9000 REM- subroutine for supplementary analyses

9005 OPEN "B:DETLIBRY.LIB" FOR INPUT AS \#3

9010 CLS

9020 PRINT"Supplementary Aralyses - as applicable to current spectrum": PRINT

9030 PRINT" (1) Background file development (GRABBACK)"

9040 PRINT" (2) Detector efficiency calibration (GRABCALB) "

9050 PRINT" (3) Peak/spectrum diagnostics (GRABDIAG)"

9060 PRINT" (4) Peak/multiplet plot analysis (GRABPLOT)"

9070 PRINT" (5) Analyses per isotopes (GRABISOS) ": PRINT

9080 PRINT"Data files are now being transferred to RAM disk (b:) for analyses"

9090 PRINT:PRINT"Type selected analysis (e.g. GRABBACK) after": PRINT"C-prompt (

C>, and press enter"

9095 CLOSE \#3

9100 RETURN

10000 REM-sub for least squares fit to hyperbola

10010 REM - calculate initial so

10020 GOSUB 11000: REM calc $s=c h i-2$

$10030 \mathrm{SO}=\mathrm{S}$

10040 INPUT"Increment divisor (usualiy 2) ":INCR

10100 REM - calculate 1st and 2nd derivitives for minimum cases

$10110 \mathrm{DSDD}=0: \mathrm{D} 2 \mathrm{SDD} 2=0: \mathrm{DSDA}=0: \mathrm{D} 2 \mathrm{SDA} 2=0$

$10120 \mathrm{DSDB}=0: \mathrm{D} 2 \mathrm{SDB} 2=0: \mathrm{DSDC}=0: \mathrm{D} 2 \mathrm{SDC} 2=0$

10130 FOR $\mathrm{K}=1$ TO NCAL

$10140 X K=$ LOG $(E C A L(K)): Y K=\operatorname{LOG}(\operatorname{EFFCAL}(K))$

10150 EYK=ERRCAL $(K) / \operatorname{EFFCAL}(K): W T K=E Y K \wedge-2$

10160 DYK $=D+A * S Q R(B \wedge 2+(C-X K) \wedge 2)-Y K$

10170 YKROOT $=S Q R\left(B^{\wedge} 2+(C-X K)^{\wedge} 2\right)$

10180 DSDD $=D S D D+W T K * D Y K$

10290 D2SDD2 $=\mathrm{D} 2 \mathrm{SDD} 2+\mathrm{WTK}$

10200 DSDA $=\mathrm{DSDA}+W T K \star Y K R O O T * D Y K$

$10210 \mathrm{D} 2 \mathrm{SDA} 2=\mathrm{D} 2 \mathrm{SDA} 2+\mathrm{WTK} * \mathrm{YKROOT}{ }^{\wedge} 2$

$10220 \mathrm{DSDB}=\mathrm{DSOB}+\mathrm{WTK} * \mathrm{~B} *((\mathrm{D}-\mathrm{YK}) / \mathrm{YKROOT}+\mathrm{A})$

10230 D2SDB2 $=$ D2SDB2+WTK* $\left((D-Y K) *(C-X K)^{\wedge} 2 /\right.$ YKROOT$\left.^{\wedge} 3+A\right)$

$10240 \mathrm{DSDC}=\mathrm{DSDC}+\mathrm{WTK} *(\mathrm{C}-\mathrm{XK}) *((\mathrm{D}-\mathrm{YK}) / \mathrm{YKROOT}+\mathrm{A})$

10250 D2SDC2 $=D 2 S D C 2+W T K \star((D-Y K) \star B \wedge 2 / Y K R O O T \wedge 3+A)$

10260 NEXT $K$

$10270 \mathrm{D}=\mathrm{D}-\mathrm{DSDD} / \mathrm{D} 2 \mathrm{SDD} 2 / \mathrm{INCR}$

$10280 \mathrm{~A}=\mathrm{A}-\mathrm{DSDA} / \mathrm{D} 2 \mathrm{SDA} 2 / \mathrm{INCR}$

$10290 \quad B=B-D S D B / D 2 S D B 2 / I N C R$

$10300 \mathrm{C}=\mathrm{C}-\mathrm{DSDC} / \mathrm{D} 2 S \mathrm{SDC} / \mathrm{INCR}$

10310 GOSUB 11000:REM - Calc new s with above parameters

10320 IF S>SO THEN PRINT:PRINT"Use increment factor > "; INCR:GOTO 10040

10330 IF ABS $(S-S O)>.001 * S O$ THEN SO=S:GOTO 10110

10400 REM print results

10410 CLS

10420 PRINT" Fit to hyperbola LNEFF $=D+A \star S Q R\left(B^{\wedge} 2+(\mathrm{C}-\operatorname{LNEN})^{\wedge} 2\right)$

10430 PRINT

10440 PRINT"D = ":D

10445 PRINT"A $=" ; A$

10450 PRINT"B $=": B$

10455 PRINT"C = ";C;" or "; $\operatorname{EXP}(\mathrm{C}) ; " \mathrm{keV} ":$ PRINT

10460 PRINT"Chi-2 = "is

10465 PRINT"Points fitted $=$ ";NCAL:PRINT

10470 INPUT"Press enter to continue"; $\mathrm{ZZ}$

10500 RETURN 
19000 REM LSQ cubic fit to deviations from hyperbola - $\mathrm{Ch} i-2$ calc

$19005 \mathrm{SP}=0$

19010 FOR $K=1$ TO NCAL

$19020 X K=\operatorname{LOG}(\operatorname{ECAL}(\mathrm{K})): \mathrm{YHY} P K=D+A * S Q R\left(B^{\wedge} 2+(C-X K) \wedge 2\right)$

$19025 \mathrm{YK}=(\mathrm{LOG}(\mathrm{EFFCAL}(\mathrm{K}))-\mathrm{D}) /(\mathrm{YHYPK}-\mathrm{D})$

$19030 \mathrm{EYK}=(\operatorname{ERRCAI}(\mathrm{K}) / \operatorname{EFFCAL}(\mathrm{K})) /(\mathrm{XHYPK}-\mathrm{D}): \mathrm{WTK}=\mathrm{EYK}^{\wedge}-2$

19035 YFITK $=A(0)+A(1) * X K+A(2) * X K^{\wedge} 2+A(3) * X K^{\wedge} 3$

$19040 \mathrm{SP}=S P+\mathrm{WTK}^{\star}(\mathrm{YK}-\mathrm{YFITK})^{\wedge} 2$

19050. NEXT K

19060 PRINT"Ch $\dot{i}-2=$ "; $S P$

19070 PRINT"Points fitted $=$ ":NCAL:PRINT

19100 RETURN

20000 REM - subroutine for date to days

20010 INPUT"Date of standard certification (eg 052484)":T1

20020 INPUT"Date of calibration counting (eg 031585)":T2

$20030 \mathrm{MT} 2=\operatorname{INT}(\mathrm{T} 2 / 10000): \mathrm{MT} 2=\operatorname{INT}(\mathrm{T} 2 / 10000)$

$20040 \mathrm{DT} 2=\operatorname{INT}((\mathrm{T} 1-\mathrm{MT} 1 * 10000) / 100): \mathrm{DT} 2=\operatorname{INT}((\mathrm{T} 2-\mathrm{MT} 2 * 10000) / 100)$

$20050 \mathrm{YT} 1=\mathrm{T} 1-\mathrm{MT} 1 * 10000-\mathrm{DT} 1 * 100: \mathrm{YT} 2=\mathrm{T} 2-\mathrm{MT} 2 * 10000-\mathrm{DT} 2 * 100$

$20060 \mathrm{LDI}=\operatorname{INT}(\mathrm{YT} 1 / 4)$

20070 IF YTI $/ 4=$ INT $(Y T 1 / 4)$ THEN IF MTI<3 THEN IF DTI<29 THEN LD $1=L D I-1$

20080 LD2 $=$ INT $\left(\mathrm{XT}_{2} / 4\right)$

20090 IF YT2 $/ 4=$ INT $(Y T 2 / 4)$ THEN IF MT2<3 THEN IF DT2<29 THEN LD2=LD2 - 1

20100 TDAY $=365 *($ YT2-YT1 $)+$ MONTH $($ MT2-1)-MONTH $($ MT1-1) + DT2-DT1 + LD2-ID1

21000 RETURN

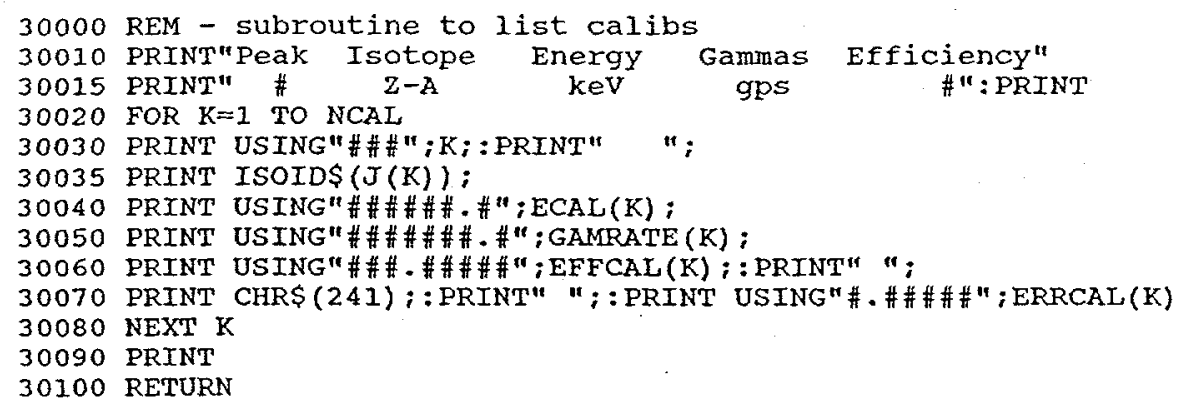

31000 REM - sub to correct input data

31010 PRINT"Editing options": PRINT

31020 PRINT" (1) Add calibration peak"

31030 PRINT" (2) Delete calibration peak"

31040 PRINT" (3) Change calibration peak"

31050 PRINT" (4) List current calibration peaks"

31060 PRINT" (5) Exit - editing complete": PRINT

31070 INPUT"Select option";OPE

31075 ON OPE GOSUB $32000,33000,34000,30000$

31080 IF OPE $<>5$ THEN 31010

31100 RETURN

32000 REM - sub to add peak

32010 PRINT"Calibration peak number ( 0 if first peak), after which new peak is $t$ o be added"

32015 INPUT PNUM

32020 FOR $K=$ NCAL TO PNUM+1 STEP - 1

32030 GAMRATE $(K+1)=$ GAMRATE $(K)$

32040 EFFCAL $(K+1)=E F F C A L(K)$

32050 ERRCAL $(K+1)=\operatorname{ERRCAL}(K)$

$32060 \operatorname{ECAL}(K+1)=\operatorname{ECAL}(K)$

$32070 \mathrm{~J}(\mathrm{~K}+\mathrm{I})=\mathrm{J}(\mathrm{K})$

32080 NEXT K

32090 INPUT"New peak to be added (peak number on GRABGAM output)";J

$32100 \mathrm{~J}($ PNUM +1$)=\mathrm{J}$

32110 FOR $L=1$ TO LMAX

32120 IF ISOIDS(J) $>$ ISOS(L) THEN 32150

32130 ISOTH=ISOTH (L)

$32140 \quad I=$ LMAX

32150 NEXT I

32160 INPUT"Gammas/sec at certification date";GAMRATE (PNUM+I)

$32170 \operatorname{ECAL}(\operatorname{PNUM}+1)=\operatorname{LIBEN}(J): \operatorname{IF} \operatorname{LIBEN}(J)=0 \operatorname{THEN} \operatorname{ECAL}(\operatorname{PNUM}+1)=\operatorname{ENERGY}(J)$

32180 EFFCAL (PNUM+1) =RATE (J) *2^(TDAY/ISOTH)/GAMRATE (PNUM+1)

32190 ERRCAL (PNUM+1) $=\operatorname{RATERR}(J) * 2 \wedge(T D A Y /$ ISOTH)/GAMRATE $($ PNUM+1)

32200 PRINT"EfF = ";:PRINT USING" \# . \#\#\#";EFFCAL (PNUM+1)

32210 PRINT" ":CHR\$ (241): : PRINT USING"\#.\#\#\#\#";ERRCAL (PNUM+1) : PRINT

32250 NCAL $=$ NCALH 1

32300 RETURN 
33010 INPUT"Calibration peak number to delete"; PNUM

33020 FOR $\mathrm{K}=$ PNUM TO NCAL

33030 GAMRATE $(K)=\operatorname{GAMRATE}(K+1)$

$33040 \operatorname{EFFCAL}(K)=\operatorname{EFFCAL}(K+1)$

33050 ERRCAL $(K)=\operatorname{ERRCAL}(K+1)$

$33060 \operatorname{ECAL}(\mathrm{K})=\operatorname{ECAL}(\mathrm{K}+1)$

$33070 J(K)=J(K+1)$

33080 NEXT $K$

$33090 \mathrm{NCAL}=\mathrm{NCAL}-1$

33100 RETURN

34000 REM - sub to change peak inputs

34010 PRINT"Note - only input to change is certified gammas/sec."

34020 PRINT" (If want to replace peak, use Delete and Add options)"

34022 PRINT:INPUT"Do you still want this option ( $y / n)$ "IYE\$:IF YE\$<> "Y" THEN 3410 0

34025 PRINT

34030 INPUT"Calibration peak number to alter"; PNUM

34040 INPUT"Gammas/sec a certification date"; GAMRATE

34050 EFFCAL (PNUM) =EFFCAL (PNUM) *GAMRATE (PNUM) / GAMRATE

34060 ERRCAL (PNUM) =ERRCAL (PNUM) *GAMPATE (PNUM) / GAMRATE

34070 GAMRATE $($ PNUM $)=$ GAMRATE

34080 PRINT"Eff = ";:PRINT USING"\#\#.\#\#\#\#";EFFCAL(NCAL)

34090 PRINT" ";CHR\$ (241);:PRINT USING"\#.\#\#\#\#";ERRCAL (NCAL) : PRINT

34100 RETURN

40000 REM - suming correction for close geometry

40005 PRINT"Reading in data for total detection information"

40010 GOSUB 4000: REM - get npctot

40020 TOTNPC=TOTNPC $*$ ENCH $/($ ENCH-STCH $):$ REM approximation fixup

40030 TOTRATE $=$ TOTNPC/LTIME:REM - total spectral rate sec-1

40040 CLS

40050 INPUT"Average active thickness estimate for detector (cm) ";TATT

40060 SUMGAM $=0$

40070 FOR $\mathrm{K}=1$ TO NCAL

40080 FOR $I=1$ TO 20

40090 IF ECAL $(\mathrm{K})>=\operatorname{ENATT}(\mathrm{I})$ THEN IF ECAL $(\mathrm{K})<=\operatorname{ENATT}(\mathrm{I}+1)$ THEN ENATT=ECAL $(\mathrm{K}): \mathrm{GOSUB}$

$41000: I=20: R E M$ gets value of muatt

40100 NEXT $I$

40110 SUMGAM $=$ SUMGAM $+\operatorname{GAMRATE}(\mathrm{K}) * 2 \wedge(-\operatorname{TDAY} / \operatorname{ISOTH}(\mathrm{J}(\mathrm{K}))) *(1-\operatorname{EXP}(-\operatorname{MUATT} *$ TATT $))$

40120 NEXT K

40130 COINCON $=$ TOTRATE/SUMGAM

40140 PRINT

40150 INPUT"Peak number to be corrected ( 0 if none)" ; PNUM: IF PNUM=0 THEN 40900

40155 PRINT: PRINT"Peak \#";PNUM;" has energy = ";:PRINT USING"\#\#\#\#";ECAL(PNUM); :PRINT" keV":PRINT

40160 INPUT"Energy of interferring coincident peak"; ECOINC: PRINT

40170 INPUT"Fraction of coincident cases (per decay scheme) ";FCOINC

40180 FOR $I=1$ TO 20

40190 IF ECOINC>=ENATT(I) THEN IF ECOINC<=ENATT(I+1) THEN ENATT=ECOINC:GOSUB 410 $00: I=20$ :REM gets value of muatt

40200 NEXT I

40210 COINFIX $=$ COINCON * $(1-E X P(-M U A T T * T A T T)) *$ FCOINC

40220 EFFCAL=EFFCAL (PNUM) : ERRCAL=ERRCAL (PNUM)

40230 EFFCAL (PNUM) $=$ EFFCAL (PNUM) $/(1$-COINFIX)

40240 ERRCAL $($ PNUM $)=$ ERRCAL $($ PNUM $) /(1-$ COINFIX $)$

40245 SUMCOR (PNUM) $=1 /(1-$ COINFIX)

40250 GOSUB 51000

40260 GOSUB 50000

40270 LOCATE 24,4

40280 INPUT"ACcept correction $(y / n)$ ";OKS:IF OK\$="Y" THEN 40300

40290 EFFCAL (PNUM) =EFFCAL: ERRCAL (PNUM) $=$ ERRCAL: SUMCOR (PNUM) $=1$

40300 CLS:SCREEN 2:SCREEN 0

40320 PRINT"Next case selection below": PRINT

40330 PRINT" (1) Input active detector thickness and gamma peak"

40340 PRINT" (2) Input gamma peak alone (use current detector thickness)"

40350 PRINT" (3) Exit - summing corrections completed": PRINT

40360 INPUT"Option"; OPSC

40365 CLS

40370 ON OPSC GOTO $40050,40150,40900$

40900 RETURN

41000 REM - subroutine to interpolate muatt

41010 LNMUATT $=$ LOG (MUATT (I)) + (LOG (MUATT $(I+1))-$ LOG $($ MUATT (I))) * (LOG (ENATT) -LOG ( $\operatorname{ENATT}(I))) /(\operatorname{LOG}(\operatorname{ENATT}(I+1))-\operatorname{LOG}(\operatorname{ENATT}(I)))$

41020 MUATT=EXP (LNMUATT)

41100 RETURN 


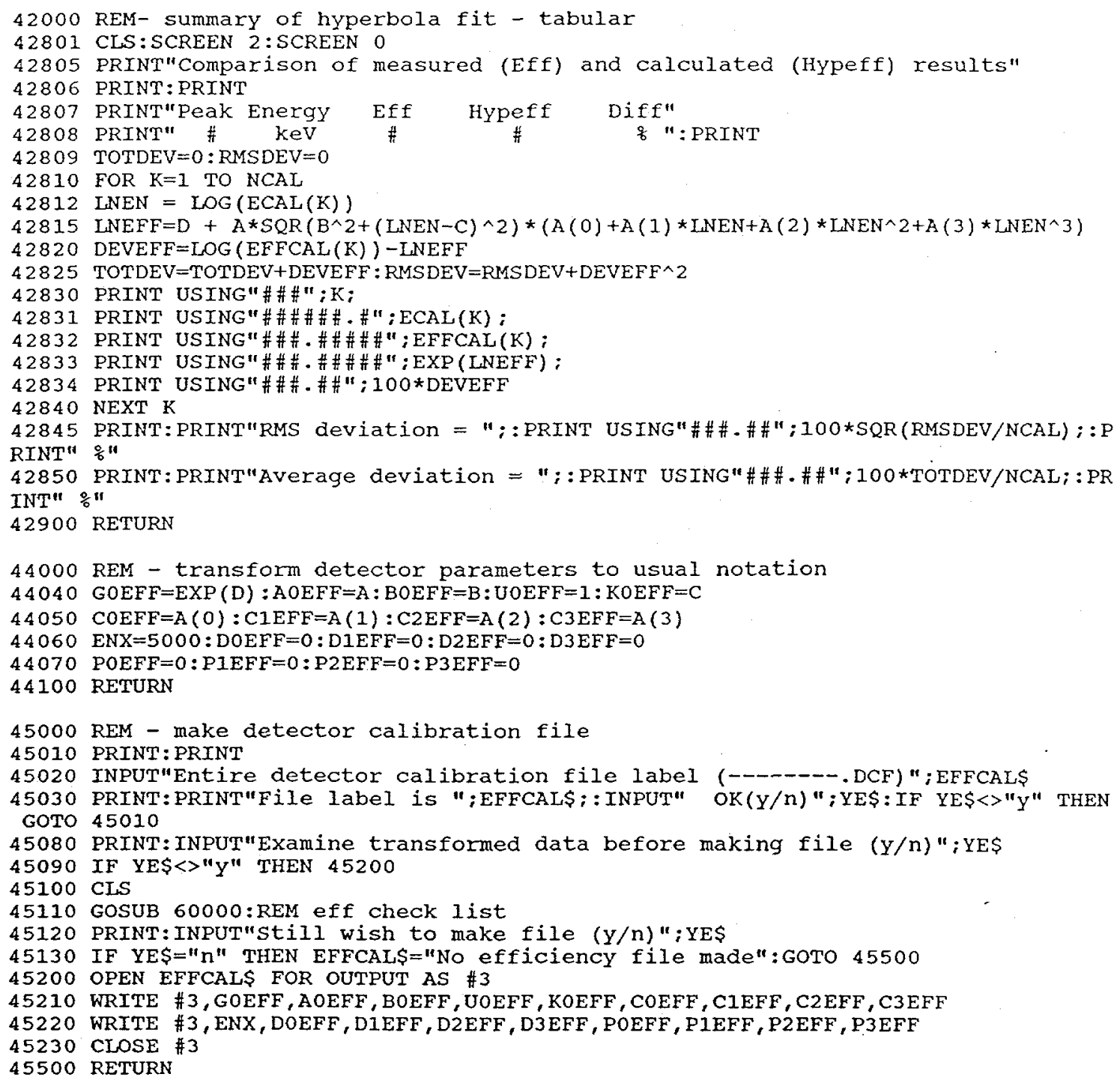


$46000 \mathrm{REM}$ - sub to printout results

46010 CLS: INPUT"Line feed printer as needed, and press enter to print";zZ

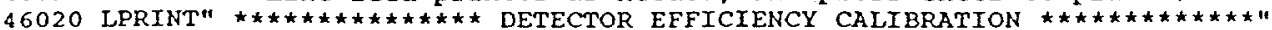

46030 LPRINT:LPRINT

46040 LPRINT"Title: ";NACALS:LPRINT

46050 LPRINT"Calibration file generated: ";EFFCAL\$:LPRINT

46330 REM - this segment on file DETPRINT.BAS in A-format

46335 LPRINT

$46355^{\circ}$ LPRINT"--------EFFICIENCY CALIBRATION FORMULA-----

46370 LPRINT

46380 LPRINT"Efficiency calibration: EFF $=G \star E X P($ HYPERBOLA * POLYNOMIAL) * $(1+P E R T$ URBATION)"

46385 LPRINT

46390 LPRINT" F)

46395 IPRINT

46400 LPRINT"

46410 IPRINT"

46415 LPRINT

46420 LPRINT"

ues below:"

46430 LPRINT"

$G=$ global calibration factor $=" ;$ GOEFF;" $D=L N(G)=$ "; LOG (GOEF

HYPERBOLA $=A \star S Q R\left(B^{\wedge} 2+(L N(E N)-C)^{\wedge} 2\right)$ with values below:

$(A="$ AOEFF;" $B=$ ";BOEFF;" $C=" ; K O E F F ; ") "$

POLXNOMIAL $=\mathrm{CO}+\mathrm{CI} \star \mathrm{LN}(E N)+\mathrm{C} 2 \star \mathrm{LN}(E N)^{\wedge} 2+\mathrm{C} 3 \star \operatorname{LN}(E N) \wedge 3$ with val

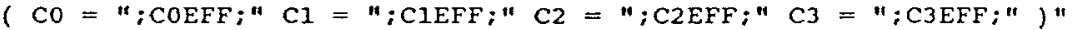

46432 LPRINT"

w) cases"

":ENX;" $\mathrm{keV}=$ crossover between low EN (above) and high EN (belo

46434 LPRINT"

$(\mathrm{CO}=$ ";TOEFF;" $\mathrm{C1}=$ ";TIEFF;" $\mathrm{C2}=$ "iT2EFF;" C3 = "iT3EFF;")"

46435 LPRINT

46440 LPRINT"

alues below:"

46450 LPRINT"

PERTURBATION $=P O+P 1 * I N(E N)+P 2 * L N(E N) \wedge 2+P 3 * I N(E N) \wedge 3$ with $v$

$(\mathrm{PO}=$ ":POEFF;" $\mathrm{P1}=$ ";P1EFF;" $\mathrm{P2}=$ " $\mathrm{P} 2 \mathrm{EFF} ; " \mathrm{P} 3=$ ":P3EFF;" $) "$

46460 LPRINT

46470 LPRINT"

46480 LPRINT

46505 LPRINT"Comparison of measured (Eff) and calculated (Hypeff) results"

46506 LPRINT: LPRINT

46507 LPRINT"Peak Energy Eff Hypeff Diff"

46508 LPRINT". \# $\mathrm{keV} \#$ \# \#

46509 TOTDEV $=0:$ RMSDEV $=0$

46510 FOR $\mathrm{K}=1$ TO NCAI

46512 LNEN $=$ LOG $(\operatorname{ECAL}(\mathrm{K}))$

46515 LNEFF $=D+A * \operatorname{SQR}(B \wedge 2+(\operatorname{LNEN}-C) \wedge 2) *\left(A(0)+A(1) * \operatorname{LNEN}+A(2) * \operatorname{LNEN} \wedge 2+A(3) \star \operatorname{LNEN}^{\wedge} 3\right)$

46520 DEVEFF $=$ LOG $($ EFFCAL $(\mathrm{K}))-\mathrm{LNEFF}$

46525 TOTDEV=TOTDEV+DEVEFF : RMSDEV=RMSDEV+DEVEFF^

46530 LPRINT USING"\#\#"; K;

46531 LPRINT USING" \#\#\#\#\#"; $\operatorname{ECAL}(\mathrm{K})$

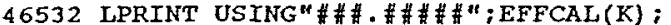

46533 LPRINT USING"\#\#\#- \#\#\#\#"; ;EXP (LNEFF);

46534 LPRINT USING" \#\# - \#\#";100*DEVEFF

46540 NEXT K

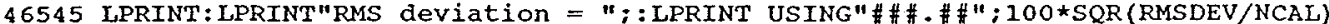

i: LPRINT" \& "

46550 LPRINT:LPRINT"Average deviation = ";:LPRINT USING"\#\#.\#\#"; 100*TOTDEV/NCAL;

:LPRINT" \&"

46560 LPRINT:LPRINT"Chi-2 for hyperbola = "iS:IF $S=0$ THEN 46580

46570 LPRINT"SQR (chi-2/n-r) = "SSQR (S/(NCAL-4))

46580 LPRINT: LPRINT"Chi-2 for cubic perturbation = ";SP:IF SP=0 THEN 46600

46590 LPRINT"SQR $(\mathrm{Chi}-2 / n-r)="$; SQR $(\mathrm{SP} /(\mathrm{NCAL}-4))$

46600 LPRINT

46610 LPRINT"--_-_-_-_-_--_RAW DATA REFERENCE

46620 LPRINT: LPRINT

46630 LPRINT"Num Isotope Energy Gammas

um Corr"

46640 LPRINT" \# $\mathrm{z}-\mathrm{A} \quad \mathrm{keV}$ gp

"

46650 LPRINT

46660 FOR $\mathrm{K}=1$ TO NCAI

46670 LPRINT USING"\#\#"; K;:LPRINT" ";

46680 LPRINT ISOID $(\mathrm{J}(\mathrm{K}))$ :

46690 LPRINT USING"\#\#\#\#\#"; $\operatorname{ECAL}(K)$;

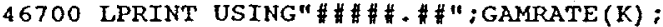

46710 LPRINT USING"\#\#\#\#.\#\#";RATE $(J(K)) ;:$ LPRINT" $+/-"$;

46720 LPRINT USING"\#\#.\#\#"; RATERR(J(K));

46730 LPRINT USING" \#\#-\#\#\#";

46740 LPRINT USING"\#,\#\#\#";

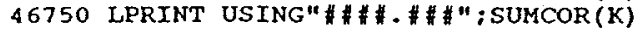

46760 NEXT $K$

46770 LPRINT: LPRINT"Average active detector thickness $=$ ":TATT;" $\mathrm{cm} "$

46780 LPRINT:LPRINT"Decay time since standard certification = ";TDAY;" days"

46900 RETURN 
50000 REM - sub to plot data points

50010 FOR $\mathrm{K}=1$ TO NCAL.

50020 XEN $=19+100 *$ LOG $(\operatorname{ECAL}(\mathrm{K})) /$ LOG $(10)-100$

50030 YEFF $=100-100 *$ ( LOG (EFFCAL $(K)) / L O G(10)-$ LGEFMD)

50040 YEFFA $=100-100 *($ LOG $(E F F C A L(K)+E R R C A L(K)) /$ LOG (10) - LGEFMD)

50050 YEFFB $=100-100 *(\operatorname{LOG}(\operatorname{EFFCAL}(\mathrm{K})-\operatorname{ERRCAL}(\mathrm{K})) /$ LOG $(10)-$ LGEFMD $)$

$50060 \operatorname{LINE}(\mathrm{XEN}-1, \mathrm{YEFF}-1)-(\mathrm{XEN}+1, \mathrm{YEFF}+1), 3, \mathrm{~B}: \mathrm{REM}$ point plotted

50070 LINE (XEN, YEFFA) - (XEN, YEFFB), 3:REM error plotted

50080 NEXT K

50900 RETURN

51000 REM - subroutine for graph paper

51600 REM - plot initial results and continue analysis

51610 SCREEN 1:CLS

51620 COLOR 8,0

51625 MINEFF $=1: M A X E F F=0$

51630 FOR $K=1$ TO NCAL:REM find graph limits

51632 IF EFFCAL $(K)>$ MAXEFF THEN MAXEFF $=$ EFFCAL $(K)$

51634 IF EFFCAL $(\mathrm{K})<\mathrm{MINEFF}$ THEN MINEFF $=\operatorname{EFFCAL}(\mathrm{K})$

51636 NEXT K

51640 LGEFMD $=($ LOG $($ MAXEFF $)+$ LOG $($ MINEFF $)) /(2 *$ LOG $(10)):$ REM mid $y$-axis

$51650 \operatorname{LINE}(19,0)-(319,199), 1, B: \operatorname{REM}$ draw axis frame

$51651 \operatorname{LINE}(119,0)-(119,199), 1$

$51652 \operatorname{LINE}(219,0)-(219,199), 1$

51654 IF IGEFMD = INT (LGEFMD) THEN YGRI=100:YGR2=100:LINE $(19,100)-(319,100), 1: G 0$

TO 51660

51655 YGR $1=\operatorname{INT}(100+100 *$ (IGEFMD-INT (LGEFMD) ) +

51656 IF GRI<199 THEN $\operatorname{LINE}(19$, YGRI) $-(319$, YGRI), I

51657 YGR2 $=$ YGRI -100

51658 IF YGR2>0 THEN $\operatorname{LINE}(19, \mathrm{YGR} 2)-(319, \mathrm{YGR} 2)$, I

51660 FOR XXGRID $=19$ TO 219 STEP 100

51662 FOR XGRID=1 TO 10

51664 XTIC $=$ INT $(100 * \operatorname{LOG}($ XGRID $) / \operatorname{LOG}(10)+.5)+$ XXGRID

51666 IINE (XTIC, 0)-(XTIC, 5), 1

51667 IINE (XTIC, 199)-(XTIC, 194), 1

51668 NEXT XGRID

51669 NEXT XXGRID

51670 FOR YYGRID=YGR $1+100$ TO YGR2 STEP - 100

51671 FOR YGRID=1 TO 10

51672 YTIC=YYGRID - INT (100*IOG (YGRID)/LOG $(10)+.5)$

51673 IF YTIC > 199 THEN 51677

51674 IF YTIC $<0$ THEN 51677

$51675 \operatorname{LINE}(19$, YTIC $)-(24$, YTIC $), 1$

51676 LINE (319, YTIC) - (314, YTIC), 1

51677 NEXT YGRID

51678 NEXT YYGRID

51900 RETURN

52000 REM - sub to draw point

$52010 \operatorname{LINE}(X P-1, Y P-1)-(X P+1, Y P+1)$, COLOUR, BF

52030 RETURN

52100 REM - sub to erase point

52110 LINE $(X P-1, Y P-1)-(X P+1, Y P+1), 0, B F$

52130 RETURN

52200 REM - sub to move red point for max of hyperbola

52210 VECT $\$=$ INKEY $\$:$ IF VECT $\$="$ THEN 52210

52220 IF INT (VAL (VECTS)/2) <>VAL (VECTS)/2 THEN 52270

$52225 \mathrm{XP}=\mathrm{XR}: \mathrm{YP}=\mathrm{YR}$ : GOSUB 52100

52230 IF VECT $\$=8$ " THEN YR=YR-1:XP=XR:YP=YR:COLOUR=RED:GOSUB 52000:GOTO 52210

52235 IF VECTS="2" THEN YR=YR+1:XP=XR:YP=YR:COLOUR=RED:GOSUB 52000:GOTO 52210

52240 XP $=\mathrm{XY}: \mathrm{YP}=\mathrm{YY}: \mathrm{GOSUB} 52100$

52245 IF VECTS="6" THEN 52260

$52250 \mathrm{XR}=\mathrm{XR}-1: \mathrm{XP}=\mathrm{XR}: \mathrm{YP}=\mathrm{YR}:$ COLOUR=RED: GOSUB 52000

$52255 \quad X Y=X Y-1: X P=X Y: Y P=Y Y: C O L O U R=Y E L L O W: G O S U B \quad 52000:$ GOTO 52210

$52260 X R=X R+1: X P=X R: Y P=Y R: C O L O U R=R E D:$ GOSUB 52000

$52265 X Y=X Y+1: X P=X Y: Y P=Y Y: C O L O U R=Y E L L O W: G O S U B \quad 52000:$ GOTO 52210

52270 IF VECTS<>"5" THEN 52210

52290 RETURN 
52300 REM - sub to move yellow point for origin of hyperbola 52310 VECT $\$=$ INKEY $\$$ : IF VECT\$ " " THEN 52310

52320 IF INT (VAL (VECT\$)/2) <>VAL (VECT\$)/2 THEN 52370

$52325 \mathrm{XP}=\mathrm{XY}: \mathrm{YP}=\mathrm{YY}: \mathrm{GOSUB} 52100$

52330 IF VECT $\$=8 "$ " THEN $Y Y=Y Y-1: X P=X Y: Y P=Y Y: C O L O U R=Y E L L O H: G O S U B \quad 52000: G O T O 52310$

52335 IF VECT $\$=" 2 "$ THEN $Y Y=Y Y+1: X P=X Y: Y P=Y Y:$ COLOUR=XELLOW:GOSUB $52000: G O T O 52310$

$52340 X P=X R: Y P=Y R: G O S U B \quad 52100$

52345 IF VECT $\$=6 "$ THEN 52360

$52350 \quad X R=X R-1: X P=X R: Y P=Y R: C O L O U R=R E D: G O S U B 52000$

$52355 X Y=X Y-1: X P=X Y: Y P=Y Y:$ COLOUR $=Y E L L O W:$ GOSUB $52000:$ GOTO 52310

$52360 \quad X R=X R+1: X P=X R: Y P=Y R: C O L O U R=R E D:$ GOSUB 52000

$52365 X Y=X Y+1: X P=X Y: Y P=Y Y: C O L O U R=Y E L L O W: G O S U B \quad 52000: G O T O 52310$

52370 IF VECT\$ $<>" 5 "$ THEN 52310

52390 RETURN

52400 REM - sub to move green point for asymptote of hyperbola

52410 VECT $\$=$ INKEY $\$$ IF VECT $\$="$ " THEN 52410

52420 IF INT (VAL (VECT\$) / 2 ) <>VAL (VECT\$) $/ 2$ THEN 52470

$52425 X P=X G: Y P=X G$ :GOSUB 52100

52430 IF VECTS $=" 8$ " THEN YG=YG-1:XP=XG:YP=YG: COLOUR=GREEN:GOSUB 52000:GOTO 52410

52435 IF VECT $\$=2$ " THEN YG=YG+1:XP=XG:YP=YG:COLOUR=GREEN:GOSUB 52000:GOTO 52410

52445. IF VECT $\$=" 6 "$ THEN 52460

$52450 X G=X G-1: X P=X G: Y P=Y G: C O L O U R=G R E E N: G O S U B \quad 52000: G O T O 52410$

$52460 X G=X G+1: X P=X G: Y P=Y G: C O L O U R=G R E E N: G O S U B \quad 52000: G O T O 52410$

52470 IF VECT\$C>"5" THEN 52410

52490 RETURN

52500 REM - sub to draw hyperbola characteristics

$52510 \operatorname{LINE}(X R, Y R)-(X Y, Y Y), G R E E N$

52520 IINE $(X Y, Y Y)-(X G, Y G), G R E E N$

$52530 X R E=X R: Y R E=Y R: X Y E=X Y: Y Y E=Y Y: X G E=X G: Y G E=Y G$

52590 RETURN

52600 REM - sub to erase hyperbola characteristics

52610 IINE (XRE, YRE) - (XYE, YYE), 0

52620 LINE (XYE, YYE) - (XGE, YGE), 0

52690 RETURN

53000 REM - sub to plot hyperbola calib

53780 CLS:GOSUB 51000:GOSUB 50000

53785 FOR $X E N=20$ TO 318

53787 LNEN $=((100-19+$ XEN $) / 100) * \operatorname{LOG}(10)$

$53788 L N E F F=D+A * S Q R\left(B^{\wedge} 2+(L N E N-C) \wedge 2\right) *\left(A(O)+A(1) * L N E N+A(2) * \operatorname{LNEN} N^{\wedge} 2+A(3) * \operatorname{LNEN} \wedge 3\right)$

53789 YEFF $=100-100 *$ (LNEFF/LOG (10) - LGEFMD)

53790 IF YEFF $>198$ THEN 53795

53791 IF YEFF $<1$ THEN 53795

53792 PSET (XEN, YEFF), RED

53795 NEXT XEN

53796 GOSUB 50000

53900 RETURN

60000 REM temp check on eff

60005 PRINT"Efficiency (EFF) per standard energy (EN) for ";EFFCAL\$

60006 PRINT

60010 PRINT "EN", "EFF"

60011 PRINT"keV"," "\#"

60020 PRINT USING"\#\#\#-\#"; 88.03; : PRINT USING"\#\#-\#\#\#\#"; FREFF(88.03)

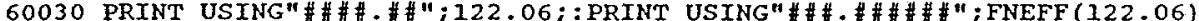

60040 PRINT USING"\#\#\#. \#"; $165.85 ;:$ PRINT USING"\#\#.\#\#\#\#"; FNEFF (165.85)

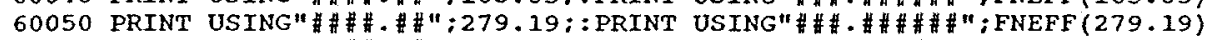

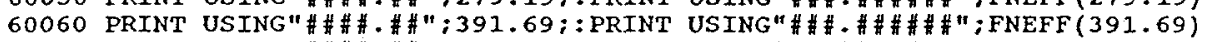

60070 PRINT USING"

60080 PRINT USING"\#\#\#-\#\#";661.64;:PRINT USING"\#\#-\#\#\#\#" ; FNEFF(661.64)

60090 PRINT USING"\#\#\#.\#";898.02; : PRINT USING"\#\#\#.\#\#\#\#"; FNEFF (898.02)

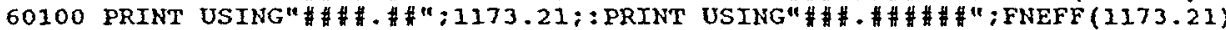

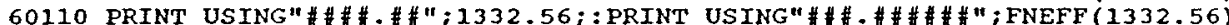

60120 PRINT USING"\#\#\#.\#";1836.01; : PRINT USING"\#\#\#.\#\#\#\#"; FNEFF (1836.01)

60140 RETURN

61000 REM month days data

61010 DATA $31,28,31,30,31,30$

61020 DATA $31,31,30,31,30,31$

62000 REM - data for mass atten coeffs in barns/atom - convert to cm-1 by

$62010 \mathrm{REM}$ - multiplying by $0.008297 \times 5.35 \mathrm{gm} / \mathrm{cm} 3$

62020 REM Energy (kev) b/atom, etc

62030 DATA $15,11000,20,5070,30,1680,40,746,50,400,60,243,80,115$

62040 DATA $100,66.4,150,29,6,200,20,0,300,13.5,400,11.2,500,9.87$

62050 DATA $600,8.96,800,7.73$

62060 DATA $1000,6.89,1500,5.60,2000,4.92,3000,4.24,4000,3.95,5000,3.81$ 


\title{
GRABDIAG: Program structure Reference
}

Main

$5-28 /$ DIM setup

30-35/Input data
--- Subroutines and [files]

$$
\begin{aligned}
<--- & 1000-1100 / \text { Miscellaneous data } \\
& <--- \text { B:DATAMISC.DAT } \\
<--- & 2000-2200 / \text { Efficiency data } \\
& <--- \text { B:DATACALB. DAT }
\end{aligned}
$$

41-65/Eff Formula

70-95/Input data <--- 3000-3100/Gamma peaks <-- B:DATAPEAK. DAT

97-250/Print peak diagnosis

900-990/Continue/STOP <--- 9000-9100/Supplementary analysis menu

\author{
Lines not used in execution \\ 4000-4100/Spectrum input of B:DATASPEC.DAT \\ 5000-5080/Isotope data input of B:DATAISOS.DAT \\ 6000-6100/Background input of backgnd. BKG \\ 7000-7200/Efficiency parameters of DETLIBRY.LIB \\ 8000-8100/Isotope library of B:DETLIBRY.LIB \\ 13000-13100/Energy to channel transformer \\ 60000-60140/Efficiency vs energy table for calib gammas
}


5 REM file GRABDIAG.BAS

21 DIM H1 (100), H2(100)

$22 \operatorname{DIM} \operatorname{GOEFF}(5,3), \operatorname{HOEFF}(5,3), \operatorname{AOEFF}(5,3), \operatorname{BOEFF}(5,3), \operatorname{KOEFF}(5,3)$

23 DIM CEOHO $(5,3), \operatorname{CEIHO}(5,3), \operatorname{CEOH} 1(5,3), \operatorname{CE} 2 \mathrm{HO}(5,3), \operatorname{CE} 1 \mathrm{H} 1(5,3), \operatorname{CEOH} 2(5,3)$

$24 \operatorname{DIM} \operatorname{CE} 3 \mathrm{HO}(5,3), \operatorname{CE} 2 \mathrm{H} 1(5,3), \operatorname{CEIH} 2(5,3), \operatorname{CEOH} 3(5,3)$

25 DIM YLOC (20), DETNAM\$(10), BNERGY (100), BRATE (100), BERR(100), DETLAB\$ (10)

26. DIM ISOTH(100), MDA (100), ISOACT (100), IIBEN (100), SBRATE (100), SBERR(100)

27 DIM RATE (100), ENERGY (100), ISOEN (100), ISOID\$ (100), ISOS (100), ISOGAM(100)

28 DIM NPC (4096), AREA (100), EAREA (100), IOCH(100), FWHM(100), TAIL(100), CENT(100)

30 GOSUB 1000:REM read file B:DATAMISC.DAT

35 GOSUB 2000:REM read file B:DATACALB.DAT

41 DEF FNENC $($ CHAN $)=$ COENC + CIENC CHAN

44 DEF FNFWHM (CHAN) $=$ SQR $($ COFWHM +CIFWHM*CHAN $)$

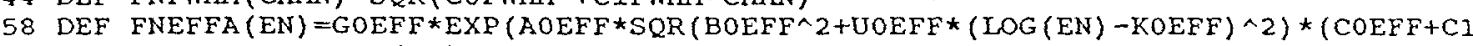

$\left.E F F^{\star} L O G(E N)+C 2 E F F \star L O G(E N) \wedge 2+C 3 E F F \star L O G(E N) \wedge 3\right)+.5 *(1+S G N(E N-E N X)) *(D O E F F+D 1 E F F \star L O G$

$\left.\left.(E N)+D 2 E F F \star L O G(E N) \wedge 2+D 3 E F{ }^{\star} \operatorname{LOG}(E N) \wedge 3\right)\right)$

$59 \operatorname{DEF} \operatorname{FNEFFB}(E N)=1+\mathrm{POEFF}+\mathrm{P} 1 \mathrm{EFF} * \mathrm{LOG}(\mathrm{EN})+\mathrm{P} 2 \mathrm{EFF} * \mathrm{LOG}(\mathrm{EN}) \wedge 2+\mathrm{P} 3 E F F \star \operatorname{LOG}(\mathrm{EN}) \wedge 3$

60 DEF FNEFF (EN) =FNEFFA (EN) *FNEFFB (EN)

61 REM INPUT"Do you wish to see EFF VS EN data for standard energies $(y / n)$ " EFFV EN\$:CLS:IF EFEVEN\$ <> "Y" THEN GOTO 65

62 REM GOSUB 60000:REM check on efficiency data EFF VS EN

65 REM - tempory continue

70 GOSUB 3000:REM read file B:DATAPEAK.DAT

75 REM GOSUB 4000:REM read file B:DATASPEC.DAT

80 REM GOSUB 5000:REM read file B:DATAISOS.DAT

85 REM gOSUB 6000:REM read file DETFILE\$.BKG

90 REM GOSUB 7000:REM read file B:DETLIBRY. LIB

95 REM gosub 8000 :rem read file B:ISOLIBRY. LIB (when needed for B:DATAISOS.DAT)



1000 REM - subroutine to read miscellaneous parameters file B:MISCDAT.DAT 1010 OPEN "B:DATAMISC.DAT" FOR INPUT AS $\# 3$ 1020 INPUT \#3, LTIME, STCH, ENCH, AUNIT\$, UNUM, UDEM, TDAYS, DETN, DETNAM\$ (DETN), DETLABS ( DETN), STDATE\$

1030 CLOSE \#3

1100 RETURN

2000 REM - subroutine to read data calib file B:DATACALB. DAT 2100 OPEN "B:DATACALB. DAT" FOR INPUT AS \#3

2110 INPUT \#3, COENC, C1ENC, COFWHM, C1FWHM, GOEFF, AOEFF, BOEFF, UOEFF, KOEFF, COEFF, C1EF $F, C 2 E F F, C 3 E F F, E N X, D O E F F, D 1 E F F, D 2 E F F, D 3 E F F, P O E F F, P I E F F, ~ P 2 E F F, P 3 E F F$ 2160 CLOSE \#3 2200 RETURN

3000 REM - subroutine to read data peak file B:DATAPEAK. DAT 3010 OPEN "B:DATAPEAK.DAT" FOR INPUT AS \#3

$3015 \mathrm{KP}=1$

3020 IF EOF (3) THEN MPMAX=KP-1: GOTO 3060

3040 INPUT $\$ 3$, CENT (KP), ENERGY (KP), FWHM (KP), TAIL (KP), AREA (KP), RATE (KP), SBRATE (KP)

, ISOIDS (KP), ACTRAT, LIBEN (KP), RATERR, SBERR (KP) , HI (KP) , H2 (KP)

$3050 \mathrm{KP}=\mathrm{KP}+1$ : GOTO 3020

3060 CLOSE \#3

3100 RETURN 
4000 REM -subroutine to read in spectrum file B:DATASPEC. DAT

4010 OPEN "B:DATASPEC.DAT" FOR INPUT AS \# 3

4020 FOR I $=$ STCH TO ENCH

4030 INPUT 3, NPC (I)

4040 NEXT I

4050 CLOSE \#3

4100 RETURN

5000 REM - subroutine to read in isotope library file B:DATAISOS. DAT

5010 OPEN "B:DATAISOS.DAT" FOR INPUT AS \#3

$5020 \quad L=0$

$5030 \quad \mathrm{~L}=\mathrm{L}+1$

5040 INPUT \#3, ISOS(L), ISOTH (L), ISOEN (L), ISOGAM (L), MDA (L)

5050 IF ISOS(L)="limit " THEN 5070

5060 GOTO 5030

5070 CLOSE \#3

5080 RETURN

6000 REM - subroutine to read in background libraxy

6010 DETFILE $\$=$ DETLAB $\$(D E T N)+"$. BKG"

6020 OPEN DETFILES FOR INPUT A.S \#2

6030 CBACK $=1$

6040 IF EOF (2) THEN BAMAX $=$ CBACK-1:GOTO 6070

6050 INPUT $\# 2$, BNERGY (CBACK), BRATE (CBACK), BERR (CBACK)

$6060 \mathrm{CBACK}=\mathrm{CBACK}+1$ : GOTO 6040

6070 CLOSE \#2

6100 RETURN

7000 REM - subroutine to read in detector library B:DETLIBRY.LIB

7005 OPEN "B:DETLIBRY. LIB" FOR INPUT AS \#3

7010 FOR $I=1$ TO 5

7020 FOR $J=1$ TO 3

7030 INPUT \#3, GOEFF $(I, J), \operatorname{AOEFF}(I, J), \operatorname{BOEFF}(I, J), \operatorname{KOEFF}(I, J), \operatorname{HOEFF}(I, J)$

7040 INPUT \#3,CEOHO $(I, J)$

7050 INPUT \#3,CE1HO (I,J), CEOHI (I,J)

7060 INPUT $\# 3, \operatorname{CE} 2 H O(I, J), \operatorname{CE} 1 H 1(I, J), \operatorname{CEOH} 2(I, J)$

7070 INPUT \#3, CE3HO $(I, J), \operatorname{CE} 2 H 1(I, J), \operatorname{CE} 1 \mathrm{H} 2(I, J), \operatorname{CEOH} 3(I, J)$

7080 NEXT J

7090 NEXT I

7095 CLOSE \#3

$7100 \quad I=0: J=0$

7200 RETURN

8000 REM - subroutine to read in isotope library data B:ISOLIBRY.LIB

8001 REM - note that B:DATAISOS.DAT is used instead usually

$8005 \mathrm{NMDA}^{2}=0$

8007 OPEN "B:ISOLIBRY, LIB" FOR INPUT AS. 3

8010 FOR ISO $=1$ TO 100

8020 INPUT \#3, ISOS(ISO), ISOTH (ISO), ISOEN (ISO), ISOGAM(ISO), MDA (ISO)

$8025 \operatorname{ISOGAM}$ (ISO) $=$ ISOGAM (ISO) $/ 100$

8027 IF MDA (ISO) $=1$ THEN NMDA $=$ MMDA +1

8030 IF ISOS(ISO) $=$ "limit " THEN ISO $=100$

8040 NEXT ISO

8050 CLOSE \#3

B100 RETURN

9000 REM- subroutine for supplementary analyses

9005 OPEN "B:DETLIBRY.LIB" FOR INPUT AS \#3

9010 CLS

9020 PRINT"Supplementary Analyses - as applicable to current spectrum": PRINT

9030 PRINT" (1) Background file development (GRABBACK)"

9040 PRINT" (2) Detector efficiency calibration (GRABCALB)"

9050 PRINT" (3) Peak/spectrum diagnostics (GRABDIAG)"

9060 PRINT" (4) Peak/multiplet plot analysis (GRABPLOT)"

9070 PRINT" (5) Analyses per isotopes (GRABISOS) ": PRINT

9080 PRINT"Data files are now being transferred to RAM disk (b:) for analyses"

9090 PRINT: PRINT"TYpe selected analysis (e.g. GRABBACK) after": PRINT"C-prompt

C>, and press enter"

9095 CIOSE H3

9100 RETURN

13000 REM sub from sub 3000 - calc channel from energy

13010 AOEN $=$ FNENC $(0)$

13020 AIEN $=$ FNENC $(1)$-FNENC $(0)$

13030 CHANO $=($ ENERGY - AOEN $) /$ A.IEN

13040 CHAN $=$ CHANO $+($ ENERGY - FNENC $($ CHANO $)) /$ AIEN

13050 IF ABS (ENERGY-FNENC (CHAN)) >. 1 THEN CHANO=CHAN: GOTO 13040

13055 RCHAN $=$ CHAN

13060 CHAN $=$ INT $($ CHAN+ . 5)

13100 RETURN 
60000 REM temp check on eff

60005 PRINT"Efficiency (EFF) pex standard energY (EN) for ";DETNAM\$ (DETN)

60006 PRINT

60010 PRINT "EN", "EFF"

60011 PRINT"KeV" "\#"

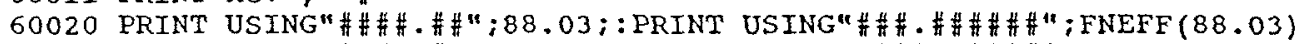

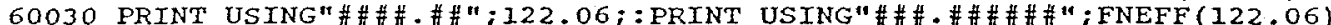

60040 PRINT USING"\#\#\#\#\#\#"; 165.85;:PRINT USING"\#\#\#.\#\#\#\#\#";FNEFF(165.85)

60050 PRINT USING"\#\#\#,\#\#":279.19; : PRINT USING"\#\#\#.\#\#\#\#\#";FNEFF(279.19)

60060 PRINT USING"苂\#\#.\#\#";391.69; : PRINT USING"\#\#\#.\#\#\#\#\#"; FNEFF (391.69)

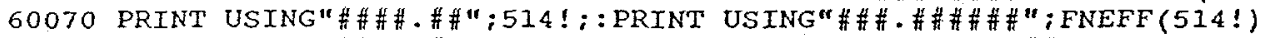

60080 PRINT USING"\#\#\#\#.\#\#";661.64;:PRINT USING"\#\#\#.\#\#\#\#\#";FNEFF (661.64)

60090 PRINT USING" \#\#\#\#.\#\#";898.02;:PRINT USING"\#\#\#.\#\#\#\#\#";FNEFF(898.02)

60100 PRINT USING"

60110 PRINT USING"\#\#\#\#\#\#";1332.56;:PRINT USING"\#\#\#\#\#\#\#\#";FNEFF (1332.56)

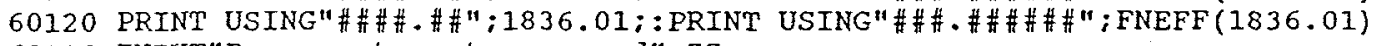

60130 INPUT"Press return to proceed"; 22

60140 RETURN 


\section{GRABPLOT: Program structure Reference}

Main

$5-28 /$ DIM setup

30-35/Input data

$$
\begin{aligned}
&<-- 1000-1100 / \text { Miscellaneous data } \\
&<--- \text { B:DATAMISC.DAT } \\
&<--- \text { 2000-2200/Efficiency data } \\
&<--- \text { B:DATACALB.DAT }
\end{aligned}
$$

41-65/Eff Formula

70-95/Input data

$$
\begin{aligned}
<-- & 3000-3100 / \text { Gamma peaks } \\
& <--- \text { B:DATAPEAK. DAT } \\
<--- & 4000-4100 / \text { Gamma spectrum } \\
& <--- \text { B: DATASPEC. DAT } \\
<--- & 5000-5080 / \text { Isotope data } \\
& <--- \text { B:DATAISOS.DAT }
\end{aligned}
$$

100-140/Plot menu

150-160/Exit option

200-240/All peaks optn <--- 20000-21000/Printout single peak

300-350/Exam peak optn <--- 30000-31000/Screen display of peak <--- 32000-32900/Peak area calc

<--- 40000-40900/Change ROIs

<--- 41000-41100/Expand ROI \#1 <--- 32000-32900/Area calc <-- 33000-33900/Scrn info

<--- 42000-42100/Expand ROI \#2 <--- 32000-32900/Area calc <-- 33000-33900/Scrn info

--- 43000-43100/Expand ROI \#3 $<--$ 32000-32900/Area calc $<--$ 33000-33900/Scrn info

<--- 44000-44100/Expand ROI \#4 $<---32000-32900 /$ Area calc $<--33000-33900 /$ Scrn info

$<---45000-45100 /$ Expand ROI \#5 $<---32000-32900 /$ Area calc <-- 33000-33900/Scrn info <-- 20000-21000/Printout single peak 980-990/Continue/STOP <--- 9000-9100/Supplementary analysis menu 


\section{GRABPLOT: Program structure Reference (continued)}

Lines not used in execution

6000-6100/Background input of backgnd. BKG

7000-7200/Efficiency parameters of DETLIBRY.LIB

8000-8100/Isotope library of B:DETLIBRY.LIB

13000-13100/Energy to channel transformer

60000-60140/Efficiency vs energy table for calib gammas

B-86 
10 PRINT: PRINT"Data being read from files"

21 DIM HI (100), H2 (100), RATERR(100)

22 DIM $\operatorname{GOEFF}(5,3), \operatorname{HOEFF}(5,3), \operatorname{AOEFF}(5,3), \operatorname{BOEFF}(5,3), \operatorname{KOEFF}(5,3)$

23 DIM CEOHO $(5,3), \operatorname{CElHO}(5,3), \operatorname{CEOH} 1(5,3), \operatorname{CE} 2 \mathrm{HO}(5,3), \operatorname{CE} 1 \mathrm{H} 2(5,3), \operatorname{CEOH} 2(5,3)$

24 DIM CE3HO $(5,3), \operatorname{CE} 2 H 1(5,3), \operatorname{CEIH2}(5,3), \operatorname{CEOH} 3(5,3)$

25 DIM YLOC (20), DETNAM\$ (10), BNERGY (100), BRATE (100), BERR (100), DETLAB\$ (10)

26 DIM ISOTH (100), MDA (100), ACTRAT (100), LIBEN (100), SBRATE (100), SBERR(100)

27 DIM RATE $(100)$, ENERGY $(100), \operatorname{ISOEN}(100), \operatorname{ISOID} \$(100), \operatorname{ISO}(100), \operatorname{ISOGAM}(100)$

28 DIM NPC (4096), AREA(100), EAREA (100), LOCH (100), FWHM $(100), \operatorname{TAIL}(100), \operatorname{CENT}(100)$

30 GOSUB 1000:REM read file B:DATAMISC.DAT

35 GOSUB 2000:REM read file B:DATACALB.DAT

41 DEF FNENC (CHAN) $=$ COENC + CIENC $*$ CHAN

44 DEF FNFWHM (CHAN) $=$ SQR ( COFWHM + CIFWHM *CHAN $)$

58 DEF FNEFFA (EN) =GOEFF*EXP ( $\triangle O E F F \star S Q R(B O E F F \wedge 2+U O E F F *(L O G(E N)-K O E F F) \wedge 2) \star(C O E F F+C 1$

$E F F * L O G(E N)+C 2 E F F \star L O G(E N) \wedge 2+C 3 E F F \star L O G(E N) \wedge 3)+.5 *(1+\operatorname{SGN}(E N-E N X)) *(D O E F F+D 1 E F F \star L O G$ $(E N)+D 2 E F F * \operatorname{LOG}(E N) \wedge 2+D 3 E F F * \operatorname{LOG}(E N) \wedge 3))$

59 DEF FNEFFB (EN) $=1+P O E F F+P I E F F * L O G(E N)+P 2 E F F \star L O G(E N) \wedge 2+P 3 E F F \star L O G(E N) \wedge 3$

60 DEF FNEFF (EN) =FNEFFA (EN) *FNEFFB (EN)

61 REM INPUT"Do you wish to see EFF VS EN data for standard energies $(y / n)$ ";EFFV

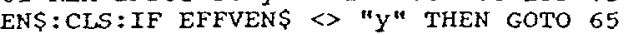

62 REM GOSUB 60000:REM check on efficiency data EFF VS EN

65 REM - tempory continue

70 GOSUB 3000:REM read file E:DATAPEAK. DAT

75 GOSUB 4000:REM read file B:DATASPEC.DAT

80 GOSUB 5000:REM read file B:DATAISOS.DAT

85 REM GOSUB 6000:REM read file DETFILE $\$$.BKG

90 REM GOSUB 7000:REM read file B:DETLIBRY. LIB

95 REM gosub 8000:rem read file B:ISOLIBRY.LIB (when needed for B:DATAISOS.DAT)

99 CLS

100 REM - main menu for program

110 PRINT"Select plot option below": PRINT

120 PRINT" (1) Plot all peaks on printer (GRABGAM ROI's only)"

130 PRINT" (2) Plot individual peaks on screen and/or printer (user selected $R$

OI'S)"

140 PRINT" (3) Exit program": PRINT

150 INPUT"Option"; OPP:IF OPP=3 THEN 980

160 IF OPP $<1$ THEN 300

200 REM-printout all peaks

210 FOR $I=1$ TO MPMAX

220 GOSUB 20000: REM printer plot of peak

230 NEXT I

240 GOTO 100: REM- return to initial menu

300 INPUT"Peak number to be plotted ( 0 for none)"; I: IF I=0 THEN 99

310 GOSUB 30000

350 GOTO 300

980 GOSUB 9000:REM - continuation menu

990 STOP

1000 REM - subroutine to read miscellaneous parameters file B:MISCDAT.DAT

1010 OPEN "B:DATAMISC.DAT" FOR INPUT AS \#3

1020 INPUT \# 3, LTIME, STCH, ENCH, AUNIT\$, UNUM, UDEM, TDAYS, DETN, DETNAM\$ (DETN), DETLAB\$(

DETN) , STDATE\$

1030 CLOSE \#3

1100 RETURN

2000 REM - subroutine to read data calib file B:DATACALB.DAT

2100 OPEN "B:DATACALB. DAT" FOR INPUT AS \#3

2110 INPUT $\$ 3$, COENC, CIENC, COFWHM, CIFWHM, GOEFF, AOEFF, BOEFF, UOEFF, KOEFF, COEFF, CIEF

$F, C 2 E F F, C 3 E F F, E N X, D O E F F, D 1 E F F, D 2 E F F$, D3EFF, POEFF, P1EFF, P2EFF , P3EFF

2160 CLOSE \#3

2200 RETURN

3000 REM - subroutine to read data peak file B:DATAPEAK. DAT

3010 OPEN "B:DATAPEAK.DAT" FOR INPUT AS \#3

$3015 \mathrm{KP}=1$

3020 IF EOF (3) THEN MPMAX $=\mathrm{KP}-1$ : GOTO 3060

3040 INPUT $\$ 3, \operatorname{CENT}(K P)$, ENERGY (KP), FWHM(KP), TAIL(KP), AREA (KP), RATE (KP), SBRATE(KP)

, ISOID\$(KP), ACTRAT (KP), LIBEN (KP), RATERR(KP), SBERR(KP),H1 (KP),H2(KP)

$3050 \mathrm{KP}=\mathrm{KP}+1$ : GOTO 3020

3060 CLOSE \#3

3100 RETURN

4000 REM - subroutine to read in spectrum file B:DATASPEC.DAT

4010 OPEN "B:DATASPEC.DAT" FOR INPUT AS *3

4020 FOR I $=S T C H$ TO ENCH

4030 INPUT 3, NPC $(I)$

4040 NEXT I

4050 CLOSE \#3

4100 RETURN 
5000 REM - subroutine to read in isotope library file B:DATAISOS.DAT 5010 OPEN "B:DATAISOS.DAT" FOR INPUT AS \#3

$5020 \quad \mathrm{~L}=0$

$5030 \quad \mathrm{~L}=\mathrm{L}+1$

5040 INPUT $\# 3, \operatorname{ISO}(L), \operatorname{ISOTH}(L), \operatorname{ISOEN}(L), \operatorname{ISOGAM}(L), \operatorname{MDA}(L)$

5050 IF ISOS(L)="limit "THEN 5070

5060 GOTO 5030

5070 CLOSE

5080 RETURN

6000 REM - subroutine to read in background Iibrary

6010 DETFILE\$=DETLAB $(D E T N)+"$. BKG"

6020 OPEN DETFILES FOR INPUT AS $\hbar^{\prime}$

6030 CBACK=1

6040 IF EOF (2) THEN BAMAX=CBACK-1:GOTO 6070

6050 INPUT \#2, BNERGY (CBACK), BRATE (CBACK), BERR (CBACK)

$6060 \mathrm{CBACK}=\mathrm{CBACK}+1:$ GOTO 6040

6070 CLOSE \#2

6100 RETURN

7000 REM - subroutine to read in detector library B:DETLIBRY.LIB

3005 OPEN "B:DETLIBRY. LIB" FOR INPUT AS $\$ 3$

7010 FOR $I=1$ TO 5

7020 FOR $\mathrm{J}=1$ TO 3

7030 INPUT $3, \operatorname{GOEFF}(I, J), \operatorname{AOEFF}(I, J), \operatorname{BOEFF}(I, J), \operatorname{KOEFF}(I, J), \operatorname{HOEFF}(I, J)$

7040 INPUT \#3, CEOHO $(\mathrm{I}, \mathrm{J})$

7050 INPUT $\# 3, C E 1 H O(I, J), C E O H 1(I, J)$

7060 INPUT $\# 3, C E 2 H O(I, J), C E 1 H 1(I, J), \operatorname{CEOH} 2(I, J)$

7070 INPUT $\# 3, \operatorname{CE} 3 \mathrm{HO}(I, J), \operatorname{CE} 2 \mathrm{H} 1(I, J), \operatorname{CE} 1 \mathrm{H} 2(I, J), \operatorname{CEOH} 3(I, J)$

7080 NEXT J

7090 NEXT I

7095 CLOSE

$7100 \quad I=0: J=0$

7200 RETURN

$8000 \mathrm{REM}$ - subroutine to read in isotope Iibrary data B:ISOLIBRY.LIB

8001 REM - note that B:DATAISOS.DAT is used instead usually

$8005 \mathrm{NMDA}=0$

8007 OPEN "B: ISOLIBRY.LIB" FOR INPUT AS \#3

8010 FOR ISO $=1$ TO 100

8020 INPUT \#3,ISO\$(ISO), ISOTH (ISO), ISOEN(ISO), ISOGAM(ISO), MDA (ISO)

8025 ISOGAM (ISO) =ISOGAM (ISO) $/ 100$

8027 IF $M D A(I S O)=1$ THEN NMDA $=$ NMDA +1

8030 IF ISO\$(ISO) = "limit "THEN ISO $=200$

8040 NEXT ISO

8050 CLOSE \#3

8100 RETURN

9000 REM- subroutine for supplementary analyses

9005 OPEN "B:DETLIBRY. LIB" FOR INPUT AS \#3

9010 CLS

9020 PRINT"Supplementary Analyses - as applicable to current spectrum":PRINT

9030 PRINT" (1) Background file development (GRABBACK)"

9040 PRINT" (2) Detector efficiency calibration (GRABCALB)"

9050 PRINT" (3) Peak/spectrum diagnostics (GRABDIAG)"

9060 PRINT" (4) Peak/multiplet plot analysis (GRABPLOT)"

9070 PRINT" (5) Analyses per isotopes (GRABISOS) ": PRINT

9080 PRINT"Data files are now being transferred to RAM disk (b:) for analyses"

9090 PRINT: PRINT"TYpe selected analysis (e.g. GRABBACK) after": PRINT"C-prompt (

C>, and press enter"

9095 CLOSE \#3

9100 RETURN

13000 REM sub from sub 3000 - calc channel from energy

13010 AOEN $=$ FNENC $(0)$

13020 AIEN $=$ FNENC $(1)-F N E N C(0)$

13030 CHANO $=($ ENERGY - AOEN $) /$ A $1 E N$

13040 CHAN $=$ CHANO $+($ ENERGY-FNENC $($ CHANO $)) / A I E N$

13050 IF ABS(ENERGY-FNENC(CHAN)) >. 1 THEN CHANO=CHAN:GOTO 13040

13055 RCHAN $=$ CHAN

$13060 \mathrm{CHAN}=\mathrm{INT}(\mathrm{CHAN}+.5)$

13100 RETURN 
20000 REM - sub for plot of single peak to printer

20010 LPRINT: NPCMAX $=0$

20015 IF OPP $=2$ THEN 20040:REM - uses screen plot ROI's

$20020 \mathrm{GCHS}=\mathrm{H} 2$ (I) $-\mathrm{HI}$ (I) $+1: \mathrm{B} 1 \mathrm{CH}=\mathrm{H} 2$ (I) $-\mathrm{GCHS} / 2: \mathrm{B} 2 \mathrm{CH}=\mathrm{H} 2(\mathrm{I})+\mathrm{GCHS} / 2$

$20030 \mathrm{LCH}=\mathrm{H} 2$ (I) $-\mathrm{GCHS}: \mathrm{HCH}=\mathrm{H} 2$ (I) + GCHS: $\mathrm{H} 1 \mathrm{CH}=\mathrm{H} 1(\mathrm{I}): \mathrm{H} 2 \mathrm{CH}=\mathrm{H} 2$ (I)

20040 FOR $\mathrm{J}=\mathrm{LCH}$ TO $\mathrm{HCH}$

20050 IF NPC (J) $>$ NPCMAX THEN NPCMAX $=\mathrm{NPC}(J)$

20060 NEXI J

20070 SCALP=1:IF NPCMAX>50 THEN SCALP $=50 /$ NPCMAX

20080 LPRINT"Channel energy counts

20087 LCHPR $=\mathrm{B} 1 \mathrm{CH}-5: \mathrm{HCHPR}=\mathrm{B} 2 \mathrm{CH}+5$

20090 FOR J ICHPR TO HCHPR

20095 PLOTCH=INT $(S C A L P \star N P C(J)+.5)$

20100 LPRINT USING"\#\#\#\#":J: : LPRINT USING"

20110 LPRINT USING" \#\#"

20120 LPRINT TAB(29) "1":

20130 IF $J<B I C H$ THEN LPRINT STRINGS(PLOTCH, "O") : GOTO 20180

20140 IF $\mathrm{J}<\mathrm{H} 1 \mathrm{CH}$ THEN LPRINT STRINGS (PLOTCH, "*"): GOTO 20180

20150 IF $\mathrm{J}<=\mathrm{H} 2 \mathrm{CH}$ THEN LPRINT STRING (PLOTCH, " $X "$ ) : GOTO 20180

20160 IF $\mathrm{J}<=\mathrm{B} 2 \mathrm{CH}$ THEN LPRINT STRING $($ PLOTCH, **): GOTO 20180

20170 LPRINT STRING\$(PLOTCH, "O")

20180 NEXT $J$

20185 LPRINT

20188 IF OPP=I THEN AREA=AREA(I): ERRA=INT (LTIME RRATERR(I) + .5)

20190 LPRINT TAB(29) "Peak area = ":AREA;

20200 LPRINT " +/-";INT(ERRA+.5)

20210 IPRINT

20220 ACT=ACTRAT (I) *AREA/LTIME

20230 ERRACT $=$ ACTRAT $(I) *$ ERRA $/$ LTIME

20235 LPRINT TAB(29);

20240 LPRINT ISOIDS(I);:LPRINT" "

20242 LPRINT USING" \#\#";ENERGY(I);:LPRINT " keV" :LPRINT

20243 LPRINT TAB(29)

20244 LPRINT USING"

20245 LPRINT TAB $(29)$

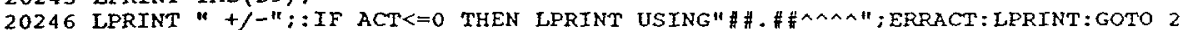

300

20247 ARGACT $=10^{\wedge}(\operatorname{LOG}(A C T) / \operatorname{LOG}(10)-\operatorname{INT}(\operatorname{LOG}(A C T) / \operatorname{LOG}(10)))$

20248 PRERR $=A$ ARGACT $*$ ERRACT/ACT

20249 LPRINT USING"

21000 RETURN

30000 REM - subroutine to put peak on screen

30010 SCREEN 1 : CLS

30015 COLOR 8 ,

$30020 \mathrm{H} 1 \mathrm{CH}=\mathrm{H}_{1}(\mathrm{I}): \mathrm{H} 2 \mathrm{CH}=\mathrm{H} 2(\mathrm{I}): \mathrm{GCHS}=\mathrm{H} 2 \mathrm{CH}-\mathrm{H} 1 \mathrm{CH}+2$

$30020 \mathrm{H} 1 \mathrm{CH}=\mathrm{H} 1(\mathrm{I}): \mathrm{H} 2 \mathrm{CH}=\mathrm{H} 2(\mathrm{I}): \mathrm{GCHS}=\mathrm{H} 2 \mathrm{CH}-\mathrm{H}$

30040 LCH $=\mathrm{H} 1 \mathrm{CH}-50: \mathrm{HCH}=\mathrm{H} 2 \mathrm{CH}+50$

30050 NPCMAX $=0$

30060 FOR $J=L C H$ TO HCH

30070 IF NPC (J) >NPCMAX THEN NPCMAX $=N P C(J)$

30080 NEXT J

30090 SCALE $=1:$ IF NPCMAX $>100$ THEN SCALE $=100 / \mathrm{NPCMAX}$

30100 XZERO $=2 \mathrm{CH}-160$

$30105 \quad B=0: G=0: B N U M=0: G N U M=0$

30110 FOR $\mathrm{J}=\mathrm{LCH}$ TO $\mathrm{HCH}$

30120 PX $=J-X Z E R O$

$30130 \quad$ PY $=$ INT (SCALE* NPC $(J)+.5)$

30140 IF $J<B 1 C H$ THEN LINE (PX,110)-(PX,110-PY), 1: GOTO 30200

30150 IF $J<H I C H$ THEN LINE (PX, 120)-(PX, 110-PY), $2: B=B+N P C(J): B N U M=B N U M+1: G O T O 3020$

30160 IF $J<=H 2 C H$ THEN LINE(PX,110)-(PX,110-PX), 3:G=G+NPC(J):GNUM=GNUM+1:GOTO 302 30170 IF $J<=B 2 C H$ THEN LINE $(P X, 110)-(P X, 110-P Y), 2: B=B+N P C(J): B N U M=B N U M+1: G O T O 302$ 3017

30180 LINE $(P X, 110)-(P X, 110-P Y), 1$

30200 NEXT J

30210 LOCATE 15,1

30215 GOSUB 32000:REM - calculate peak area and error

30220 PRINT TAB(17) LCH TAB(25) INT(CENT(I) +.5) TAB(33) HCH

30230 LOCATE 2 , 3

30240 PRINT ISÓDS $(x):$ PRINT

30244 PRINT USING" $\#$. \#AAAMN;ACT;:PRINT" " AUNTTS

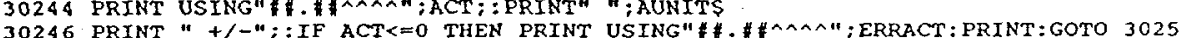
30

30247 ARGACT $=10^{\wedge}$ (LOG (ACT) / LOG (10)-INT (LOG (ACT)/LOG (10)))

30248 PRERR $=$ ARGACT *ERRACT/ACT

30249 PRINT USING" \#" \# : PRERR: PRINT

30250 PRINT USING" \#\# " " "ENERGY (I) ;:PRINT " keV" :PRINT

30260 PRINT AREA;"+/-";INT(ERRA +.5);" counts": PRINT

30270 PRINT"Peak ";I:PRINT

30275 LOCATE 17,1

OO280 INPUT" 1 Change ROT'S $(Y / n)$ ":YES

(

30200 IF YES

30305 LOCATE 19,1

30310 INPUT"2. Make hardCOPY $(y / n) " ; Y E \$:$ PRINT

30320 IF YES=" $Y$ " THEN GOSUB 20000

30330 INPUT" 3 . Done (0), redo II (1), Redo \$2 (2) ";OPT

30340 ON OPT GOTO 30275,30305

30995 SCREEN 2:SCREEN O

31000 RETURN 
32000 REM - sub to calculate peak area and error/activity

32010 AREA $=G-B \star(G N U M / B N U M): A R E A=I N T(A R E A+.5)$

32020 IF G + $B^{*}($ GNUM/BNUM) $\wedge 2<=0$ THEN PRINT" illegal square root": GOTO 32900

32030 ERRA $=S Q R(G+B *(G N U M / B N U M) \wedge 2)$

32040 ACT $=$ ACTRAT $(I) \star A R E A / L T I M E$

32050 ERRACT $=$ ACTRAT $(I) * E R R A / L T I M E$

32900 RETURN

33000 REM - print peak info after roi changes

33200 LOCATE 15,1

33220 PRINT TAB(27) LCH TAB(25) INT(CENT(I)+.5) TAB(33) HCH

33230 LOCATE 2, 1:FOR PBLANK $=1$ TO $7: \operatorname{PRINT}$ STRINGS $(20, "$ "):NEXT PBLANK

33235 LOCATE 2,1

33240 PRINT ISOIDS(I) : PRINT

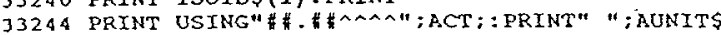

33246 PRINT "+/-":IIF ACT $<=0$ THEN PRINT USING" \#\#MA":ERRACT: PRINT:GOTO 3325

33247 ARGACT $=10^{\wedge}(\operatorname{LOG}(\operatorname{ACT}) / \operatorname{LOG}(10)-\operatorname{INT}(\operatorname{LOG}(\operatorname{ACT}) / \operatorname{LOG}(10)))$

33248 PRERR $=$ ARGACT $\star E R R A C T / A C T$

33249 PRINT USING" \# \#";PRERR:PRINT

33250 PRINT USING" \#\# "ENERGY(I);:PRINT " keV" :PRINT

33260 PRINT AREA;"+/" ; INT (ERRA +.5);" counts": PRINT

33270 PRINT"Peak ": I: PRINT

33275 LOCATE 17,1

33900 RETURN

40000 REM - roi adjustment subroutine

40010 LOCATE 17,1

40020 PRINT"ROI increases to decrease adjacent ROI"

40030 PRINT STRING\$(39," ")

40040 PRINT" First press key for ROI ( $O=$ done) per:"

40050 PRINT"1-green 2-red 3-yellow 4-red 5-green":PRINT STRING\$ (39," ")

40070 ROI $\$=$ INKEY $\$$ : IF ROI $\$="$ "THEN 40070

40080 IF VAL(ROI\$) $<0$ THEN 40070

40090 IF VAL(ROI\$) $>5$ THEN 40070

40100 IF VAL(ROI\$) $=0$ THEN 40800

40110 PRINT"Next, increase region (":ROI\$;") per:"

40125 PRINT"

40120 ON VAL(ROI\$) GOSUB 41000,42000,43000,44000,45000

40130 GOTO 40000

40800 IOCATE 17,1

40810 FOR PBLANK $=1$ TO 7:PRINT STRING $(39, "$ ") : NEXT PBLANK

40900 RETURN

41000 REM - roi expansion for region 1

41010 DROIS=INKEY $:$ IF DROIS = H" THEN 41010

41015 IF DROI $\$=" O$ " THEN 41100

41020 PYP=INT (SCALE*NPC (B1CH) +.5):PYQ=INT (SCALE*NPC $(\mathrm{LCH}-1)+.5)$

41020 PYP $=$ INT (SCALE*NPC (BICH) +5 ):PYQ

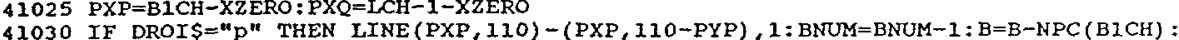

41030 IF DROI $\$=" p "$ THEN LINE (PXP, 110)-(PXP, $110-P$

GOSUB $32000:$ GOSUB $33000: B 1 C H=B 1 C H+1:$ GOTO 41000
41040 IF DROI\$ " G" THEN LCH $=$ ICH-1:LINE(PXQ, 110)-(PXQ, 110-PYQ), 1: GOTO 41000

41100 RETURN

42000 REM - roi expansion for region 2

42010 DROI $\$=$ INKEY $\$$ : IF DROI\$ $=$ " "THEN 42010

42015 IF DROI $\$=" 0 "$ THEN 42100

42020 PYP=INT (SCALE*NPC $(H 1 C H)+.5): P Y Q=I N T(S C A L E \star N P C(B 1 C H-1)+.5)$

42020 PYP=

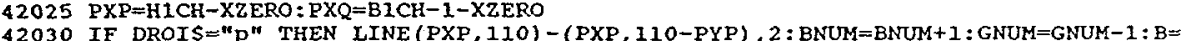

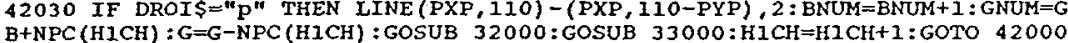

42040 IF DROI $\$=" \mathrm{q}$ " THEN $\mathrm{BICH}=\mathrm{BICH}-1:$ LINE $(\mathrm{PXQ}, 110)-(\mathrm{PXQ}, 110-\mathrm{PYQ}), 2: \mathrm{BNUM}=\mathrm{BNUM}+1: \mathrm{B}=$ $B+N P C(B 1 C H)$ : GOSUB 32000: GOSUB 33000:GOTO 42000

42100 RETURN

43000 REM - roi expansion for region 3

43010 DROIS=INKEY $\$$ IF DROI $=m n$ THEN 43010

43015 IF DROI\$="O" THEN 43100

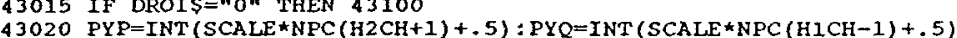

43020 PYP=INT (SCALE 4 NPC $(\mathrm{H} 2 \mathrm{CH}+1)+5)$ : PYQ $=$

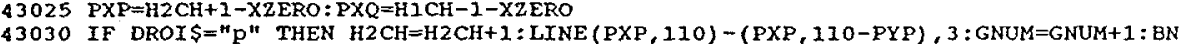
UM $=\mathrm{BNUM}-1: \mathrm{B}=\mathrm{B}-\mathrm{NPC}(\mathrm{H} 2 \mathrm{CH}): \mathrm{G}=\mathrm{G}+\mathrm{NPC}(\mathrm{H} 2 \mathrm{CH}): \mathrm{GOSUB} 32000: \mathrm{GOSUB} 33000:$ GOTO 43000

43040 IF DROI $\$=" q$ " THEN HICH=H1CH-1:LINE (PXQ, 110)-(PXQ, 110-PYQ), $3:$ GNUM=GNUM+1:BN $U M=B N U M-1: B=B-N P C(H 1 C H): G=G+N P C(H 1 C H): G O S U B$ 32000:GOSUB 33000:GOTO 43000

43100 RETURN

44000 REM - roi expansion for region 4

44010 DROIS=INKEYS:IF DROIS = "THEN 44010

44010 DROI\$=INKEY \$: IF DROI\$

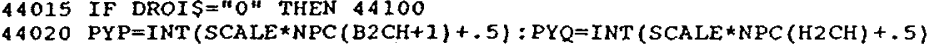

$44025 \mathrm{PXP}=\mathrm{B} 2 \mathrm{CH}+1-X 2 \mathrm{ERO}: \mathrm{PXQ}=\mathrm{H} 2 \mathrm{CH}-\mathrm{XZERO}$

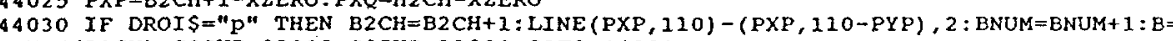
$B+N P C(B 2 C H): G O S U B$ 32000:GOSUB $33000:$ GOTO 44000

44040 IF DROI $\$=" q$ " THEN LINE (PXQ, 110)-(PXQ, 110-PYQ), $2: B N U M=B N U M+1: G N U M=G N U M-1: B=$ $B+N P C(\mathrm{H} 2 \mathrm{CH}): \mathrm{G}=\mathrm{G}-\mathrm{NPC}(\mathrm{H} 2 \mathrm{CH}):$ GOSUB $32000: \mathrm{GOSUB} 33000: \mathrm{H} 2 \mathrm{CH}=\mathrm{H} 2 \mathrm{CH}-1: \mathrm{GOTO} 44000$

44100 RETURN

45000 REM - roi expansion for region 5

45010 DROI $=$ INKEY $\$$ IF DROI\$ N THEN 45010

45015 IF DROI\$="O" THEN 45100

45020 PYP=INT (SCALE*NPC (KCH+1)+.5): PYQ=INT (SCALE*NPC (B2CH)+.5)

45025 PXP $=\mathrm{HCH}+1-X Z E R O: P X Q=B 2 \mathrm{CH}-X Z E R O$

45030 IF DROI\$" "Q" THEN HCH=HCH+2:LINE (PXP, 110)-(PXP, 110-PYP), 1:GOTO 45000

15040 IF DROI $\$=" q^{\prime \prime}$ THEN LINE (PXQ, 120)-(PXQ, 110-PYQ), 1: BNUM=BNUM-1:B=B-NPC (B1CH):

GOSUB 32000:GOSUB 33000 : B2CH=B2CH-1:GOTO 45000

45100 RETURN

.. 
60000 REM temp check on eff

60005 PRINT"Efficiency (EFF) per standard energy (EN) for ":DETNAMS(DETN)

60006 PRINT

60010 PRINT "EN", "EFF"

60011 PRINT"keV"," " " "

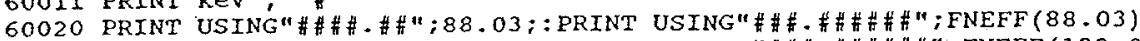

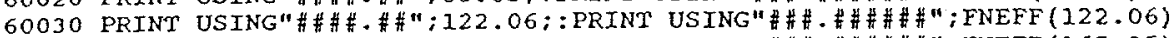

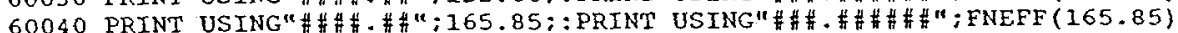

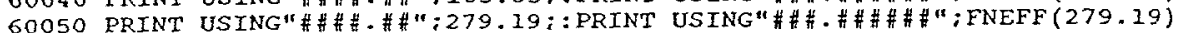

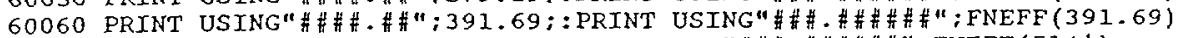

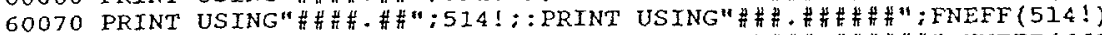

60080 PRINT USING"

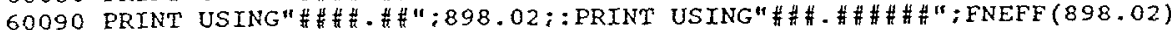

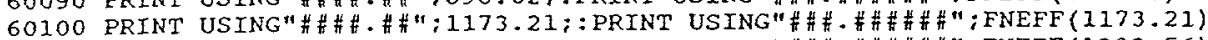

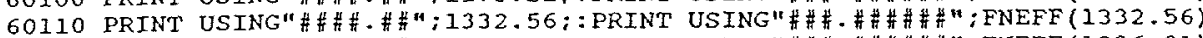

60120 PRINT USING"

60130 INPUT"Press return to proceed"; $Z Z$

60140 RETURN 
PEAKPART: Program structure Reference

Main

I-16/DIM setup

<--- 7000-7999/Gaussian F-function <--- 8000-8140/DATA lines for $F$

20-140/Multiplet data 150-180/Peak region Fs

200-220/New peak areas

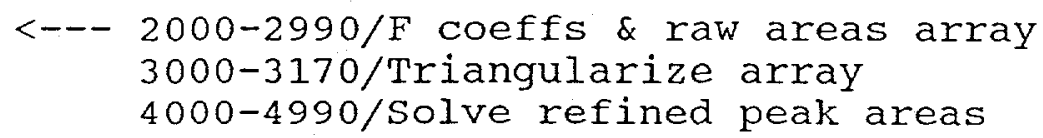

$300-400 /$ Screen results

$500-680 /$ Printout results

$1000 / \mathrm{STOP}$ 
1 CLS

5 REM PEAKPART.BAS

10 REM Note this and NEQUATNX require all $\mathrm{Ci}$ i not equal to 0

15 DIM $F(80), X(80)$

16 GOSUB $7000: R E M$ read in $F$ function values

20 INPUT"Number of Peaks in Multiplet"; $M: M=M-1$

25 PRINT:REM INPUT"Number of data points";N:PRINT

$30 \operatorname{DIM} A(M), T C(M, M), C(M, M), \operatorname{TD}(M), T N(M, M), C H M A X(M), C H L O(M), C H H T(M), A O(M)$

90 PRINT

100 PRINT" Input Data":PRINT

104 PRINT

105 INPUT"FWHM for individual multiplet peak (channels)";FWHM:PRINT

$106 \mathrm{SIGCH}=\mathrm{FWHM} /(2 *(2 * \operatorname{LOG}(2)) \wedge .5)$

110 FOR $I=0$ TO $M$

115 PRINT"Input for peak number "; I+1:PRINT

120 INPUT"Channels - $10 \mathrm{~min}$; CHLO(I): IF I>0 THEN CHHI(I-1) $=$ CHLO(I)

125 INPUT"

130 INPUT"

135 PRINT:INPUT"Min-to-min area of peak":TD(I):AO(I) =TD(I):PRINT:PRINT

140 NEXT I

150. FOR $\mathrm{J}=0$ TO $\mathrm{M}$

$155 \mathrm{CHMAX}=\mathrm{CHMAX}(\mathrm{J})$

160 FOR $I=0$ TO $M$

$165 \mathrm{CHLO}=\mathrm{CHLO}(\mathrm{I}): \mathrm{CHHI}=\mathrm{CHHI}$ (I)

170 GOSUB 5000:REM calculate coefficients

175 NEXT I

180 NEXT J

190 CLS

200 GOSUB 2000

204 PRINT

205 INPUT"Is this correct matrix (y-proceed/n-redo data) "; YE $\$: I F \quad Y E \$=" n " T H E N$ CL S:GOTO 100

210 GOSUB 3000

220 GOSUB 4000

300 REM printout final information

$305 \mathrm{CIS}$

310 PRINT"FWHM (channels) = ";FWHM

315 PRINT:PRINT

320 PRINT"------- Multiplet Peaks

321 PRINT

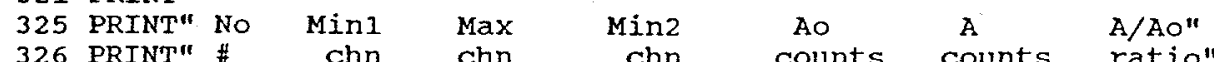

327 PRINT

330 FOR $I=0$ TO $M$

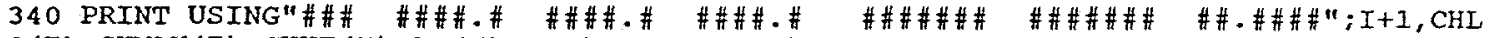

$O(I), \operatorname{CHMAX}(I), \mathrm{CHHI}(I), \mathrm{AO}(I), \mathrm{A}(\mathrm{I}), \mathrm{A}(\mathrm{I}) / \mathrm{AO}(\mathrm{I})$

350 NEXT I

400 REM printout matrix

410 PRINT

420 PRINT

420 PRINT
$+\quad \mathrm{A} 9+\mathrm{A} 10^{\prime \prime}$

422 PRINT

425 PRINT $\mathrm{X}$ "

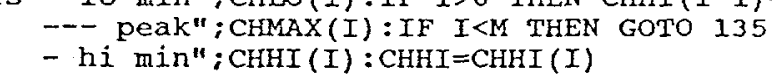

- peak"; CHMAX(I) :IF I<M THEN GOTO 135

- hi min";CHHI (I): CHHI=CHHI (I)

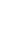
$A O(i)=x$

A3

A4 + cig cilo" cil 1
X
$X$

$X$

ci 4

ci5

ci 6

ci7

430 PRINT

440 FOR $I=0$ TO $M$

445 PRINT USING" \#\#\#\#\#\# ";AO (I);

450 FOR $J=0$ TO $M$

455 IF J=M THEN PRINT USING" \#.\#\#\#";C(I,J):GOTO 465

460 PRINT USING" \#. \#\#\#";C(I,J) :

465 NEXT J

470 NEXT I

480 PRINT 
500 INPUT"Print out hardcopY $(\mathrm{Y} / \mathrm{n})$ ":YES:IF YES=" $\mathrm{Y}$ " OR YES="N" THEN 1000

505 LPRINT:LPRINT

510 LPRINT"FWHM (channels) = ";FWHM

515 LPRINT: LPRINT

520 LPRINT

521 LPRINT

526 LPRINT" \# chn chn chn counts counts ratio"

527 LPRINT

530 FOR $I=0$ TO $M$

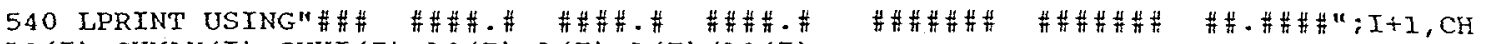

LO(I), $\operatorname{CHMAX}(I), \operatorname{CHHI}(I), A O(I), A(I), A(I) / A O(I)$

550 NEXT I

600 REM printout matrix

610 LPRINT

620 LPRINT

$+\mathrm{A} 9^{+} \mathrm{A} 10^{\prime \prime}$

622 LPRINT

625 LPRINT Ci9 " $A \circ(i)=x$

$A 1+A 2+$

A3 +

A4

A5

A 6

$A 7+A 8$
$x$
ci7

630 LPRINT

640 FOR $I=0$ TO $M$

645 LPRINT USING"\#\#\#\#\#\#" ";AO(I):

650 FOR $J=0$ TO $M$

655 IF J=M THEN LPRINT USING" \#.\#\#\#";C(I,J):GOTO 665

660 LPRINT USING" \#.\#\#\#";C (I,J):

665 NEXT J

670 NEXT I

680 LPRINT

1000 STOP

2000 REM display coefficient array

2002 PRINT

2005 FOR IP=0 TO M:PRINT TAB $(1+(I P) * 10)$ "a ("; IP+I;")";:NEXT IP

2006 PRINT"

2010 FOR IP=0 TO $M$

2020. FOR JP=O TO $M$

2030 PRINT TAB $(1+(J P) * 10)$ TC $(I P, J P)$;

2040 NEXT JP

2050 PRINT"

2060 NEXT IP

$=" ; \mathrm{TD}(\mathrm{IP})$

2990 RETURN

3000 REM -triangulation of equations

3010 FOR $\mathrm{J}=0$ TO $\mathrm{M}$

3015 REM - set first non zero coeff $=1$

3020 FOR $K=J$ TO $M$

3025 $\mathrm{TN}(\mathrm{K}, \mathrm{J})=\mathrm{TC}(\mathrm{K}, \mathrm{J})$ : IF $\operatorname{TN}(\mathrm{K}, \mathrm{J})=0$ THEN GOTO 3070

3030 FOR $\mathrm{L}=\mathrm{J}$ TO $\mathrm{M}$

$3040 \mathrm{TC}(\mathrm{K}, \mathrm{L})=\mathrm{TC}(\mathrm{K}, \mathrm{L}) / \mathrm{TN}(\mathrm{K}, \mathrm{J})$

3050 NEXT L

$3060 \mathrm{TD}(\mathrm{K})=\mathrm{TD}(\mathrm{K}) / \mathrm{TN}(\mathrm{K}, \mathrm{J})$

3070 NEXT $K$

3075 GOSUB 2000

3080 REM - subtract out first non zero coefficients

3085 IF $\mathrm{J}+1>\mathrm{M}$ THEN GOTO 3150

3090 FOR $\mathrm{K}=\mathrm{J}+1$ TO $\mathrm{M}$

3095 IF TC $(K, J)=0$ THEN GOTO 3140

3100 FOR $L=J$ TO $M$

$3110 \mathrm{TC}(K, L)=\mathrm{TC}(J, L)-\mathrm{TC}(K, L)$

3120 NEXT L

$3130 \mathrm{TD}(\mathrm{K})=\mathrm{TD}(\mathrm{J})-\mathrm{TD}(\mathrm{K})$

3140 NEXT $K$

3145 GOSUB 2000

3150 NEXT J

3170 RETURN

4000 REM final results

4002 PRINT: PRINT

4005 PRINT "values of a(i) listed below": PRINT

4010 FOR L $=M$ TO O STEP - 1

$4020 \mathrm{~A}(\mathrm{~L})=\mathrm{TD}(\mathrm{L}):$ IF $\mathrm{L}=\mathrm{M}$ THEN GOTO 4060

4030 FOR $J=L+1$ TO $M$

$4040 \mathrm{~A}(\mathrm{~L})=\mathrm{A}(\mathrm{L})-\mathrm{TC}(\mathrm{L}, J) * \mathrm{~A}(\mathrm{~J})$

4050 NEXT J

$4060 \mathrm{NEXT} I$

4080 FOR $L=0$ TO M:PRINT"a(";I+I;") = ";A(L):NEXT L

4090 PRINT

4990 RETURN 
5000 REM subroutine for coefficients for peak

$5010 X I=($ CHLO-CHMAX) $/ S I G C H: I F \quad I=0$ THEN XI $=-100$

$5015 \mathrm{X}=\mathrm{X} 1$ : GOSUB $6000: \mathrm{F} 1=\mathrm{F}: \mathrm{REM}$ lower integral limit

$5020 \times 2=($ CHHI-CHMAX) /SIGCH: IF I=M THEN X2=100

$5025 \mathrm{X}=\mathrm{X} 2:$ GOSUB $6000: \mathrm{F} 2=\mathrm{F}: \mathrm{REM}$ upper integral limit

$5030 \mathrm{TC}(I, J)=F 2-F 1$

$5035 \mathrm{C}(I, J)=F 2-F 1$

5999 RETURN

6000 REM error function (erf) calculation $F$

6010 IF $X \Rightarrow 3.9$ THEN $F=1$ : GOTO 6999

6020 IF $X<-3.9$ THEN $F=0:$ GOTO 6999

$6030 I X I=I N T(X / .05): I X H=I X I+I: X=X / .05$

$6040 \mathrm{~F}=.5+\mathrm{SGN}(\mathrm{X}) *(\mathrm{~F}(\mathrm{ABS}(\mathrm{IXL}))+(\mathrm{X}-\mathrm{IXL}) *(\mathrm{~F}(\mathrm{ABS}(\mathrm{IXH}))-F(\mathrm{ABS}(\mathrm{IXL}))))$

6999 RETURN

7000 REM sub to read in $F(x)$ function

7010 FOR IX=0 TO $80: X(I X)=.05 * I X: N E X T$

$7015 \quad F(0)=0$

7020 FOR IX=1 TO $80:$ READ F(IX):NEXT

7999 RETURN

8000 REM Data for $F(x)$

$\begin{array}{lllllllllll}8010 & \text { REM n. n. } & \text { n.10 n.15 n.20 n.25 } & \text { n.30 } & \text { n.35 } & \text { n.40 } & \text { n.45 } & \text { n.50 }\end{array}$

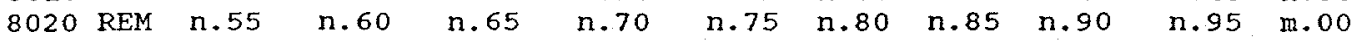

8030 REM $n=0 \quad m=1$

8040 DATA $0.0199,0.0398,0.0596,0.0793,0.0987,0.1179,0.1368,0.1554,0.1736,0.1915$

8050 DATA $0.2088,0.2258,0.2422,0.2580,0.2734,0.2881,0.3023,0.3159,0.3289,0.3413$

8060 REM $n=1 \quad m=2$

8070 DATA $0.3531,0.3643,0.3749,0.3849,0.3944,0.4032,0.4115,0.4192,0.4265,0.4332$

8080 DATA $0.4394,0.4452,0.4505,0.4554,0.4599,0.4641,0.4678,0.4713,0.4744,0.4773$

8090 REM $n=2 \quad m=3$

8100 DATA $0.4798,0.4821,0.4842,0.4861,0.4878,0.4893,0.4906,0.4918,0.4929,0.4938$

8110 DATA $0.4946,0.4953,0.4960,0.4965,0.4970,0.4974,0.4978,0.4981,0.4984,0.4987$

8120 REM $n=3 \quad m=4$

8130 DATA $0.4989,0.4990,0.4992,0.4993,0.4994,0.4995,0.4996,0.4996,0.4997,0.4998$

8140 DATA $0.4998,0.4998,0.4999,0.4999,0.4999,0.4999,0.4999,0.5000,0.5000,0.500$ 


\section{BDATRANS: Program structure Reference}

Main

<-- Subroutines and [files]

$$
5-28 / \text { DIM setup }
$$

30-35/Input data

$$
\begin{gathered}
<-- \text { 1000-1100/Miscellaneous data } \\
<-- \text { B:DATAMISC.DAT } \\
<---2000-2200 / \text { Efficiency data } \\
\text { <--- B:DATACALB.DAT }
\end{gathered}
$$

$41-65 /$ Eff Formula

--- 60000-60140/Eff Vs E for calibs

70-95/Input data

$$
\begin{aligned}
<-- & 3000-3100 / \text { Gamma peaks } \\
& <--- \text { B: DATAPEAK. DAT } \\
<--- & 4000-4100 / \text { Gamma spectrum } \\
& <--- \text { B:DATASPEC. DAT } \\
<--- & 5000-5080 / \text { Isotope data } \\
& <--- \text { B:DATAISOS. DAT } \\
<--- & 6000-6100 / \text { Existing background } \\
& <--- \text { backgnd.BKG } \\
<--- & 7000-7200 / \text { Efficiency parameters } \\
& <--- \text { B:DETLIBRY.LIB }
\end{aligned}
$$

980-990/Continue/STOP <--- 9000-9100/Supplementary analysis menu

Iines not used in execution

$$
\text { 8000-8100/Isotope Iibrary of B:DETLIBRY.LIB }
$$

13000-13100/Energy to channel transformer

$$
\text { B-96 }
$$


5 REM file BDATRANS. BAS

21 DIM HI (100), H2 (100), RATERR (100)

$22 \operatorname{DIM} \operatorname{GOEFF}(5,3), \operatorname{HOEFF}(5,3), \operatorname{AOEFF}(5,3), \operatorname{BOEFF}(5,3), \operatorname{KOEFF}(5,3)$

$23 \operatorname{DIM} \operatorname{CEOHO}(5,3), \operatorname{CE} 1 \mathrm{HO}(5,3), \operatorname{CEOH} 1(5,3), \operatorname{CE} 2 \mathrm{HO}(5,3), \operatorname{CE} 1 \mathrm{HI}(5,3), \mathrm{CEOH} 2(5,3)$

24 DIM CE3HO $(5,3), \operatorname{CE} 2 H 1(5,3), \operatorname{CE} 1 H 2(5,3), \operatorname{CEOH} 3(5,3)$

25 DIM YLOC (20), DETNAM\$ (10), BNERGY (100), BRATE (100), BERR (100), DETLAB\$(10)

26 DIM ISOTH(100), MDA (100), ACTRAT (100), LIBEN (100), SBRATE (100), SBERR(100)

27 DIM RATE (100), ENERGY (100), ISOEN (100), ISOID\$(100), ISO\$ (100), ISOGAM(100)

28 DIM NPC (4096), AREA (100), EAREA (100), LOCH(100), FWHM(100), TAIL(100), CENT(100)

30 GOSUB 1000:REM read file B:DATAMISC.DAT

35 GOSUB 2000:REM read file B:DATACALB.DAT

41 DEF FNENC $($ CHAN $)=C O E N C+C I E N C * C H A N$

44 DEF FNFWHM (CHAN) $=$ SQR $($ COFWHM + C1FWHM $*$ CHAN $)$

58 DEF FNEFFA $(E N)=$ GOEFF*EXP $(A O E F F * S Q R(B O E F F \wedge 2+U O E F F *(L O G(E N)-K O E F F) \wedge 2) *(C O E F F+C 1$ $E F F \star \operatorname{LOG}(E N)+C 2 E F F * \operatorname{LOG}(E N) \wedge 2+C 3 E F F \star \operatorname{LOG}(E N) \wedge 3)+.5 *(1+\operatorname{SGN}(E N-E N X)) \star(D O E F F+D 1 E F F * L O G$ $(E N)+D 2 E F F \star L O G(E N) \wedge 2+D 3 E F F * \operatorname{LOG}(E N) \wedge 3))$

$59 \mathrm{DEF} \quad \mathrm{FNEFFB}(\mathrm{EN})=1+\mathrm{POEFF}+\mathrm{P} \perp E F F \star L O G(E N)+\mathrm{P} 2 \mathrm{EFF} \star \operatorname{LOG}(\mathrm{EN}) \wedge 2+\mathrm{P} 3 E F F \star \operatorname{LOG}(\mathrm{EN}) \wedge 3$

60 DEF FNEFF (EN) =FNEFFA (EN) *FNEFFB (EN)

61 INPUT"Do you wish to see EFF VS EN data for standard energies $(y / n)$ "; EFFVEN\$: CIS:IF EFFVENS $<>$ "Y" THEN GOTO 65

62 GOSUB 60000:REM check on efficiency data EFF VS EN

65 REM - tempory continue

70 GOSUB 3000:REM read file B:DATAPEAK. DAT

75 GOSUB 4000:REM read file B:DATASPEC.DAT

80 GOSUB 5000:REM read file B:DATAISOS.DAT

85 GOSUB 6000:REM read file DETFILE\$.BKG

90 GOSUB 7000:REM read file B:DETLIBRY. LIB

95 REM gosub 8000 : rem read file B:ISOLIBRY. LIB (when needed for B:DATAISOS.DAT)

980 GOSUB 9000:REM - continuation menu

990 STOP

1000 REM - subroutine to read miscellaneous parameters file B:MISCDAT. DAT

1010 OPEN "B:DATAMISC.DAT" FOR INPUT AS \#3

1020 INPUT \#3, LTIME, STCH, ENCH, AUNIT\$, UNUM, UDEM, TDAYS, DETN, DETNAMS (DETN), DETLAB\$(

DETN) STDATE $\$$

1030 CLOSE \#3

IIO0 RETURN

2000 REM - subroutine to read data calib file B:DATACALB.DAT

2100 OPEN "B:DATACALB. DAT" FOR INPUT AS \#3

2110 INPUT \#3, COENC, C1ENC, COFWHM, C1FWHM, GOEFF, AOEFF, BOEFF, UOEFF, KOEFF, CQEFF, CIEF

$F, C 2 E F F, C 3 E F F, E N X, D O E F F, D 1 E F F, D 2 E F F, D 3 E F F, P O E F F, P 1 E F F, P 2 E F F, P 3 E F F$

2160 CLOSE \#3

2200 RETURN

3000 REM - subroutine to read data peak file B:DATAPEAK. DAT

3010 OPEN "B:DATAPEAK. DAT" FOR INPUT AS \#3

$3015 \mathrm{KP}=1$

3020 IF EOF (3) THEN MPMAX $=$ KP-I: GOTO 3060

3040 INPUT \#3, CENT (KP), ENERGY (KP), FWHM (KP), TAIL (KP), AREA (KP), RATE (KP), SBRATE (KP)

, ISOID (KP) , ACTRAT (KP), LIBEN (KP), RATERR (KP), SBERR (KP), H1 (KP), H2 (KP)

$3050 \mathrm{KP}=\mathrm{KP}+1$ : GOTO 3020

3060 CLOSE \#3

3100 RETURN

4000 REM -subroutine to read in spectrum file B:DATASPEC.DAT

4010 OPEN "B:DATASPEC. DAT" FOR INPUT AS \#3

4020 FOR I=STCH TO ENCH

4030 INPUT \#3, NPC (I)

4040 NEXT I

4050 CLOSE \#3

4100 RETURN

5000 REM - subroutine to read in isotope library file B:DATAISOS.DAT

5010 OPEN "B:DATAISOS.DAT" FOR INPUT AS \#3

$5020 \quad L=0$

$5030 \quad \mathrm{~L}=\mathrm{L}+1$

5040 INPUT \#3, ISOS(L), ISOTH (L), ISOEN(L), ISOGAM(L), MDA (L)

5050 IF ISOS $(L)=" 1$ imit "THEN 5070

5060 GOTO 5030

5070 CLOSE \#3

5080 RETURN 
6000 REM - subroutine to read in background library

6010 DETFILES=DETLABS (DETN) +". BKG"

6020 OPEN DETFILES FOR INPUT AS $\# 2$

$6030 \quad \mathrm{CBACK}=1$

6040 IF EOF (2) THEN BAMAX $=\mathrm{CBACK}-1$ : GOTO 6070

6050 INPUT \#2, BNERGY (CBACK), BRATE (CBACK), BERR (CBACK)

$6060 \mathrm{CBACK}=\mathrm{CBACK}+1:$ GOTO 6040

6070 CIOSE $\# 2$

6100 RETURN

7000 REM - subroutine to read in detector library B:DETLIBRY. LIB

7005 OPEN "B:DETLIBRY. LIB" FOR INPUT AS \#3

7010 FOR $I=1$ TO 5

3020 FOR $J=1$ TO 3

7030 INPUT \#3, GOEFF $(I, J), \operatorname{AOEFE}(I, J), \operatorname{BOEFF}(I, J), \operatorname{KOEFF}(I, J), \operatorname{HOEFF}(I, J)$

7040 INPUT $\# 3, \mathrm{CEOHO}(I, J)$

7050 INPUT $3, \mathrm{CE} 1 \mathrm{HO}(\mathrm{I}, \mathrm{J}), \mathrm{CEOH} 1(\mathrm{I}, \mathrm{J})$

7060 INPUT $3, \operatorname{CE} 2 H O(I, J), C E 1 H 1(I, J), C E O H 2(I, J)$

7070 INPUT $\# 3, \operatorname{CE} 3 H O(I, J), \operatorname{CE} 2 \mathrm{H1}(I, J), \operatorname{CE} 1 \mathrm{H} 2(I, J), \operatorname{CEOH} 3(I, J)$

7080 NEXT J

$7090 \mathrm{NEXT}$

7095 CLOSE \#3

$7100 \quad I=0: J=0$

7200 RETURN

8000 REM - subroutine to read in isotope library data $8:$ ISOLIBRY. LIB

8001 REM - note that B:DATAISOS.DAT is used instead usualiy

$8005 \mathrm{NMDA}=0$

8007 OPEN "B:ISOLIBRY.LIB" FOR INPUT AS \#3

8010 FOR ISO=1 TO 100

8020 INPUT \#3, ISO\$(ISO), ISOTH(ISO), ISOEN(ISO), ISOGAM(ISO), MDA (ISO)

8025 ISOGAM (ISO) =ISOGAM (ISO) $/ 100$

8027 IF $\mathrm{MDA}$ (ISO) $=1$ THEN $\mathrm{NMDA}=\mathrm{NMDA}+1$

8030 IF ISOS(ISO) $=$ "limit " THEN ISO $=100$

8040 NEXT ISO

8050 CLOSE \#3

8100 RETURN

9000 REM- subroutine for supplementary analyses

9005 OPEN "B:DETLIBRY. LIB" FOR INPUT AS \#3

9010 CLS

9020 PRINT"Supplementary Analyses - as applicable to current spectrum":PRINT

9030 PRINT" (I) Background file development (GRABBACK)"

9040 PRINT" (2) Detector efficiency calibration (GRABCALB)"

9050 PRINT" (3) Peak/spectrum diagnostics (GRABDIAG) "

9060 PRINT" (4) Peak/multiplet plot analysis (GRABPLOT)"

9070 PRINT" (5) Analyses per isotopes (GRABISOS) ": PRINT

9080 PRINT"Data files are now being transferred to RAM disk (b:) for analyses"

9090 PRINT:PRINT"Type selected analysis (e.g. GRABBACK) after":PRINT"C-prompt (

C>, and press enter"

9095 CLOSE H

9100 RETURN

13000 REM calc channel from energy

13010 AOEN $=$ FNENC $(0)$

13020 AIEN $=$ FNENC $(1)-$ FNENC $(0)$

13030 CHANO $=($ ENERGY - AOEN $) /$ AIEN

13040 CHAN $=$ CHANO + (ENERGY -FNENC $($ CHANO $)) / A 1 E N$

13050 IF ABS (ENERGY -FNENC (CHAN)) >. I THEN CHANO=CHAN: GOTO 13040

13055 RCHAN $=$ CHAN

13060 CHAN $=$ INT $($ CHAN +.5$)$

13100 RETURI

60000 REM temp check on eff

60005 PRINT"Efficiency (EFF) per standard energy (EN) for "; DETNAMS(DETN)

60006 PRINT

60010 PRINT "EN", "EFF"

60011 PRINT"keV"," \#"

60020 PRINT USING'"\#\#\#+\#\#";88.03;:PRINT USING"\#\#\#.\#\#\#\#\#";FNEFF(88.03)

60030 PRINT USING"\#\#\#\#\#":122.06;:PRINT USING"\#\#\#.\#\#\#\#";FNEFF(122,06)

60040 PRINT USING"\#\#\#, \#":165.85: : PRINT USING"\#\#\# \#\#\#\#\#":FNEFF(165.85)

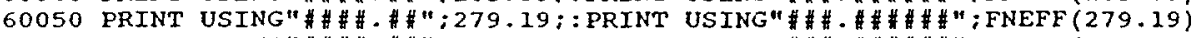

60060 PRINT USING" \#\#\#\#.\#";391.69;:PRINT USING"\#\#\#.\#\#\#\#\#";FNEFF(391.69)

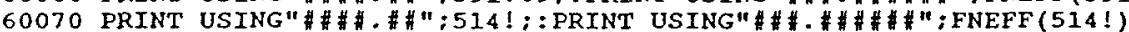

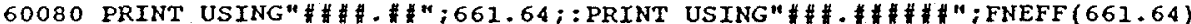

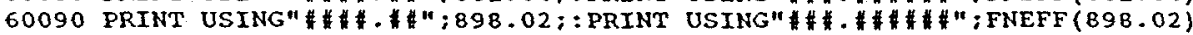

60100 PRINT USING"\#\#\#.\#";1173.21;:PRINT USING"\#\#\#\#\#\#\#; \#NEFF(1173.21)

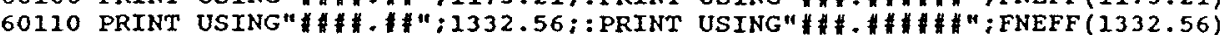

60120 PRINT USING"\#\#\#.\#";1836.01;:PRINT USING"\#\#\#\#\#\#\#;FNEFF(1836.01)

60130 INPUT"Press return to proceed" $; 2 Z$

60140 RETURN 


\section{GEFFCX1: Program structure Reference}

Main

$1-135 /$ DIM setup

140-170/Initialize fit

200-320/Initial funct

$500-630 / L-S$ min loop

$$
\begin{aligned}
& <---10000-10011 / D A T A \text { Effs vs E } \\
& <---6000-6070 / \log (\text { eff })-\log (E) \text { trans }
\end{aligned}
$$

<--- 1000-1040/Parameter definitions

<--- 5000-5070/Log-Log hyperbola

<--- 4000-4090/Derivitive search sign <--- 5000-5070/Log-Log hyperbola

<--- 5000-5070/Log-Log hyperbola

Subcode options - run from line number 12000

12000-12180/Display Eff vs $E$ of fit over designated range 13000-13110/Display efficiencies for fit vs measurements 
100 REM-input section

110 INPUT"number of data points";N:PRINT

111 INPUT"Log of data to be taken $(Y / n)$ "; YES:PRINT

115 DIM X(N),Y(N),SY (N)

120 FOR $J=1$ TO $N: \operatorname{READ} X(J), Y(J), S Y(J): N E X T J$

125 IF YE $\$=" y$ " THEN GOSUB 6000

130 INPUT" number of parameters"; NP

135 DIM V(NP), VO(NP), V\$(NP), SN(NP), VT(NP)

140 PRINT"Initial estimates of parameters"

145 GOSUB 1000

150 FOR $I=1$ TO NP

160 PRINT VS(I);" = ";:INPUT $V O(I): V(I)=V O(I)$

170 NEXT I

200 GOSUB 5000

$210 \quad S A=S$

300 PRINT: PRINT

310 FOR I=1 TO NP:PRINT V\$(I), :NEXT I

320 PRINT "S"

500 REM-test minimum routine

510 FOR $I=I$ TO NP

$520 \mathrm{~K}=0$

530 GOSUB 4000

$535 \mathrm{SN}(I)=-\mathrm{SN}$

$540 \mathrm{~K}=\mathrm{K}+1$

545 IF $K>15$ THEN GOTO 610

$550 \mathrm{AV}=\mathrm{VO}(\mathrm{I}) *(.5) \wedge \mathrm{K}: \mathrm{AV}=\mathrm{ABS}(\mathrm{AV})$

$555 \mathrm{VT}(\mathrm{I})=\mathrm{V}(\mathrm{I})$

$560 \mathrm{~V}(I)=\mathrm{V}(I)+\mathrm{AV} * \mathrm{SN}(I)$

565 GOSUB 4000

566 IF SN $<>-S N(I)$ THEN V(I) $=\mathrm{VT}(I)$

567 IF SN $\longleftrightarrow-S N(I)$ THEN 540

$570 \quad \mathrm{SB}=\mathrm{SA}$

580 GOSUB 5000

$590 \quad S A=S$

600 IF ABS $((S A-S B) / S A)>.001$ THEN GOTO 540

610 PRINT V(I)

620 NEXT I

625 PRINT SA

630 GOTO 500

1000 REM parameter definitions

1010 V\$ $(1)=" \mathrm{~A} "$

1020 VS $(2)=" B "$

$1030 \mathrm{~V} \$(3)=" \mathrm{C"}$

$1040 \mathrm{~V} \$(4)=" \mathrm{D} "$

1100 RETURN

4000 REM-test the derivitive sign

4010 GOSUB 5000

$4020 \mathrm{SO}=S$

$4030 \mathrm{~V}(I)=\mathrm{V}(I)+.001 * \mathrm{ABS}(\mathrm{VO}(\mathrm{I}))$

4040 GOSUB 5000

$4050 \mathrm{SI}=\mathrm{S}$

$4060 \mathrm{~V}(\mathrm{I})=\mathrm{V}(\mathrm{I})-.001 * \mathrm{ABS}(\mathrm{VO}(\mathrm{I}))$

$4080 \mathrm{SN}=\mathrm{SGN}(\mathrm{S} 1-\mathrm{SO})$

4090 RETURN

5000 REM S calculation and function definition $5010 A=V(1): B=V(2): C=V(3): D=V(4)$

$5020 \mathrm{~S}=0$

5030 FOR $J=1$ TO $N$

$5040 \quad \mathrm{FY}=\mathrm{A} * \mathrm{SQR}(\mathrm{B} \wedge 2+(\mathrm{X}(\mathrm{J})-\mathrm{C}) \wedge 2)+\mathrm{D}$

$5050 \mathrm{~S}=\mathrm{S}+(\mathrm{Y}(\mathrm{J})-\mathrm{FY}) \wedge 2 / \mathrm{SY}(J) \wedge 2$

5060 NEXT J

5070 RETURN

6000 REM SUB FOR LOG DATA

6005 INPUT"Equal weights $(Y)$ or individual $(n)$ "; YE\$

6010 FOR $\mathrm{J}=1$ TO $\mathrm{N}$

$6017 S Y(J)=S Y(J) / Y(J)$

$6020 X(J)=\operatorname{LOG}(X(J)): Y(J)=\operatorname{LOG}(Y(J))$

6030 IF YE $\$=" Y$ " THEN $S Y(J)=1$

6035 NEXT $J$

6040 PRINT"logx" "logy" "error/wt"

6050 FOR $J=1$ TO $N$

6060 PRINT X(J), Y(J),SY(J)

6065 NEXT J

6070 RETURN 
10000 REM data $x(i), y(i)$, sy $(i)$
10001 DATA $88,0.1206,1$
10002 DATA $122,0.1354,1$
10003 DATA $166,0.1060 ; 1$
10004 DATA $279,0.0700,1$
10005 DATA $393,0.0476,1$
10006 DATA $514,0.0353,1$
10007 DATA $662,0.0280,1$
10008 DATA $898,0.0201,1$
10009 DATA $1173,0.0158,1$
10010 DATA $1333,0.0138,1$
10011 DATA $1836,0.01005,1$

12000 REM calc curve with parameters

12010 CLS

12020 INPUT "a $=": A$

12030 INPUT $" b=": B$

12040 INPUT " $\mathrm{C}="$ "; $\mathrm{C}$

12050 INPUT "d $="$ ":D

12060 PRINT

12062 INPUT"compare with data (d) or calc range ( $r$ ) ":DRS:IF DR $\$=$ " $d$ " THEN GOSUB 1

3000

12063 IF DR\$="d" THEN 12062

12070 INPUT "start energy";ES

12080 INPUT "end energy";EE

12090 INPUT "energy step";ET

12100 PRINT

12110 PRINT "energy", "efficiency"

12120 FOR EN=ES TO EE STEP ET

$12130 \mathrm{X}=$ LOG (EN)

$12140 \mathrm{Y}=\mathrm{A} * \mathrm{SQR}\left(\mathrm{B}^{\wedge} 2+(\mathrm{X}-\mathrm{C}) \wedge 2\right)+\mathrm{D}$

$12150 \mathrm{EFF}=\mathrm{EXP}(\mathrm{Y})$

12155 PRINT EN, EFE

12160 NEXT EN

12170 PRINT

12180 GOTO 12070

13000 REM compare calc to data

13010 DIM X(11), Y(11), SY(II)

13020 FOR $J=1$ TO 11 :READ $X(J), Y(J), S Y(J): N E X T ~ J$

13025 PRINT

13030 PRINT "energy", "meas eff", "calc eff","

13040 FOR $\mathrm{J}=1$ TO 11

$13050 \mathrm{X}=\mathrm{LOG}(\mathrm{X}(\mathrm{J}))$

$13060 \mathrm{Y}=\mathrm{A} * \mathrm{SQR}(\mathrm{B} \wedge 2+(\mathrm{X}-\mathrm{C}) \wedge 2)+\mathrm{D}$

$13070 \quad \mathrm{EFF}=\mathrm{EXP}(\mathrm{Y})$

$13080 \mathrm{PD}=100 *(\mathrm{Y}(\mathrm{J})-\mathrm{EFF}) / \mathrm{EFF}$

13090 PRINT X(J), Y(J),EFF, PD

13100 NEXT J

13110 RETURN 


\section{TEFFPERF: Program structure Reference}

Main - - Subroutines and [files]

5-110/Data set info <--- 10000-10011/DATA Effs vs E 120-180/Read eff data <--- 12200-12610/DATA hypbla, ho, eff vs h 200-290/Basis norm eff <--- 1000-1100/Efficiency calculation 300-396/Meas-fit effs $400-429 /$ Print basis eff

$431 /$ GOTO 440 if need perturb analysis

433-439/Print perturbation polynomial coeffs

440-640/Print meas vs fit 650/GOTO exit if anal perturbation done

$660-830 / \mathrm{L}-\mathrm{S}$ perturb terms

840-910/Solve perturb polynom coeffs

<--- 2000-2990/Display coefficient matrix <-- 3000-3170/Triangularize matrix <--- 2000-2990/Display matrix status <-- 4000-4490/Calc perturb polynom coeffs

$920 /$ GOTO 200 to output results

$999 /$ STOP 
5 CLS

8 DEFDBL $T$

20 PFLAG $=0$

90 INPUT "Description of Data Set"; DS\$

100 INPUT"number of energies";NE

110 INPUT" number of heights";NH

120 READ A, B, C, HO

130 DIM $H(N H), E N(N E), E F F(N E, N H), \operatorname{PERDV}(N E, N H), X(N E), C(10,10), D(10)$

$135 \operatorname{DIM} \mathrm{K}(10), \mathrm{L}(10), \operatorname{TC}(10,10), \operatorname{TD}(10), A(10), \operatorname{TN}(10,10)$

140 FOR $\mathrm{J}=1$ TO $\mathrm{NH}: \operatorname{READ} \mathrm{H}(\mathrm{J}): \mathrm{NEXT} J$

150 FOR $\mathrm{I}=1$ TO $\mathrm{NE}$

160 READ EN(I)

170 FOR J=I TO NH:READ $\operatorname{EFF}(I, J): N E X T ~ J$

180 NEXT I

200 REM calculations for normalization factor

$210 \mathrm{G}=0$

220 FOR $\mathrm{I} \doteq 1$ TO $\mathrm{NE}$

230 FOR $\mathrm{J}=1$ TO $\mathrm{NH}$

$240 \mathrm{X}=\mathrm{LOG}(\mathrm{EN}(\mathrm{I}))$

$245 \mathrm{H}=\mathrm{H}(\mathrm{J})$

250 GOSUB 1000

$255 \mathrm{GCAL}=\mathrm{EFF}(\mathrm{I}, \mathrm{J}) / \mathrm{EFFUN}$

$260 \mathrm{G}=\mathrm{G}+\mathrm{GCAI}$

270 NEXT J

280 NEXT I

$290 \mathrm{G}=\mathrm{G} /(\mathrm{NE} * \mathrm{NH})$

300 REM calculate efficiencies and compare with experimental values

302 PRINT:PRINT:PRINT "Results for : ";DS\$:PRINT

305 AVEDEV $=0$

310 FOR $I=1$ TO $\mathrm{NE}$

320 FOR $\mathrm{J}=1$ TO $\mathrm{NH}$

$322 \mathrm{X}=\operatorname{LOG}(\mathrm{EN}(\mathrm{I}))$

$324 \mathrm{H}=\mathrm{H}(\mathrm{J})$

330 GOSUB 1000

340 EFFCAL $=$ G*EFFUN

350 PERDEV $=100 *(\operatorname{EFF}(I, J) / E F F C A L-1)$

355 AVEDEV=PERDEV^2 + AVEDEV

360 PRINT USING"\#\#\#\#\#\#";PERDEV;

$365 \operatorname{PERDV}(I, J)=\operatorname{PERDEV}$

370 NEXT J

380 PRINT

390 NEXT I

392 AVEDEV $=\mathrm{SQR}($ AVEDEV $/(\mathrm{NE} * \mathrm{NH}-1))$

394 PRINT:PRINT"G = "; $G$

396 PRINT "ave deviation $="$; AVEDEV

400 REM list calculated efficiencies

410 PRINT: PRINT:-PRINT "Results for : ";DS\$

420 PRINT: PRINT" Parameters for eff $=G^{\star} \operatorname{EXP}\left(A * S Q R\left(B^{\wedge} 2+(X-C) \wedge 2\right)\right) /(H+H 0)^{\wedge} 2^{\prime \prime}$

421 PRINT"

425 PRINT"G $="$; G

426 PRINT"A $=" ; A$

427 PRINT"B $=" ; B$

428 PRINT"C $=" ; \mathrm{C}$

429 PRINT"HO = ";HO:PRINT:PRINT: PRINT

431 IF PFLAG $=0$ THEN GOTO 440

433 PRINT "Efficiency includes perturbation correction factor below" 434 PRINT " $1+A(0,0)+A(1,0) * X+A(0,1) * H+\ldots \ldots+A(0,3) * H^{\wedge} 3 "$ 435 PRINT: PRINT"above coefficients below": PRINT

437 FOR IA=1 TO 10:PRINT"A(";K(IA);",";L(IA);") = ":A(IA)/100:NEXT IA 439 PRINT 
440 PRINT"Comparison of experimental/calculated efficiencies below"

450 PRINT: PRINT

460 PRINT" sample height $(\mathrm{cm}) "$

470 PRINT"energy (KeV)" ;

480 FOR J=1 TO NH:PRINT USING"\#\#\# . \#\#";H(J);:NEXT J

490 PRINT: PRINT

500 FOR I $=1$ TO NE

510 PRINT USING"\#\#\#\#. \#\#": EN(I) : : PRINT" ":

520 FOR $\mathrm{J}=1$ TO $\mathrm{NH}$

530 PRINT USING"\#\#.\#\#\#\#";EFF (I,J);

540 NEXT $J$

550 PRINT

560 PRINT"

$570 \mathrm{X}=$ LOG (EN (I))

580 FOR $J=1$ TO NH

$590 \mathrm{H}=\mathrm{H}(\mathrm{J})$

600 GOSUB 1000

610 PRINT USING"\#\#.\#\#\#\#"; G*EFFUN;

620 NEXT J

630 PRINT: PRINT

640 NEXT I

650 IF PFLAG $=1$ THEN GOTO 999

660 PFLAG $=1$

700 REM fit to perturbation array $\operatorname{PERDV}(I, J)$

710 FOR I=1 TO NE: $X(I)=\operatorname{LOG}(E N(I)):$ NEXT I

$715 K(1)=0: K(2)=1: K(3)=0: K(4)=2: K(5)=1: K(6)=0: K(7)=3: K(8)=2: K(9)=1: K(10)=0$

$720 \mathrm{~L}(1)=0: L(2)=0: L(3)=1: L(4)=0: L(5)=1: L(6)=2: L(7)=0: L(8)=I: L(9)=2: L(10)=3$

730 FOR IA $=1$ TO 10

735 FOR $J A=1$ TO 10

$740 \mathrm{C}(\mathrm{IA}, J A)=0:$ REM coefficient of expansion constant a $(\mathrm{k}(\mathrm{ia}), \mathrm{l}(\mathrm{ja}))$

750 FOR $I=1$ TO $\mathrm{NE}$

760 FOR $\mathrm{J}=1$ TO $\mathrm{NH}$

$770 \mathrm{C}(I A, J A)=\mathrm{C}(I A, J A)+\mathrm{X}(I) \wedge(\mathrm{K}(\mathrm{JA})+\mathrm{K}(\mathrm{IA})) * \mathrm{H}(\mathrm{J}) \wedge(\mathrm{L}(\mathrm{JA})+\mathrm{L}(\mathrm{IA}))$

775 NEXT J

780 NEXT I

785 PRINT IA, JA, C (IA,JA)

790 NEXT JA

$795 \mathrm{D}(\mathrm{IA})=0$

800 FOR $I=1$ TO $\mathrm{NE}$

805 FOR $J=1$ TO NH

$810 \mathrm{D}(I A)=\mathrm{D}(\mathrm{IA})+\operatorname{PERDV}(I, J) * \mathrm{X}(\mathrm{I})^{\wedge} \mathrm{K}(I A) * \mathrm{H}(\mathrm{J}) \wedge \mathrm{L}(\mathrm{IA})$

815 NEXT J

820 NEXT I

825 PRINT IA, "d", D(IA) : PRINT

830 NEXT IA

840 REM - solve for constants $a(k, 1)$ of expansion

$845 M=10$

850 FOR $I A=1$ TO 10

855 FOR $J A=1$ TO 10

$860 \mathrm{TC}(\mathrm{IA}, J A)=\mathrm{C}(I A, J A)$

865 NEXT JA

$870 \mathrm{TD}(I A)=\mathrm{D}(\mathrm{IA})$

875 NEXT IA

890 GOSUB 2000:REM display matrix

900 GOSUB 3000:REM triangularize matrix

910 GOSUB 4000:REM print solution of a

920 GOTO 200:REM go do original calculation with perturbation fixup

999 STOP

1000 REM sub for uncal efficiency calculation

$1010 \mathrm{Z}=\mathrm{A} * \mathrm{SQR}\left(\mathrm{B}^{\wedge} 2+(\mathrm{X}-\mathrm{C}) \wedge 2\right)$

1020 EFFUN $=\operatorname{EXP}(\mathrm{Z}) *(\mathrm{H}+\mathrm{HO})^{\wedge}-2$

1030 IF PFLAG $=0$ THEN GOTO 1100

1040 PERT $=0$

1050 FOR $I A=1$ TO 10

$1060 \mathrm{PERT}=$ PERT $+\mathrm{A}(\mathrm{IA}) * \mathrm{X}^{\wedge} \mathrm{K}(\mathrm{IA}) * \mathrm{H}^{\wedge} L(I A)$

1070 NEXT IA

1080 PERT $=1+$ PERT $/ 100$

1090 EFFUN $=$ EFFUN $*$ PERT

1100 RETURN 
2000 REM display coefficient array

2002 PRINT

2005 FOR IP=1 TO M:PRINT TAB(1+(IP-1)*7) "a(";IP;")";:NEXT IP

2006 PRINT" "; "Constant" :PRINT

2010 FOR IP=1 TO $M$

2020 FOR $J P=1$ TO $M$

2030 PRINT USING"\#\#\#\#\#\#";TC (IP, JP) :

2040 NEXT JP

2050 PRINT" = ";:PRINT USING"\#\#莐\#.\#".;TD(IP)

2060 NEXT IP

2070 PRINT

2990 RETURN

3000 REM -triangulation of equations

3010 FOR $\mathrm{J}=1$ TO $M$

3015 REM - set first non zero coeff $=1$

3020 FOR $\mathrm{K}=\mathrm{J}$ TO $\mathrm{M}$

$3025 \operatorname{TN}(K, J)=T C(K, J): I F \operatorname{TN}(K, J)=0$ THEN GOTO 3070

3030 FOR L-J TO $M$

$3040 \mathrm{TC}(K, \mathrm{~L})=\mathrm{TC}(\mathrm{K}, \mathrm{L}) / \mathrm{TN}(\mathrm{K}, \mathrm{J})$

3050 NEXT L

$3060 \mathrm{TD}(\mathrm{K})=\mathrm{TD}(\mathrm{K}) / \mathrm{TN}(\mathrm{K}, \mathrm{J})$

3070 NEXT $K$

3075 GOSUB 2000

3080 REM - subtract out first non zero coefficients

3085. IF $\mathrm{J}+\mathrm{I}>10$ THEN GOTO 3150

3090 FOR $\mathrm{K}=\mathrm{J}+\mathrm{I}$ TO $\mathrm{M}$

3095 IF TC $(K, J)=0$ THEN GOTO 3140

3100 FOR $\mathrm{L}=\mathrm{J}$ TO $\mathrm{M}$

$3110 \mathrm{TC}(\mathrm{K}, \mathrm{L})=\mathrm{TC}(\mathrm{J}, \mathrm{L})-\mathrm{TC}(\mathrm{K}, \mathrm{L})$

3120 NEXT L

$3130 \mathrm{TD}(\mathrm{K})=\mathrm{TD}(\mathrm{J})-\mathrm{TD}(\mathrm{K})$

$3140 \mathrm{NEXT} K$

3145 GOSUB 2000

3150 NEXT J

3160 GOSUB 2000

3170 RETURN

4000 REM final results

4002 PRINT

4005 PRINT "values of a(i) listed below"

4010 FOR $I=M$ TO $I$ STEP -1

$4020 \mathrm{~A}(\mathrm{~L})=\mathrm{TD}(\mathrm{L}):$ IF $\mathrm{L}=\mathrm{M}$ THEN GOTO 4060

4030 FOR $\mathrm{J}=\mathrm{L}+1$ TO $M$

$4040 A(L)=A(L)-T C(L, J) * A(J)$

4050 NEXT J

4060 NEXT L

4080 FOR L=1 TO M:PRINT"a ("; L;") = ";A (L):NEXT L

4990 RETURN

12200 REM data for well det - medium vials

12300 REM hyperbola inverse square parameters $A, B, C, H O$

12350 DATA $-1.038801, .3110960,4.711060,6.330$

12370 REM

12400 REM experimental efficiencies below

12450 DATA $\quad .268, .518, .963,1.538,1.999,2.399,2.959$

12500 REM en h1 h2 h3 h4 h5 h6 h7

12510 DATA $88,0.1664,0.1512,0.1361,0.1149,0.1028,0.0938,0.0791$

12520 DATA $122,0.1869,0.1737,0.1519,0.1290,0.1169,0.1015,0.0879$

12530 DATA $166,0.1405,0.1341,0.1195,0.1003,0.0896,0.0842,0.0740$

12540 DATA $279,0.0945,0.0869,0.0795,0.0653,0.0613,0.0537,0.0490$

12550 DATA $393,0.0637,0.0598,0.0535,0.0451,0.0422,0.0373,0.0326$

12560 DATA $514,0.0468,0.0443,0.0391,0.0330,0.0305,0.0283,0.0254$

12570 DATA $662,0.0372,0.0351,0.0308,0.0268,0.0238,0.0221,0.0200$

12580 DATA $898,0.0266,0.0247,0.0214,0.0193,0.0176,0.0165,0.0146$

12590 DATA $1173,0.0206,0.0197,0.0175,0.0152,0.0136,0.0130,0,0110$

12600 DATA $1332,0.0186,0.0169,0.0154,0.0135,0.0117,0.0109, .00984$

12610 DATA $1836,0.0128,0.0226,0.0111, .00977, .00874, .00784, .00750$ 